BNWL -1144

UC-25, Meta1s, Ceramics and Materials

\author{
QUARTERLY PROGRESS REPORT \\ APRIL, MAY, JUNE, 1969 \\ REACTOR FUELS AND MATERIALS DEVELOPMENT PROGRAMS \\ FOR \\ FUELS AND MATERIALS BRANCH \\ $O F$ \\ USAEC DIVISION OF REACTOR DEVELOPMENT AND TECHNOLOGY
}

Edited By

A. L. Bement

G. J. Dau

E. A. Evans

R. E. Nightingale

August 1969

FIRST UNRESTRICTED

DISTRIBUTION MADE

AUG20'69

BATTELLE MEMORIAL INSTITUTE

PACIFIC NORTHWEST LABORATORY

RICHLAND, WASHINGTON 99352.

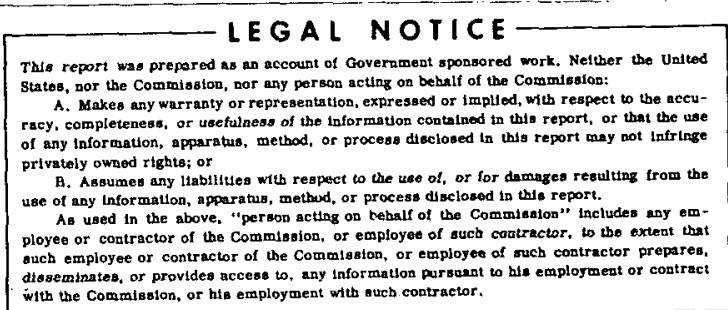

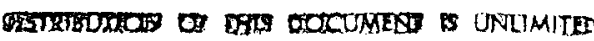

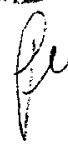




\section{DISCLAIMER}

This report was prepared as an account of work sponsored by an agency of the United States Government. Neither the United States Government nor any agency Thereof, nor any of their employees, makes any warranty, express or implied, or assumes any legal liability or responsibility for the accuracy, completeness, or usefulness of any information, apparatus, product, or process disclosed, or represents that its use would not infringe privately owned rights. Reference herein to any specific commercial product, process, or service by trade name, trademark, manufacturer, or otherwise does not necessarily constitute or imply its endorsement, recommendation, or favoring by the United States Government or any agency thereof. The views and opinions of authors expressed herein do not necessarily state or reflect those of the United States Government or any agency thereof. 


\section{DISCLAIMER}

Portions of this document may be illegible in electronic image products. Images are produced from the best available original document. 


\section{PREVIOUS QUARTERLY REPORTS}

Quarter

First

Second

Third

Fourth

First

Second

Third

Fourth

First

Second

Third

Fourth
Year

1966

1967

1968
Report Number

BNWL - CC - 694

BNWL - CC - 761

BNWL-CC - 821

BNWL-CC-957

BNWL -435

BNWL -473

BNWL- 658

BNWL - 668

BNWL - 768

BNWL - 842

BNWL-919

BNWL - 971

1969

First

BNWL- 1058 


\section{TABLE OF CONTENTS}

SUMMARY .

NUCLEAR GRAPHITE - R. E. Nightingale

Inert-Gas-Sensitized Radiolysis Studies -

G. L. Tingey .

Radiation-Induced Creep in Graphite -

W. J. Gray

HTGR GRAPHITE

The Radiolytic Reaction of Graphite

with Water Vapor - R. E. Woodley.

NUCLEAR CERAMICS - R. E. Nightingale

Properties of Molten Fast-Reactor Oxide

Fuels - R. P. Nelson, J. J. Rasmussen, and O. D. Slagle

Electrical Conductivity of Cerium Oxide

J. L. Bates . . . . . . .

Preparation of $\mathrm{UO}_{2}-25$ wt: $\mathrm{PuO}_{2}$ Specimens

for High-Temperature Creep Studies -

O. D. Slagle and J. A. Basmajian . . . . . . 5.10

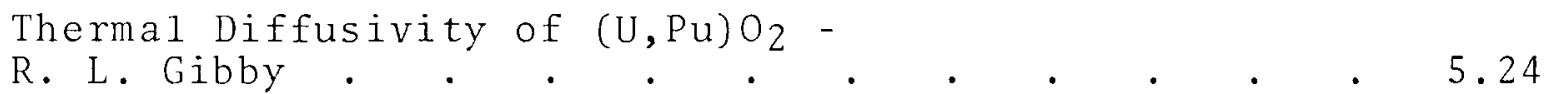

Determination of Oxygen/Metal Ratios

for Oxide Fuels - R. E. Woodley.

Characterization of Mixed-Oxide Fue 1

Materials - J. L. Daniel and S. J. Mayhan. . . . 5.29

FAST REACTOR NITRIDES RESEARCH • • • • • • • • 6.1

NONDESTRUCTIVE TESTING . . . . . . . . . . .

METALLIC FUELS .

BASIC SWELLING STUDIES - C. R. Hann. . . . . . 9.1

Postirradiation Examination - C. R. Hann,

B. Mastel.

Mixed Nitrides Fuel Irradiation -

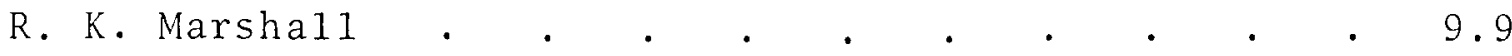

ATR GAS LOOP OPERATION AND MAINTENANCE. • • . . . 10.1

FAST REACTOR DOSIMETRY AND DAMAGE ANALYSIS -

R. E. Nightingale 
EBR-II Dosimetry Test - J. L. Jackson, W. N. McElroy, J. A. Ulseth, L. S. Kellogg, and F. S. Kirn

Damage Functions and Data Correlation

W. N. McElroy and C. Z. Serpan, Jr.*.

Computer Simulation of Radiation Damage

D. G. Doran.

Computer Simulation of Irradiation

Displacement Cascade Formation -

G. E. Russcher • • . . . . . . . . . . 11.15

Computer Experimental Study on Carbon

Inclusions in Grain Boundaries in FCC

Gamma - Iron - R. E. Dah 1, Jr.,

$\mathrm{J}$. R. Beeler, Jr., and R. D. Bourquin . . . . . 11.17

IRRADIATION DAMAGE TO REACTOR METALS • • • • • • • 12.1

Reactor Metals Research . . . . . . . . . . . . 12.1

Irradiation Facilites Operation -

A. L. Ward.

Microstructural Modifications to Stain-

less Steels and Nickel-Base Alloys -

I. S. Levy.

In-Reactor Measurements of Mechanical

Properties - E. R. Gilbert, N. E. Harding. • . . 12.5

Formation of Voids in Iron During

High-Temperature Neutron Irradiation -

G. L. Kulcinski and B. Maste1. . . . . . . 12.8

Sma11-Angle X-Ray Scattering by Voids

in Irradiated Metals - H. E. Kissinger. . . . . 12.12

Fast Reactor Supporting Studies . . . . . . . . 12.15

Damage Analysis - J. L. Straalsund and

H. R. Brager . . . . . . . . . . 12.15

EBR-II Irradiations - P. K. McDaniel • • . . . 12.22

Acceptance Testing and Clad Characterization -

Uniaxial Creep-Rupture Studies.

A. J. Love11 . . . . . . . . . . . . 12.48

Biaxial Stress-Rupture Studies -

R. W. Barker . . . . . . . . . . . . 12.53

FTR Vessel Weldment Studies - A. L. Ward . • • . 12.67

LMFBR Fuel and Cladding Information Center - 


\author{
QUARTERLY PROGRESS REPORT \\ APRIL, MAY, JUNE, 1969 \\ REACTOR FUELS AND MATERIALS \\ DEVELOPMENT PROGRAMS \\ FOR FUELS AND MATERIALS BRANCH \\ $O F$ \\ USAEC DIVISION \\ OF REACTOR DEVELOPMENT AND TECHNOLOGY
}

Edited By

A. L. Bement

G. J. Dau

E. A. Evans

R. E. Nightingale

SUMMARY

\title{
NUCLEAR GRAPHITE
}

The $100-\mathrm{eV}$ yield of the radiolytic reaction of $\mathrm{CO}_{2}$ and $\mathrm{H}_{2}$ in a helium carrier decreases with $\mathrm{CO}_{2}$ and $\mathrm{H}_{2}$ concentration below $3500 \mathrm{ppm}$. At $350{ }^{\circ} \mathrm{C}$ the $\mathrm{G}(\mathrm{CO})$ for the mixture is 1.9 molecules/100 eV at concentrations of $\mathrm{CO}_{2}$ and $\mathrm{H}_{2}$ above $3500 \mathrm{ppm}$. At $\mathrm{H}_{2}$ and $\mathrm{CO}_{2}$ concentrations of $300 \mathrm{ppm}$, the $\mathrm{G}(\mathrm{CO})$ is 1.5 and 0.65 molecules $/ 100 \mathrm{eV}$, respectively.

Design of an in-reactor creep experiment for graphites of interest to the Molten Salt Breeder Reactor are complete. The test is designed to measure in-reactor creep for graphite samples with a constant compressive load. This experiment is scheduled to begin in the ETR in October, 1969. 


\section{HTGR GRAPHITE}

THE RADIOLYTIC REACTION OF GRAPHITE WITH WATER VAPOR

Measurements of the radiolytic reaction of graphite-water vapor are presently being carried out in a single-pass flow system. Product concentrations are very small, a few tenths of $1 \mathrm{vpm} . \mathrm{CO}_{2}$ concentrations of the same magnitude in the helium carrier gas interfere with radiolytic yield determinations.

\section{NUCLEAR CERAMICS}

\section{PROPERTIES OF MOLTEN FAST-REACTOR OXIDE FUELS}

Installation has been completed of the high-temperature vacuum resistance furnace within a plutonium glove box located in the Shielded Materials Facility. This arrangement will be used for measurements of liquid density, viscosity, surface tension, and compressibility on both unirradiated and irradiated mixed-oxide fuels to $3000{ }^{\circ} \mathrm{C}$.

Techniques are described for obtaining the surface tension of liquid oxides by analyzing the shapes of pendant drops and capillary menisci which have been radiographed in closed refractory-metal capsules. Values of the surface tension of liquid $\mathrm{Al}_{2} \mathrm{O}_{3}$ found by using these techniques are in good agreement with values reported in the literature.

\section{ELECTRICAL CONDUCTIVITY OF CERIUM OXIDE}

The electrical conductivity of $\mathrm{CeO}_{2-x}$ was measured to $2000^{\circ} \mathrm{C}$ in argon. The increase in conductivity with a decrease in oxygen content and the anomalous decrease above $1900{ }^{\circ} \mathrm{C}$ was confirmed.

PREPARATION OF UO $\mathrm{O}_{2}-25 \mathrm{wt} \% \mathrm{PUO}_{2}$ SPECIMENS FOR HIGH-TEMPERATURE CREEP STUDIES

A study was carried out to determine a method of preparing polycrystalline $\mathrm{UO}_{2}-25 \mathrm{wt} \% \mathrm{PuO}_{2}$ creep specimens. Several 
different mechanically-mixed and coprecipitated powders were compacted and sintered under various conditions, and the resultant microstructures were examined. The study concluded thatin order to obtain uniform pellets for creep studies, coprecipitated powders must be used.

THERMAL DIFFUSIVITY OF $(\mathrm{U}, \mathrm{PU}) 0_{2}$

Photomicrographs were obtained for coprecipitated mixed oxide thermal diffusivity specimens which contained $0,5,12$, $20,25,30$, and $45 \mathrm{wt} \% \mathrm{PuO}_{2}$. The information obtained from the photomicrographs was correlated with thermal diffusivity data previously reported.

\section{DETERMINATION OF OXYGEN/METAL RATIOS FOR OXIDE FUELS}

An experimental system has been constructed to examine the feasibility of measuring oxygen/metal ratios in oxide fuel samples weighing only about $1 \mathrm{mg}$. It has been found that outgassing of the graphite crucible used in the fuel reduction contributes an appreciable fraction of the $\mathrm{CO}_{2}$ measured to determine the oxygen content of the fuel sample.

CHARACTERIZATION OF MIXED-OXIDE FUEL MATERIALS

The study of mixed-oxide fuels, using scanning electron microscopy, continued with detailed examination of calcination of plutonium oxalate and nitrate to form $\mathrm{PuO}_{2}$, and of sintering of $\mathrm{PuO}_{2}$ and $\mathrm{UO}_{2}-\mathrm{PuO}_{2}$. Correlations between calcination temperature, physical treatment of powders, measured particle sizes, sintered densities, microstructure and micro-composition are being developed.

\section{BASIC SWELLING STUDIES}

Swe11ing was low in specimens of uranium, U-5 wt: $\mathrm{Pu}$, and U-14 wt\% Pu-12 wt\% $\mathrm{Zr}$ irradiated at 1000 psi between $375^{\circ} \mathrm{C}$ and $625^{\circ} \mathrm{C}$. Swelling in $\mathrm{U}_{3} \mathrm{Si}$ specimens was greater at lower temperatures. 
When fissionable metals are irradiated, the ordered metallic structure is perturbed in a number of ways. High energy neutrons and fission fragments collide with metal atoms, knocking them out of their structural positions. The resultant defects, vacancies, interstitials, dislocation loops, etc., can adversely affect metallic properties. Similarly, the fission products generated, some of which are noble gases, may be incompatible with the structure and so precipitate or coalesce as second phase inclusions or gas pores. Furthermore, the high, localized temperatures associated with the fission event can cause anisotropic fissionable metals such as uranium to drastically change shape in accordance with the crystallography of the specimens.

These effects and their interactions are being studied with regard to the influence of irradiation variables such as the specimen temperature, burnup, burnup rate, and external pressure, and with regard to the influence of metallurgical variables such as composition, structure, and geometry. The data thus far obtained on this program have established that, contrary to previous beliefs, swelling at low burnup in alpha uranium is due to mechanical processes associated with the irradiation "growth" phenomena and with fission-event induced defects rather than with the agglomeration and growth of fission gas pores. This is manifested as a maximum in the swel1ing-temperature curve in the 400 to $600{ }^{\circ} \mathrm{C}$ range.

A few tenths of a percent alloying addition or an applied external pressure have been found to be effective in overcoming the "mechanica1" type of swelling. Swelling continues to decrease above $600{ }^{\circ} \mathrm{C}$ up to approximately $700{ }^{\circ} \mathrm{C}$. Above $700{ }^{\circ} \mathrm{C}$, fission gas swelling begins to occur. Efforts are continuing to better define the basic mechanisms involved and the interrelationship between burnup, temperature, pressure and metallurgical state. Fundamental information developed by this program 
will provide a basis for engineering exploitation of the many beneficial attributes of metal fuels for use in reactor applications.

\section{FAST-REACTOR DOSIMETRY AND DAMAGE ANALYSIS}

Reaction rate ratios can be used to identify changes in neutron spectra since monitors respond differently to neutrons of different energies. Data from the recent EBR-II dosimetry test show a possible change in the spectrum between the lowand high-power tests. Other data from the high-power tests show the spectrum was constant axially in Row 2 up to 4 in. above midplane. Such information on spectra is useful in the analysis of both monitor and irradiation damage data.

A previous report discussed the development of a method for generating energy-dependent damage functions for the correlation and prediction of neutron-induced property change. A damage function was previously derived for a $200{ }^{\circ} \mathrm{F}$ ductilebrittle transition temperature $(\triangle T T)$ increase generated by neutron irradiation at temperatures less than $450^{\circ} \mathrm{F}$ in ASTM A302-B pressure-vessel steel. In the present study, a set of groupaveraged valued of this damage function was selected and used to compare measured and damage-function calculated fluences for new experimental $\triangle \mathrm{TT}$ data. The results provide further vali dation of the applicability of the damage function.

Recent indications of a significant contribution by thermal neutrons to the embrittlement of some ferritic steels have prompted computer experiments on low-energy displacement spikes such as produced by $(n, y)$ recoils. Preliminary results with individual $400 \mathrm{eV}$ spikes indicate some clustering at low temperatures but not at elevated temperatures.

The CASCADE-type computer code is being reformulated and programmed to simulate damage generation in the FCC lattice 
structure. It will permit a more realistic simulation and widen the scope of simulation to include effects in previously damaged lattices and effects of knock-on atoms with energies greater than $20 \mathrm{keV}$.

In computer simulation studies using the GRAINS code, a $6^{\circ}$ tilt boundary in a lattice simulating fcc $y$ iron was observed to heal upon introduction of a carbon atom in the vicinity of the boundary. A significant reduction in the energy of the system occurred as the carbon atom reached its equilibrium position.

\section{IRRADIATION DAMAGE TO REACTOR METALS}

\section{REACTOR METALS RESEARCH}

Irradiation Facilities Operation

A total of 162 tensile, creep, and corrosion specimens were discharged from the ETR at the conclusion of Cycle 100.

Core I testing in the ATR was completed on June 6, 1969. Cores II and III and Cycle 1 are scheduled for June 15, 1969; July 6, 1969; and September 20, 1969, respectively.

MICROSTRUCTURAL MODIFICATIONS TO STAINLESS STEELS AND NICKELBASE ALLOYS

A comparison was made of the stacking fault hardening rates produced by quenching, straining at room-temperature, straining at $700{ }^{\circ} \mathrm{C}$, and straining at $700{ }^{\circ} \mathrm{C}$ followed by a half-hour hold under load at $700^{\circ} \mathrm{C}$. The results showed that hardening-rate increased in the order: straining plus hold > straining > quenching. That straining plus hold treatment produced a faster hardening-rate than did straining alone was rationalized in terms of the added effect of vacancy-enhanced diffusion.

IN-REACTOR MEASUREMENTS OF MECHANICAL PROPERTIES

Discontinuous yielding during neutron irradiation has been measured in annealed 304 SS at $370{ }^{\circ} \mathrm{C}$ stressed to 35,000 psi. 
This phenomenon, induced by irradiation, resulted in an average creep-rate of $6 \times 10^{-5} \mathrm{hr}^{-1}$.

The values of the activation parameters and the stressdependence of the creep-rate in $\mathrm{zr}-2.5 \mathrm{Nb}$ are consistent with the "dislocation-climb" model for creep with short-circuited diffusion. Neutron irradiation can be thought of as adding a stress component for faster creep. The stress arised from an osmotic force on climbing dislocations resulting from the supersaturation of point defects created by irradiation. FORMATION OF VOIDS IN IRON DURING HIGH-TEMPERATURE NEUTRON IRRADIATION

Irradiation of high purity Fe to $3 \times 10^{21} \mathrm{n} / \mathrm{cm}^{2}$ ( $\mathrm{E}>0.1 \mathrm{Mev}$ ) at $450{ }^{\circ} \mathrm{C}$ produces $\sim 1 \times 10^{14}$ voids of average diameter $\sim 280 \AA$. SMALL-ANGLE X-RAY SCATTERING BY VOIDS IN IRRADIATED METALS

Analysis of small-angle scattering from metals irradiated at elevated temperatures yields void diameters consistent with those measured by electron microscopy.

\section{FAST REACTOR SUPPORTING STUDIES}

DAMAGE ANALYSIS

An equation describing the effect of fluence and temperature on swelling in solution-treated 304 SS has been refined.

Transmission electron microscopy studies of irradiated SS indicates that the nucleation rate of cavities may increase with accumulated exposure.

An analysis of carbide distributions in 316 Ss indicates an increase of carbides precipitation in irradiated material.

\section{EBR-I I I RRADIATIONS}

At the present time there are seven active experiments (swelling, weldment and structural materials) in EBR-II. Eight 
BNWL structural materials experiments have been discharged from EBR-II. The flux monitors from these discharged experiments are in the process of being counted. Four BNWL weldment experiment pins in subassembly $x-067$ are to have a goal exposure of 1 $x 10^{22} \mathrm{n} / \mathrm{cm}^{2}(\mathrm{E}>0.1 \mathrm{MeV})$.

\section{ACCEPTANCE TESTING AND CLADDING CHARACTERIZATION}

Elevated-temperature burst tests and $1200{ }^{\circ} \mathrm{C}$ stress-rupture tests for times less than $1400 \mathrm{hr}$ have been completed on tubing lots E, F, G, E H. Metallography and check chemical analyses have been completed on tubing lot G. Biaxial creep curves on tubing lots $E$ \& F have been completed.

UNIAXIAL CREEP RUPTURE STUDIES

The results of postirradiation creep-rupture tests on 304 and 316 stainless steel are reported for specimens irradiated in the temperature range of $700{ }^{\circ} \mathrm{F}\left(371{ }^{\circ} \mathrm{C}\right)$ to $900{ }^{\circ} \mathrm{F}\left(482{ }^{\circ} \mathrm{C}\right)$ and to total fluences from $1 \times 10^{21} \mathrm{n} / \mathrm{cm}^{2}$ to $1 \times 10^{22} \mathrm{n} / \mathrm{cm}^{2}$ (EBR-II calculated). Rupture-1ife reductions were observed for all irradiated specimens. Both increased and decreased creeprates were observed depending on temperature and stress-level of test and irradiation fluence.

\section{BI AXIAL STRESS-RUPTURE STUDIES}

Biaxial stress-rupture tests at $1200^{\circ} \mathrm{F}$ have been initiated on AISI type $304 \mathrm{SS}$ irradiated to $0.8 \times 10^{22} \mathrm{n} / \mathrm{cm}^{2}$ ( $\mathrm{E}>0.1 \mathrm{Mev}$ ) in EBR-II. Specimens were stressed sufficiently to cause rupture in 0.1 to $1000 \mathrm{hr}$. in unirradiated material. Based on these initial tests, the data suggest some increase in rupture strength for short rupture times and loss in rupture strength for long rupture times for irradiated $304 \mathrm{sS}$. Strain is observed to be sharply reduced from unirradiated values.

\section{FTR VESSEL WELDMENT STUDIES}

Characterization of candidate FTR vessel weldment processes is in progress. Tensile test results are reported for 
as-fabricated specimens from weldments in 1-inch-thick 304 SS plate. The testing matrix includes four welding processes, three specimen types, and four testing temperatures. This matrix constitutes the baseline mechanical property information to be used on conjunction with the weldment irradiation experiment. Four MK-B-7 type pins containing tensile, creep-rupture, and fatigue specimens have been shipped to the EBR-II site for inclusion in subassembly X067-4F2.

\section{LMFBR FUEL AND CLADDING INFORMATION CENTER}

An information storage, retrieval, and data analysis system consisting of six sections (cladding fabrication, fuel fabrication, fuel-pin fabrication, fuel-subassembly fabrication, irradiation history, and postirradiation examination) is being designed to store information related to the irradiation performance of LMFBR fuel pins. The cladding fabrication section is completed and being used. 
NUCLEAR GRAPHITE

R. E. Nightingale

\section{INERT-GAS-SENSITIZED RADIOLYSIS STUDIES}

\section{G. L. Tingey}

Gasification of graphite in helium-cooled, graphitemoderated reactors occurs due to reactions of impurities in the helium coolant. In the high radiation field of a nuclear reactor, radiation-induced reactions as well as thermallyinduced processes occur.

In a high-purity system such as the HTGR, most of the radiation energy is absorbed initially in the helium coolant. Thus, the rate of gasification is largely dependent upon the effectiveness of the energy transfer from excited helium to the reactive impurities.

Previous studies (1) have shown that the energy absorbed in helium is just as effective in producing reaction as that energy absorbed directly in the reactive gases when the impurity concentration is greater than about $0.6 \%$. More recently, we have demonstrated ${ }^{(2)}$ a significant decrease in the efficiency of energy transfer when the total impurity concentration was $0.06 \%$.

Studies have now been conducted to determine the efficiency of energy transfer at impurity concentrations as low as $54 \mathrm{ppm}$. For this study, we have measured the $\mathrm{G}(\mathrm{CO})$ for the reaction of carbon dioxide with hydrogen in a large excess of helium. The measured $\underline{G}(\mathrm{CO})$ at $350{ }^{\circ} \mathrm{C}$ at $\mathrm{CO}_{2}$ and $\mathrm{H}_{2}$ concentrations above $3500 \mathrm{ppm}$ is 1.9 molecules/100 eV. This value decreases slightly as the $\mathrm{CO}_{2}$ and $\mathrm{H}_{2}$ concentration decreases below $500 \mathrm{ppm}$. At a concentration of $\mathrm{H}_{2}$ and $\mathrm{CO}_{2}$ of $300 \mathrm{ppm}$, the $\underline{G}(\mathrm{CO})=1.5$ molecules $/ 100 \mathrm{eV}$. As the $\mathrm{CO}_{2}$ and $\mathrm{H}_{2}$ concentrations decrease further, there is a further decrease in $\underline{G}(\mathrm{CO})$ to a value of 0.65 molecules/100 eV when the $\mathrm{CO}_{2}$ and $\mathrm{H}_{2}$ concentrations are each $54 \mathrm{ppm}$. 
Further experiments are planned to extend the measurements down to impurity levels near $1 \mathrm{ppm}$.

RADIATION-INDUCED CREEP IN GRAPHITE - W. J. Gray

Molten-salt reactors of the types being considered by oak Ridge National Laboratory require a graphite capable of remaining impermeable both to the molten salt itself and also to fission gases. ORNL has assumed that a graphite that was initially impermeable to the salt and fission gases would remain so, at least until it began to expand rapidly at high fast-neutron fluences. Also, it is known that stresses built up within the graphite by thermal gradients and neutron flux gradients would be relaxed, at least at low fluences, by radiation-induced creep thereby preventing cracking of the graphite. It remains to be demonstrated, however, that the creep constant remains high enough to accommodate the anticipated stresses at high fluences. Consequently, a study has been started to measure creep constants at fluences up to $3 \times 10^{22} \mathrm{n} / \mathrm{cm}^{2}$ $(\mathrm{E}>50 \mathrm{keV})$.

Although irradiations for this study have not yet been started, ORNL and PNL have reached general agreement on the design of this study. Specifically:

- Three types of graphite will be irradiated: AXF-80BG, a fine-grained, isotropic graphite manufactured by POCO Graphite, Inc.; $\mathrm{H}-337$, a raw coke, isotropic graphite manufactured by Great Lakes Carbon Corp.; and AGX (CS-112). The latter will be included only as an analogue to AGOT graphite on which ORNL already has some creep data.

- Irradiation temperatures will be 550 and $800{ }^{\circ} \mathrm{C}$ with a goal of $\pm 30{ }^{\circ} \mathrm{C}$ control.

- Stress levels will be set at 1000 , 2000, and 3000 psi, determined by a fixed load but with varied sample cross sections. Stress will be applied by a pneumatic bellows. 
- Although tensile and compressive creep should be identical at low fluences, they may very well differ at high fluences. However, only compressive experiments will be done at first, with the idea that tensile experiments will be started after experience is acquired with the compressive tests.

- Samples will be irradiated in the L8 test position of the ETR reactor. Compressive creep capsules will go in two of the quadrants, one capsule for each irradiation temperature. Eventually, a third quadrant will likely be occupied by a tensile creep capsule. Irradiation of the compressive creep capsules will be started in October, 1969.

- A careful determination of the flux profile in the L 8 position will be made, taking into account neutrons with energies greater than $50 \mathrm{keV}$. The desirability of holding the flux profile constant will necessitate the same configuration in the test facility at all times. To achieve this, all four quadrants will be occupied by graphite samples.

\section{REFERENCES}

1. G. I. Tingey. Inert-Gas Sensitization in the Radiolysis of Gaseous Mixtures, BNWL-SA-590. Batteile-Northwest, Richland, Washington, March 21, 1966.

2. A. I. Bement, G. J. Dau, E. A. Evans and R. E. Nightingale. Quarterly Progress Report, January, February, March, 1969, Reactor Fuels and Materials Development Programs for Fuels and Materials Branch of USAEC Division of Reactor Development and Technology, BNWL-1058. Battelle-Northwest, Richland, Washington, May, 1969. 


\section{HTGR GRAPHITE}

\section{THE RADIOLYTIC REACTION OF GRAPHITE WITH WATER VAPOR -}

R. E. Woodley

As a consequence of impurity problems in the previous ampoule irradiations, the radiolytic reaction of graphite with water vapor is presently being investigated in a single-pass flow system. In this system, approximate1y 20,000 volume parts per minute ( $\mathrm{vpm})$ of water vapor are added to the helium carrier gas following purification of the helium by passage over hot copper turnings and through a liquid nitrogen-cooled molecular sieve trap. After humidification, the helium is flowed past a TSX graphite sample positioned in the cobalt-60 gamma facility at the point of highest dose rate $\left(\sim 1.7 \times 10^{7} \mathrm{R} / \mathrm{hr}\right)$. To determine the reaction rate, the influent and effluent gas streams are sampled simultaneously and the gas samples analyzed on a Varian Trace Gas Analyzer. Changes in the concentrations of oxides of carbon can then be related to the rate of reaction. In order to obtain the radiolytic yield, one must know the volume of "activated" gas effective in promoting reaction. For this reason, the graphite sample was machined to fit tightly within its container. Measurements of the apparent density $\left(1.700 \mathrm{~g} / \mathrm{cm}^{3}\right)$ and the helium density $\left(2.188 \mathrm{~g} / \mathrm{cm}^{3}\right)$ allow the calculation of the open pore volume of the graphite sample. It is this volume which is used to calculate radiolytic yields.

Under the experimental conditions presently employed $\left(\mathrm{C}_{2} \mathrm{O} \simeq 20,000 \mathrm{vpm}, \overline{\mathrm{T}}_{\text {graphite }}=117{ }^{\circ} \mathrm{C}\right.$, and helium flow rate $=30 \mathrm{~cm}^{3} / \mathrm{min}$ ) changes in the concentration of $\mathrm{CO}_{2}$, the major product analyzed, are very small, amounting to only a few tenths of $1 \mathrm{vpm}$. The presence in the influent gas stream of $\mathrm{CO}_{2}$ at concentrations ranging from about 0.2 to $0.6 \mathrm{vpm}$ tends to mask the graphite - water vapor reaction, because $\mathrm{CO}_{2}$ also undergoes a radiolytic reaction with graphite. One source of this $\mathrm{CO}_{2}$ appears to be the water used to humidify the helium, 
even though the water was initially purified by distillation followed by alternate freezing and pumping. Another source may be $\mathrm{CO}_{2}$ adsorbed on the walls and in the stopcock grease of the gas sampling bulbs.

The very small changes observed in the $\mathrm{CO}_{2}$ concentration upon irradiation have been both positive and negative. When the inlet $\mathrm{CO}_{2}$ concentration is relatively high, 0.5 to $0.6 \mathrm{vpm}$, a decrease in the concentration has been observed. This decrease is presumably a result of radiolytic reaction with the graphite. The average radiolytic yield for this process is $\mathrm{G}\left(-\mathrm{CO}_{2}\right)=1.7$. At lower initial $\mathrm{CO}_{2}$ concentrations, $<0.5 \mathrm{vpm}$, an increase in the $\mathrm{CO}_{2}$ concentration upon passage through the gamma facility has been noted. This increase may arise from the graphite - water vapor reaction and exhibits $\mathrm{G}\left(\mathrm{CO}_{2}\right)$ values ranging from 0.8 to 1.6 . At the present time, it is difficult to draw any firm conclusions from these data, other than it seems likely that the radiolytic yield for the graphite - water vapor reaction must be small. Obviously, as much $\mathrm{CO}_{2}$ as possible must be removed from the inlet gas in order to reduce its interference with the vapor reaction. Improved analytical results will be obtained by alternately flowing the inlet and outlet gas streams directly through the sampling system of the gas chromatograph rather than relying on sample bulbs which are always potentially contaminated with $\mathrm{CO}_{2}$. 
NUCLEAR CERAMICS

R. E. Nightingale

PROPERTIES OF MOLTEN FAST-REACTOR OXIDE FUELS - R. P. Nelson, J. J. Rasmussen, and O. D. Slagle

\section{Measurements System}

Installation of the high-temperature vacuum resistance furnace within a plutonium glove box located in the shielded Materials Facility has been completed. This arrangement will allow measurements of liquid density, viscosity, surface tension, and compressibility on both unirradiated and irradiated mixed-oxide fuels to $3000{ }^{\circ} \mathrm{C}$. The furnace employs a tungstenmesh resistance element and a split radiation shield assembly allowing $x$-radiographic determination of liquid density and surface tension with a minimum of absorbing material in the image-forming $X$-ray beam. Preliminary measurements of surface tension and density will be made of $\mathrm{UO}_{2}$ before the system is committed to plutonium.

A second furnace intended specifically for surface tension measurements of mixed oxides by the pendant-drop method is being designed. This furnace, which employs a self-resistance heated capsule, will replace an older furnace which is unsuitable for glove box operation.

Surface Tension

Surface tension is being measured by two liquid surface shape techniques: pendant drop shape and equilibrium meniscus shape. In both cases, a profile of the liquid surface is obtained by $x$-radiography of the material contained in a closed refractory-metal capsule. The pendant drop shape technique has the advantage that the liquid oxide is only in contact with solid oxide of the same composition. Thus, impurities which 
can affect the surface tension value are not picked up from the capsule. However, the surface tension can only be obtained at the melting point temperature. The equilibrium meniscus shape technique can be used at temperatures well above the melting point.

Pendant drops are formed on the end of the sintered oxide rods which are suspended vertically in the refractory-metal capsule in such a way that the free end of the rod coincides with the center of the capsule length. The capsule walls are thinned slightly from each end to the center in order to establish a temperature gradient when the capsule is selfresistance heated. In this way, only the free end of the rod is melted and a stable pendant drop is formed. If the temperature is raised, the drop falls off the rod and a new drop is formed. In this way, several different drops can be radiographed during a single experiment. The equilibrium meniscus shape is obtained by melting a rod of the oxide in a capsule having a uniform temperature. The rod volume is adjusted so that the melt fills the lower portion of the capsule.

When two fluids are separated by an interface, the shape of the interface is governed by the fundamental equation for the definition of surface tension,

$$
\frac{1}{\mathrm{R}_{1}}+\frac{1}{\mathrm{R}_{2}}=\frac{\mathrm{P}}{\gamma}
$$

where $R_{1}$ and $R_{2}$ are the principal radii of curvature at a point on the surface, $P$ is the pressure difference across the interface at the point, and $\gamma$ is the interfacial tension. When the pressure difference is due to gravitation, Equation (1) leads to the differential equation describing the shape of a cylindrically symmetric drop, 


$$
\begin{gathered}
b f^{\prime}(z)+\frac{b}{\bar{x}}\left\{1+\left[f^{\prime}(z)\right]^{2}\right\} f^{\prime}(z) \\
=\left(2+\frac{\beta Z}{b}\right)\left\{1+\left[f^{\prime}(z)\right]^{2}\right\}^{3 / 2},
\end{gathered}
$$

where

$$
\begin{aligned}
f^{\prime}(z) & =\frac{d z}{d X}, \quad f^{\prime}(z)=\frac{d^{2} z}{d X^{2}}, \\
\beta & =\frac{g b^{2} \Delta \rho}{\gamma},
\end{aligned}
$$

$b$ is the radius of curvature at the base of the drop, $g$ is the gravitational acceleration, $\Delta \rho$ is the difference in fluid densities, $\gamma$ is the surface tension, and $X$ and $Z$ are the coordinates of points along the line of intersection of the drop surface and a plane containing the radius of curvature b. In most cases, the capsule is sealed in vacuum and $\Delta \rho$ is simply the liquid density. The parameter $\beta$ describes the shape of the drop, and b is a measure of drop size. All drops with the same value of $\beta$ are geometrically similar. $\beta$ is positive for oblate figures of revolution, i.e., for a sessile drop or a meniscus in a capillary and negative for prolate figures of revolution, i.e., for a pendant drop.

A computer program has been written which determines the surface tension by analyzing the shape of a pendant arop or meniscus. Using the pendant drop as an example, the program is set up by measuring $X, Z$ pairs from the drop profile along the arc segment from $\phi=0^{\circ}$ to $\phi=90^{\circ}$, (Figure 5.1). The largest value of $X$ and the associated $Z$ value are found. These are assumed to be $X_{90}$ and $Z_{90}$, the drop coordinates at the equator. A table of $x_{90} / Z_{90}$ as a function of $\beta$, taken from Bashforth and Adams, (1) is searched to obtain the initial value of $\beta$. The function $Z(X, b, \beta)$ is generated from Equation (2) and compared with the experimental $X, Z$ pairs. The parameters $b$ and 
BNWL -1144

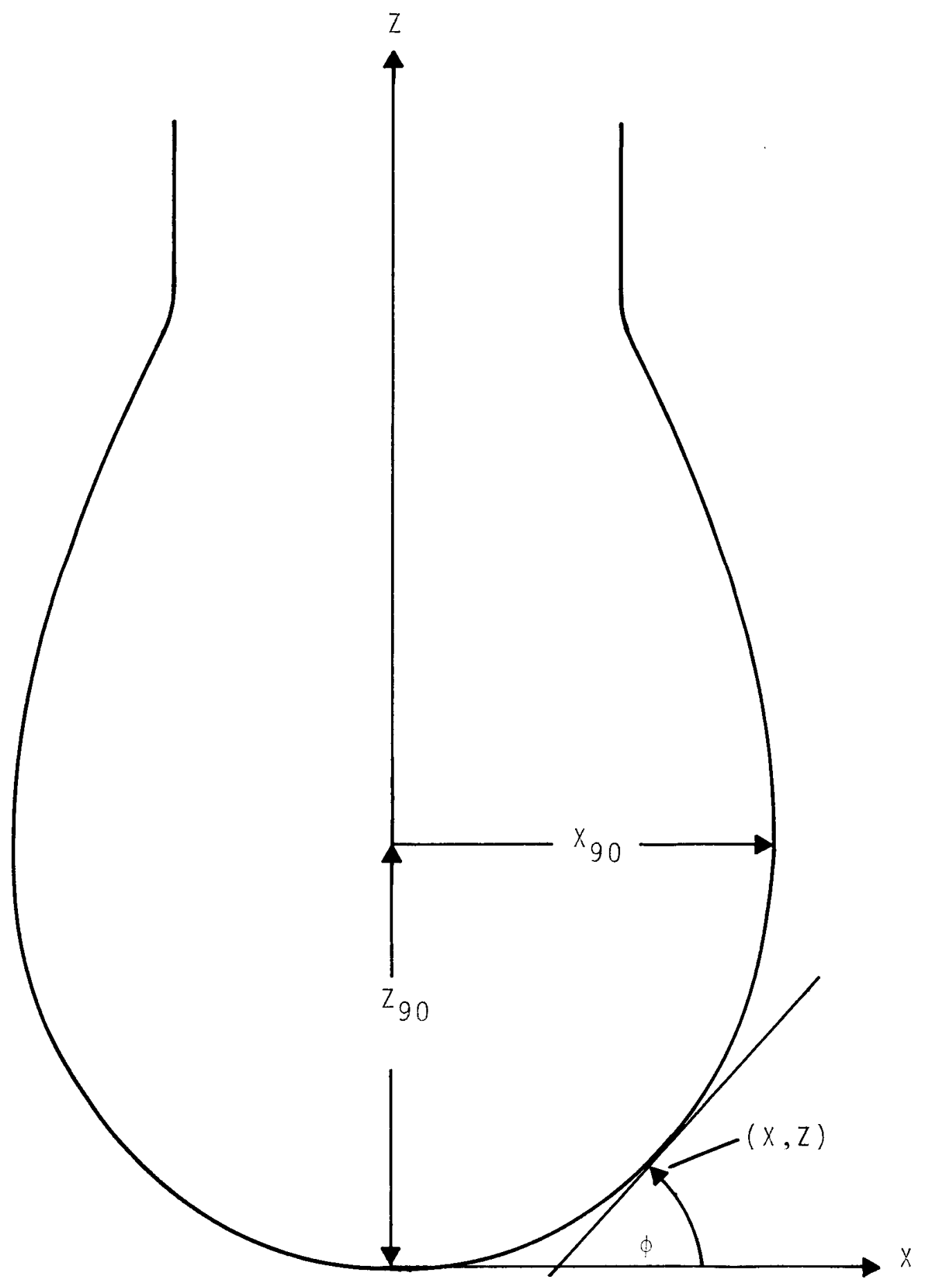

FIGURE 5.1. Parmeters for Determination of Surface Tension from the Shape of a Pendant Drop 
$\beta$ are then adjusted to obtain the best fit between the experimental values and the calculated values. The surface tension is then calculated from Equation (3) using the adjusted values of $b$ and $\beta$.

The techniques have been checked using $\mathrm{Al}_{2} \mathrm{O}_{3}$. Preliminary values are in good agreement for the surface tension found by the pendant-drop technique and the equilibrium meniscus-shape technique and with values for the surface tension reported in the literature. $\mathrm{A}_{2} \mathrm{UO}_{2}$ pendant-drop capsule is presently being prepared.

\section{ELECTRICAL CONDUCTIVITY OF CERIUM OXIDE - J. L. Bates}

Cerium oxide has a fluorite structure and properties similar to that of $\mathrm{PuO}_{2}$ and is often used as a non-radioactive stand-in for $\mathrm{PuO}_{2}$. The purpose of this study was to determine the electrical conductivity $(\sigma)$ of cerium oxide from room temperature to a temperature as near the melting point as possible in an effort to understand the high temperature physical and structural properties of related oxides of plutonium.

Initial electrical conductivity measurements (2) have been reported for three thermal cycles to $1000^{\circ} \mathrm{C}$ and for a fourth cycle extending to $1995^{\circ} \mathrm{C}$. This report describes the electrical conductivity results of a fifth thermal cycle to $2000{ }^{\circ} \mathrm{C}$, and the characterization of the sample after the electrical measurements were completed. Figure 5.2 illustrates the results and heating conditions for all five cycles.

The electrical conductivity of the starting stoichiometric $\mathrm{CeO}_{2}$ near room temperature was below the measurable limits $\left(10^{-6}\right.$ mios $\left./ \mathrm{cm}\right)$ of the apparatus. Therefore, the initial measurements in the first four thermal cycles began between 200 and $300{ }^{\circ} \mathrm{C}$. The conductivity increased rapidly with temperature and exhibited two discontinuities in the $\log \sigma$ versus $1 / \mathrm{T}$ curve (Figure 5.2). These breaks occurred at approximately 


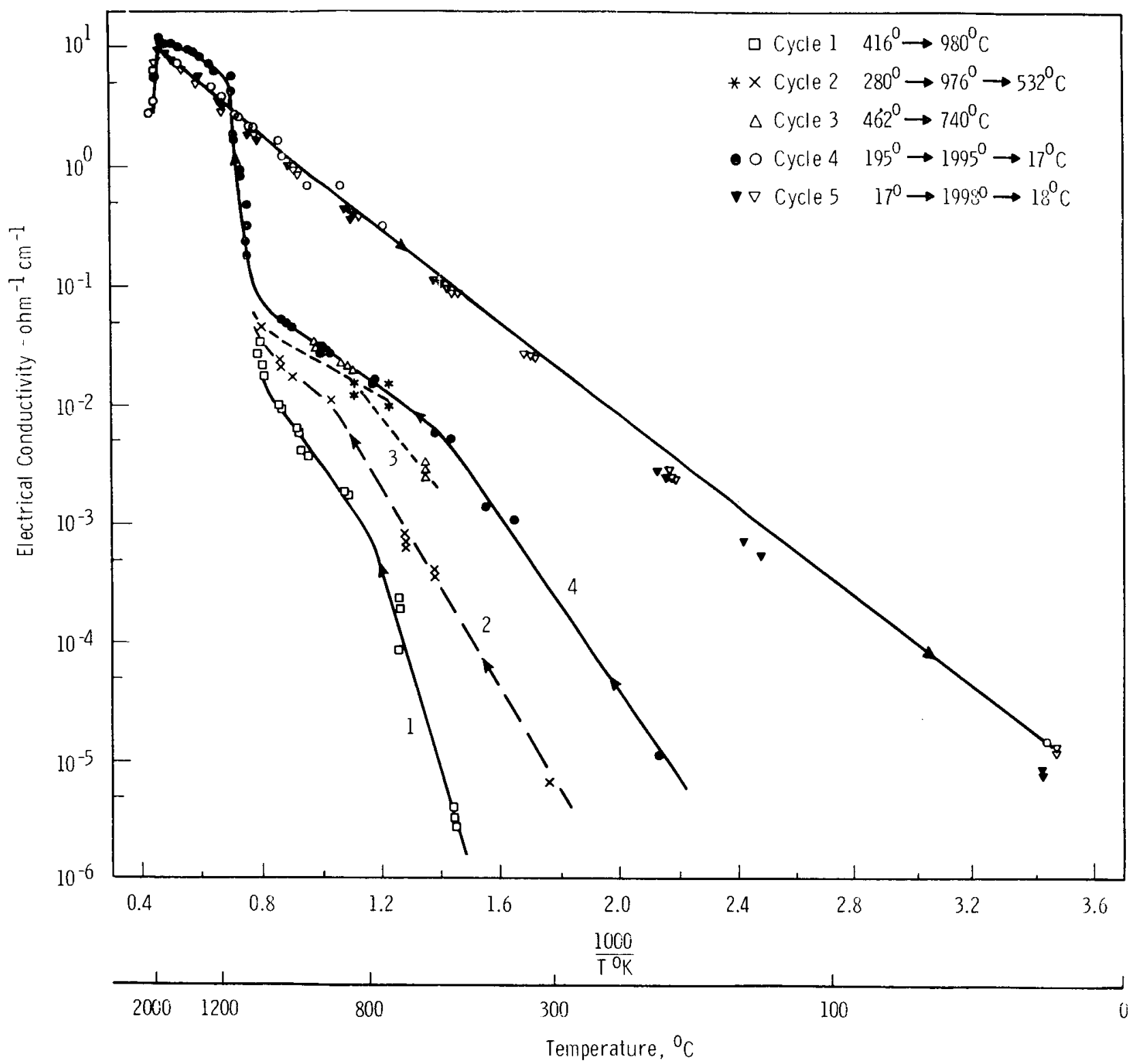

FIGURE 5.2. Electrical Conductivity of CeO $2-x$. 
550 and $950{ }^{\circ} \mathrm{C}$ with the slope of the curve between these two temperatures less than the slope at higher or lower temperatures. Similarly shaped curves were observed during Cycles 1 through 4 below $1000^{\circ} \mathrm{C}$. Each cycle resulted in significant increases in conductivity and in a reduction of activation energy. In each instance, the slope above and below the break at approximately 200 to $300{ }^{\circ} \mathrm{C}$ decreased during subsequent heating cycles.

Above approximately $1000^{\circ} \mathrm{C}$, the electrical conduction increases significantly with increasing temperature and is associated with an activation energy of approximately $5 \mathrm{eV}$. A11 of the conductivity curves for which the maximum temperature hand not exceeded $1000{ }^{\circ} \mathrm{C}$ converge into this straight line, observed in Cycle 4. At approximately $1130{ }^{\circ} \mathrm{C}$, another sudden change occurs in the temperature dependence of the log $\sigma$ versus $1 / \mathrm{T}$ curve. In the small temperature range between approximately 1000 and $1130{ }^{\circ} \mathrm{C}$, the electrical conductivity increased approximately 250 times compared to an increase of 2 to 3 in the larger temperature interval from 1130 to $1900{ }^{\circ} \mathrm{C}$. The electrical conductivity decreased from 12 to 3 mhos/cm during an increase in temperature from 1900 to $1995^{\circ} \mathrm{C}$.

Measurements during a fifth cycle were conducted to determine if the unusual changes in the electrical conductivity observed during the cooling portion of Cycle 4 could be reproduced.

The electrical conductivity during both heating and cooling agree very closely with the electrical conductivity values measured during cooling of Cycle 4 (Figures 5.2 and 5.3). The values during heating were slightly less than those during the previous high temperature cycle. Both exhibited a decrease in conductivity above $1900{ }^{\circ} \mathrm{C}$ with the change occurring at a slightly higher temperature during the final heating cycle. 


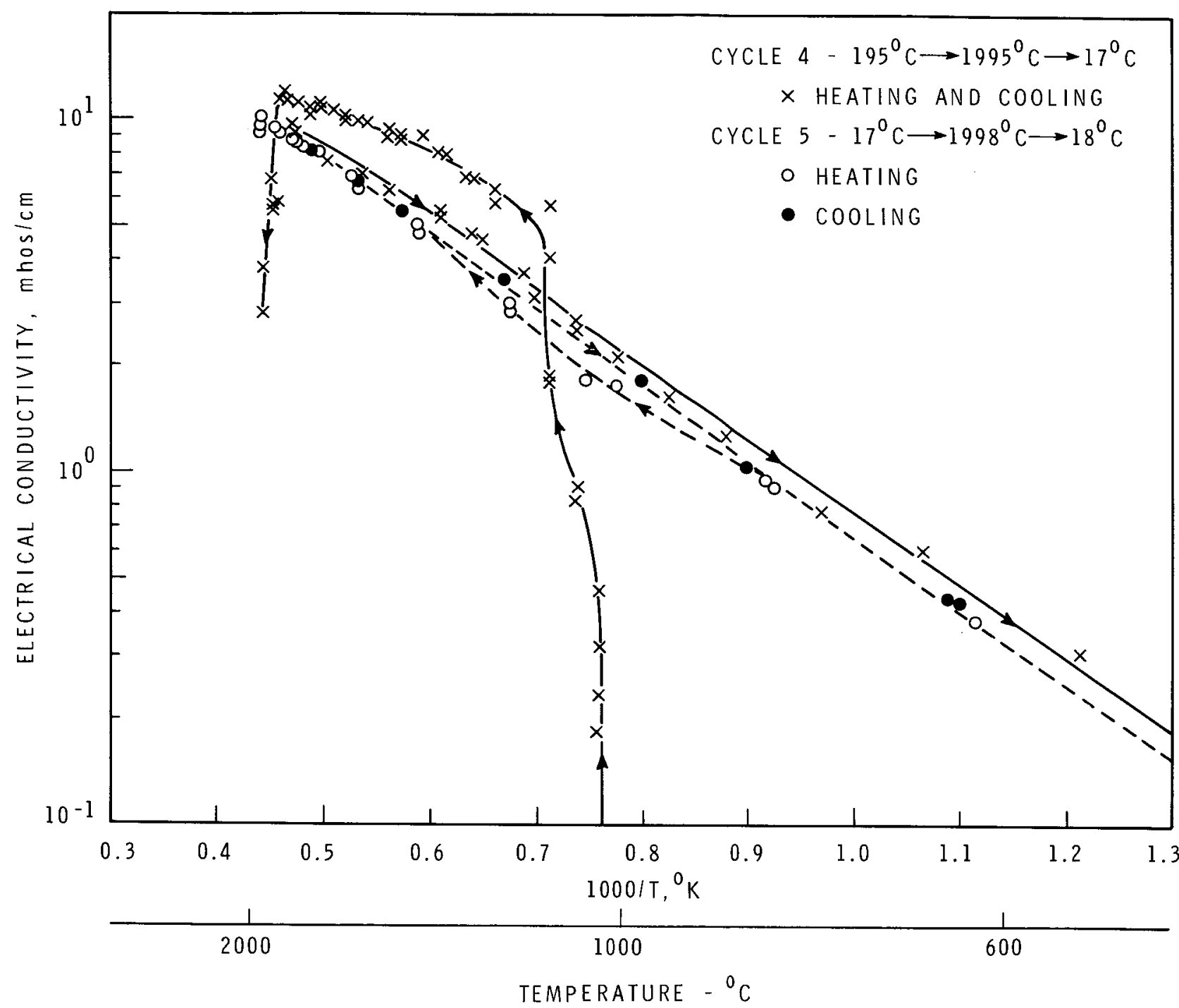

FIGURE 5.3. High-Temperature Electrical Conductivity of CeO $2-x$ (Values not corrected for dimensional changes which occurred near apparent melting point.) 
Slight changes in linearity in the $10 \mathrm{~g} \sigma$ versus $1 / \mathrm{T}$ curve between 1000 and $1300{ }^{\circ} \mathrm{C}$ were observed in both high-temperature cycles. A slight hysteresis was observed on heating and cooling in this temperature range in Cycle 5 (Figure 5.3). Therefore, the electrical conductivity values in Cycles 4 and 5 appear to be representative of the $\mathrm{CeO}_{2-x}$ removed from the furnace.

The appearance of the sample changed considerably during the electrical conductivity measurements. The color of the original stoichiometric sample was white with a yellowish cast. The sample at the termination of the experiments was a dark blue-black. The sample, although still intact, showed a glassly-like appearance and evidence of material flow. This was interpreted to have resulted from partial melting of the $\mathrm{CeO}_{2}$ sample. Some changes in sample and electrode probe dimensions were observed (Figure 5.4). The $\mathrm{CeO}_{2-\mathrm{x}}$ was extremely friable and broke into small pieces when removed from the tungsten holders.

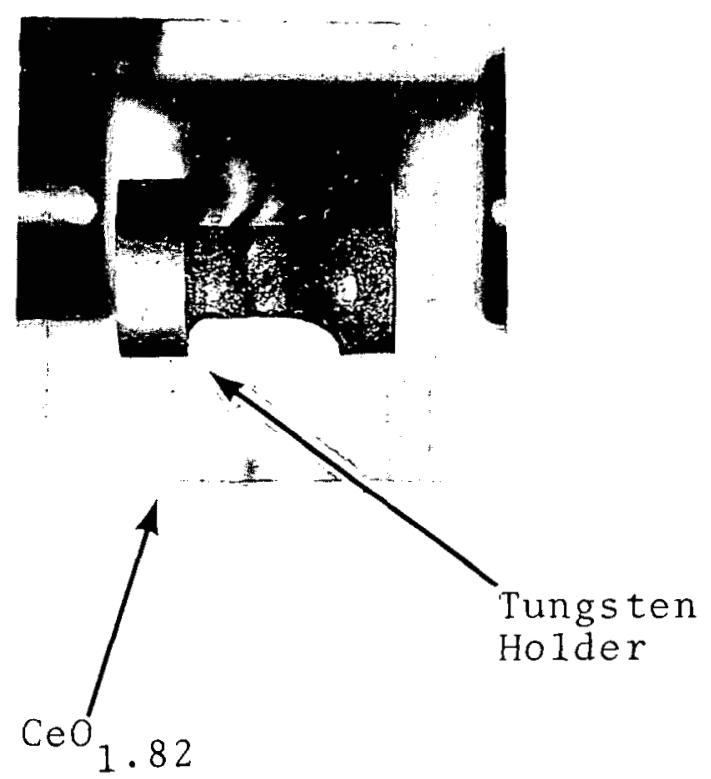

FIGURE 5.4. Bottom View of CeO 1 sample in Tungsten Holder Showing Glassy Appẹarance of oxide Surface and Areas of Sample Elow. $\quad(0.80 X)$ 
An analysis of the changes in the sample cross sectional area (A) and the voltage probe spacing ( $l$ ) showed a decrease of $85 \%$ in the $A / l$ ratio resulting during the electrical conductivity measurements. These changes are small compared to the gross changes in conductivity. The curves corrected for these dimensional changes are shown in Figure 5.5.

Thermogravimetric analysis in air of the $\mathrm{CeO}_{2-x}$ showed a strong oxidation reaction between 200 to $250{ }^{\circ} \mathrm{C}$ and a smaller reaction near $450{ }^{\circ} \mathrm{C}$. Very little weight change was observed from 450 to $950{ }^{\circ} \mathrm{C}$. The $\mathrm{O} / \mathrm{Ce}$ ratio for two samples was 1.82 .

The microstructure of the $\mathrm{CeO}_{1.82}$ after the conductivity measurements is illustrated in Figures 5.6 and 5.7. The oxide near the outer shiny sample surface was made up of large grains relatively free of porosity. This area, which was near the tungsten holders, contained metallic inclusions of tungsten, a darker second phase, and was grossly cracked.

A sharp demarkation is apparent between the high density area near the surface and the interior of the sample. The interior was free of metaliic and darker oxide second phases. The oxide was interlaced with fine cracks, which made the sample very friable and difficult to polish. This structure is very similar to structure observed in $\mathrm{CeO}_{2}$ which had formed during melting point measurements.

Preliminary $X-r a y$ diffraction examination indicated a twophase system with the major phase being a fluorite cubic structure. Additional $\mathrm{X}$-ray analyses are being conducted. PREPARATION OF UO $2-25$ wt ${ }_{2}$ PU0 2 SPECIMENS FOR HIGH-TEMPERATURE CREEP STUDIES - 0. D. Slagle and J. A. Basmajian

A program was initiated to determine a method of fabricating $\mathrm{UO}_{2}-25$ wt\% $\mathrm{PuO}_{2}$ pellets from which creep test specimens could be prepared. The minimum requirements of such pellets are: 


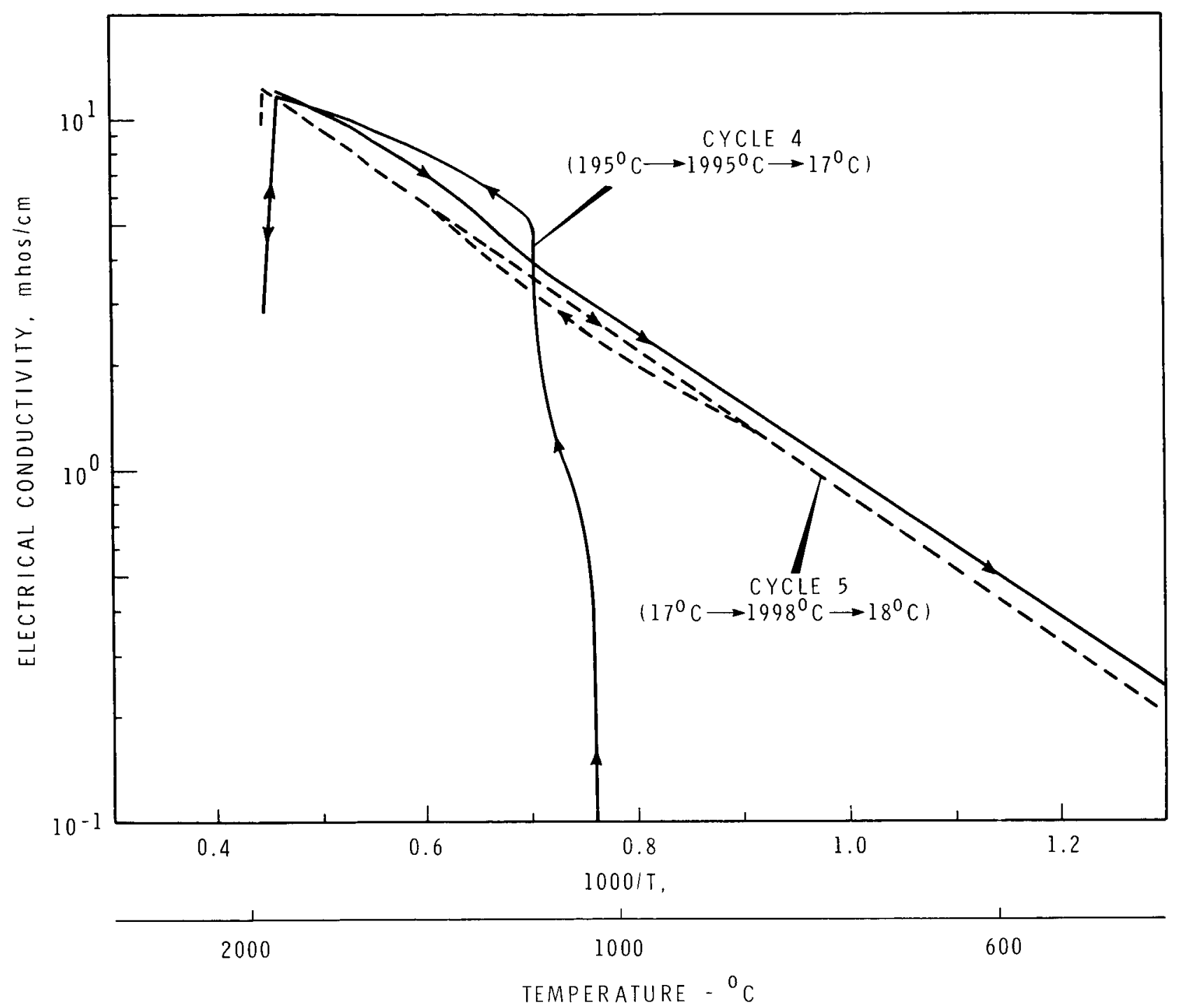

FIGURE 5.5 High-Temperature Electrical Conductivity Ceo Corrected for Dimensional Changes Estimated after Tempéraxture Measurements. 
BNWL -1144

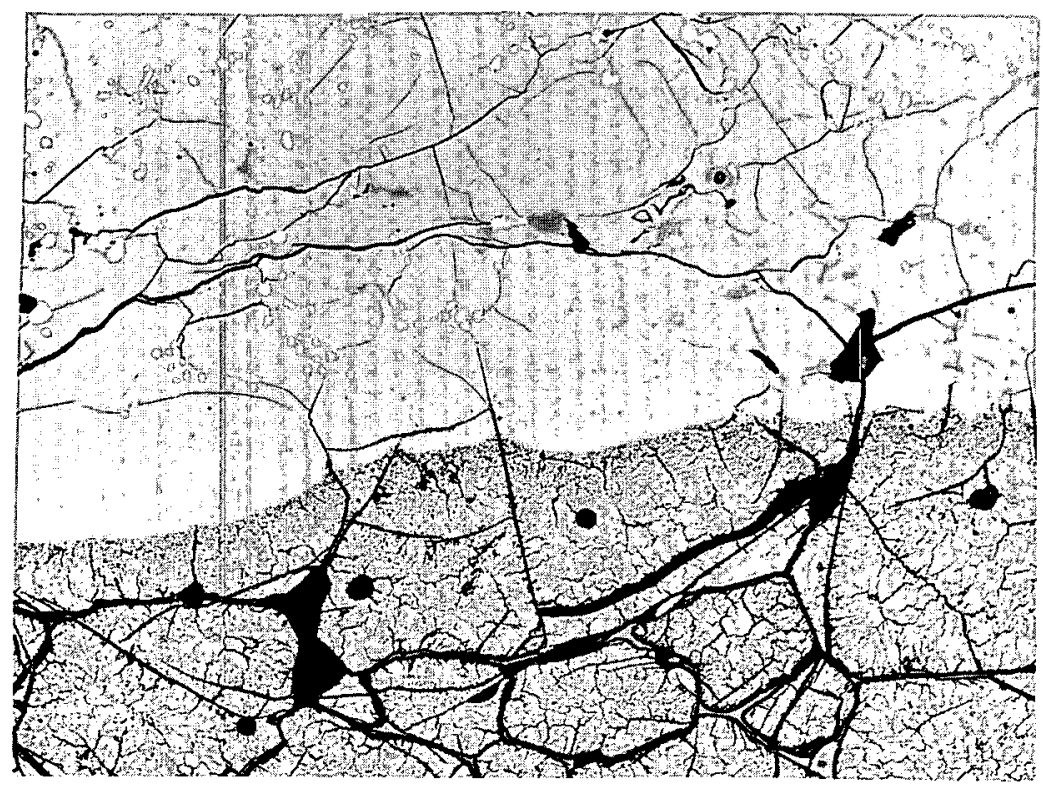

Sample

Surface

Neg $469618 \mathrm{~A}$

$0.05 \mathrm{~cm}$

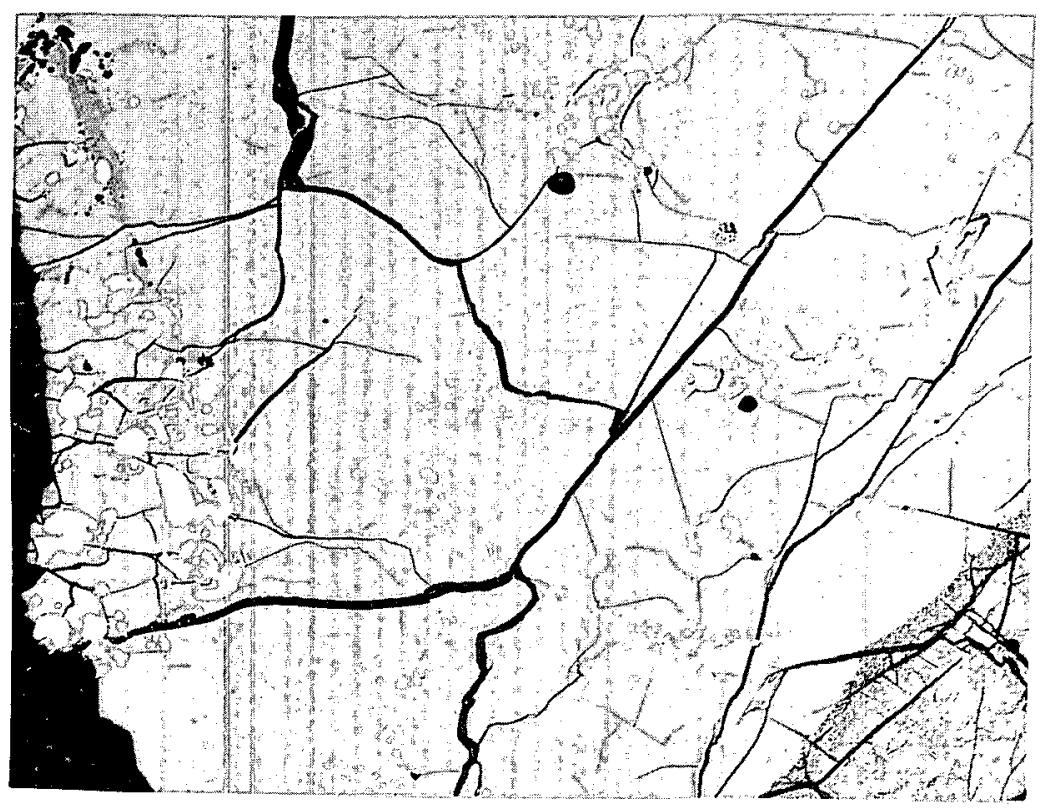

Sample

Surface

Neg $469618 B$

FIGURE 5.6. Microstructures of CeO1.82 After Electrical Conductivity Measurements Showing Large Grains Near Sample Surface in Areas of Sample Flow. (AsPolished 100X) 
BNWL-1144
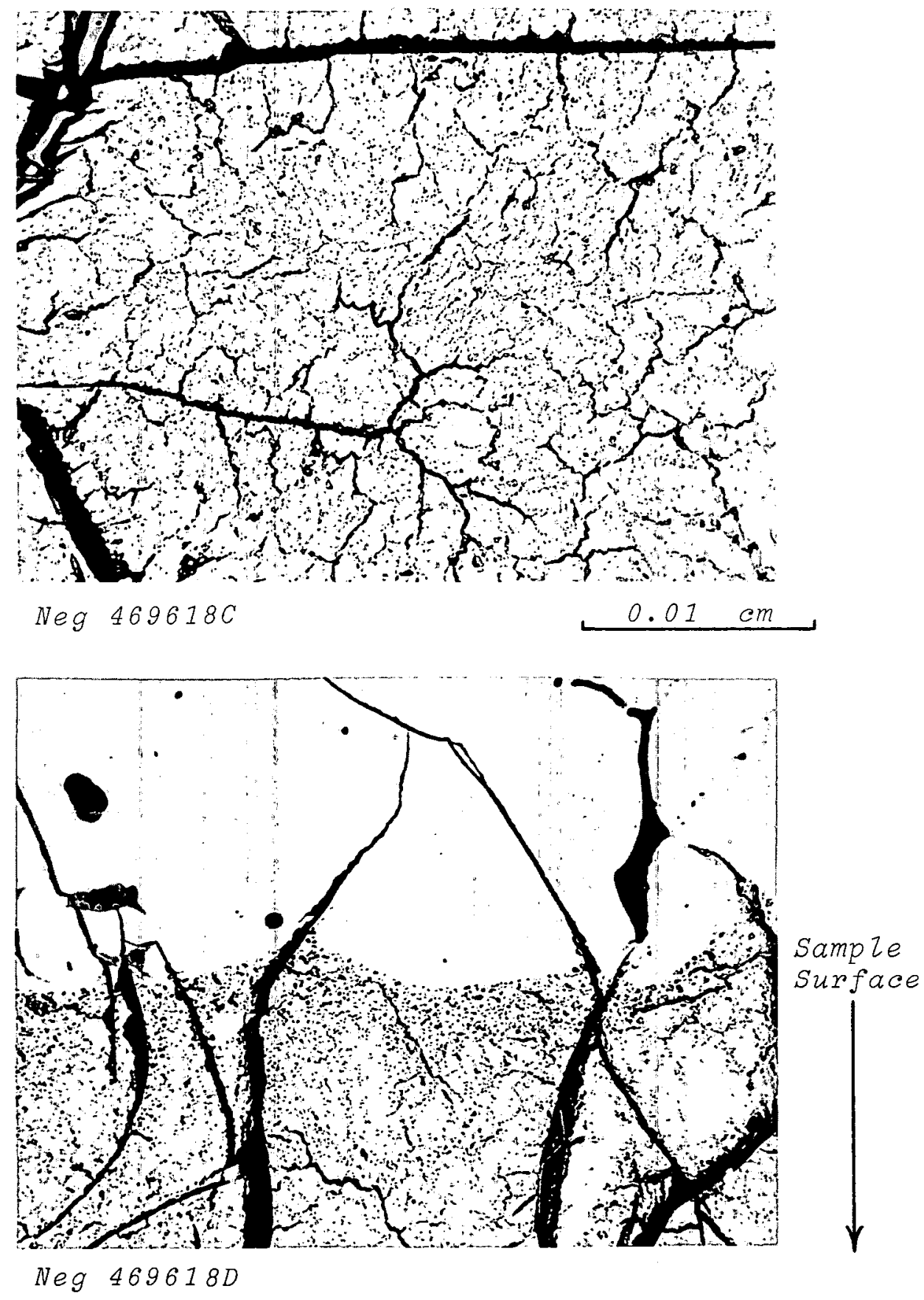

FIGURE 5.7. Microstructure of CeO 1.82 Sample after Electrical Conductivity Measurements $500 \mathrm{X}$ 
- Densities in excess of $90 \%$ TD.

- Uniform size and distribution of grains and pores, with no macro- or micro-cracks.

- Large enough to cut creep specimens, 1-1/8 in. long, for four-point bend tests.

The length of the sample requires a fairly large pellet size. This large size complicates sample preparation due to problems of density and nonuniformity produced during pressing and subsequent cracking during heating and cooling. Two different pellet press shapes have been tried:

- A rectanglular die $1 / 2$ in. $x$ 1-1/2 in.

- A cylindrical die 1-1/2 in. in diameter.

The pressed pellets are $1 / 2$ in. thick. The rectangular shape is more desirable because there is much less wastage when cutting the bar-shaped creep specimens. However, since rectangular pellets tended to laminate more easily during pressing, all the pellets in this study were pressed in the cylindrical die.

A number of techniques were considered for obtaining crackfree, uniform pellets, and the resulting study is outlined in Table 5.1. The UO ${ }_{2}$ used in preparing the mechanical mixtures was ceramic grade powder. All pellets except those containing butyl stearate as a binder were pressed using butyl stearate as a die-wall lubricant. Sintering was carried out in an argon - 8\% hydrogen atmosphere. The sintering schedule was $80{ }^{\circ} \mathrm{C} / \mathrm{hr}$ to $600{ }^{\circ} \mathrm{C}, 100{ }^{\circ} \mathrm{C} / \mathrm{hr}$ to $1650{ }^{\circ} \mathrm{C}$, an 8 -hour hold at $1650{ }^{\circ} \mathrm{C}$, and a cooling rate of $250{ }^{\circ} \mathrm{C} / \mathrm{hr}$.

Table 5.2 1ists the densities before and after sintering of samples prepared from Type 1 powder. In general, increasing the pressing pressure increased the green densities but little or no systematic effect on the final densities was observed. In general, addition of carbowax or butyl stearate gives higher green densities together with a reduction in sintered density, 
TABLE.5.1. Outzine of Sample Preparation Study for $\mathrm{NO}_{2}-25$ wt\% $\mathrm{PuO}_{2}$.

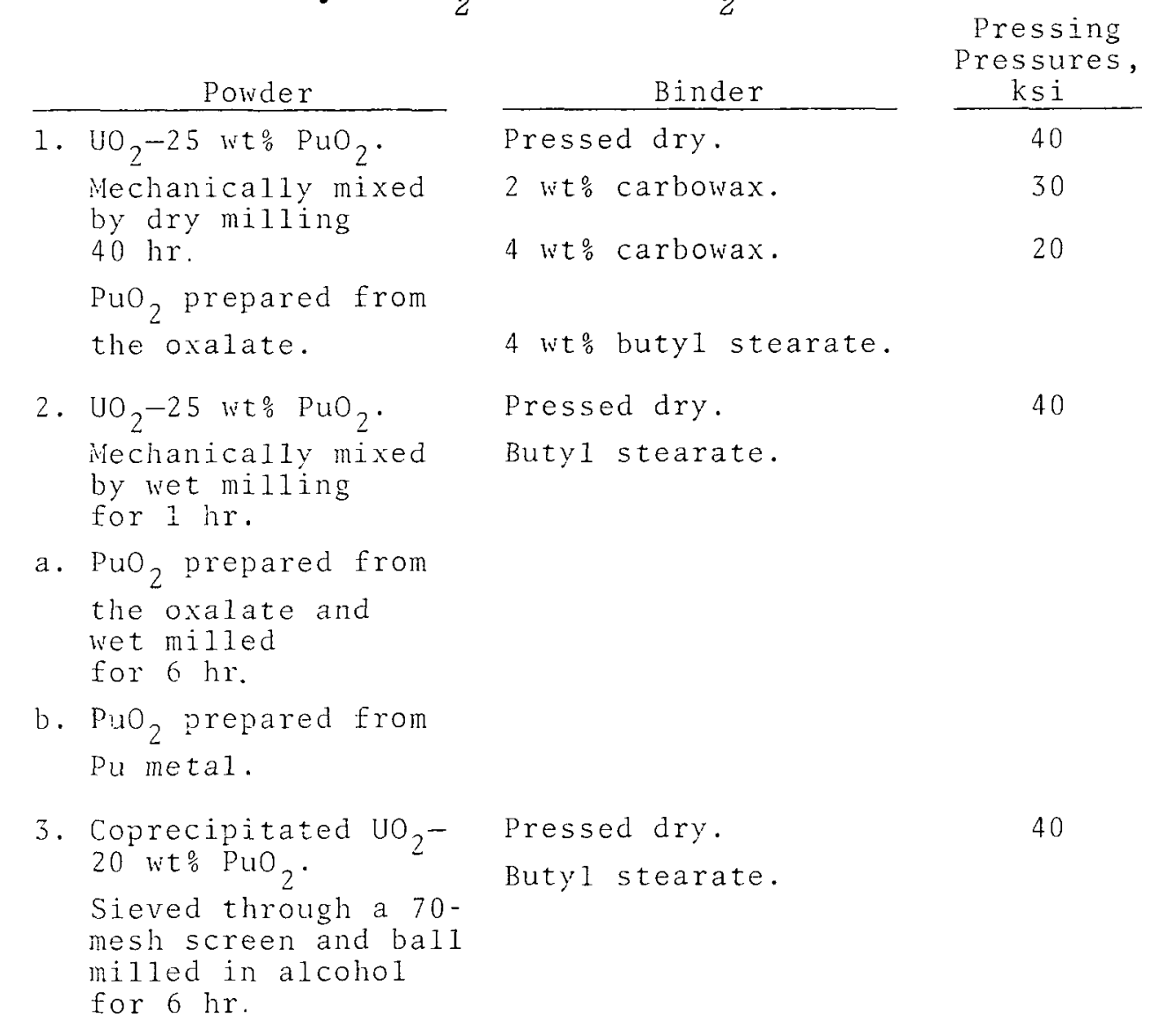

TABLE 5.2. Theoretical Density Before and After Sintering for Type 1 Powder Pellets.

(Percentages of theoretical density before sintering are in parentheses.)

$\frac{\begin{array}{c}\text { Powder } \\ \text { Additive }\end{array}}{\text { Dry }}$
2 wt: Carbowax
4 wt: Carbowax
4 wt: Butyl Stearate

\begin{tabular}{ccc}
\multicolumn{2}{c}{ Pressing Pressure } \\
\hline $40 \mathrm{ksi}$ & 30 ksi & $\frac{20 \mathrm{ksi}}{2}$ \\
94.0 & 94.0 & 93.8 \\
$(52.0)$ & $(49.8)$ & $(46.9)$ \\
93.9 & 94.2 & 94.2 \\
$(53.8)$ & $(52.0)$ & $(49.0)$ \\
91.0 & 93.2 & 92.5 \\
$(53.0)$ & $(51.6)$ & $(49.4)$ \\
89.7 & & 89.1 \\
$(54.3)$ & & $(49.9)$
\end{tabular}


compared to pressing without a binder. For addition of 4 wt\% butyl stearate, this amounted to a $4 \%$ decrease in sintered density.

Figure 5.8 shows representative microstructures for sintered pellets of Type 1 powder pressed dry at (a) 40, (b) 30, and (c) $20 \mathrm{ksi}$. The porosity distribution is very similar for samples pressed at 40 and $20 \mathrm{ksi}$, except that the pellet pressed at $40 \mathrm{ksi}$ has some internal microcracking.

Figure 5.9 shows a similar series of micrographs for pellets pressed with the addition of $2 \mathrm{wt} \%$ carbowax. These indicate that the addition of carbowax has resulted in extensive microcracking and an inhomogeneous distribution of porosity. Figure 5.10 shows the micrographs for pellets pressed from powders having 4 wt: carbowax. For these pellets, very little microcracking occurs but the porosity distribution is very inhomogeneous.

Butyl stearate has been found to be a very effective die lubricant for dry pressing $\mathrm{UO}_{2}$ powder, and addition of butyl $s$ arate to the powder may serve as an efficient powder lubricant during compaction and may result in a higher final density. Actually, the densities in Table 5.2 indicate the opposite effect for the addition of $4 \mathrm{wt} \%$ butyl stearate. The microstructure was not uniform and and contained large spherical pores (Figure 5.11).

Scanning electron microscope studies of starting powders used in mechanically-mixed fast-reactor fuel studies indicate that $\mathrm{PuO}_{2}$ particles prepared from the oxalate are spherical in shape and appear hard and more dense than ceramic-grade $\mathrm{UO}_{2}$. This suggests that the spherical voids present in these microstructures may result from the characteristics of the $\mathrm{PuO}_{2}$ powder. The Powder Types $2 \mathrm{a}$ and $2 \mathrm{~b}$ represent attempts to eliminate the spherical pores. In the case of Type $2 \mathrm{a}$, the $\mathrm{PuO}_{2}$ 


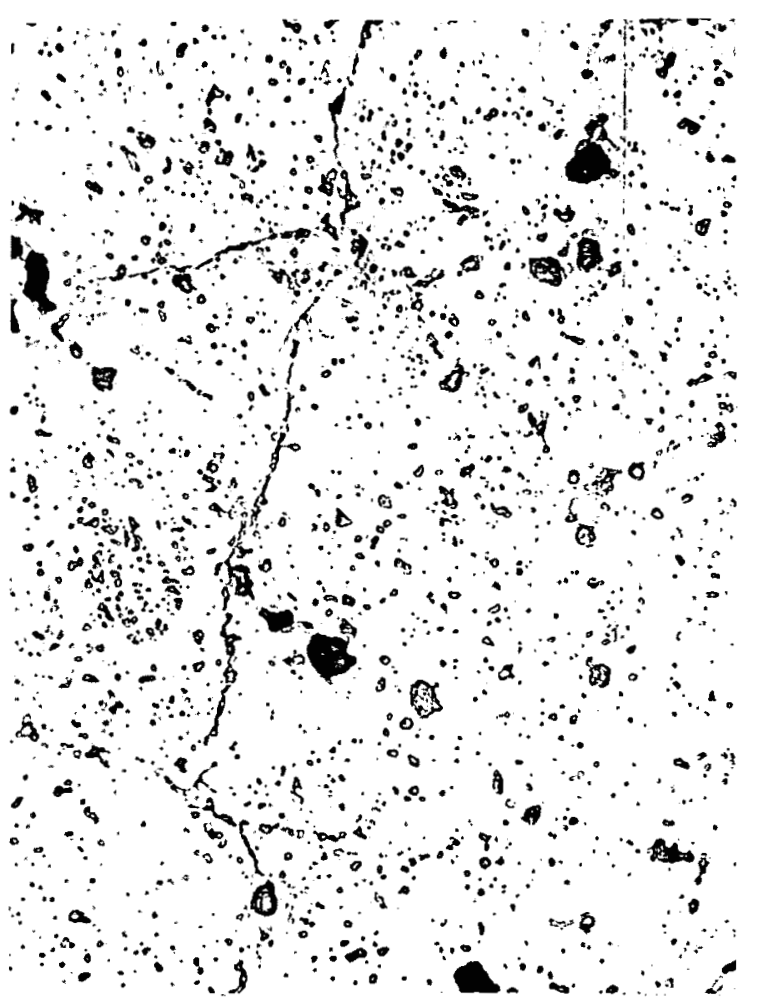

Neg $4961 B$ (a) $40 \mathrm{ksi}$.

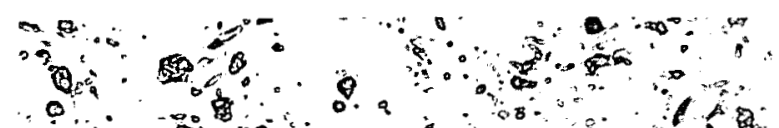

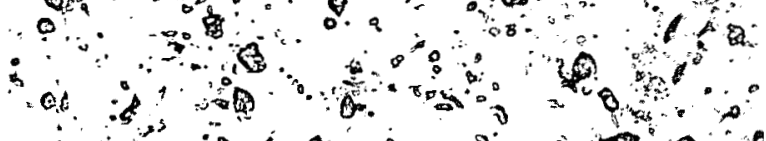

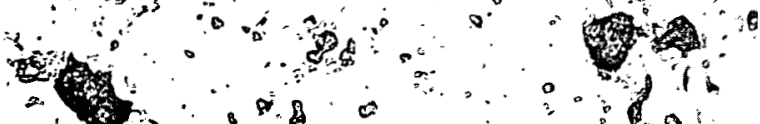
$\begin{array}{ccccc}0 & 0 & 0 & 0 & 0\end{array}$

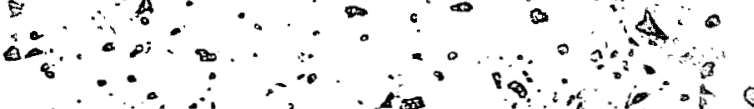

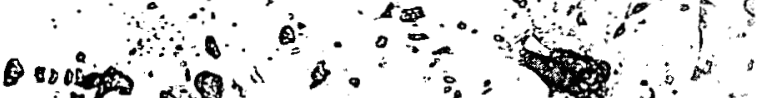

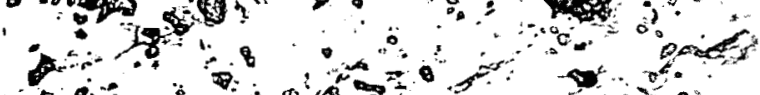

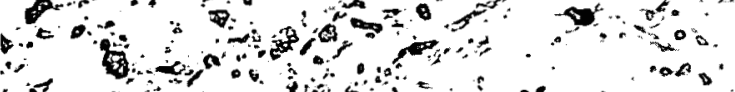

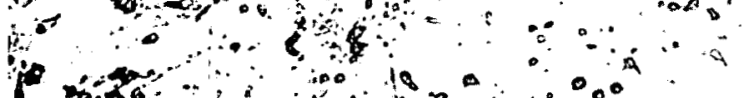

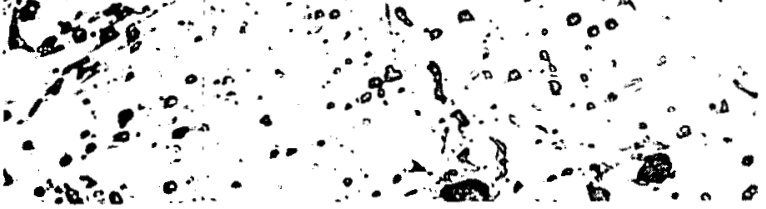

Neg $4962 B$

(b) $30 \mathrm{ksi}$.

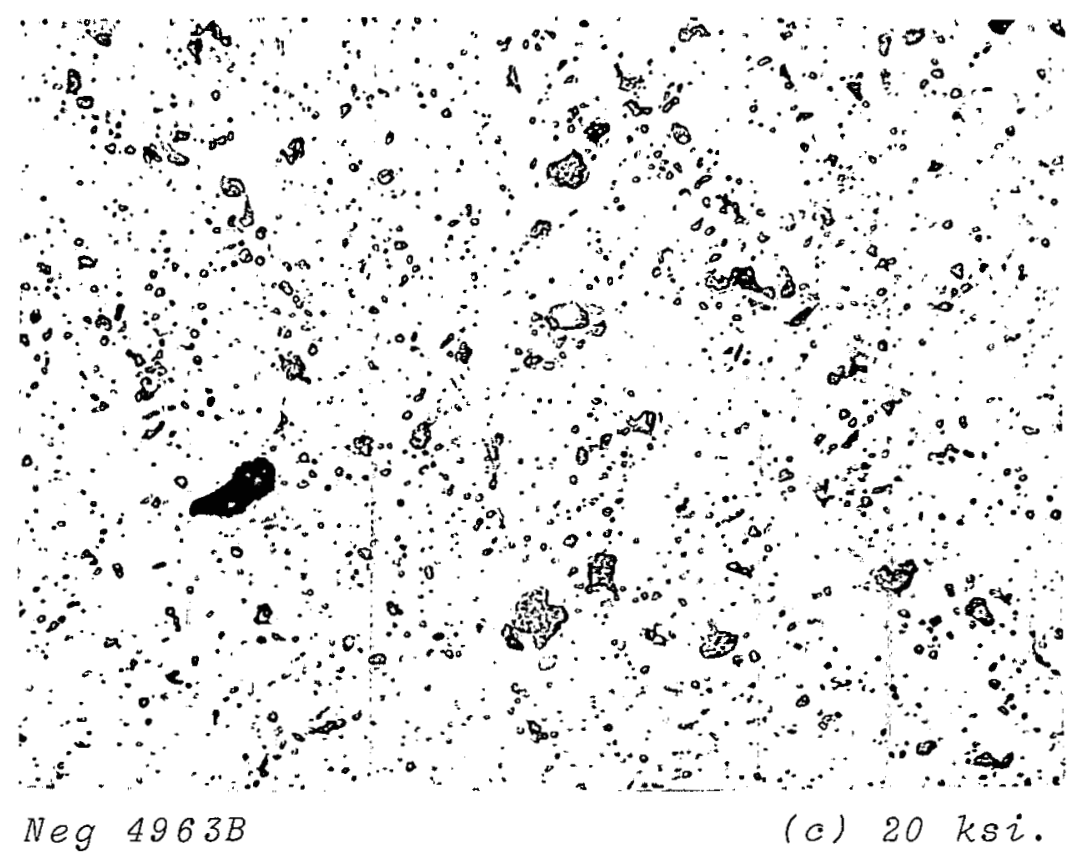
$\frac{50 H}{\text { EIGURE 5.8. }}$
$\begin{aligned} & \text { Representative Microstructures (Unetched) } \\ & \text { of Type } 1 \text { Powder Pressed Dry (500X) }\end{aligned}$ 

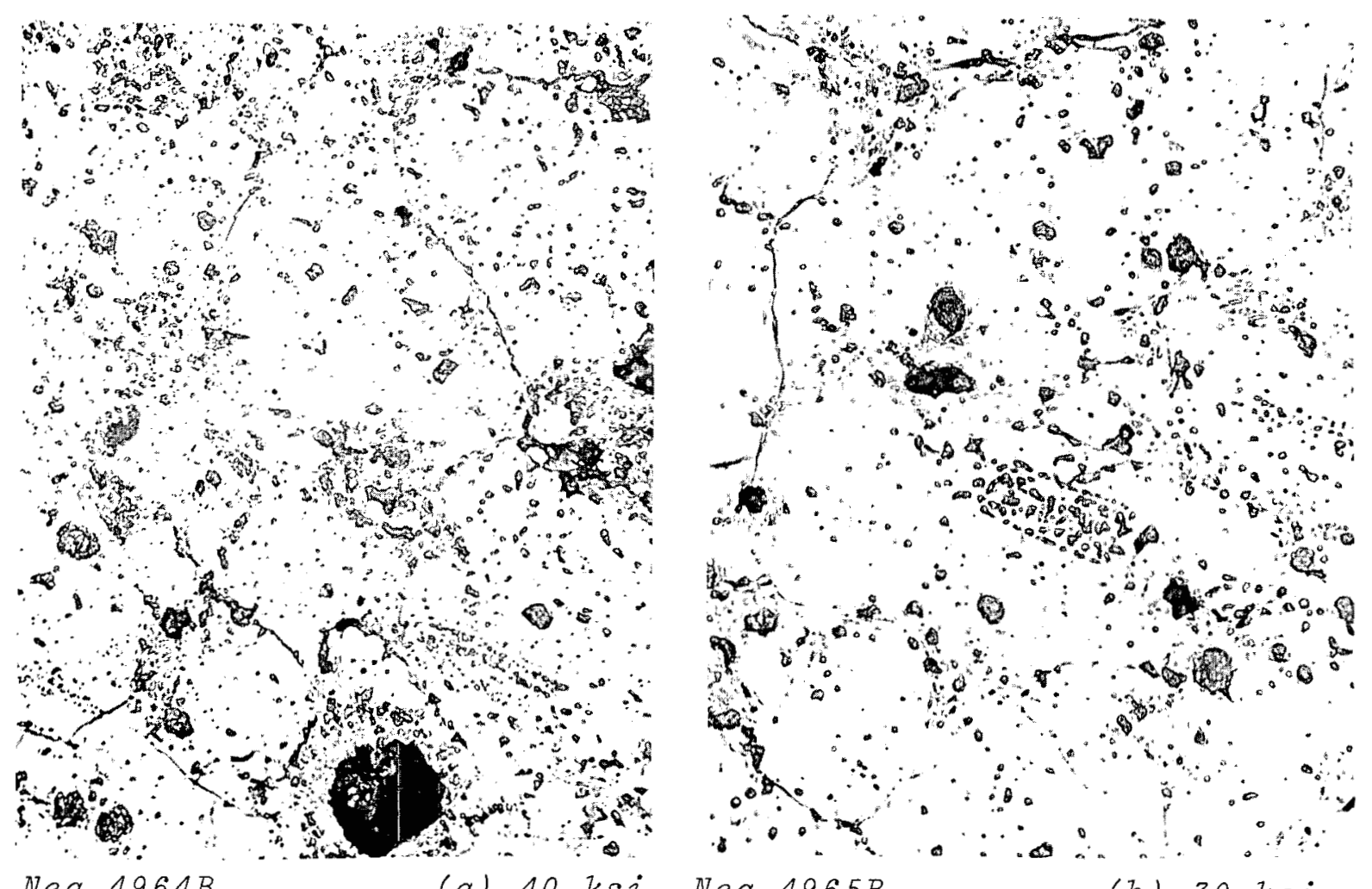

Neg $4964 B$

(a) $40 \mathrm{ksi}$. Neg $4965 \mathrm{~B}$

(b) $30 \mathrm{ksi}$.

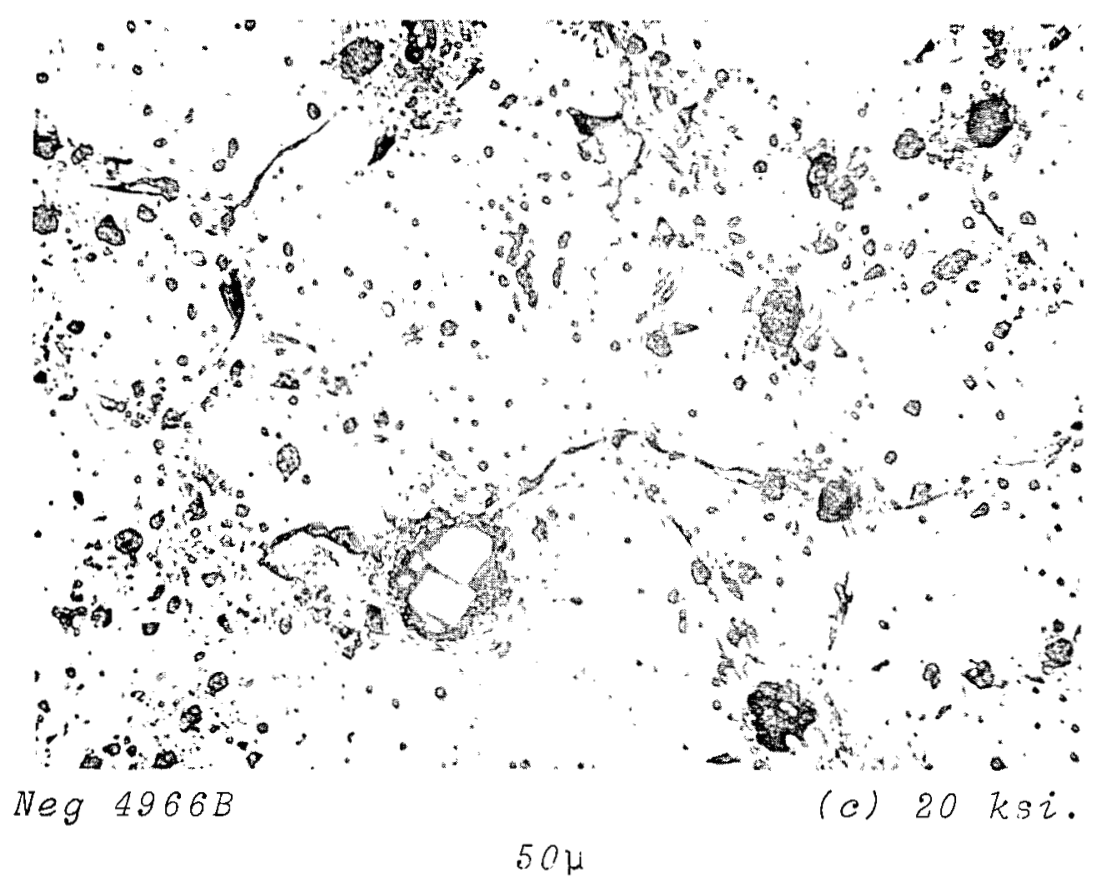

FIGURE 5.9. Representative Miorostructures (Unetched)

of Type 1 Powder with 2 wt\% Carbowax Pressed at the Indicated Pressures. (500X) 
$120 \%$ ond

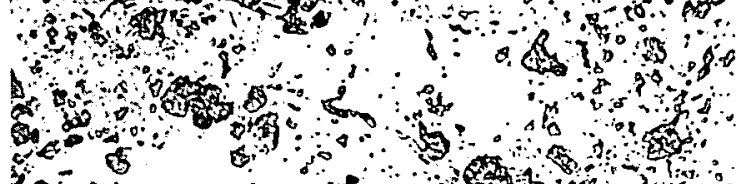
\% $\therefore \quad \therefore$ ond

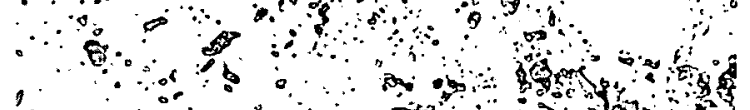

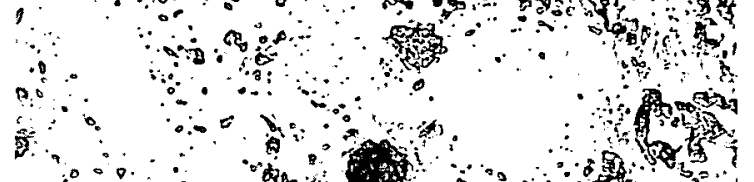

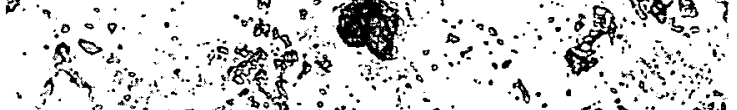
4 of

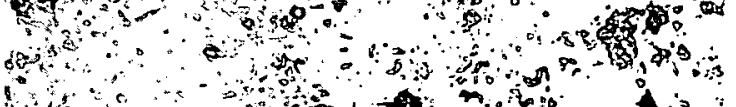
ron Neg $4967 B$

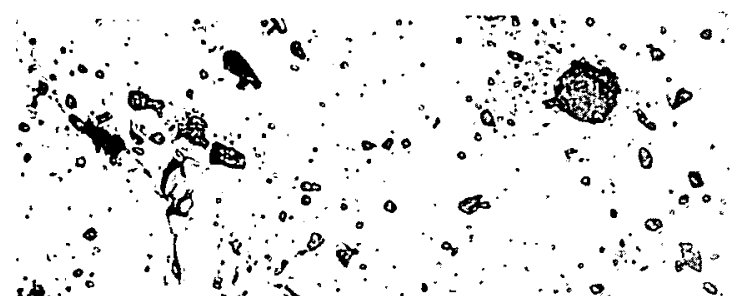

$\because \therefore$, $\because 40$ $\therefore$ ond

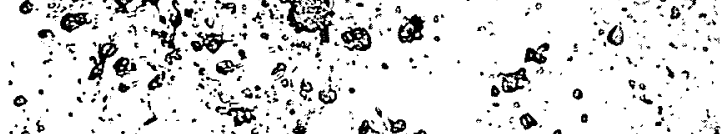
ond $\because$ rido

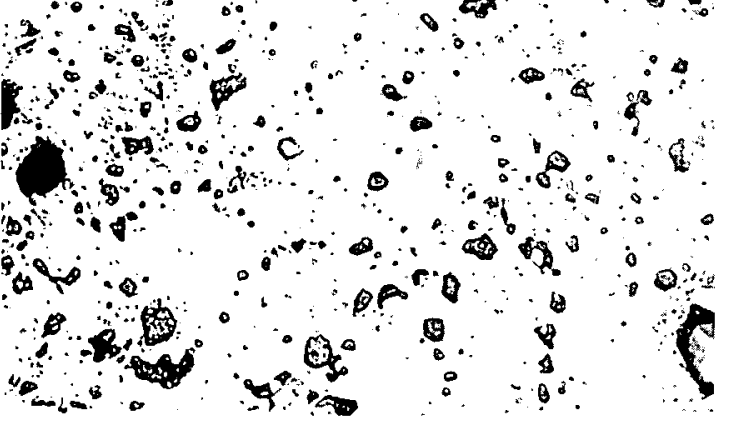
Neg $4968 B \quad$ (b) $30 \mathrm{ksi}$.

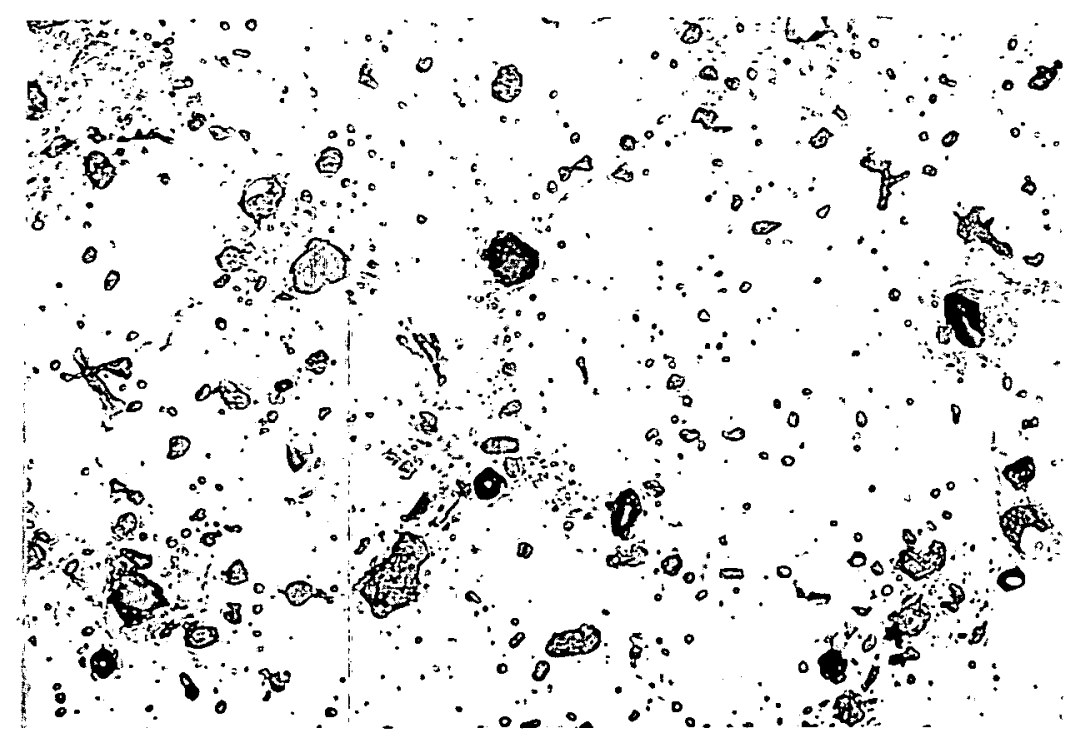

Neg $4969 B$

(c) $20 \mathrm{ksi}$

\footnotetext{
$50 \mu$

FIGURE 5.10. Representative Microstructures of Type 1 Powder with 4 wt\% Carbowax Pressed at the Indicated Pressures (500X)
} 

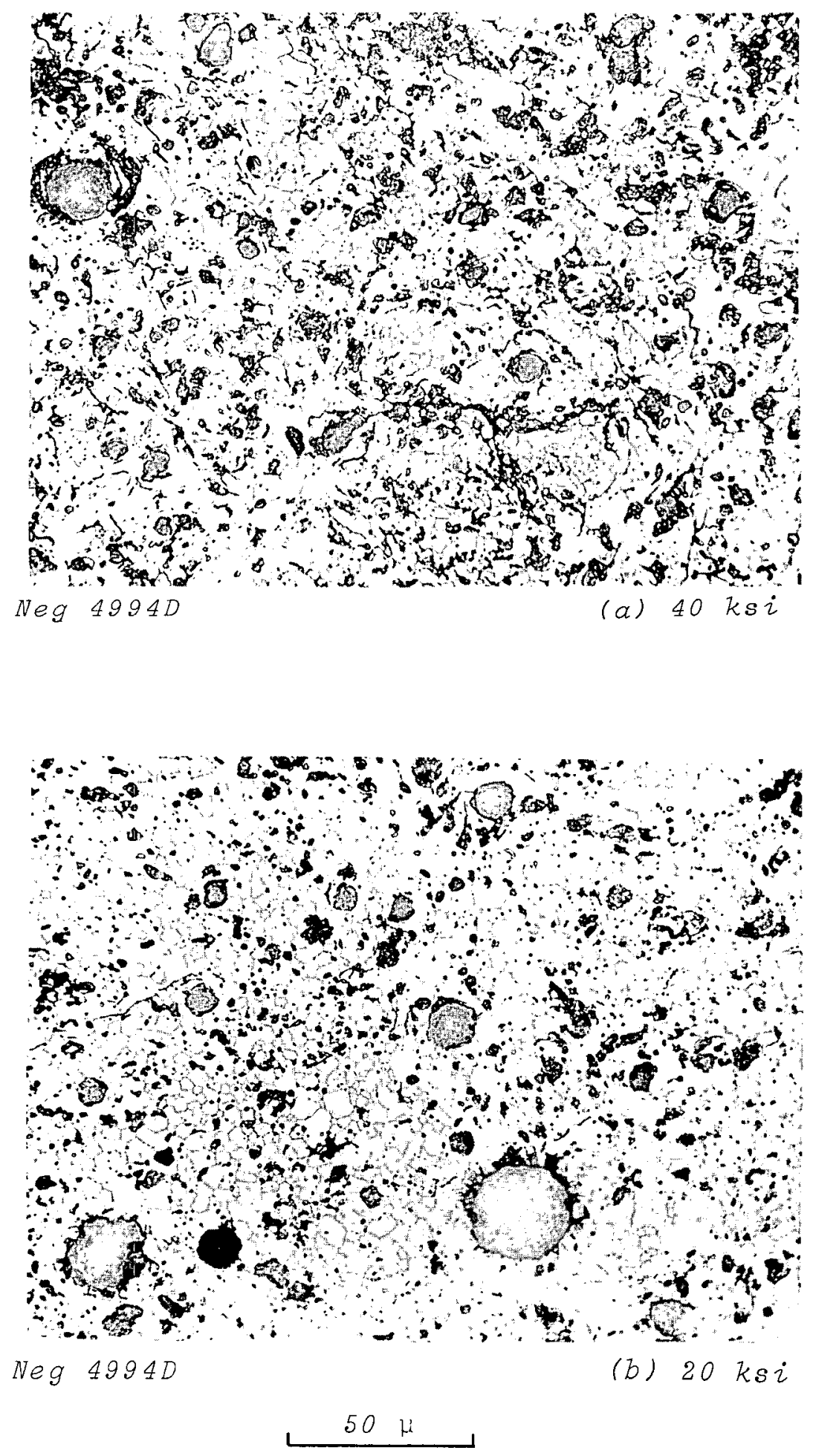

EIGURE 5.11. Representative Microstructures for MechanicallyMixed Pelzets Pressed at the Inidicated Pressures with 4 wt\% Butyz Stearate (500X) 
powder was ball milled to break down the spherical agglomerates, whereas in Type $2 \mathrm{~b}, \mathrm{PuO}_{2}$ powder was obtianed by burning the metal. Representative microstructures for pellets produced from the Type $2 \mathrm{a}$ and $2 \mathrm{~b}$ powders mixed with 4 wt $\%$ butyl stearate and pressed at $40 \mathrm{ksi}$ are shown in Figure 5.12. Ball milling the $\mathrm{PuO}_{2}$ prepared from the oxalate appears to have eliminated the spherical voids (Figure 5.12a). In the case of the mixed oxide containing $\mathrm{PuO}_{2}$ prepared from the metal, a number of large irregular-shaped pores are present (Figure 5.12b). The gray areas may be a second phase related to the $10 \mathrm{w}$ O/M of 1.95 of the sintered pellet. During sintering, a hole developed in the alumina muffle and the argon atmosphere around the graphite heating element flowed over the sample. This atmosphere probably had a high co pressure and was strongly reducing.

The difficulty of obtaining uniform microstructures by mechanically mixing two powders is to be expected when the powders are very dissimilar. This problem can be eliminated by using coprecipitated powders. Sintered pellets for this Type 3 powder had densities of $97.6 \%$ theoretical. Representative microstructures before and after etching are shown in Figure 5.13. The unetched micrographs show a marked improvement in microstructure resulting from the use of coprecipitated powder. The random light areas have previously identified as tungsten carbide from the tungsten-carbide ball mills. The etched micrographs indicate that the pellet containing 4 wt\% butyl stearate has a grain size twice as large as the one pressed dry. Furthermore, the pellet made from powder containing butyl stearate exhibits a more uniform microstructure.

It was concluded that in order to obtain uniform pellets for creep studies, coprecipitated powders must be used. Further studies will be made to determine methods for varying densities and grain sizes. 
BNWL - 1144

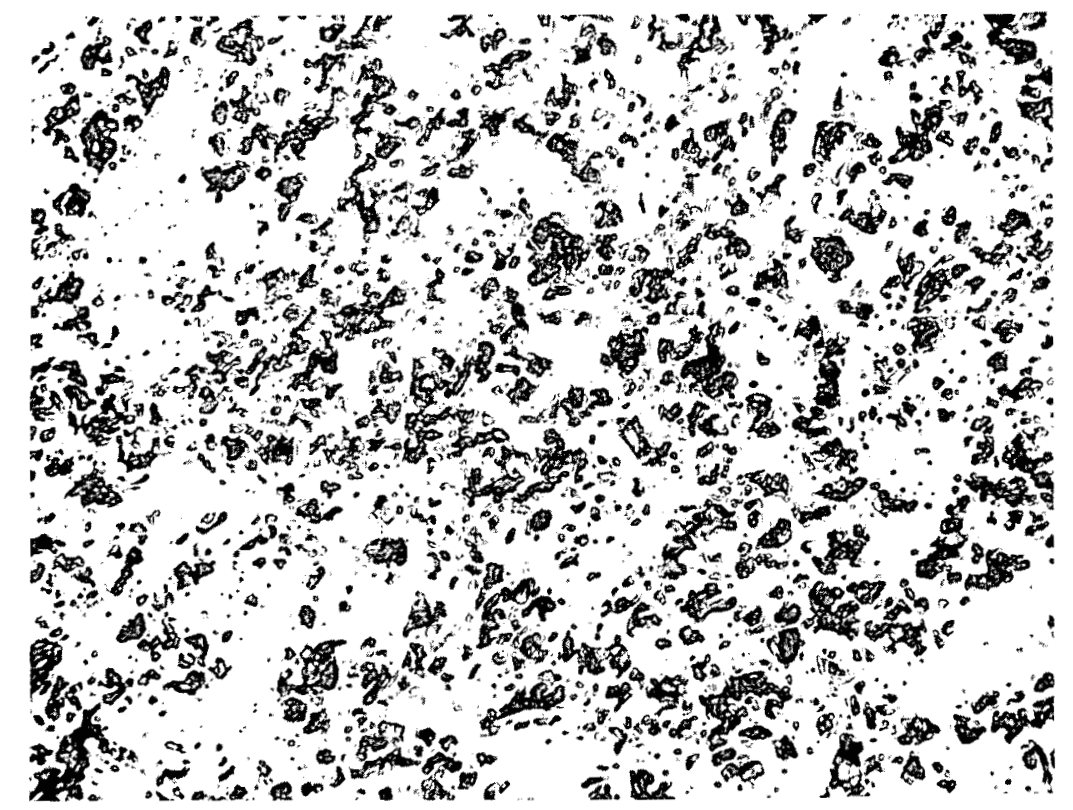

$\operatorname{Neg} 49114 B$

(a)

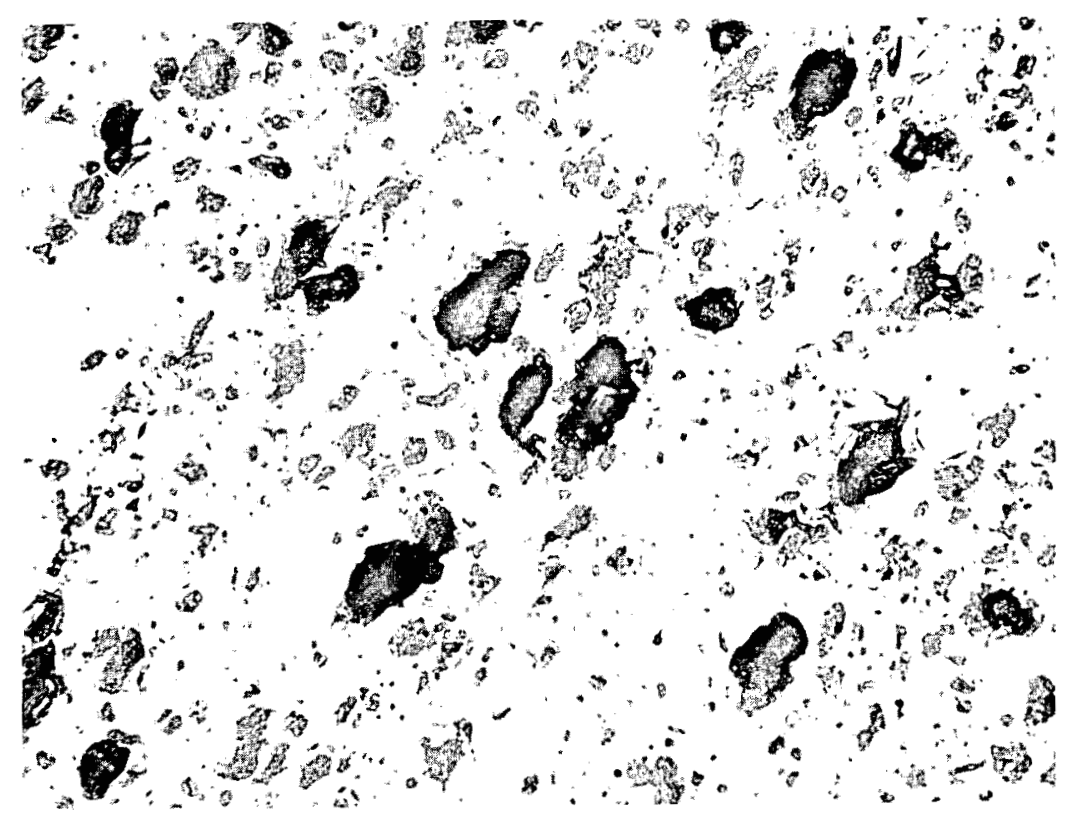

Neg $49133 \mathrm{C}$

(b)

FIGURE 5.12. Representative Microstructures (Unetched) (b)

for Type $2 a$ and $2 b$ Powders Mixed with 4 wt $\%$ Buty 2 stearate and Pressed at $40 \mathrm{ksi}$ (500X) 
BNWL- 1144
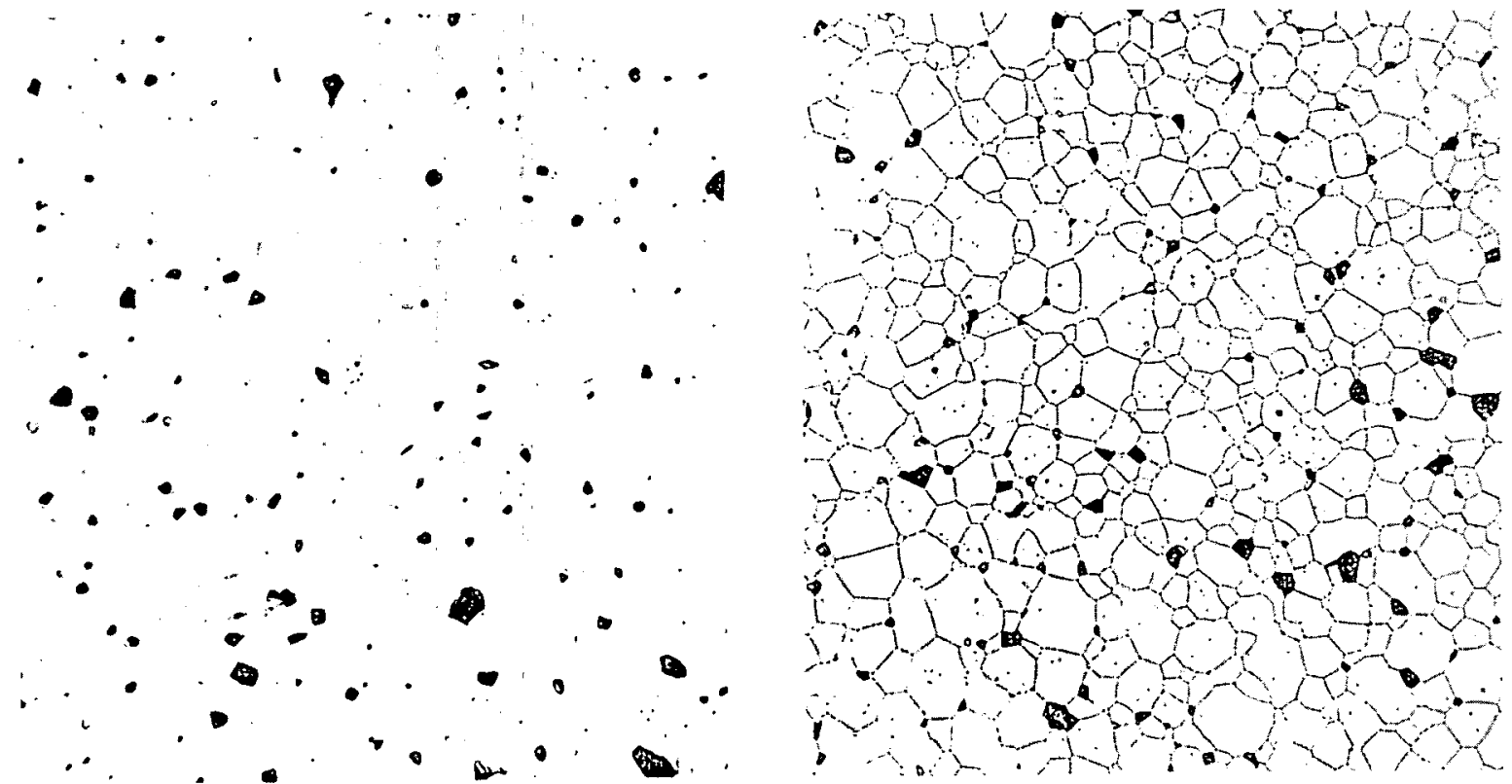

Neg $49124 B$

(a) Neg $49124 F$

(b)
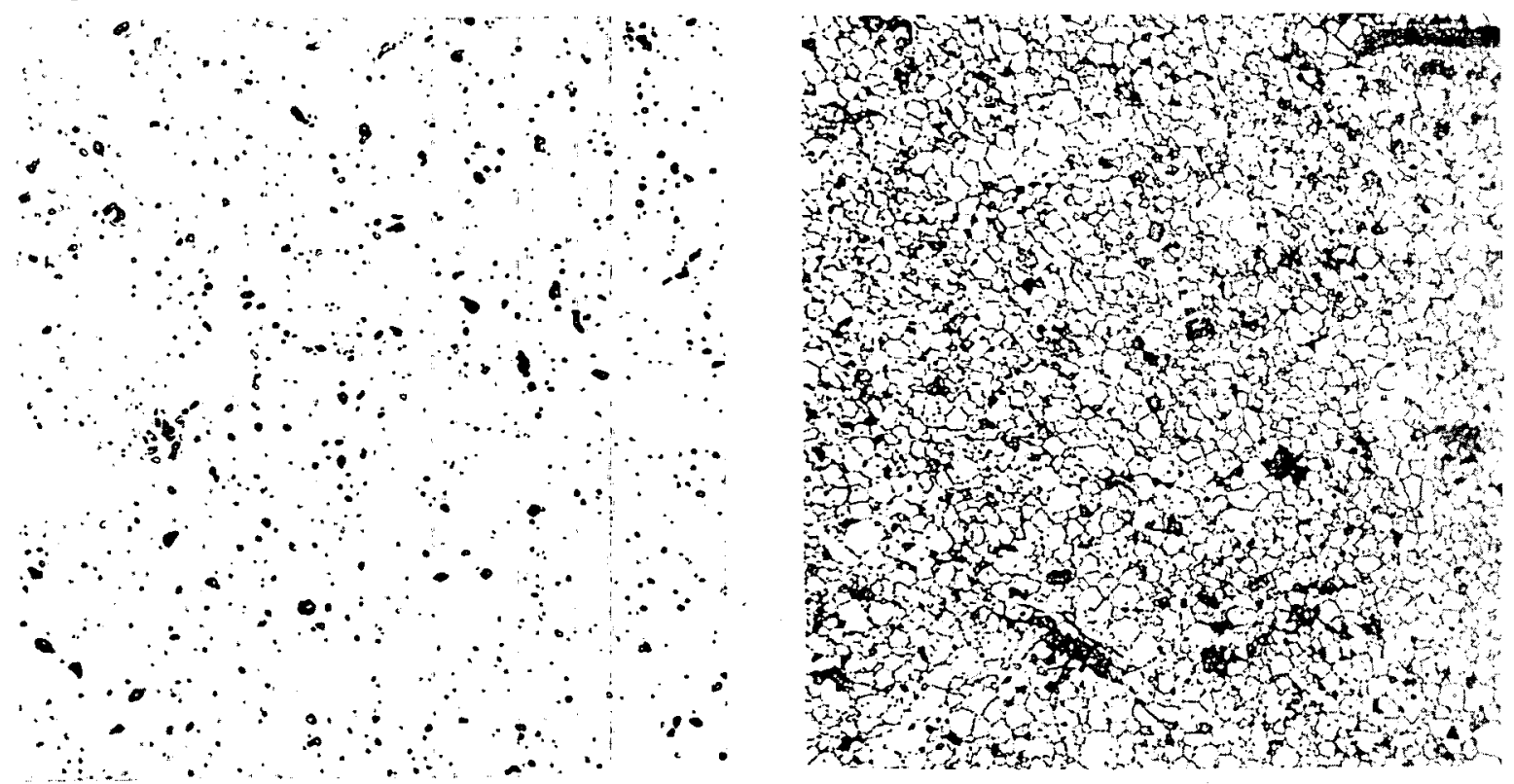

Neg $49123 B$

(c) $\operatorname{Neg} 49123 E$

(d)

$50 \mu$

EIGURE 5.13. Representative Microstructures Etched $[(b),(d)]$ and Unetched [(a), (c)] of Fowder Type 3 Pressed with 4 wt\% Butyl Stearate Added [(a), (b)] and Eressed Dr.y $[(c),(d)](500 x)$ 
THERMAL DIFFUSIVITY OF $(U, P U) 0_{2}$ - R. L. Gibby

Last quarter, thermal diffusivity data were reported for coprecipitated mixed oxide compositions containing $0,5,12,30$, and 45 wt $\mathrm{PuO}_{2}$. (3) During this quarter, the diffusivity test specimens, plus two other samples from the same coprecipitation series but containing 20 and $25 \mathrm{wt} \% \mathrm{PuO}_{2}$, were examined ceramographically and photomicrographs of typical microstructures were obtained. This information is correlated with the previously reported thermal diffusivity data.

Photomicrographs of the polished and etched samples are shown in Figures 5.14 and 5.15 . The specimens containing <30 wt\% $\mathrm{PuO}_{2}$ had densities <95\% TD. The photomicrographs of these specimens show that the porosity was uniformly distributed and located both within grains and at grain boundaries. The thermal diffusivities of these specimens were very similar, although the $\mathrm{FuO}_{2}$ content appeared to have some effect on the temperature deperdence for compositions containing <12 wt: $\mathrm{PuO}_{2}$. other minor differences in thermal diffusivity appear to be related to the slight differences in the amount of porosity.

The samples containing 30 and 45 wt\% $\mathrm{PuO}_{2}$ have densities near $90 \%$ TD. The photomicrographs of these samples (Figure 5.15) show that the lower density is associated with the presence of large void areas as well as uniformily distributed fine porosity. In addition, in the compcsition containing $45 \mathrm{wt} \% \mathrm{PuO}_{2}$, the microstructure appears to be complicated by the presence of secondary unidentified phases, as shown in both the etched and unetched microstructure. The thermal diffusivity of the compcsition containing $30 \mathrm{wt} \% \mathrm{PuO}_{2}$ is less than that for the samples with less $\mathrm{PuO}_{2}$; however, the temperature dependence is the same as the sample with $12 \mathrm{wt} \% \mathrm{PuO}_{2}$. A comparison of the microstructures of these two compositions indicates that the difference is thermal diffusivity is most likely due to the difference in pore volume and pore size distribution. 

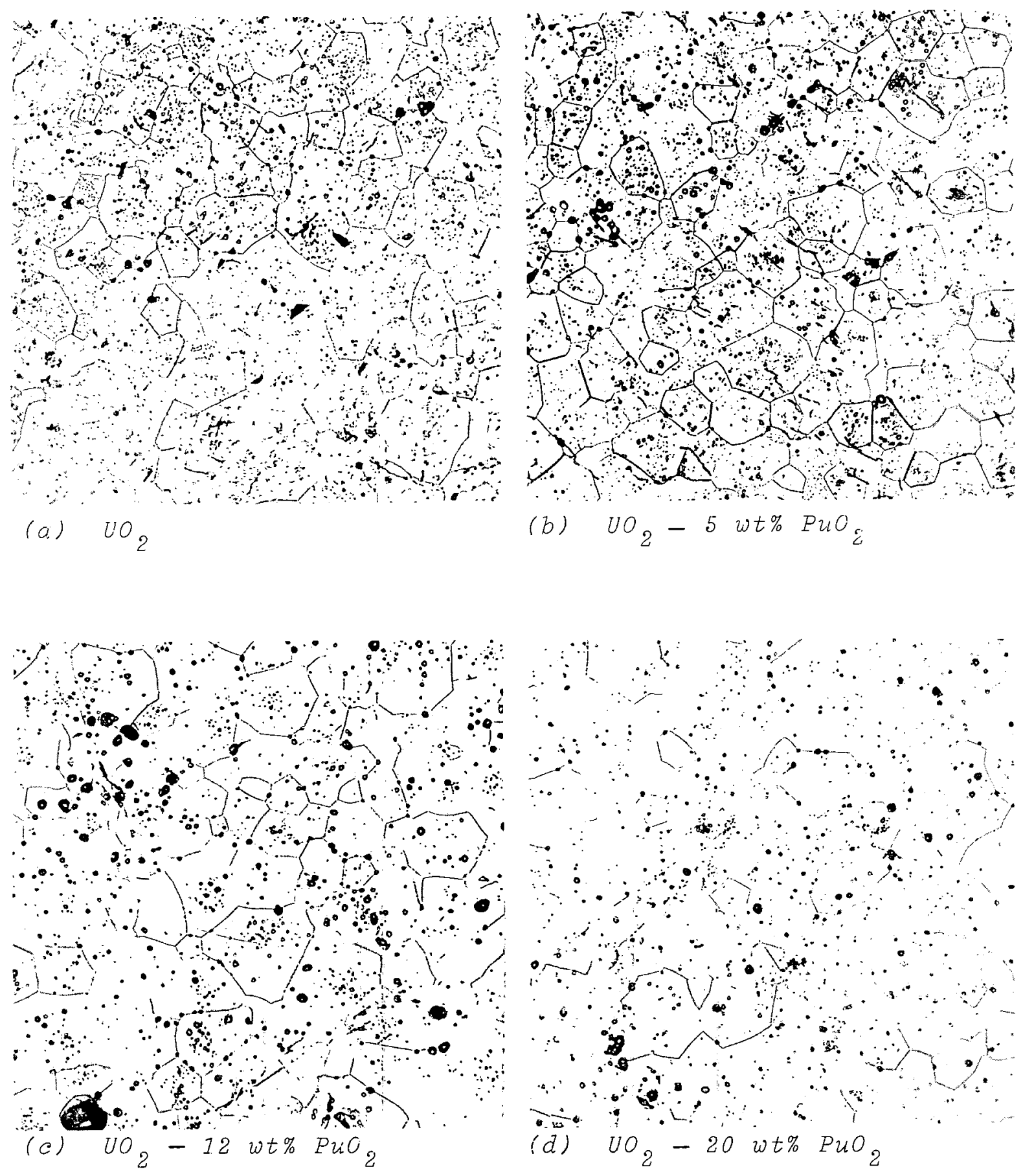

EIGURE 5.14. Photomicrographs of Coprecipitated (U,Pu) ${ }_{2}$ Compositions Sintered at $1650{ }^{\circ} \mathrm{C}$ for 4 hours Showing Microstructure of Etchea Specimens at $250 x$. 


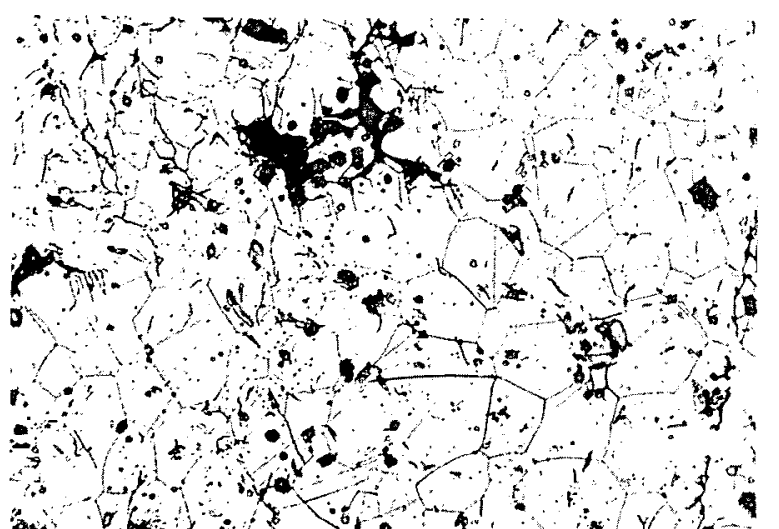

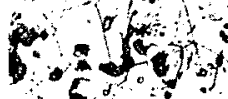

$\therefore$ colo

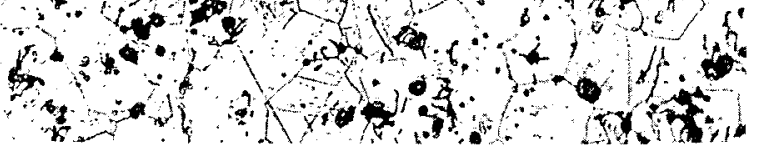
(a) $\mathrm{UO}_{2}-25$ wt\% $\mathrm{PuO}_{2}$

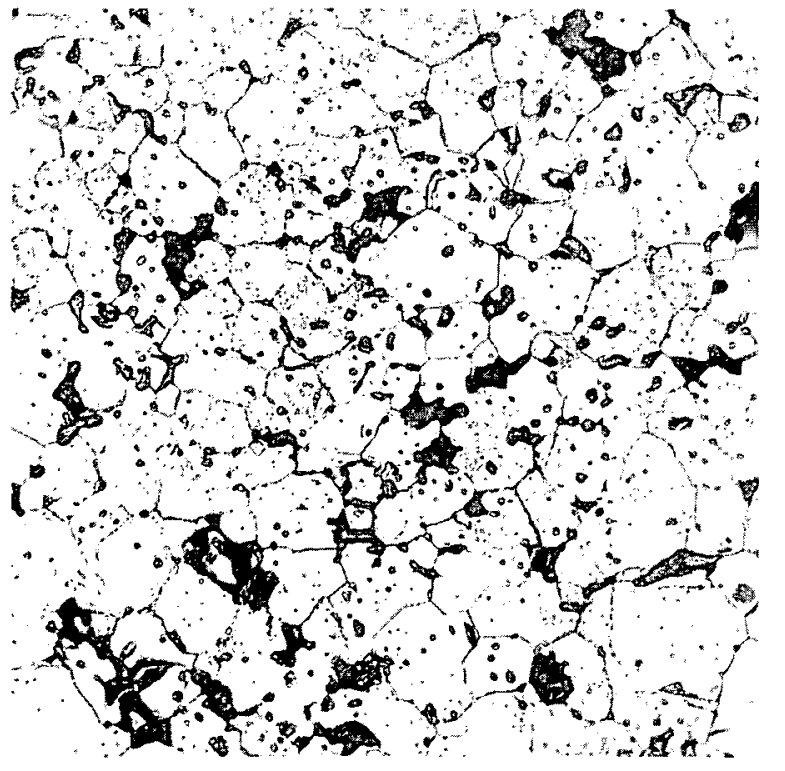

(c) $\mathrm{UO}_{2}-45$ ut\% $\mathrm{FuO}_{2}$

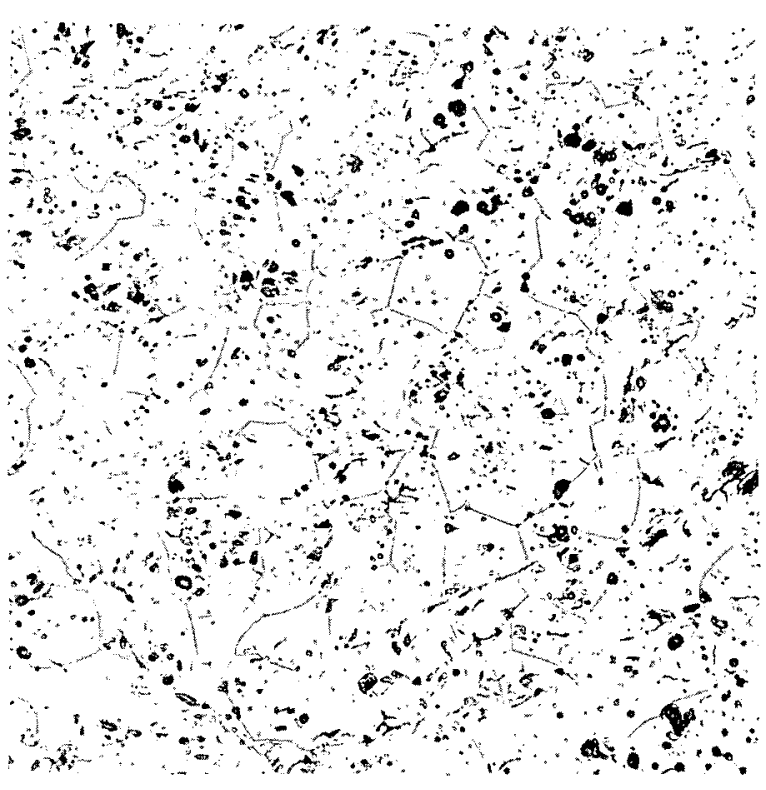

(b) $\mathrm{UO}_{2}-30 w t \% \mathrm{PuO}_{2}$

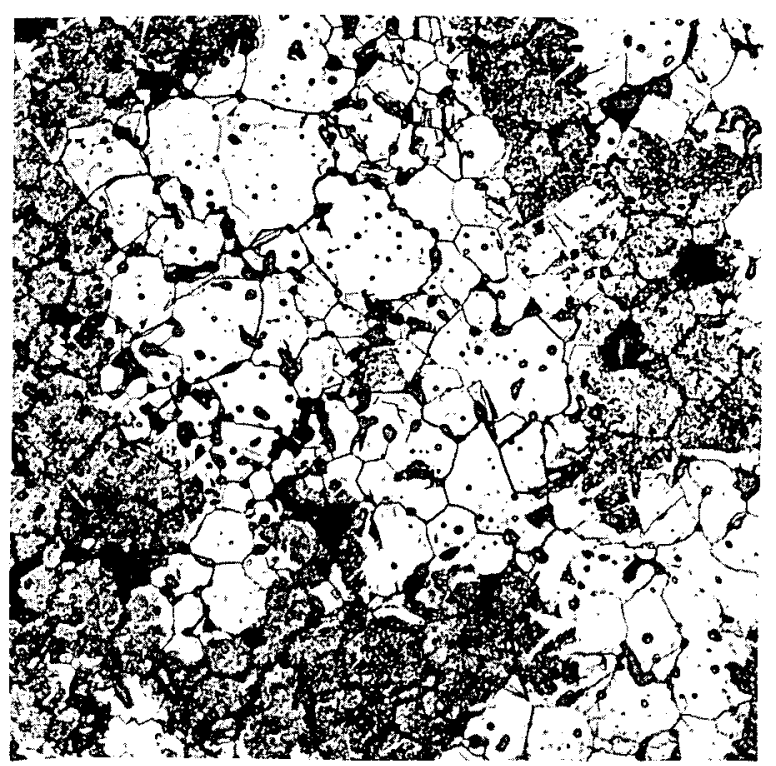

(d) $\mathrm{UO}_{2}-45 \mathrm{wi \%} \mathrm{PuO}_{2}$

FIGURE 5.15. Photomicrographs of Coprecipitated (U, PuiO Compositions Sintered at $1650{ }^{\circ} \mathrm{C}$ for 4 horrs Showing Microstructures of Etchea specimens (with exception of c) at $250 x$. 
The thermal diffusivity of the specimen containing 45 wt\% $\mathrm{PuO}_{2}$ is much less than any of the other specimens, moreover its temperature dependence is also quite different. The presence of additional phases in this composition appear to be responsible for this behavior, since the density of this specimen is not much different from the specimen containing $30 \mathrm{wt} \% \mathrm{PuO}_{2}$. It is doubtful that these phases are suboxides of the mixed oxides, since the samples were heated in a protective cover gas to prevent oxidation or reduction during the thermal diffusivity measurements. An electron microprobe analysis will be conducted on this specimen to identify the additional phases.

\section{DETERMINATION OF OXYGEN/METAL RATIOS FOR OXIDE FUELS} R. E. Woodley

The ability to determine oxygen/metal ratios on very small samples of oxide fuels would allow the measurement of oxygen distributions across the diameters of fuel elements. An experimental system has therefore been constructed to examine the feasibility of analyzing fuel samples weighing only about $1 \mathrm{mg}$. The analysis is performed by reducing a weighed sample of the fuel to the corresponding carbide plus $\mathrm{CO}_{2}$. For example:

$$
\begin{gathered}
\mathrm{UO}_{2}+4 \mathrm{C}=\mathrm{UC}_{2}+2 \mathrm{CO}, \\
\mathrm{CO}+\mathrm{CuO} \rightarrow \mathrm{CO}_{2} .
\end{gathered}
$$

The reduction is carried out in a graphite crucible heated inductively to a temperature of $\sim 2000{ }^{\circ} \mathrm{C}$. The $\mathrm{CO}_{2}$ is collected in a liquid-nitrogen-cooled trap which is subsequently attached to the sampling system of a gas chromatograph.

The precise determination of the oxygen/metal ratio depends upon the quantitative collection of the $\mathrm{CO}_{2}$ as well as the elimination of extraneous sources of this gas. At $1500^{\circ} \mathrm{K}$, the equilibrium pressure of $\mathrm{CO}$ in reaction (1) is roughly 0.05 torr, so that outgassing of the graphite crucible can be safely performed at temperatures up to $1500^{\circ} \mathrm{K}$ with negligible loss of 
fuel oxygen. Measurements of the outgassing of a TSX graphite crucible in a stream of pure helium at temperatures up to about $2000{ }^{\circ} \mathrm{C}$ indicated, however, that about $63 \%$ of the carbon oxides were evolved at temperatures in excess of $1100{ }^{\circ} \mathrm{C}$. Literature subsequently revealed that outgassing studies at ORNL (4) using TSX graphite indicated that about $46 \%$ of the CO evolved was released at temperatures between 1400 and $1800{ }^{\circ} \mathrm{C}$.

In an attempt to eliminate the excessive outgassing found with TSX graphite, a crucible was constructed from pyrolytic graphite which is essentially non-porous. Unfortunately, because of its smaller size and its lower electrical resistance, the maximum temperature attainable was only about $1600^{\circ} \mathrm{C}$. Nevertheless, in the temperature range 1300 to $1600^{\circ} \mathrm{C}$, the pyrolytic graphite released $1.57 \times 10^{-6}$ mole of $\mathrm{CO}+\mathrm{CO}_{2}$ per gram of graphite. On the other hand, TSX graphite in the temperature range 1100 to $2000^{\circ} \mathrm{C}$ released only $6.05 \times 10^{-7}$ mole of $\mathrm{CO}+\mathrm{CO}_{2}$ per gram of graphite. The reason for these outgassing results is not clear, but pyrolytic graphite will not be employed for future crucible construction.

Additional crucibles have been machined from Poco AXF graphite, but outgassing measurements have not as yet been performed. Depending upon the results with this material, it may prove necessary to outgas the graphite crucibles prior to adding the fuel sample. Following outgassing, the crucible would be maintained in an inert atmosphere to preclude reabsorption of oxygen or water vapor, and the fuel sample would then be added remotely.

Preliminary measurements of the $\mathrm{CO}_{2}$ obtained upon $\mathrm{UO}_{2}$ reduction have been performed manometrically. However, because the $\mathrm{CO}_{2}$ resulting from graphite outgassing was an appreciable fraction of the total $\mathrm{CO}_{2}$ collected, the $\mathrm{O} / \mathrm{M}$ values calculated were not reasonable. 
BNWL -1144

\section{CHARACTERIZATION OF MIXED-OXIDE FUEL MATERIALS}

J. L. Daniel and S. J. Mayhan

The study of mixed-oxide fuels continued, using scanning electron microscopy, in an intensive examination of the formation of $\mathrm{PuO}_{2}$ feed powders by calcination of plutonium oxalate. Powder specimens were dry-mounted on a cooper support block on which a thin coating of adhesive had been sprayed (Scotch Spray Mounting Adhesive, Catalog No. 6065). The spray adhesive provided excellent retention of specimen particles during mounting and subsequent transfer of the support blocks between glove box and microscope. The spray eliminated the problems which were encountered in earlier experiments from deterioration of cellulose adhesive tape in the electron beam. However, some contamination of the microscope still occurred during examination of the finest powders, and a complete containment method is still being sought.

The plutonium oxalate, as-precipitated and dried at less than $100^{\circ} \mathrm{C}$, occurs in spherical clusters of platelets of random sizes and orientations (Figure 5.16). The clusters are all between 3 and 25 microns in diameter and show no evidence of bonding to each other.

Calcination of the oxalate produces progressively tighter clusters with reorientation of the platelets to produce the slot-shaped porosity reported earlier. Densification of individual particles is readily apparent as calcination temperature increases from $450{ }^{\circ} \mathrm{C}$ to $1000{ }^{\circ} \mathrm{C}$ (Figures $5.17 \mathrm{a}, \mathrm{b}$, and c). Only a few individual platelets occur separated from the clusters, but the open structure results in a relatively large effective surface area. The efficiency of blending with $\mathrm{UO}_{2}$ for a mixed oxide fuel may be strongly influenced by the pore dimensions and stability of the $\mathrm{PuO}_{2}$ clusters during the mixing operation. An earlier report showed that blending $\mathrm{UO}_{2}$ 
BNWL - 1144

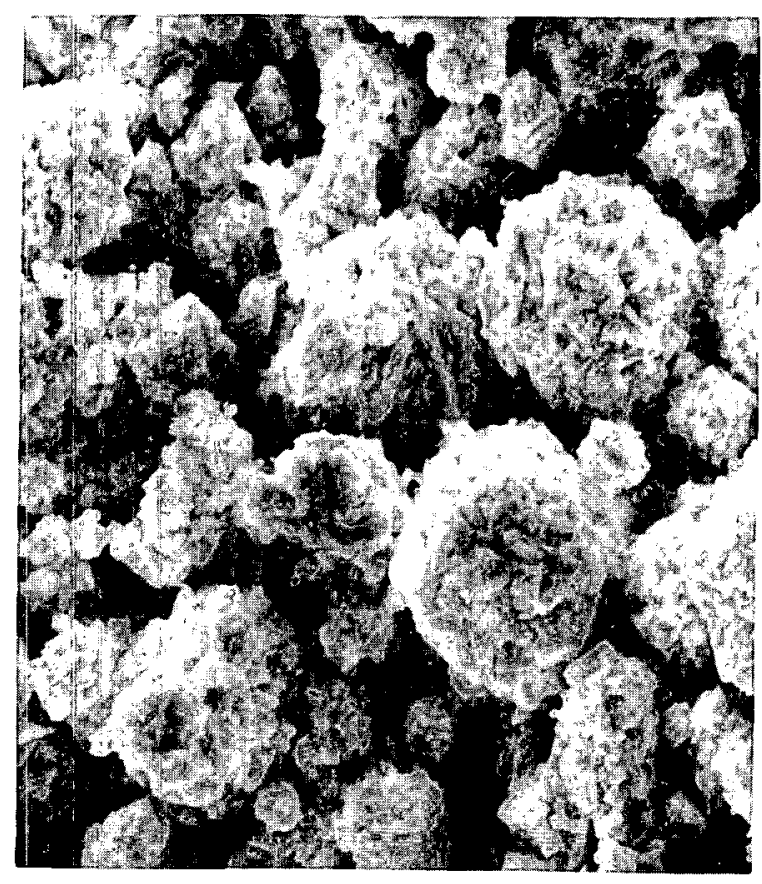

Neg 1601

$1000 X$

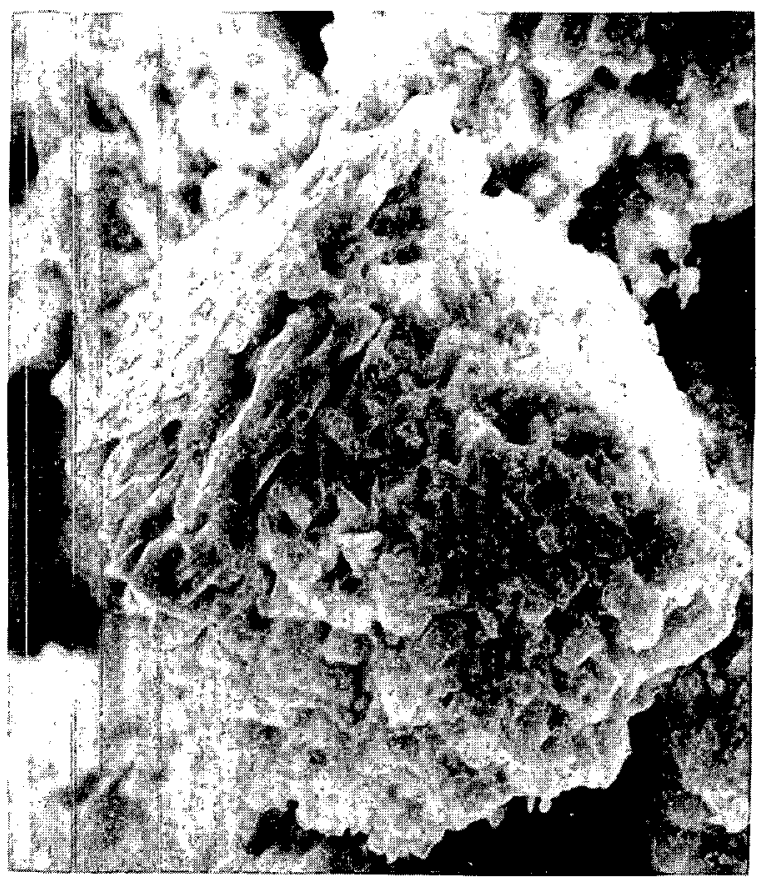

$\operatorname{Neg} 1596$

$3000 x$

FIGURE 5.I6 Plutonium oxalate, As-Precipitated and Air Dried at Less than $100{ }^{\circ} \mathrm{C}$. 

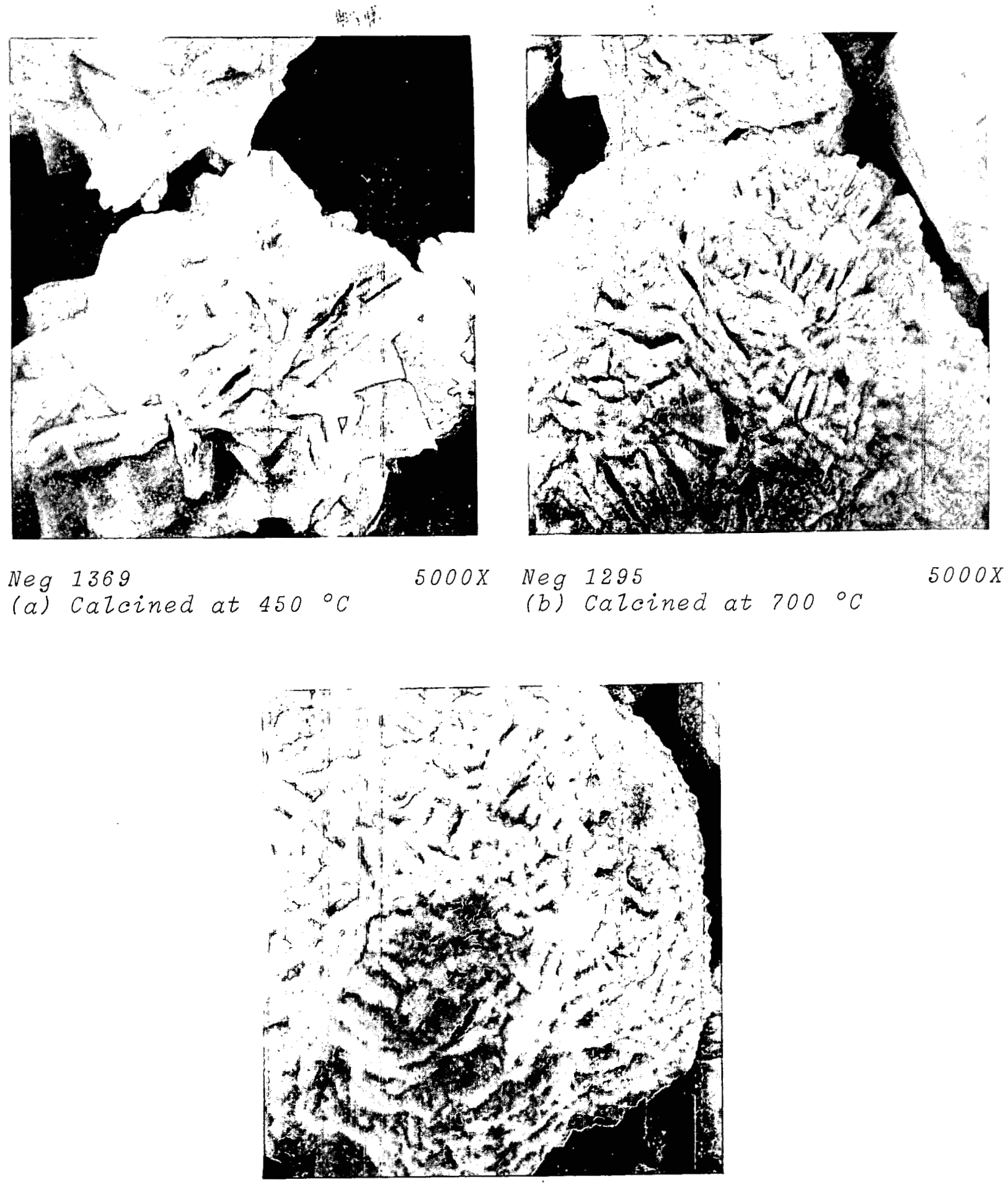

$\begin{array}{ll}\text { Neg } & 1396 \\ \text { (c) Calcined at } 1000{ }^{\circ} \mathrm{C}\end{array}$

$5000 X$

EIGURE 5.17 Effect of Calcination Temperature on Morphology of $\mathrm{PuO}_{2}$ Powder Particles Prepared from the oxalate. 
with $\mathrm{PuO}_{2}$ calcined at $700{ }^{\circ} \mathrm{C}$ produces nonporous powder particles, apparently by filling the interstices in the $\mathrm{PuO}_{2}$ spheres with fine $\mathrm{UO}_{2}$ powder.

If the oxide is produced by calcination of plutonium nitrate, a finer nonporous powder is obtained (Figure 5.18). Most of the particles are about 1 micron in diameter or smaller, roughly spherical, and show relatively little tendency to agglomerate. Different blending conditions may be required to acheive uniform mixing of this nitrate oxide with fine $\mathrm{UO}_{2}$ powder, compared to the coarser particles obtained from the oxalate.

The particle-size analyses obtained using a Stokes Law method on the calcined oxalate shows a pronounced decrease in particle size as pre-analysis dispersion time is increased (Figure 5.19). Examination of the dispersed solids revealed that considerable breakup of the original plate clusters has already occurred after $15 \mathrm{~min}$. of ultrasonic agitation. After dispersion for 120 min., nearly all of the original clusters are broken apart and the platelets destroyed, resulting in a large fraction of small particles and fine powder (Figure 5.20). Similar behavior is shown regardless of initial calcination temperature of the oxalate, although the resultant particles from the $1000{ }^{\circ} \mathrm{C}$ calcination retain some of the original rosette character. The relatively low bond strength between platelets in the oxide clusters is therefore another factor which must be considered in determining optimum blending conditions in mixed oxides preparation.

As the initial step in detailed evaluation of oxide fuel sintering, $\mathrm{PuO}_{2}$ powder was pressed and sintered at $1650{ }^{\circ} \mathrm{C}$ after calcination at 450,700 , and $1000{ }^{\circ} \mathrm{C}$. The sintered pellets were then fractured and examined directly in the scanning electron microscope. All three specimens achieved 
BNWL - 1144

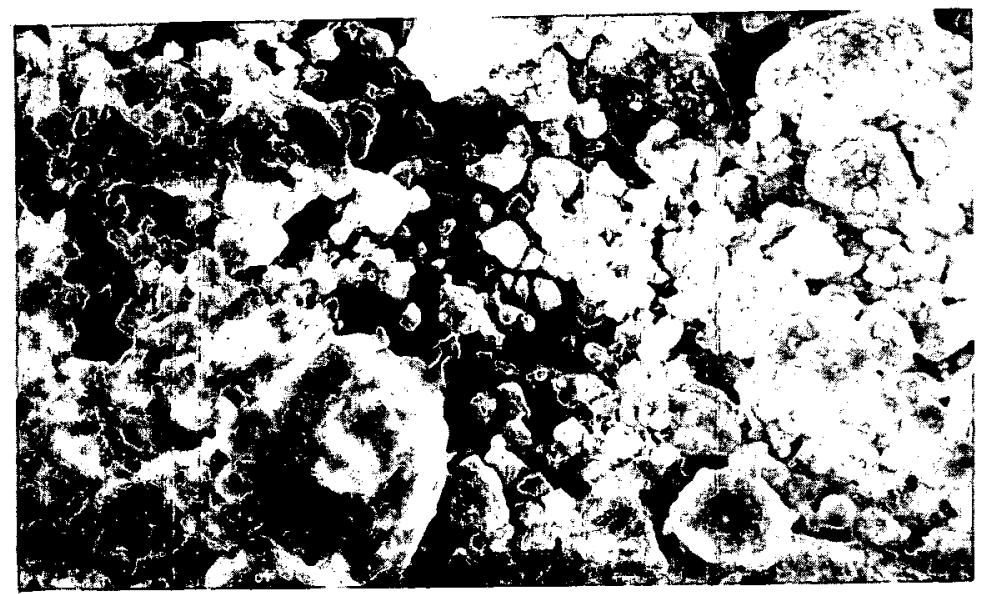

Neg 1606

$5000 X$

EIGURE 5.18 PuO Prepared by Calcination of Plutonium Nitrate
at $1000^{\circ} \mathrm{C}$ (Compare with Figure 5.17). 


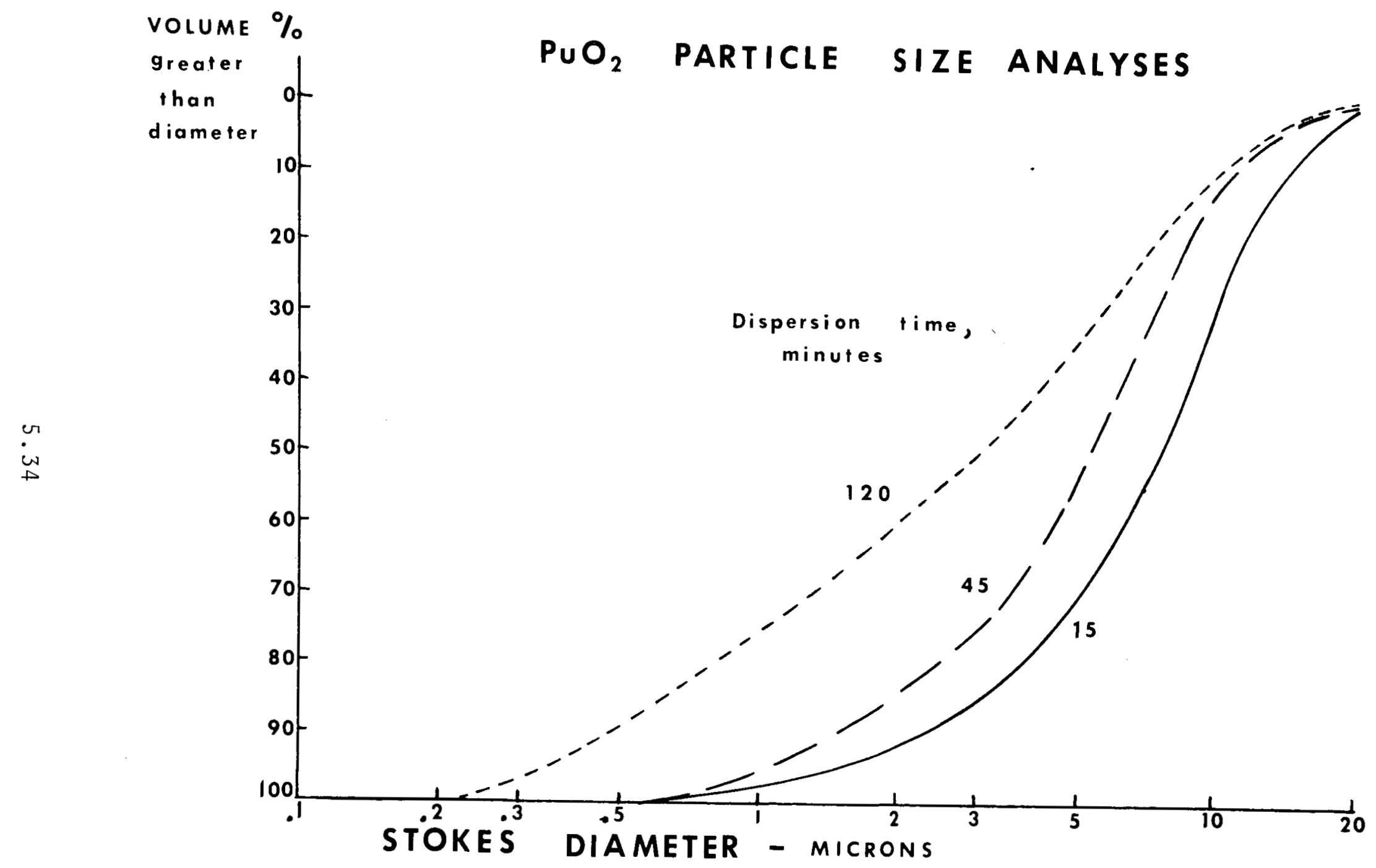

Neg PNL $0691755-1$

FIGURE 5.19 Effect of Pre-Analysis Dispersion Time on Particle-Size Distribution in Calcined-oxalate $\mathrm{PuO}_{2}$. 


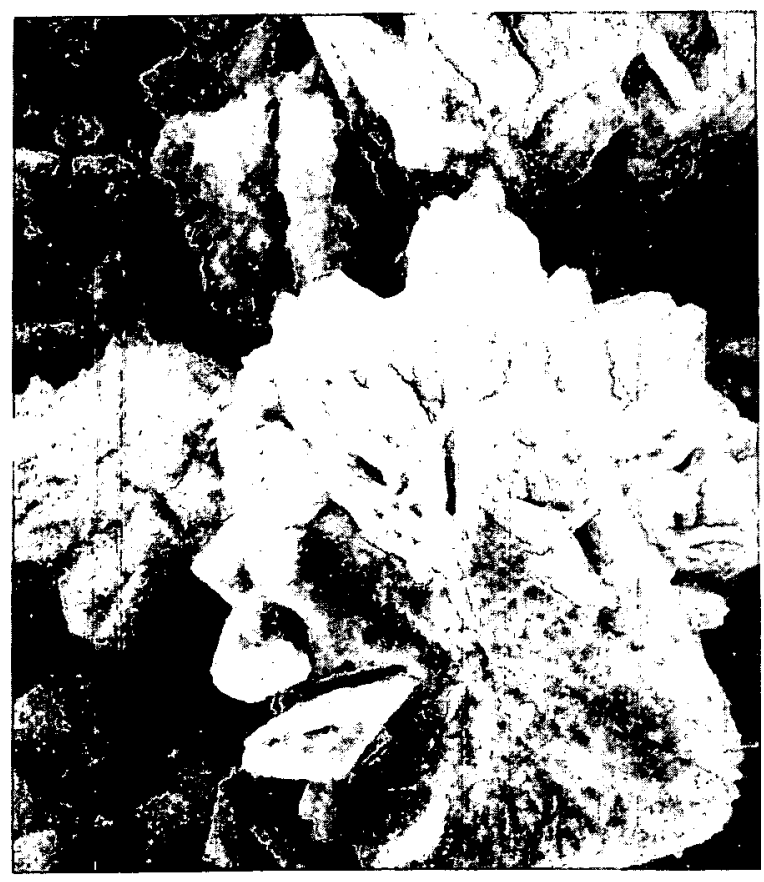

Neg 1616

$5000 X$

(a) 15-Minute Dispersion

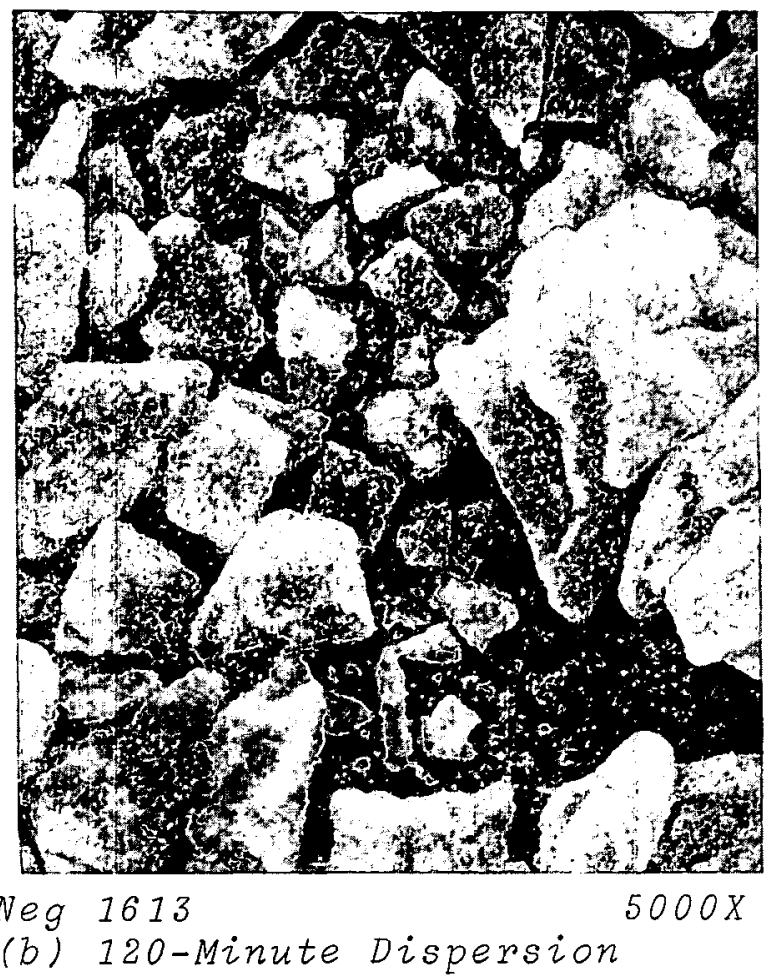

FIGURE 5.20 Effect of Pre-Analysis Dispersion Time on Particle Morphology of $\mathrm{PuO}_{2}$ from oxalate Calcined at $700{ }^{\circ} \mathrm{C}$. 
BNWL -1144

only low density $(<70 \%)$ upon sintering, perhaps reflecting the porous rosette structure of the starting powder. Pellets were sintered for about $4 \mathrm{hr}$ at $1650{ }^{\circ} \mathrm{C}$ in argon/8\% $\mathrm{H}_{2}$ atmosphere containing less than $5 \mathrm{ppm} \mathrm{H}_{2} \mathrm{O}$. Density was determined by calculation from measured lattice parameters, and based on an $\mathrm{O} / \mathrm{M}$ of 2.00 . Since sintering was under highly reducing conditions, $0 / \mathrm{M}$ is probably about 1.8 , and true density may be about 5\% higher.

Al1 three specimens were similar in fractography, the main difference being the amount of displayed porosity which appeared to correspond roughly to the measured densities. In all cases, however, Iarge intergranular porosity was predominant; virtually no pores occurred within the grains (Figure 5.21). In a11 specimens a large fraction of the $\mathrm{PuO}_{2}$ grains had smooth edges with rounded corners, suggesting a significant reduction in surface activity of the grains facing the pores. In addition, the grain boundaries in the lower density specimens were poorly defined, appearing more like melt zones than sintered bonds. Nearly all grains showed a "humped" structure; that is, the centers of the grain surfaces rose abruptly above the peripheral regions where adjacent grains joined. The highest density (700 ${ }^{\circ} \mathrm{C}$-calcined oxide) pellet displayed considerable surface debris, possibly resulting from its harder, more brittle behavior during fracturing.

The mixed oxides examined to date (25 wt $\mathrm{PuO}_{2}$ ) show a more typical brittle fracture surface. All specimens include particulate deposits or inclusions distributed randomly around the exposed surfaces and imbedded within grain boundaries (Figure 5.22), possibly resulting from the tungsten impurity content. Some specimens contained large regions of relatively small close-packed grains (Figure 5.23). A heavy "sprinkling" of 0.5 micron and smaller spherical particles also occurred in 

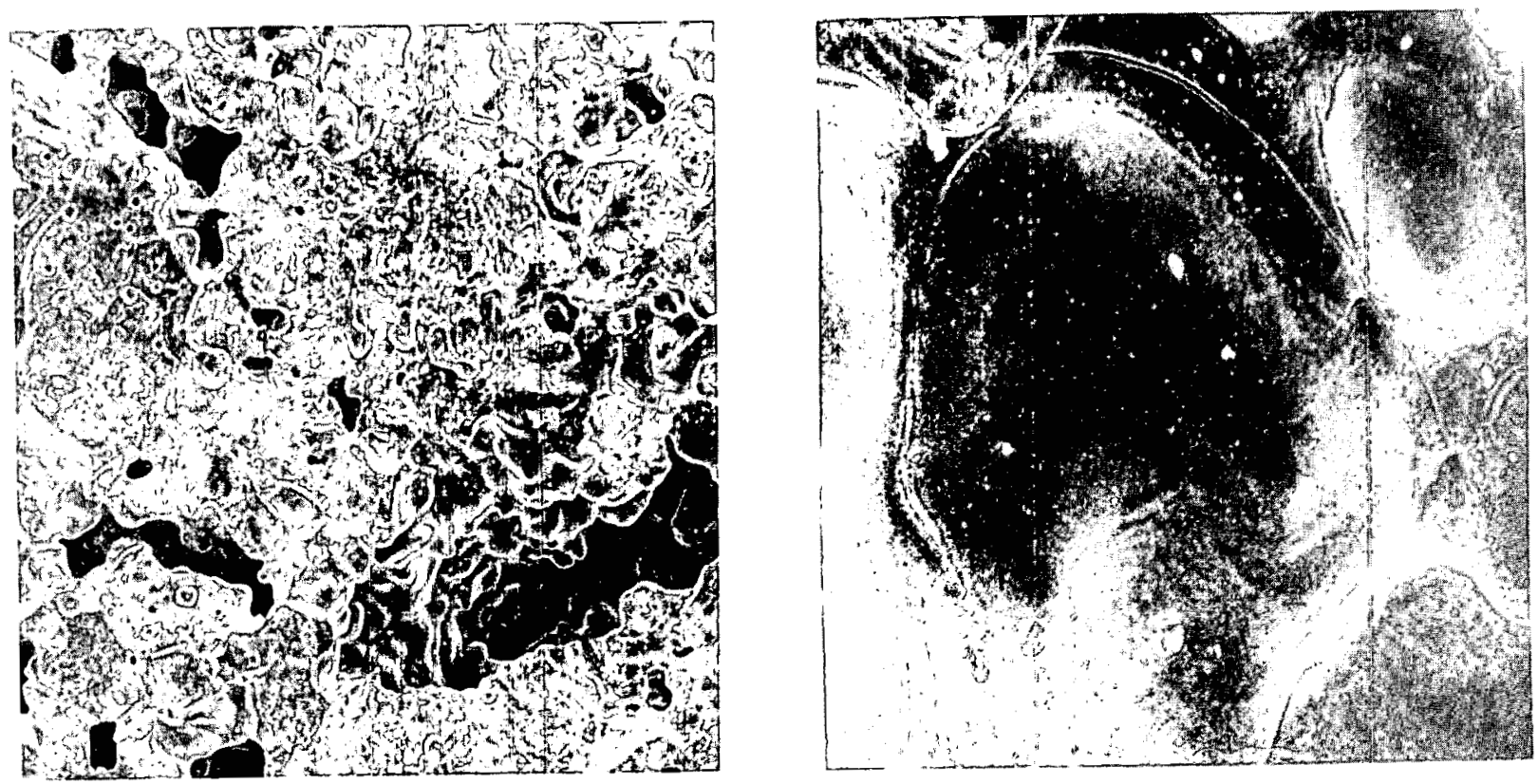

\section{Neg 1989 \\ $100 X$ \\ (a) Initial Calcination Temperature $450{ }^{\circ} \mathrm{C}$.}

$\operatorname{Neg} 1992$

$1000 X$
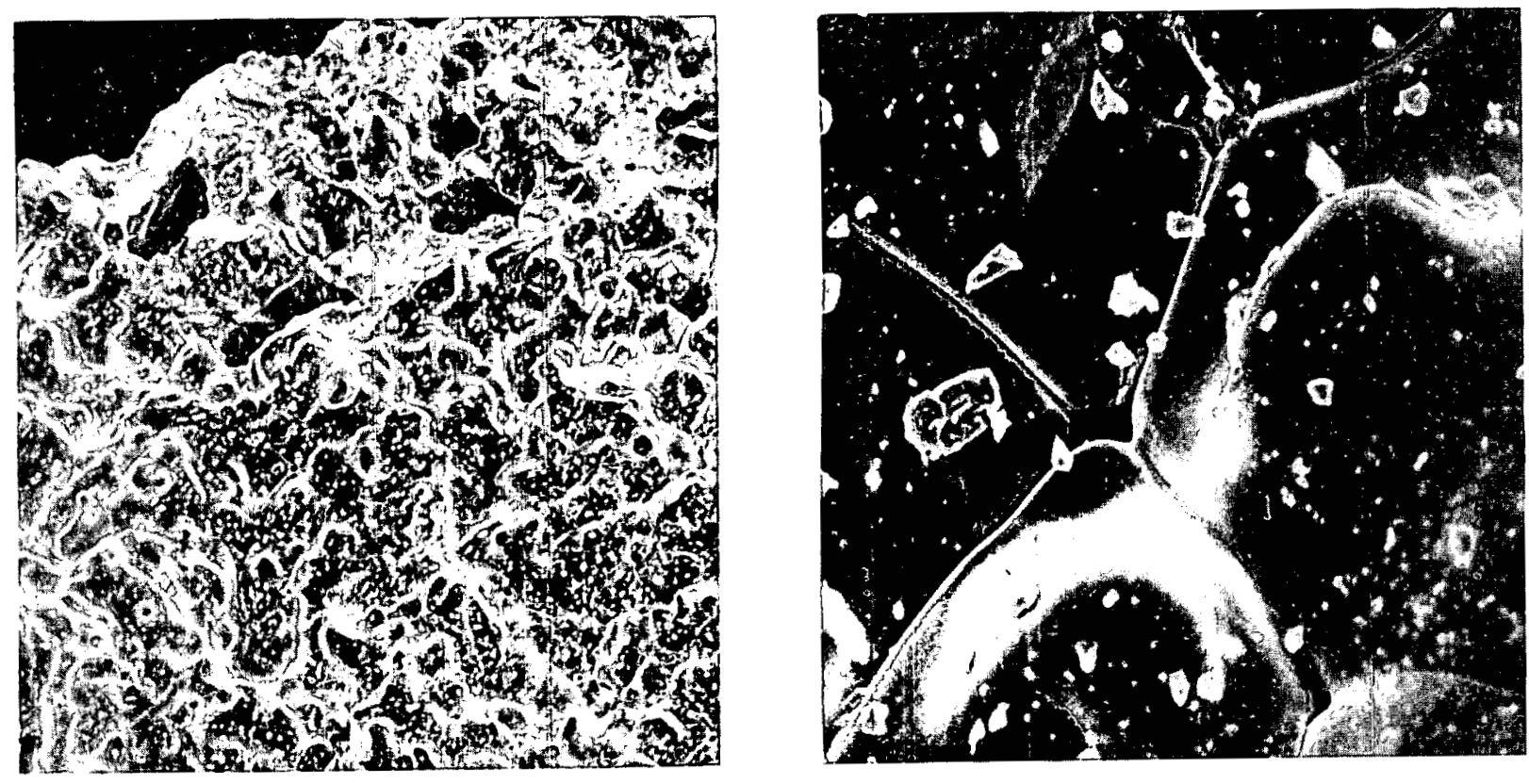

Neg 2033

$100 X$

Pelzet Density $68 \%$.

(b) Initial Calcination Temperature Pellet Density $64 \%$.

$1000 X$ $700{ }^{\circ} \mathrm{C}$.

FIGURE 5.21 Fractography of Sintered PUO Pelzets Prepared from calcined oxalate shown in Fiğure 5.17 . 
BNWL - 1144
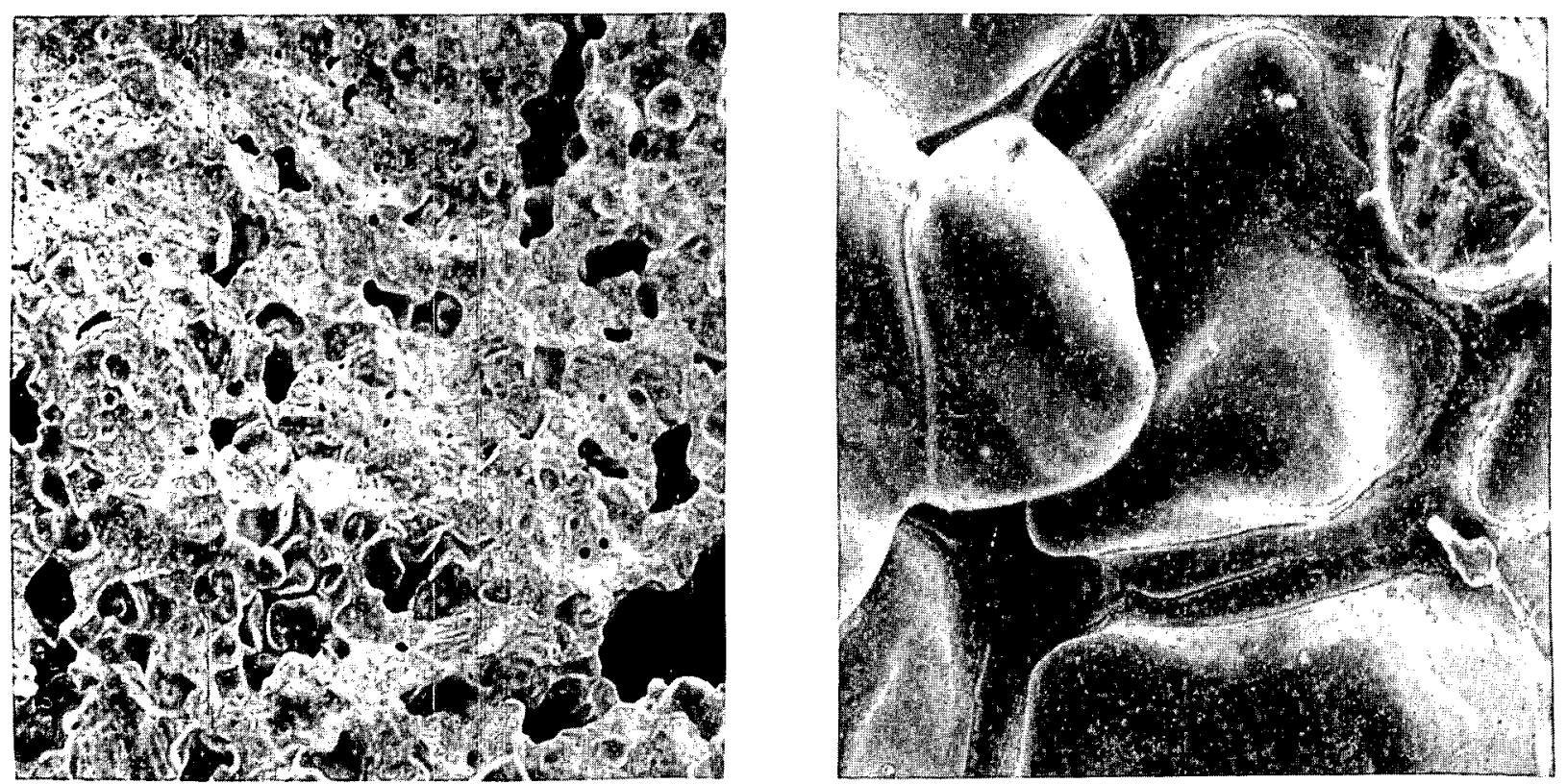

Neg 1977

$100 X$ Neg 1983

(c) Initial Calcination Temperature Pellet Density $57 \%$. $1000{ }^{\circ} \mathrm{C}$.

EIGURE 5.21 (contd)
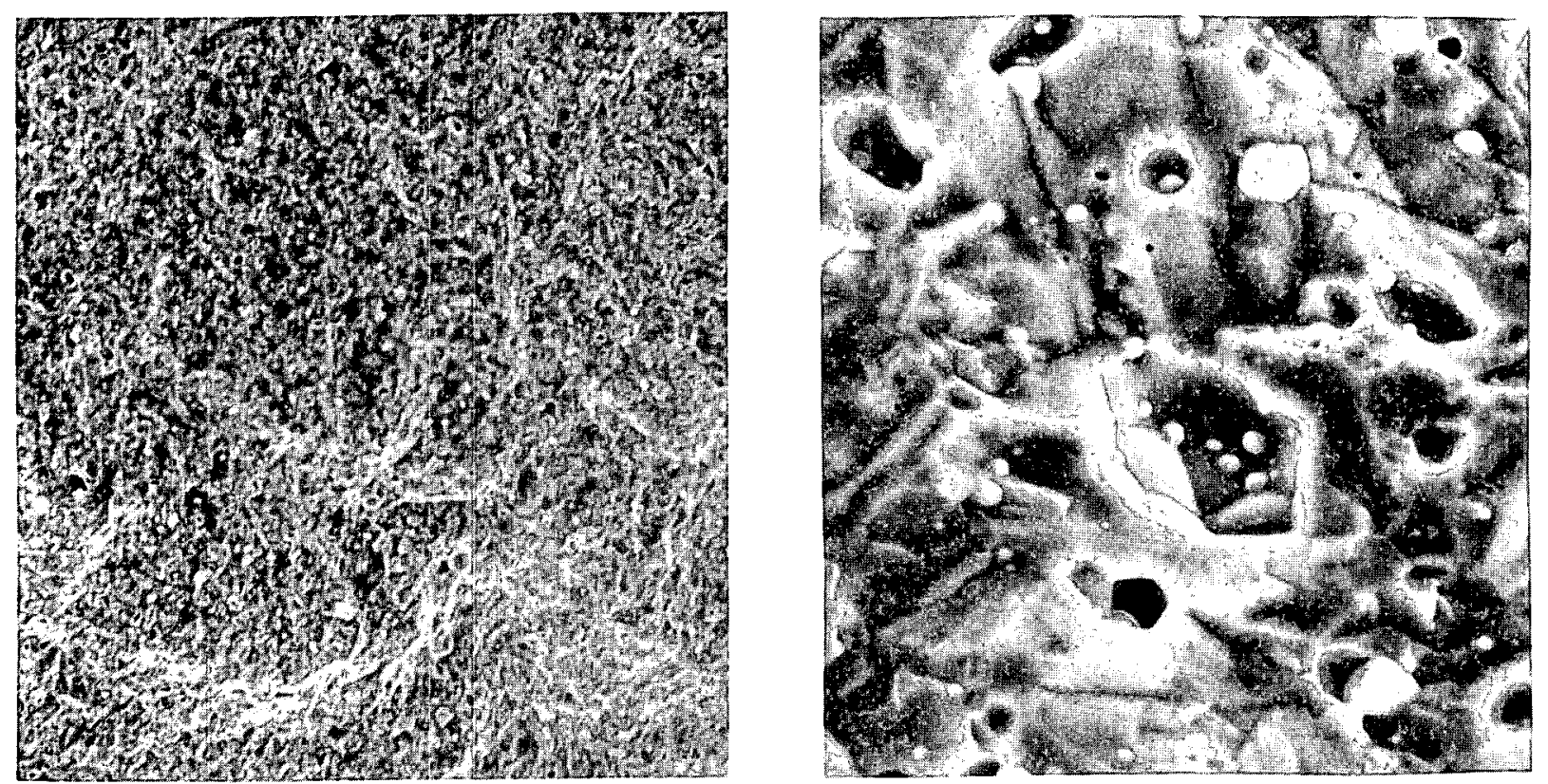

Neg 1969

$300 X$

Neg 1971

EIGURE 5.22 Fractography of $\mathrm{UO}_{2}-25$ wt\% PuO

(Tungsten Impurity Content $\sim 8.5 \%$ ) 

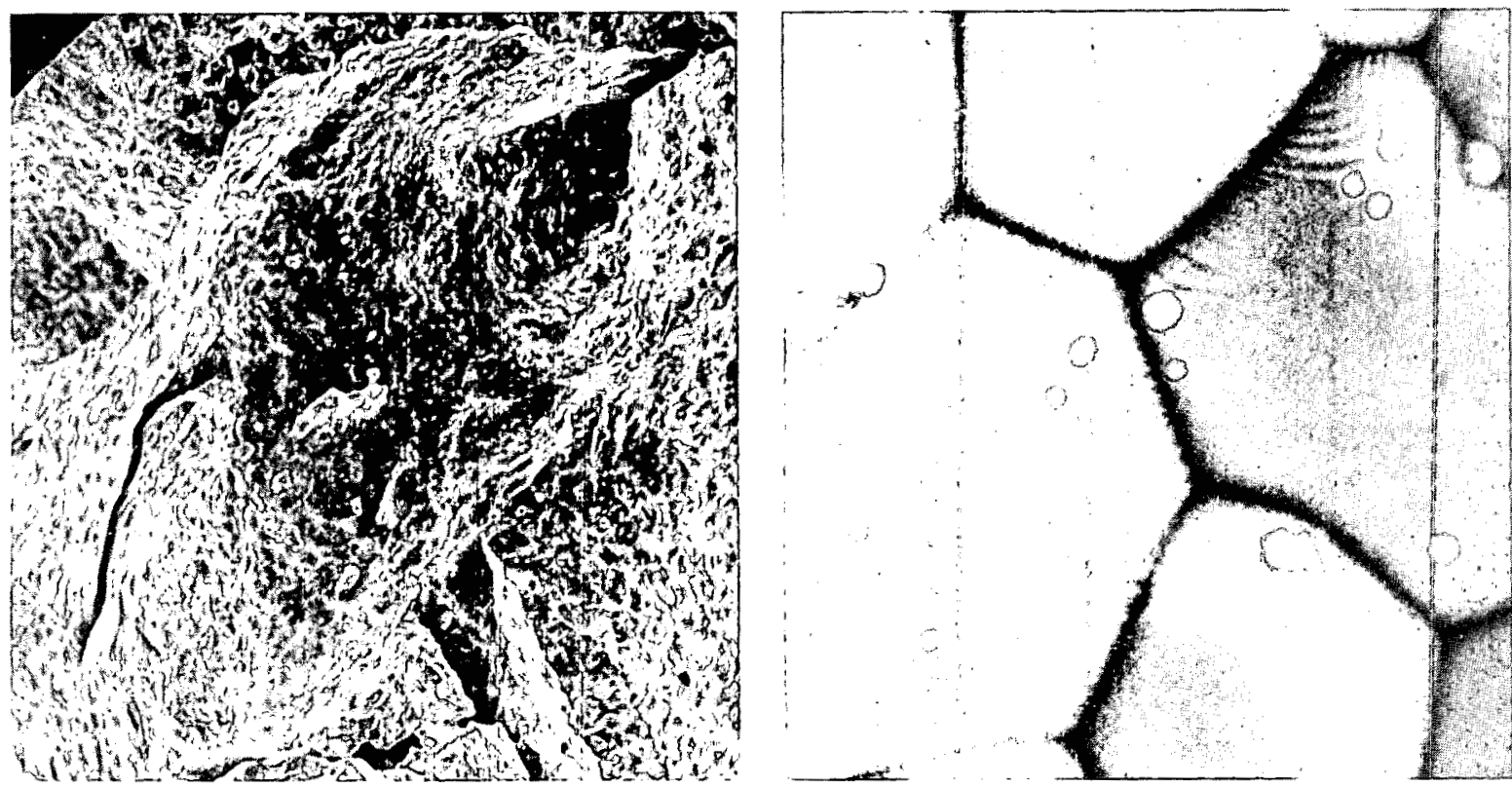

Neg 1964

$165 X \quad$ Neg 1968

$10,000 X$

EIGURE 5.23 Fractography of Sintered Pellet of UO2 - 25 wt\% $\mathrm{PuO}_{2}$ (Tungsten Impurity Content $2.5 \%$ )

those areas. The grains themselves showed faceted surfaces and deep grain boundaries more typical of freely growing regions than of a fractured cross section.

Identification of the inclusions, evaluation of relative $\mathrm{Pu}$ and $\mathrm{U}$ content in various regions, and determination of general composition of areas shown would be extremely useful in interpreting electron micrographs. Such information can be obtained by use of the $X$-ray fluorescence attachment recently added to the scanning electron microscope. Study of the mixed oxide pellets by this technique is in progress. 
BNWL -1144

\section{REFERENCES}

1. S. Bashforth and J. C. Adams. An Attempt to Test the Theory of Capilzary Action. Cambridge University Press, London, 1883 .

2. J. I. Bates. "EZectrical Conductivity of Cerium oxide," Quarterly Progress Report, January, February, March 1969, Reactor Fuels and Materials Development Programs for Fuels and Materials Branch of USAEC Division of Reactor Development and Technology, BNWL-1058, p. 5.8 Battelle-Northwest, Richiand, Washington, May 1969.

3. R. L. Gibby. "Thermal Diffusivity of (U,Pu) $0_{2}$, "Quarterly Progress Report, January, February, March 1969, Reactor Fuels and Materials Development Programs for Fuels and Mateirals Branch of USAEC Division of Reactor Development and Technology, BNWL-1058, p. 5.8 Battelle-Northwest, Richland, Washington, May 1969.

4. L. G. Overholser and J. P. Blakely. Outgassing Characteristics of Various Graphites, ORNL-3396. Oak Ridge National Laboratory, Oak Ridge, Tennessee, March 1, 1963. 
BNWL - 1144

FAST REACTOR NITRIDES RESEARCH

No Contribution

This Quarter

6.1 
BNWL - 1144

NONDESTRUCTIVE TESTING

No Contribution

This Quarter

7.1 
BNWL-1144

METALLIC FUELS

No Contribution

This Quarter

8.1 


\section{BASIC SWELLING STUDIES}

C. R. Hann

POSTIRRADIATION EXAMINATION - C. R. Hann, B. Mastel

The status of capsules currently under evaluation is indicated in Table 9.1. Four controlled temperature-pressure capsules, P-13, P-21, P-22, and P-23, were opened in the radiometallurgy facility and a total of 60 specimens recovered for density measurements and metallographic analyses. Table 9.2 gives the nominal chemical compositions of the various fuel materials. Metallurgical histories, irradiation parameters, and measured volume changes for capsules P-21, P-22, and P-23 are summarized in Tables 9.3, 9.4, and 9.5. Data from P-13 are not available at this time. Irradiation temperatures are given as time-average temperatures, and the error 1 imits represent the range of occasional temperature fluctuations caused by flux perturbations and changes in reactor power levels.

The U-0 Pu, U-5 Pu, and U-14 Pu-12 Zr specimens were supplied by ANL as part of a joint program by PNL and ANL. The specimens were prepared by vacuum melting in yttria-coated, stabilized zirconia crucibles and injection casting into yittria-coated Vycor molds. Four pins of 0.130 in. diameter by 12-in. long were obtained from each melt. Irradiation specimens were machined from void free sections. Selected specimens were wrapped in yttria-coated tantalum foil and heat-treated in evacuated Vycor tubes. Holes were drilled in some of the $1 / 2$-in. long rods for identification. Three rods were irradiated at any one position in the capsules; therefore, the first number of the specimen identification code refers to the capsule, the letter refers to the capsule position, and the number following the letter refers to the number of drilled holes.

The $\mathrm{U}_{3} \mathrm{Si}$ specimens were supplied by the Chalk River Nuclear Laboratories as part of a joint USAEC-AECL cooperative program. 
TABLE 9.1. Capsuze status

\begin{tabular}{|c|c|c|c|c|c|}
\hline $\begin{array}{l}\text { Capsule } \\
\text { Number } \\
\end{array}$ & $\begin{array}{l}\text { Control } \\
\text { Temp. },{ }^{\circ} \mathrm{C} \\
\end{array}$ & $\begin{array}{c}\text { Control } \\
\text { Pressure, psi } \\
\end{array}$ & $\begin{array}{r}\text { Gor } \\
\text { Burne } \\
\end{array}$ & $\begin{array}{l}\text { a } 1 \text { (a) } \\
\text { up, at. }\end{array}$ & Status \\
\hline $\mathrm{P}-10$ & 450 & 5000 & 0.2 & -0.8 & $\begin{array}{l}\text { Samples recovered and initial examina- } \\
\text { tions completed }\end{array}$ \\
\hline$P-11$ & 550 & 5000 & 0.2 & -0.8 & $\begin{array}{l}\text { Samples recovered and initial examina- } \\
\text { tions completed }\end{array}$ \\
\hline$P-12$ & 625 & 5000 & 0.2 & -0.8 & $\begin{array}{l}\text { Samples recovered and initial examina- } \\
\text { tions completed }\end{array}$ \\
\hline$P-14$ & 700 & 500 & 0.2 & -0.8 & $\begin{array}{l}\text { Samples recovered and initial examina- } \\
\text { tions completed }\end{array}$ \\
\hline$P-15$ & 700 & 1000 & 0.2 & -0.8 & $\begin{array}{l}\text { Samples recovered and initial examina- } \\
\text { tions completed }\end{array}$ \\
\hline$P-18$ & 825 & 50 & 0.1 & -0.7 & $\begin{array}{l}\text { Samples recovered and initial examina- } \\
\text { tions completed }\end{array}$ \\
\hline P- 19 & 725 & 50 & 0.2 & -1.5 & $\begin{array}{l}\text { Samples recovered and initial examina- } \\
\text { tions completed }\end{array}$ \\
\hline$P-20$ & 725 & 50 & 0.2 & -1.5 & $\begin{array}{l}\text { Samples recovered and initial examina- } \\
\text { tions completed }\end{array}$ \\
\hline$P-21$ & 450 & 1000 & 0.1 & -0.2 & Under examination in radiometallurgy \\
\hline$P-22$ & 550 & 1000 & 0.1 & -0.2 & Under examination in radiometallurgy \\
\hline$P-23$ & 625 & 1000 & 0.1 & -0.2 & Under examination in radiometallurgy \\
\hline
\end{tabular}
Different burnups ar
various enrichments. 


\section{TABLE 9.2. Compositions of Specimens in Swelling Capsules}

Fuel Material

\section{High Purity Uranium}

High Purity Uranium

lligh Purity Uranium

ligh Purity Uranium

bilute Uranium Alloys

bi lute Uranium Alloys

Di lute Uranium Alloys

bilute Uranium Alloys

Uranium-5 wty plutonium

Uranium-14 wt: PIutonium-12 wt:

Zircon i.um

Uranium Silicon Alloys

Uran ium Silicon Alloys

Uranium Silicon Alloys

Uraniun Silicon Alloys

Uranium Silicon Alloys

Uranium Silicon Alloys

I'horium-Uranium Alloys

Thorium-Uranium Alloys

'lhorium-Uranium Alloys
Alloy Designation

II i.

1:- 1

$1:-2$

Ui- o Pu

$\mathrm{U}+\mathrm{Pe}-\mathrm{Si}$

$U+F C-A l-S i$

WI::B

WS

$11-5 \mathrm{Pu}$

(j) $-14 \mathrm{Pu}-12 \mathrm{Zr}$

$U_{3} 5 \mathrm{~S} \quad(471)$

$115 \mathrm{si} \quad(473)$

$\mathrm{U}_{5} \mathrm{Si} \quad(501)$

$U_{5}$ Si. $\quad(501.4)$

$U_{5}$ Si $\quad(502)$

$\mathrm{U}_{5} \mathrm{Si}(506)$

Th- 1 wt: U

Th- 3.85 wt: U

l'h -5.4 wt $\mathrm{U}$
Composition (A.luitions in ppun)

$\mathrm{U}+64 \mathrm{I}: \mathrm{e}-25 \mathrm{AL}-6 \mathrm{C}$

$\mathrm{U}+9 \mathrm{SFC}-1 \mathrm{LAl}-34 \mathrm{Si}-56 \mathrm{C}$

$11+100 \mathrm{PC}-30 \mathrm{Al}-36 \mathrm{Si}-53 \mathrm{C}$

$11+50 \mathrm{Fe}-6 \mathrm{Al}-1.72 \mathrm{Si}-172 \mathrm{C}$

$11+140 \mathrm{l} 0-25 \wedge 1-95 \mathrm{Si}-400 \mathrm{C}$

$11+407 \mathrm{Pe}-645 \mathrm{Al}-95 \mathrm{Si}-500 \mathrm{C}$

$11+30.5 \mathrm{Fe}-807 \mathrm{Al}-32 \mathrm{Si}-402 \mathrm{C}$

$11+5501 \mathrm{e}-800 \mathrm{~A} 1-120 \mathrm{Si}-600 \mathrm{C}$

$11-4.96 w t . p u+5010-5.5 \wedge 1-119 \mathrm{si}-118 \mathrm{C}$

U-1.3.89 wt? Pu - 11.86 wt: $2 \mathrm{r}$

$+50 \mathrm{Fe}-20 \mathrm{~A} 1-315 \mathrm{Si}-144 \mathrm{C}$

U-3.58wt: Si + 49 Fe-44 Al-62 C-800 Zr

UI-3.98 Wt: Si $+83 \mathrm{Fe}-87 \mathrm{Al}-112 \mathrm{C}-2050 \mathrm{Zr}$ $1+3.52$ wt: $\mathrm{si}$

(I- 3.5 .3 wt: Si.

(1) -5.88 wt? Si

$\mathrm{U}-3.98$ wt: Si

Analysis Incomplete

Analysis Incomplete

Analysis Incomplete 
TABLE 9.3. Irradiation History and Swelling of Specimens in capsule P-21
Irradiated at $450{ }^{\circ} \mathrm{C}$ and 1000 psi

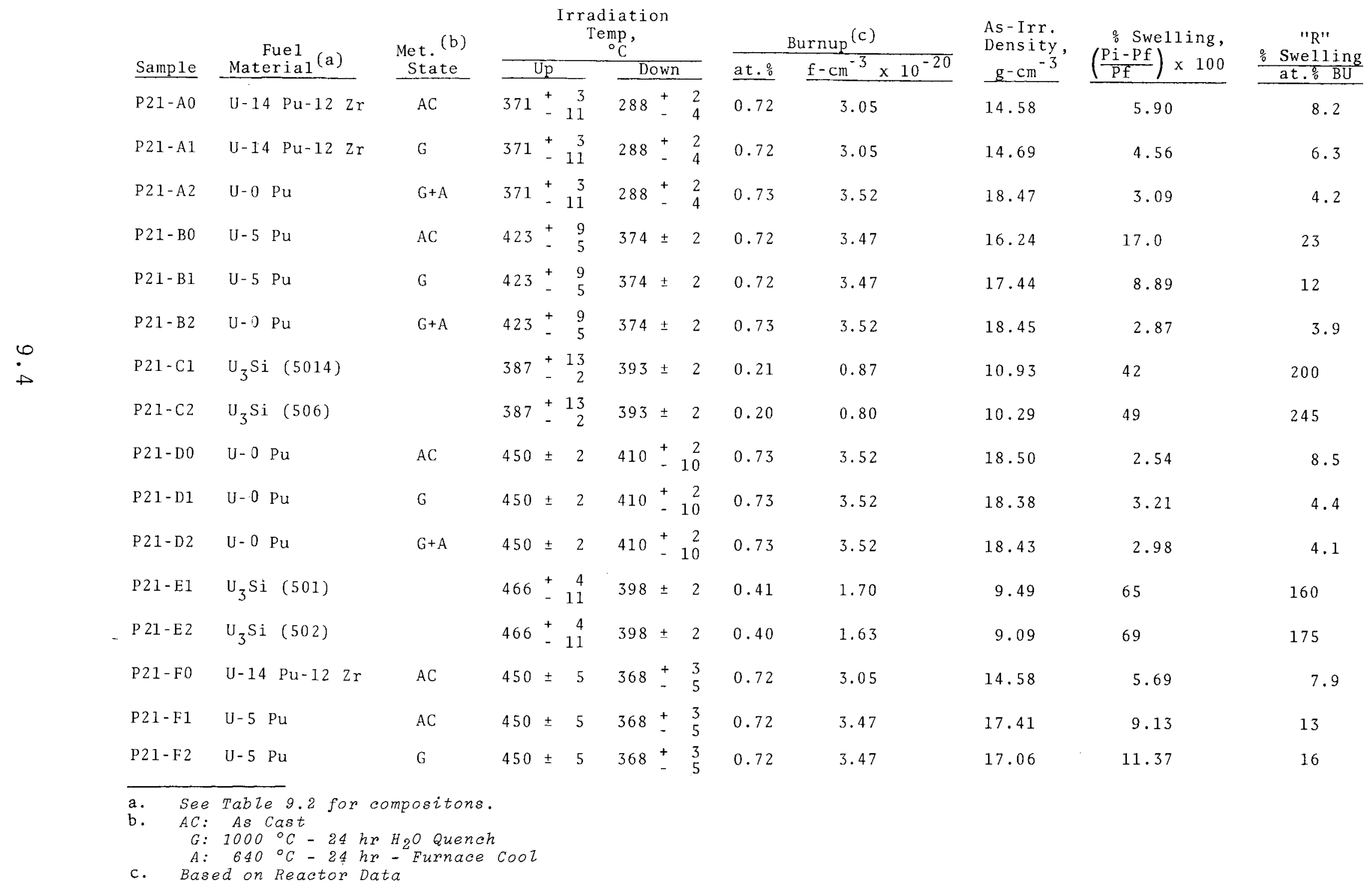


TABLE 9.4. Irradiation History and Swezling of Specimens in Capsule P-22 Irradiated at $550^{\circ} \mathrm{C}$ and $1000 \mathrm{psi}$

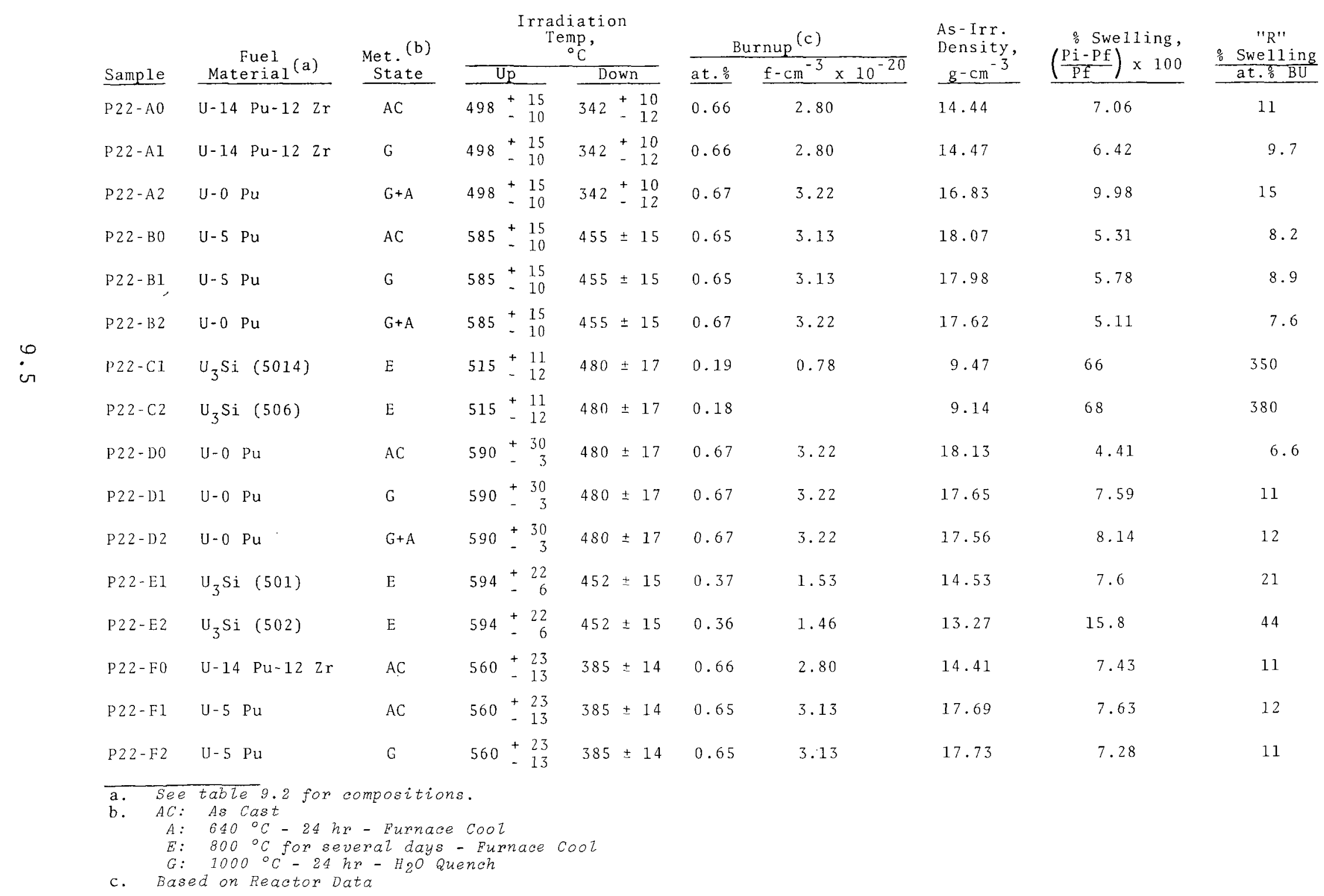


TABLE 9.5. Irradiation History and Swelling of specimens in Capsule P-23 Irradiated at $625^{\circ} \mathrm{C}$ and $1000 \mathrm{psi}$

\begin{tabular}{|c|c|c|c|c|c|c|c|c|c|c|c|}
\hline \multirow[b]{2}{*}{ Sample } & \multirow{2}{*}{$\begin{array}{c}\text { Fuel } \\
\text { Material (a) }\end{array}$} & \multirow{2}{*}{$\begin{array}{l}\text { Met. (b) } \\
\text { State } \\
\end{array}$} & \multicolumn{4}{|c|}{$\begin{array}{c}\text { Irradiation } \\
\text { Temp, } \\
\underset{\circ}{\circ} \mathrm{C}\end{array}$} & \multicolumn{2}{|c|}{ Burnup $(\mathrm{c})$} & \multirow{2}{*}{$\begin{array}{l}\text { As - Irr. } \\
\text { Density, } \\
{\mathrm{g}-\mathrm{cm}^{-3}}\end{array}$} & \multirow{2}{*}{ 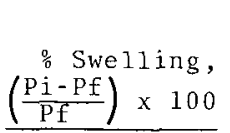 } & \multirow{2}{*}{ 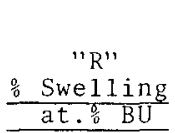 } \\
\hline & & & & $\mathrm{Up}$ & $\mathrm{DO}$ & wn & at. $\frac{0}{2}$ & $\mathrm{f}-\mathrm{cm}^{-3} \times 10^{-20}$ & & & \\
\hline $\mathrm{P} 23-\mathrm{A} 0$ & $\mathrm{U}-14 \mathrm{Pu}-12 \mathrm{Zr}$ & $\mathrm{AC}$ & 571 & $\begin{array}{l}+9 \\
-\quad 14\end{array}$ & 422 & \pm 4 & 0.66 & 2.80 & 14.26 & 8.20 & 12 \\
\hline $\mathrm{P} 23-\mathrm{A} 1$ & U-14 Pu-12 Zr & G & 571 & $\begin{array}{l}+9 \\
-\quad 14\end{array}$ & 422 & $\pm \quad 4$ & 0.66 & 2.80 & 14.36 & 7.31 & 11 \\
\hline $\mathrm{P} 23-\mathrm{A} 2$ & $\mathrm{U}-0 \mathrm{Pu}$ & $\mathrm{G}+\mathrm{A}$ & 571 & $\begin{array}{l}+\quad 9 \\
-\quad 14\end{array}$ & 422 & \pm 4 & 0.67 & 3.22 & 14.88 & 28 & 41 \\
\hline P23-B0 & $\mathrm{U}-5 \mathrm{Pu}$ & $\mathrm{AC}$ & 625 & \pm 7 & 534 & $\begin{array}{l}+3 \\
-\quad 10\end{array}$ & 0.65 & 3.13 & 19.01 & 5.55 & 8.5 \\
\hline P23-B1 & $\mathrm{U}-5 \mathrm{Pu}$ & G & 625 & \pm 7 & 534 & $\begin{array}{r}+3 \\
-\quad 10\end{array}$ & 0.65 & 3.13 & 17.95 & 6.02 & 9.3 \\
\hline P23-B2 & $\mathrm{U}-0 \mathrm{Pu}$ & $\mathrm{G}+\mathrm{A}$ & 625 & \pm & 534 & $\begin{array}{r}+3 \\
-\quad 10\end{array}$ & 0.67 & 3.22 & 18.18 & 4.51 & 6.7 \\
\hline P23-C1 & $\mathrm{U}_{3} \mathrm{Si} \quad(5014)$ & E & 560 & $\begin{array}{l}+\quad 7 \\
-\quad 5\end{array}$ & 542 & $\begin{array}{r}+3 \\
-\quad 11\end{array}$ & 0.19 & 0.78 & 13.61 & 15 & 79 \\
\hline P23-C2 & $\mathrm{U}_{3} \mathrm{Si} \quad(506)$ & E & 560 & $\begin{array}{l}+7 \\
-\quad 5\end{array}$ & 542 & $\begin{array}{r}+3 \\
-\quad 11\end{array}$ & 0.18 & 0.72 & 12.61 & 21 & 120 \\
\hline P23-D0 & $\mathrm{U}-0 \quad \mathrm{Pu}$ & $\mathrm{AC}$ & 621 & $\begin{array}{l}+3 \\
-\quad 2\end{array}$ & 540 & $\begin{array}{l}+\quad 3 \\
-\quad 16\end{array}$ & 0.67 & 3.22 & 18.33 & 3.71 & 5.5 \\
\hline P23-D1 & $\mathrm{U}-0 \quad \mathrm{Pu}$ & G & 621 & $\begin{array}{l}+3 \\
-\quad 2\end{array}$ & 540 & $\begin{array}{l}+\quad 3 \\
-16\end{array}$ & 0.67 & 3.22 & 18.28 & 3.56 & 5.3 \\
\hline P23-D2 & $\mathrm{U}-0 \quad \mathrm{Pu}$ & $G+A$ & 621 & $\begin{array}{l}+3 \\
-\quad 2\end{array}$ & 540 & $\begin{array}{l}+3 \\
-\quad 16\end{array}$ & 0.67 & 3.22 & 18.04 & 5.21 & 7.8 \\
\hline P23-E1 & $\mathrm{U}_{3} \mathrm{Si} \quad(501)$ & E & 620 & $\begin{array}{l}+6 \\
-\quad 4\end{array}$ & 517 & $\begin{array}{r}+5 \\
-\quad 11\end{array}$ & 0.37 & 1.53 & 15.11 & 3.57 & 9.6 \\
\hline $\mathrm{P} 23-\mathrm{E} 2$ & $\mathrm{U}_{3} \mathrm{Si} \quad(502)$ & E & 620 & $\begin{array}{l}+\quad 6 \\
-\quad 4\end{array}$ & 517 & $\begin{array}{l}+5 \\
-\quad 11\end{array}$ & 0.36 & 1.46 & 14.82 & 2.77 & 7.7 \\
\hline P23-F0 & U-14 Pu-12 $2 \mathrm{r}$ & G & 570 & $\begin{array}{l}+12 \\
-\quad 6\end{array}$ & 437 & $\begin{array}{l}+\quad 4 \\
-\quad 8\end{array}$ & 0.66 & 2.80 & 14.42 & 6.66 & 10 \\
\hline$P 23-F 1$ & $\mathrm{U}-5 \mathrm{Pu}$ & $\mathrm{AC}$ & 570 & $\begin{array}{r}+12 \\
-\quad 6\end{array}$ & 437 & $\begin{array}{l}+\quad 4 \\
-\quad 8\end{array}$ & 0.65 & 3.13 & 18.05 & 5.10 & 7.8 \\
\hline$P 23-F 2$ & $\mathrm{U}-5 \mathrm{Pu}$ & G & 570 & $\begin{array}{l}+\quad 12 \\
-\quad 6\end{array}$ & 437 & $\begin{array}{l}+\quad 4 \\
-\quad 8\end{array}$ & 0.65 & 3.13 & 17.99 & 5.73 & 8.8 \\
\hline $\begin{array}{ll}\text { a. } & S \\
\text { b. } & A C \\
& \\
\text { c. } & B C\end{array}$ & $\begin{array}{l}\text { Table } 9.2 \text { for } \\
\text { As Cast } \\
6400^{\circ} \mathrm{C}-24 \mathrm{~h} \\
800 \mathrm{O}^{\circ} \mathrm{C}-\mathrm{for} \\
1000 \mathrm{O}^{\circ} \mathrm{C}-24 \\
\text { d on Reactor } \\
\text { do }\end{array}$ & $\begin{array}{l}\text { compositons } \\
\text { - Furnace } \\
\text { severat days } \\
\text { hr- } H_{2} O \text { Que } \\
\text { ata }\end{array}$ & $\begin{array}{l}\text { - } \\
\text { Cool } \\
-\quad \text { En } \\
\text { noh }\end{array}$ & urnace & $\mathrm{COOZ}$ & & & & & & \\
\hline
\end{tabular}


The split tubular specimens were machined from rods that had been cast and heat treated to transform the $U_{3} \mathrm{Si}_{2}$ and $U$ to $\mathrm{U}_{3} \mathrm{Si}$.

Burnups were calculated from reactor calorimetric data or from calculated flux values and the length of irradiation; these burnups will be verified via ${ }^{137} \mathrm{Cs}$ and flux dosimetry analyses.

U-0 $\mathrm{Pu}, \mathrm{U}-5 \mathrm{Pu}$, and $\mathrm{U}-14 \quad \mathrm{Pu}-12 \mathrm{Zr}$ Specimens

The specimens of the above materials recovered from capsules P-22 and P-23 appeared to be in excellent condition. A few of the U-0 Pu and the U-5 Pu specimens shcwed evidence of swelling around the identification holes, but no gross swelling was noted. Specimen P-22-F1 (U-5 Pu) showed some marked distortion at one end that could have been caused by irradiation growth.

The U-14 Pu-12 $\mathrm{Zr}$ specimens irradiated in capsule P-21 appeared to be in good shape, but the U-O Pu and U-5 Pu specimens were generally quite distorted by irradiation growth. " $R$ " values were quite low for all the specimens, indicating that a 1000 psi pressure can be quite effective in restraining swelling in these fuel materials.

$\underline{U}_{3} \underline{\mathrm{Si} \text { Specimens }}$

Visual examination of specimens recovered from capsules P-21, P-22, and F-23 indicated 1ittle swelling had occurred, but density measurements indicate large volume increased. Two specimers, P-23-C1 and P-23-C2, were swollen at only one end. This observation indicates that swelling in $\mathrm{U}_{3} \mathrm{Si}$ is quite temperature sensitive. The density data indicate swelling is greater at lower temperatures. A plot (Figure 9.1) of " $R$ " $(\% \mathrm{AU} / \mathrm{V} \div$ at: $: \mathrm{BU})$ as a function of irradiation temperature show's a broad maximum between $400^{\circ} \mathrm{C}$ and $600^{\circ} \mathrm{C}$. Metallographic examinations have confirmed the low volume increases $(\mathrm{R}=5-8)$ of specimiens irradiated at $50 \mathrm{psi}$ between $675^{\circ} \mathrm{C}$ and 
BNWL- 1144

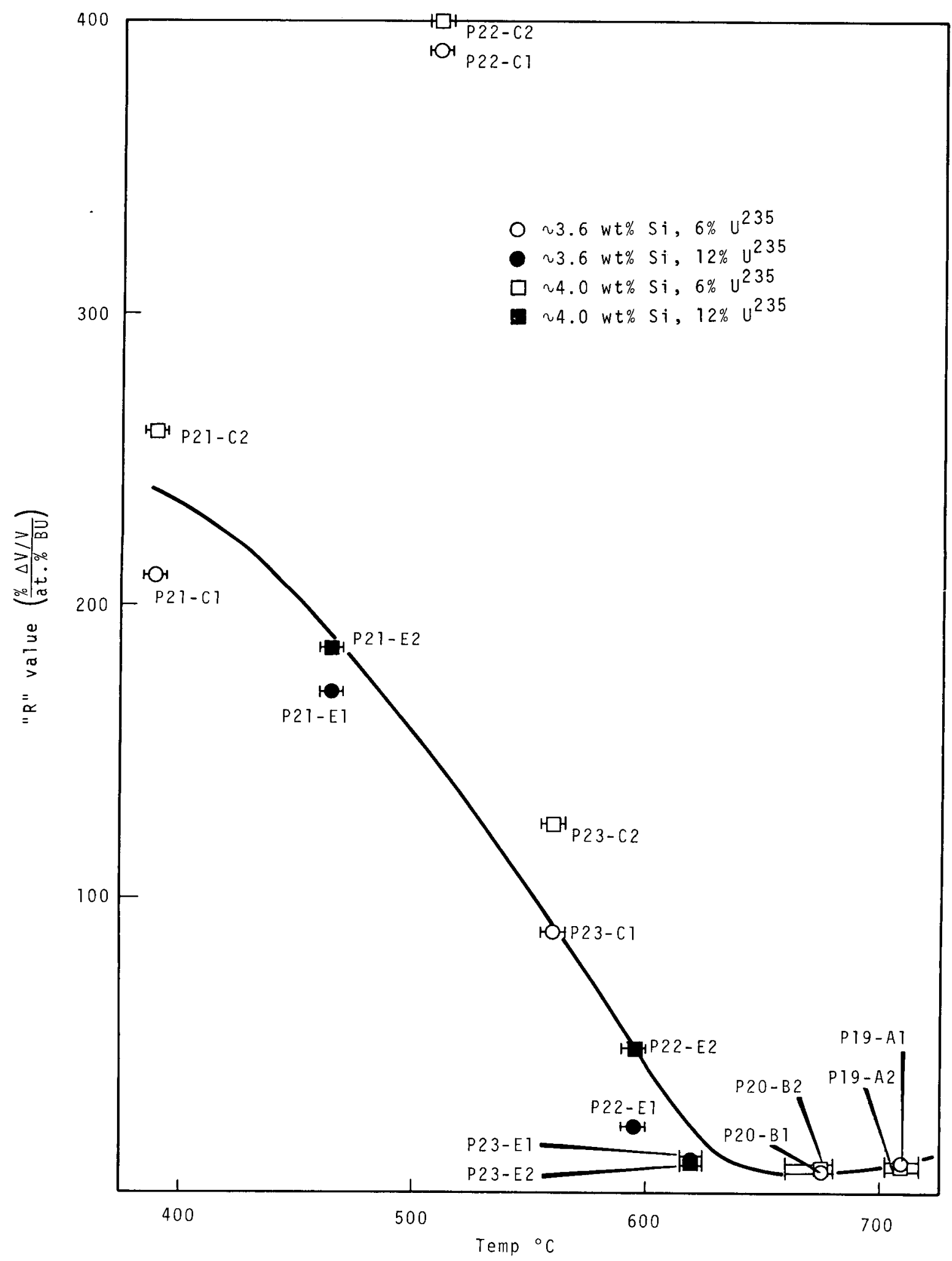

FIGURE 9.1. Irradiation Swelling of ${ }_{3}$ Si

9.8 
and $710{ }^{\circ} \mathrm{C}$. These preliminary data indicate swelling in $\mathrm{U}_{3} \mathrm{Si}$ shows the same temperature dependence as uranium metal; additional metallography will be required to verify the magnitude and to determine the nature of the swelling. MIXED NITRIDES FUEL IRRADIATION - R. K. Marshäl

A test has been designed to study the effect of irradiation on the effective thermal conductivity and structural changes which occur during the short-term irradiation of $\left(\mathrm{U}_{0.8} \quad \mathrm{Pu}_{0.2}\right)$ pellet fue1. To determine the effect of irradiation on the effective thermal conductivity, the changes in the core temperature of a pellet are monitored during irradiation. The test is so designed that any change in temperature results from a change in the effective thermal conductivity of the fuel. The test capsule was irradiated for 12 days in the specialty irradiation facility at KW Reactor. The core temperature of the pellet was initially $700{ }^{\circ} \mathrm{C}$ and then during the first several hours gradually dropped to and remained around $625{ }^{\circ} \mathrm{C}$ for the rest of the test. The predicted temperature for the pellet core was $720{ }^{\circ} \mathrm{C}$. Postirradiation examination revealed severe fragmentation of the pellets. The results of metallographic examination were inconclusive concerning the short-term irradiation effects on the microstructure of the fuel. Burnup analysis is being made from which the thermal conductivity of the fuel will be determined. 
BNWL -1144

ATR GAS LOOP OPERATION AND MAINTENANCE

No Contribution

This Quarter

10.1 


\section{FAST REACTOR DOSIMETRY AND DAMAGE ANALYSIS}

\section{R. E. Nightingale}

EBR-II DOSIMETRY TEST - J. L. Jackson, W. N. MCETroy,

J. A. Ulseth, L. S. Kellogg, and F. S. Kirn

Reaction-rate ratios can be used to identify changes in neutron spectra, since monitors differ in their response to different neutron energies. For example, at core center the $90 \%$ response ranges of the reactions is from 0.038 to $3.0 \mathrm{MeV}$ for ${ }^{235} \mathrm{U}(\mathrm{n}, \mathrm{f})$, from 2.1 to $7.9 \mathrm{MeV}$ for ${ }^{54} \mathrm{Fe}(\mathrm{n}, \mathrm{p})$, from 1.4 to $6.4 \mathrm{MeV}$ for ${ }^{238} \mathrm{U}(\mathrm{n}, \mathrm{f})$, and from 0.003 to $1.2 \mathrm{MeV}$ for ${ }^{58} \mathrm{Fe}(\mathrm{n}, \gamma)$. A change in the ratio of reaction rates indicates a change in the spectrum which must be taken into account in the analysis of both monitor and irradiation damage data.

Additional data from the recent PNL-ANL dosimetry test ${ }^{(1)}$ are provided in Table 11.1. Listed are either the fission rates or saturated activities of the different monitors irradiated at core center midplane at two power levels. Since the experimental conditions were otherwise identical, the ratios of the reaction rates at low power to those at high power should be the same for all reactions. This is not the case. For examp1e, for the ${ }^{54} \mathrm{Fe}(\mathrm{n}, \mathrm{p})$ reaction the ratio is $1.67 \times 10^{-3}$, while for the ${ }^{235} \mathrm{U}(\mathrm{n}, \mathrm{f})$ reaction the ratio is $1.82 \times 10^{-3}$. The difference between the two of approximately $8 \%$ is three times larger than the standard error for the reactions. Such a significant difference implies a change in spectrum between the high- and low-power tests.

Changes in the ratio of reaction rates for different monitors also indicate spectral shifts at different reactor positions. Data were previously reported ${ }^{(2)}$ for the radial positions of EBR-II midplane. Figure 11.1 provides ratios for the axial direction above midplane in Row 2 . The reaction rate data used to calculate the ratios in Figure 11.1 was obtained from pin 18, 
TABLE 11.1. Comparison of High and Low Power Interaction Rates

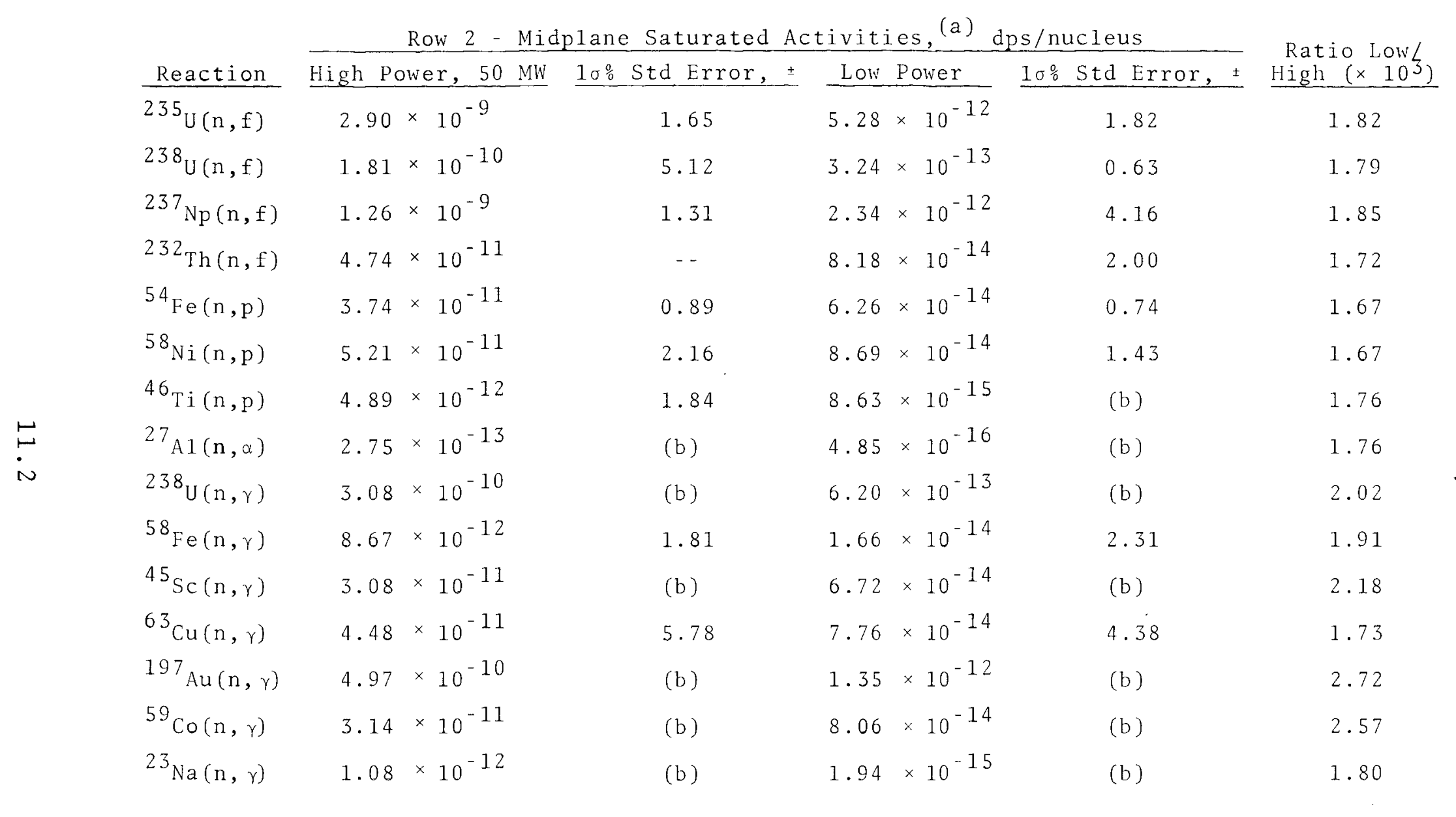

(a) Fissions/sec/nucleus for fission foils.

(b) only one or two monitors were available and no standard error could be calculated. Based on the precision obtained for the other reactions and the consistency in the data as compared with other axial and radial positions, we estimate the 10 sta error to be less than $\pm 7 \%$. 


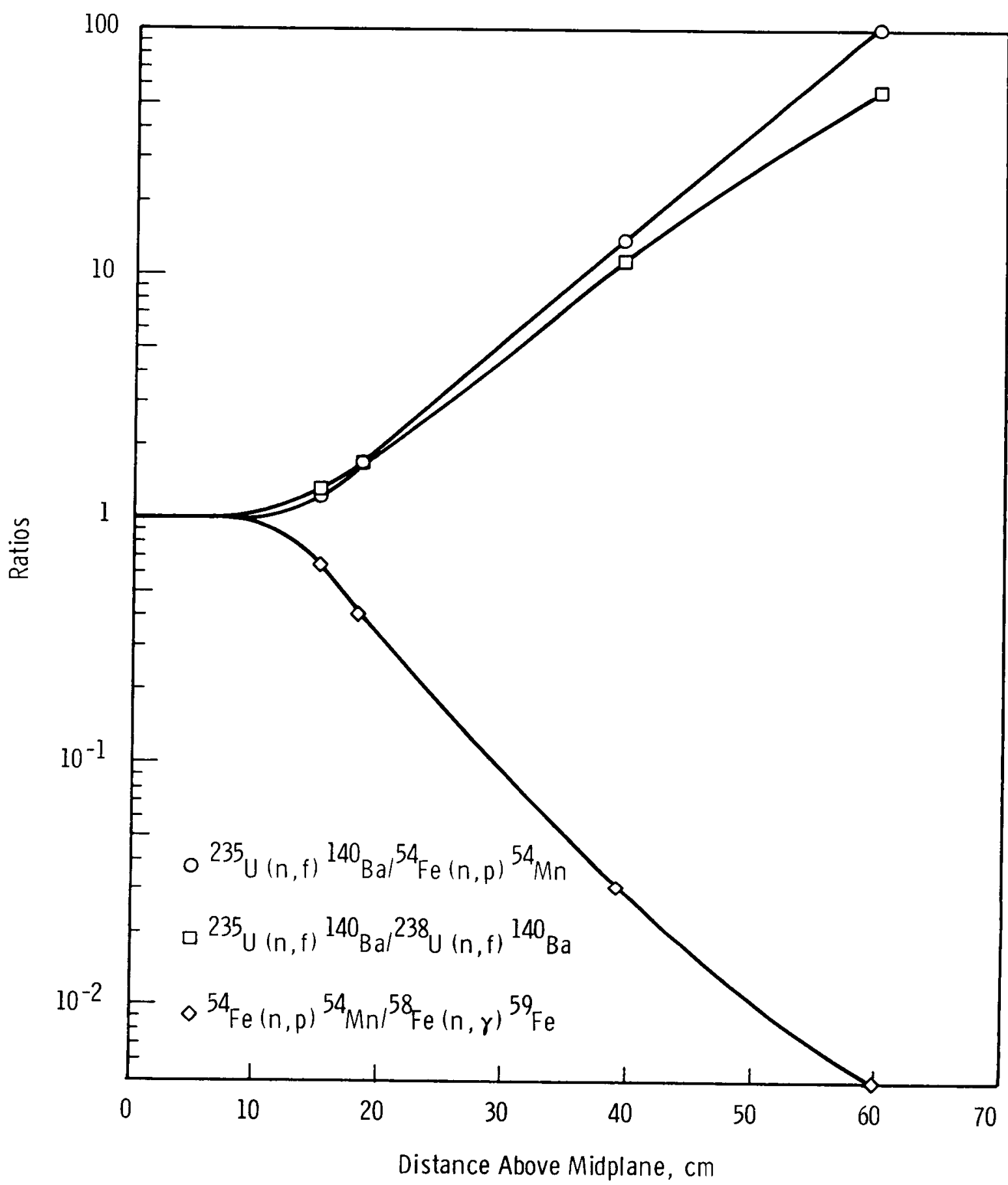

FIGURE 11.1. Ratios for the Axial Direction Above Midplane 
subassemb1y X046, position 2B1, irradiated during Run $31 \mathrm{~F}$. The ${ }^{235} \mathrm{U}(\mathrm{n}, \mathrm{f})$ to ${ }^{54} \mathrm{Fe}(\mathrm{n}, \mathrm{p})$ ratio shows no spectral shift axially up to $\sim 10 \mathrm{~cm}$ above midplane but decided changes beyond. The same effect is shown by the other ratios. Thus, it is inferred that for this reactor run the spectrum was constant in Row 2 for approximately $10 \mathrm{~cm}$ ( 4 in.) above midplane.

DAMAGE FUNCTIONS AND DATA CORRELATION - W. N. MCEIroy and C. Z. Serpan, Jr.*

\section{Introduction}

A previous report ${ }^{(3)}$ discussed the development and study of a method for generating energy-dependent damage functions for the correlation and prediction of neutron induced property changes.

The method was demonstrated by using data on ductilebrittle transition temperature increase $(\Delta \mathrm{TT})$ as a function of total neutron fluence for irradiations at $<450{ }^{\circ} \mathrm{F}\left(232^{\circ} \mathrm{C}\right)$ of ASTM A212-B and A302-B steels in widely differing neutron environments. $(3,4)$ These data with their respective neutron spectra were used to derive a damage function. An advantage of this semi-empirical method is that damage caused by mechanisms other than displacement-related processes are included in the damage function.

Reference 5 presents the results of a new set of experimental data conforming to the irradiation conditions of the derived damage function (material, temperature, and fluence). The results of this experiment help to establish the validity of the damage function.

Experimental Data

The new data on transition-temperature increase were measured at the $30 \mathrm{ft}-1 \mathrm{~b}$ level, for a 6 -in. thick plate of

* Reactor Materials Branch, Metallurgy Division, Naval Research Laboratory, Washington, D.C. 
A302-B manganese-molybdenum pressure-vessel steel. The irradiations were conducted in a reactor facility designated GMWC (Figure 11.2). Sealed capsules were contained within special shields that permitted $<240^{\circ} \mathrm{F}\left(116^{\circ} \mathrm{C}\right)$ water to pass over the capsules, but which altered the reactor spectrum incident upon the capsules to yield neutron-fluence ratios of 9,5 , and 1.8 to 1 thermal-to-fast $(>0.5 \mathrm{MeV})$. Three distinct fluence levels were attained for each set of capsules representing all three neutron energy ratios. The three reactor spectra were assigned spectrum reference numbers 39,40 , and 41 , respectively, for comparison with the previously reported spectra ( 1 through 21 in Figure 11.2) used to derive the damage function.

The data are plotted versus total neutron fluence in Figure 11.2.* Considering experimental uncertainties, the three data points for each of the three thermal-to-fast ratios in the GMWC facility conform well with the arbitrarily placed trend lines superimposed on the figure.** The trend pattern is defined as a fourfold increase in total fluence for a $100{ }^{\circ} \mathrm{F}$ $\left(56{ }^{\circ} \mathrm{C}\right) \triangle \mathrm{TT}$ in $\mathrm{A} 302-\mathrm{B}$ steel for irradiations $<450{ }^{\circ} \mathrm{F}\left(232^{\circ} \mathrm{C}\right)$. This trend was suggested by Rossin ${ }^{(6)}$ and was subsequently used as a reasonable basis for extrapolation of data to other fluence and embrittlement levels.(3-5) Its use is validated by the results of the GMWC data. Use of the straight-line trend behavior for data $\leq \Delta \mathrm{TT} 400^{\circ} \mathrm{F}\left(222^{\circ} \mathrm{C}\right)$ is further justified because full radiation embrittlement saturation for this steel irradiated at $<450{ }^{\circ} \mathrm{F}\left(232^{\circ} \mathrm{C}\right)$ has not been observed.

\footnotetext{
* Defined as the sum of the thermal, intermediate, and fast components of the neutron spectrum.

* The Charpy $V$ specimens for the GMWC test exhibited greater than average scatter, thus decreasing the overall accuracy of the final $\triangle T T$ values, see Reference 5 .
} 


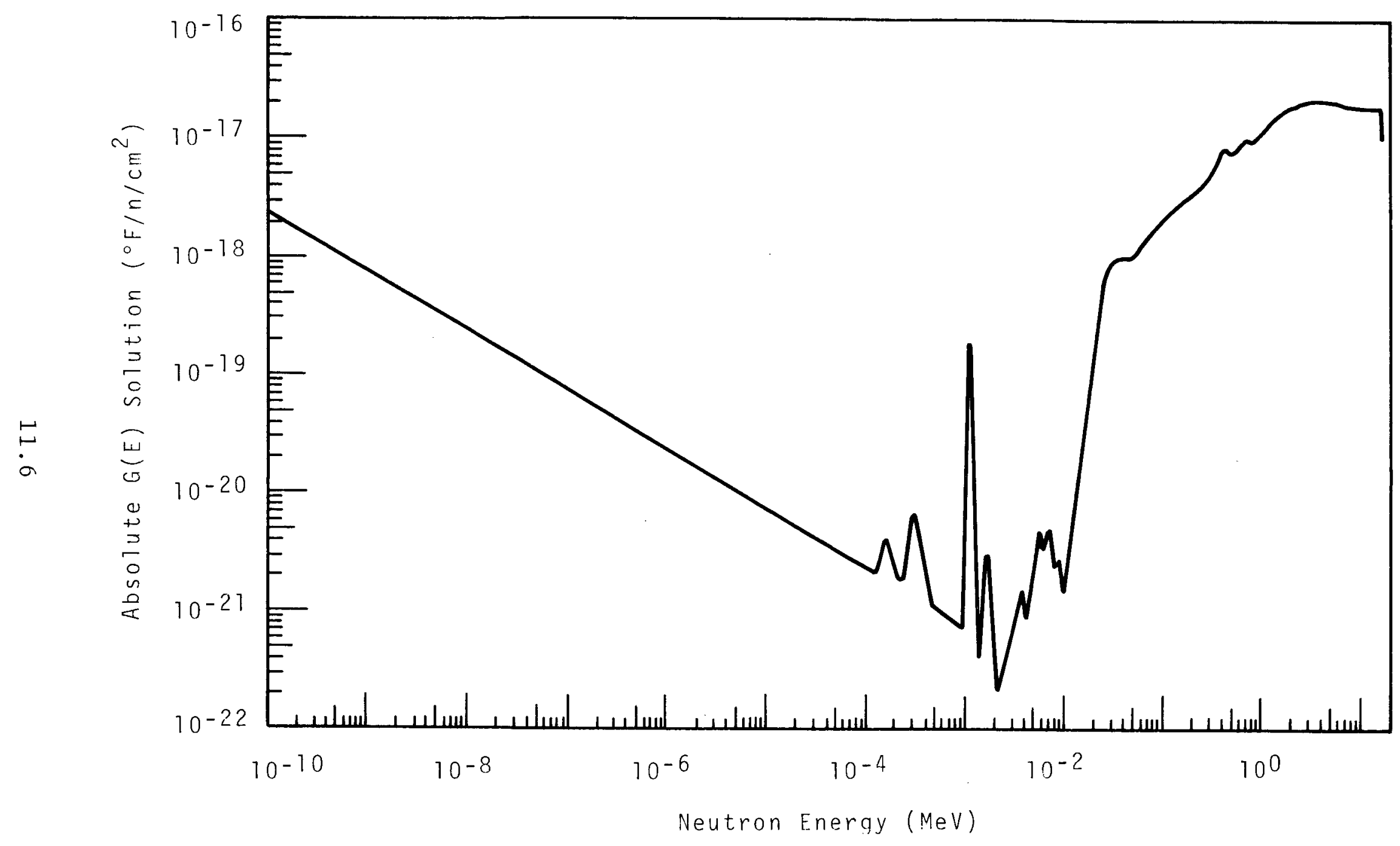

FIGURE 11.2. Charpy-V 30 fi-.h Transition Temperature Increases Versus Total Neutron Flience. Tr Irradiations <450 ${ }^{\circ} \mathrm{F}\left(232^{\circ} \mathrm{C}\right)$ of A302-B Steel 
BNWL -1144

Damage Function-Fluence Relationship

It can be seen from Figure 11.2 that the embrittlement in A302-B stee1 has a neutron-energy dependence. From such evidence, it is becoming evident that data obtained from diverse spectral environments can never be completely correlated in a simple plot of $\triangle T T$ versus neutron fluence for neutrons greater than any energy. However, for those systems in which most of the damaging neutrons are above a few tenths MeV, good correlation can be expected on a plot of $\triangle T T$ versus neutron fluence for neutrons greater than a specific energy such as 0.5 or $0.1 \mathrm{MeV} .{ }^{(7)}$ To achieve better correlations, it is necessary to plot the $\triangle \mathrm{TT}$ data versus other parameters which reflects those mechanisms other than displacements. $(8-11)$ *

Correlation can be improved by a damage model that incorporates displacement effects as a starting point and includes provisions for other damage or "annealing" mechanisms.

The data from Figure 11.2 were used to derive an empirical damage function. That absolute damage function for the calculation of the total fluence required to cause a $200{ }^{\circ} \mathrm{F}\left(111{ }^{\circ} \mathrm{C}\right)$ $\triangle T T$ in A302-B steel for irradiations at temperatures $<450^{\circ} \mathrm{F}$ $\left(232{ }^{\circ} \mathrm{C}\right)$ is presented graphically in Figure 11.3. A modified version of the SAND-II Code (12) was used to obtain the damage function solution $G(E)$ for a set of integral equations of the form:

$$
S_{j}=\iint G(E) \cdot \phi_{j}(E, t) d E d t,
$$

where $S_{j}$ is a measured integral property change such as $\triangle T T$ for a specified material, irradiated for a time $t$ in the $j$ th neutron environment (at constant temperature $T$ ), and $\phi_{j}(E, t)$ is the corresponding $j^{\text {th }}$ neutron differential spectrum. * Displacements are generally thought to be associated with
high-energy neutron effects. 


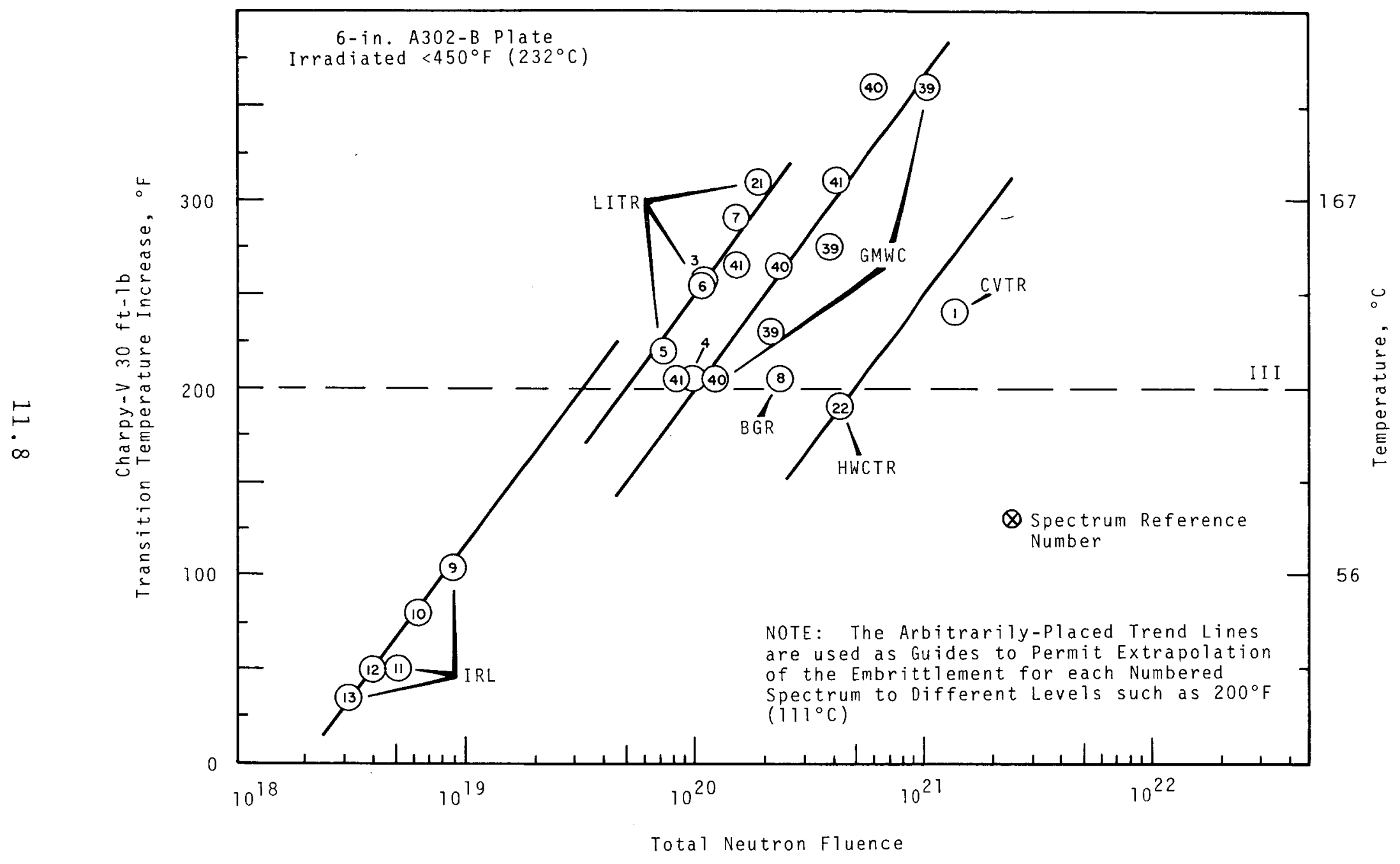

FIGURE 11.3. Absolute G(E) Damage Function Solution for a $200{ }^{\circ} \mathrm{F}\left(111{ }^{\circ} \mathrm{C}\right)$ Transition Temperature Increase in A302-B Steel for Irradiations $<450{ }^{\circ} F \quad\left(232^{\circ} \mathrm{C}\right)$ 
The derived damage function can be used with multigroup reactor physics calculations to obtain the fluence (and appropriate energy limits of damaging neutrons) required to cause the property change in any spectrum. Equation (1) is rewritten:

$$
S=\Phi t \sum_{i=1}^{m} G_{i} \cdot \Phi_{i}
$$

where

$$
\sum_{i=1}^{m} \Phi_{i}=1
$$

and $\Phi_{i}$ is the normalized integral flux within the $i^{\text {th }}$ group, $\Phi t$ is the fluence required to cause the property change specified in the derivation of $G(E)$, and $G_{i}$ is the corresponding group averaged $G(E)$ value.

To use the $G(E)$ function would then require knowledge of the neutron spectrum at the reactor location of interest. Group-averaged values of this spectrum would be multiplied by group-averaged values of the damage function, and Equation (2) would be solved for $\Phi t$ according to:

$$
\Phi t=S\left[\sum_{i=1}^{m} G_{i} \cdot \Phi_{i}\right]^{-1} .
$$

The fluence obtained from Equation (4) would be that required to cause a change of $200^{\circ} \mathrm{F}\left(111^{\circ} \mathrm{C}\right) \triangle \mathrm{TT}$ in $\mathrm{A} 302-\mathrm{B}$ stee 1 in the spectrum of interest. It was found (Table 11.2) that a single set of group-averaged values of the damage function could be used instead of the exact form, Figure 11.3, without introducing more than about a 5 to $10 \%$ variation in the calculated values of fluences for most reactor spectra.

In the development of the damage function of Figure 11.3, it was recognized that the reactor environments were not sufficiently different to provide a reliable solution for the 
TABLE 11.2. Group Averaged Values for Absolute G(E) for a $200^{\circ} F$ (111 $\left.{ }^{\circ} \mathrm{C}\right) \triangle T T$ in $A 302-B$ Steel Irradiated at $<450^{\circ}{ }^{\circ}\left(232^{\circ} \mathrm{C}\right)$ and Application to Different Spectra

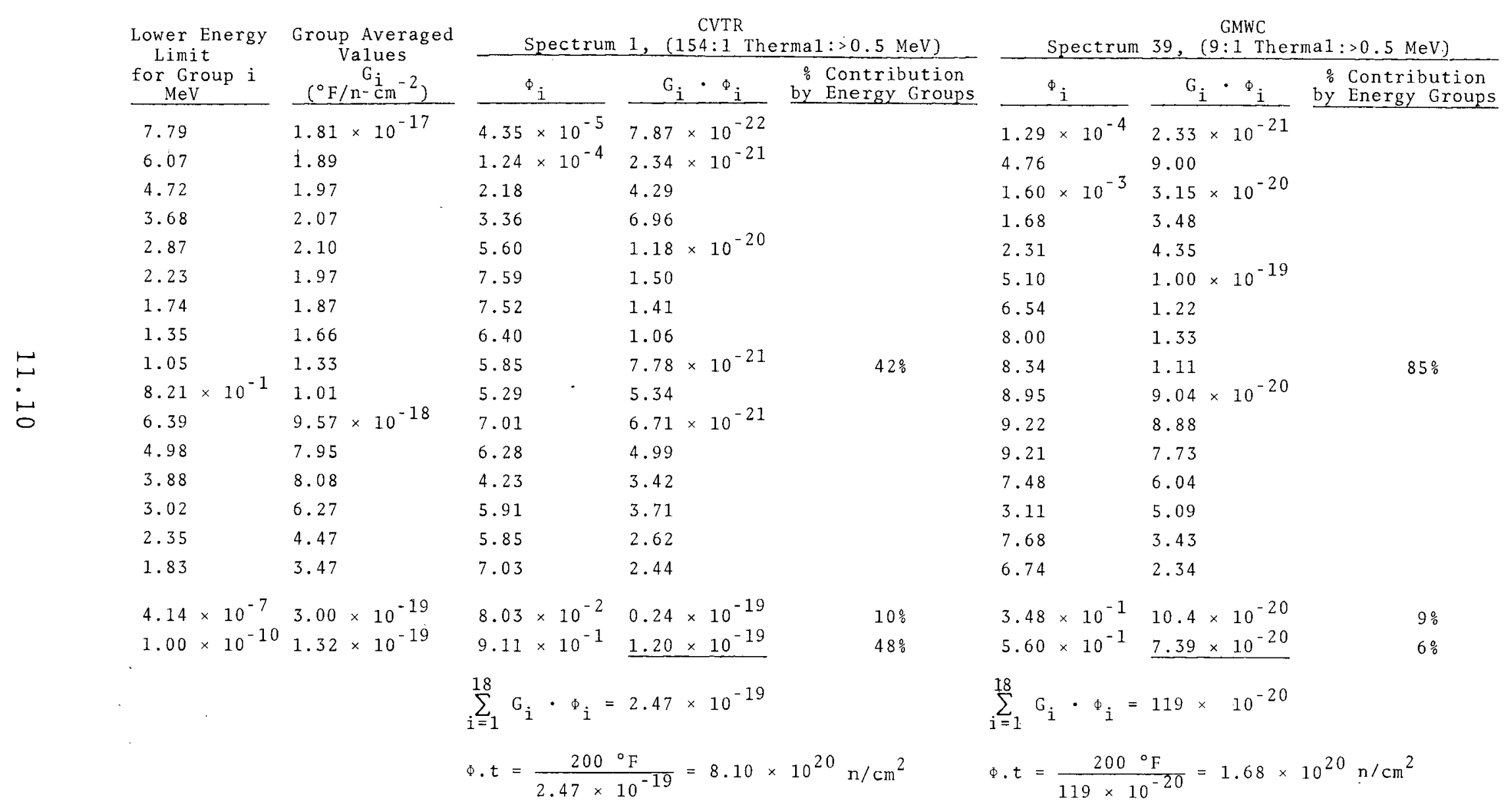


damage model in the intermediate energy region between $\sim 10^{-7}$ and $\sim 2 \times 10^{-2} \mathrm{MeV}$. In this region, therefore, the function is essentially the assumed input model. For this reason, no attempt has been made in these studies to generate or use detailed structure in this region. Furthermore, for the thermal-energy region, the magnitude of the derived damage function for A302-B steel may be too low.

The approximating procedure used in the GMWC experiment (and in References 3 to 5) for defining the magnitudes of thermal, intermediate, and fast components of the neutron spectrum has been compared with a more exact procedure. (12) This comparison revealed that the approximating procedure may have yielded high thermal fluence results. This implies that the derived damage function may be too low in the thermal energy region. Future re-evaluations of these data may reveal, therefore, that the damage from thermal neutrons is greater than the present results for A302 steel.

Damage Function Applications

Examples of the application of Equation (4) and groupaveraged values, $G_{i}$, of the damage function are considered in Table 11.2, using the group integral flux values for two of the very different reactor irradiation locations (Figure 11.2). The left column under both spectral listings gives the group fluxes as normalized to one neutron; the middle column is the product of the group flux and the group averaged damage function. The summation of these products for both spectra are then divided into $200^{\circ} \mathrm{F}$ to yield the total fluence for a $200^{\circ} \mathrm{F}$ $\triangle T T$ in A302-B steel for irradiations $<450^{\circ} \mathrm{F}$. The right column under each listing shows the thermal $\left(<4.14 \times 10^{-7} \mathrm{MeV}\right)$, intermediate $\left(4.14 \times 10^{-7} \mathrm{MeV}<\mathrm{E}<0.183 \mathrm{MeV}\right)$, and fast $(>0.183 \mathrm{MeV})$ energy region percent contribution to the total damage. 
The approximate energy limits of damaging neutrons can be inferred from the contributions of the groups to the total property change.

The total fluences in Table 11.2 were used to plot the abscissas of the respective data points appearing for these spectra in Figure 11.4. (A similar procedure was used for the other GMWC data points.) It was found that the previously derived damage function was applicable to the GMWC data. From Figure 11.2 the "measured" total fluences to cause a $200^{\circ} \mathrm{F}$ $\triangle \mathrm{TT}$ in $\mathrm{A} 302-\mathrm{B}$ steel for al1 three GMWC spectra were found and plotted versus total fluence values determined by the damagefunction-calculated process shown in Table 11.2. The measured and damage-function-calculated total fluences are compared in Figure 11.4. Perfect correlation is achieved when all points fall on the solid line; that is, using the damage function to calculate total fluences that agree exactly with measured fluences for any reactor environment. The ratios of measured to calculated fluences (Figure 11.4) have a $15.2 \%$ standard deviation about a line representing perfect correlation. The GMWC data points (spectrums 39, 40, and 41) compare favorably with this deviation. This indicates that the damage function, considering the limitations previously indicated, is applicable to the GMWC spectra shapes.

Conclusions

This study has demonstrated the applicability of groupaveraged values of a previously derived damage function to the neutron embrittlement and related total fluence for three different neutron spectra. The three CMWC spectra used to test the damage function were within the extremes of ratios of thermal to fast $(>0.5 \mathrm{MeV})$ neutrons used for the function development but are, nevertheless, significant because they cover the most reasonable range of neutrons in many test and power reactors. The good agreement between damage-function-calculated 


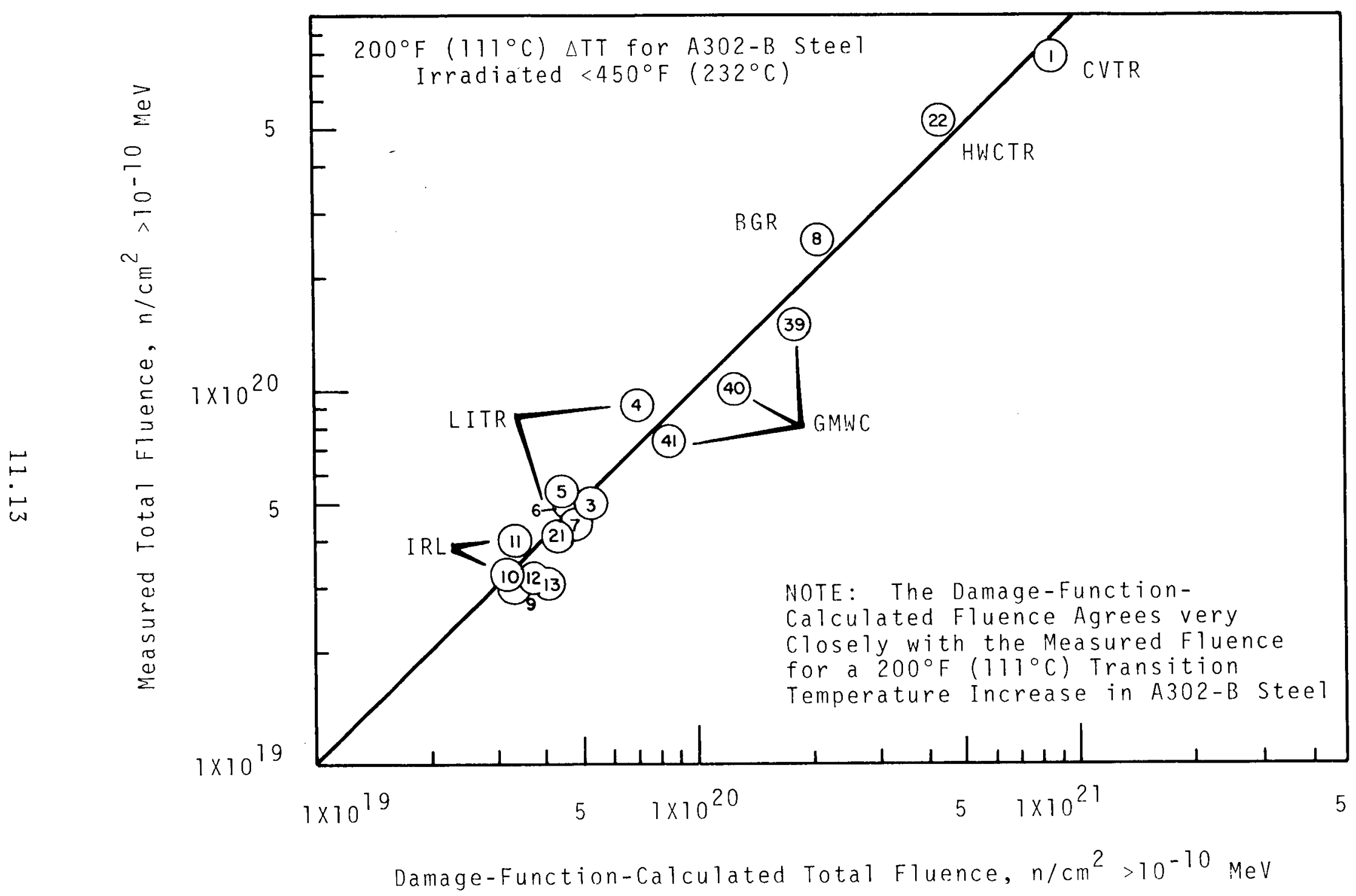

FIGURE 11.4. Verification of the G(E) Damage Function by the Graphite Moderated, Water Cooled Reactor (GMWC) Irradiation Data 
fluences and the measured fluences from the new experimental data has helped to establish the damage function technique as being valid for its intended purpose.

A final conclusion of this study is that detailed and accurate neutron dosimetry measurements are necessary for good correlations of irradiation effects data for diverse reactor environments. Good detail in spectral calculations and foil measurements is required for both low and high energy neutrons. COMPUTER SIMULATION OF RADIATION DAMAGE - D. G. DOran

Recent empirical studies at Battelle-Northwest of the neutron energy dependence of radiation damage in some ferritic steels suggest that thermal neutrons are contributing more than expected to the damage state. The particular effect studied was the increase of the ductile-brittle transition temperature.

The most likely mechanisms by which thermal neutrons can affect mechanical properties are impurity effects caused by transmutations, and displaced atoms caused by recoils from $(n, r)$ reactions. The latter, being of low energy, are generally discounted relative to the displacements produced by scattering of faster neutrons.

By means of computer simulation, a study is being made of the production of low-energy displacement spikes and their annealing characteristics. The average $(n, \gamma)$ recoil energy in iron is about $400 \mathrm{eV}$, although the spectrum of recoils extends to $1000 \mathrm{eV}$.

The $0^{\circ} \mathrm{K}$ configurations for nine isolated $400 \mathrm{eV}$ spikes have been produced with the CASCADE code. Two irradiation temperatures are presently being simulated with the ANNEAL code. As in previously reported $(2,11)$ computer experiments with more energetic spikes, the low-temperature case involves only interstitial migration, whereas the high-temperature case includes vacancy migration as well as an expanded recombination space for interstitial-vacancy pairs. 
The CASCADE runs produced an average of 4.5 displacements per spike, corresponding to an effective Kinchin and Pease displacement energy of $44 \mathrm{eV}$, in agreement with Beeler's results (13) for higher energies. No interstitial clusters were produced, but vacancy clusters averaged one per spike including 4 divacancies, 3 trivacancies, and 2 tetravacancies.

A low-temperature anneal has been performed for 100 time steps (an average of 10 jumps per single interstitial). The average number of displacements per spike has decreased to 2.4 , the total vacancy cluster population has been reduced to 2 divacancies and 2 trivacancies, and 1 di-interstitial and 1 triinterstitial have formed. The annealing simulation will be continued.

The elevated temperature simulation was also begun with 100 interstitial time steps, the vacancy motion to follow. However, the increased recombination space has already reduced the average displacements per spike to 1.2 , and the only clusters among the 9 spikes are 2 divacancies. Clearly, further annealing of the individual spikes will not result in formation of clusters.

COMPUTER SIMULATION OF IRRADIATION DISPLACEMENT CASCADE FORMATION - G. E. RUSScher

A third generation cascade-type computer code is being programmed. SLIDES (Strained Lattice Irradiation Damage Experiment Simulation) is a program designed to simulate, by computer experiment, the generation of irradiation damage in an imperfect or strained fcc lattice structure. It is being designed to study basic physical problems in an environment that more nearly simulates austenitic stainless steel in a fast-reactor irradiation.

Two main objectives for the development of this program are the capabilities of calculating damage generation for: 
(1) the highest energy neutrons of a fast irradiation spectrum and their primary knock-on atoms (PKA) and (2) high irradiation flux and fluences of greater importance to structural materials problems. About half of the PKAs produced in a fast reactor irradiation are above $20 \mathrm{keV}$, hence they contribute an important part to the generation of irradiation damage. However, the existing CASCADE program is limited to computations for PKA energies only up to $20 \mathrm{keV}$. At very high irradiation fluences and fluxes, the generation of irradiation damage is influenced by neighboring lattice displacements, the interaction between these displacements and impurity inclusions, displacement loops, and other extended defect clusters. Thus, the simulated generation of displacements in a previously irradiation-damaged lattice structure is important to a study of a high fluence fast reactor environment.

The SLIDES program incorporates several computational advances. The following three are perhaps the most important:

- Binary atomic collisions are calculated in a chronological sequence.

- Refined interatomic potentials are used to compute atomic interactions.

- Energy lost to electron excitation in inelastic atomic collisions is accounted for.

During the formation of a lattice displacement cascade, different branches of the cascade interfere with one another. This effect on the damaged lattice structure illustrates the importance of the chronological sequence to the formation of a displacement cascade. Interatomic potentials are also important to damage calculations for they determine: (1) the energy necessary to create a displacement, (2) separation distances between a pair of stable defects, and (3) the energy transferred during close interactions where atoms cannot be represented by 
hard spheres. These physical considerations are being incorporated by adding interatomic potentials developed by R. A. Johnson and O. B. Firsov to the screened coulomb and Born-Mayer interatomic potentials presently used by CASCADE. Another consideration important to all displacement cascades is the incidence of close atomic interactions resulting in energy lost due to electron shell overlap. This electronic energy loss can influence both the number and distribution of displacements, and hence the damage state produced. These refinements in the computational basis of SLIDES will make the high energy lattice damage calculations more applicable to the simulation of irradiation of fast reactor materials.

Some of the specific goals of this computer program development are:

- Calculate the displacement cascades resulting from PKAs with energy up to $700 \mathrm{keV}$.

- Simulate the lattice displacement damage of austenitic stainless steel for an irradiation fluence of $10^{23} \mathrm{n} / \mathrm{cm}^{2}$.

- Allow lattice defects to recombine on the basis of annealing statistics for the irradiation temperature.

- Reduce computations time by an order of magnitude below that presently required.

The preliminary design of the SLIDES program is complete. It has also been portrayed as a computer flow chart, and is now being programmed.

COMPUTER EXPERIMENTAL STUDY ON CARBON INCLUSIONS IN GRAIN BOUNDARIES IN FCC GAMMA - IRON - R. E. Dahl, Jr., J. R. Beeler, Jr., and R. D. Bourquin

Small concentrations of interstitial impurity atoms markedly affect the physical and mechanical properties of polycrystalline metal specimens. The mechanisms for these effects are difficult to determine since the macroscopic behavior is 
caused by atomic-scale interactions. Computer experimentation is we11-suited to this study since many parameters can be easily varied to achieve a thorough analysis not possible in a $1 \mathrm{ab}-$ oratory and the scale is at or beyond the limit of experimental observation: The results are credible if there is agreement between computer experiment results and measurements for quantities such as grain-boundary energies, vacancy migration and formation energies, and elastic constants.

The computer code GRAINS used in this study uses the pseudo-dynamic method of experimentation. (14) Atoms are moved to their equilibrium positions according to classical equations of motion. (15) The experiments in this study were conducted in a computational ce11 containing a $6^{\circ}$ tilt boundary. Carbon atoms were inserted into the misfit region of this boundary and the ensuing structural and energy changes observed. Interaction between carbon and iron atoms were calculated by the potential function developed by Johnson. (16) Carbon interactions were computed with a Born-Mayer repulsive potential which went to zero with zero slope at the carbon-carbon distance given by slater. (17)

Structural changes caused by inserting a single carbon atom into the misfit region of a $6^{\circ}$ tilt grain boundary can be seen by comparing Figures 11.5 and 11.6. These figures which are direct computer output, illustrate the structure before and after the addition of a carbon atom. The symbols in these figures denote the position and type of atoms in the computational cell. The exact location of atoms is at the end of the fiducial marks which extend into the figures. Hexagons denote movable host (i.e., iron) atoms; squares denote the immovable host atoms which comprise the cell boundary; and triangles denote carbon atoms.

The plane which is observed in the figures is a (100) plane for fcc $\gamma$-iron. The lattice constant $3.646 \mathrm{~A}$ is the 
BNWL - 1144

THIS PLOT IS OF AN FCC LATTICE VIEWED IN THE (100) PLANE GRAIN BOUNDARY AT $X=11$. IS FOR A ROTATION OF 6.00 DEGREES

THIS PLANE IS: $Z=4$

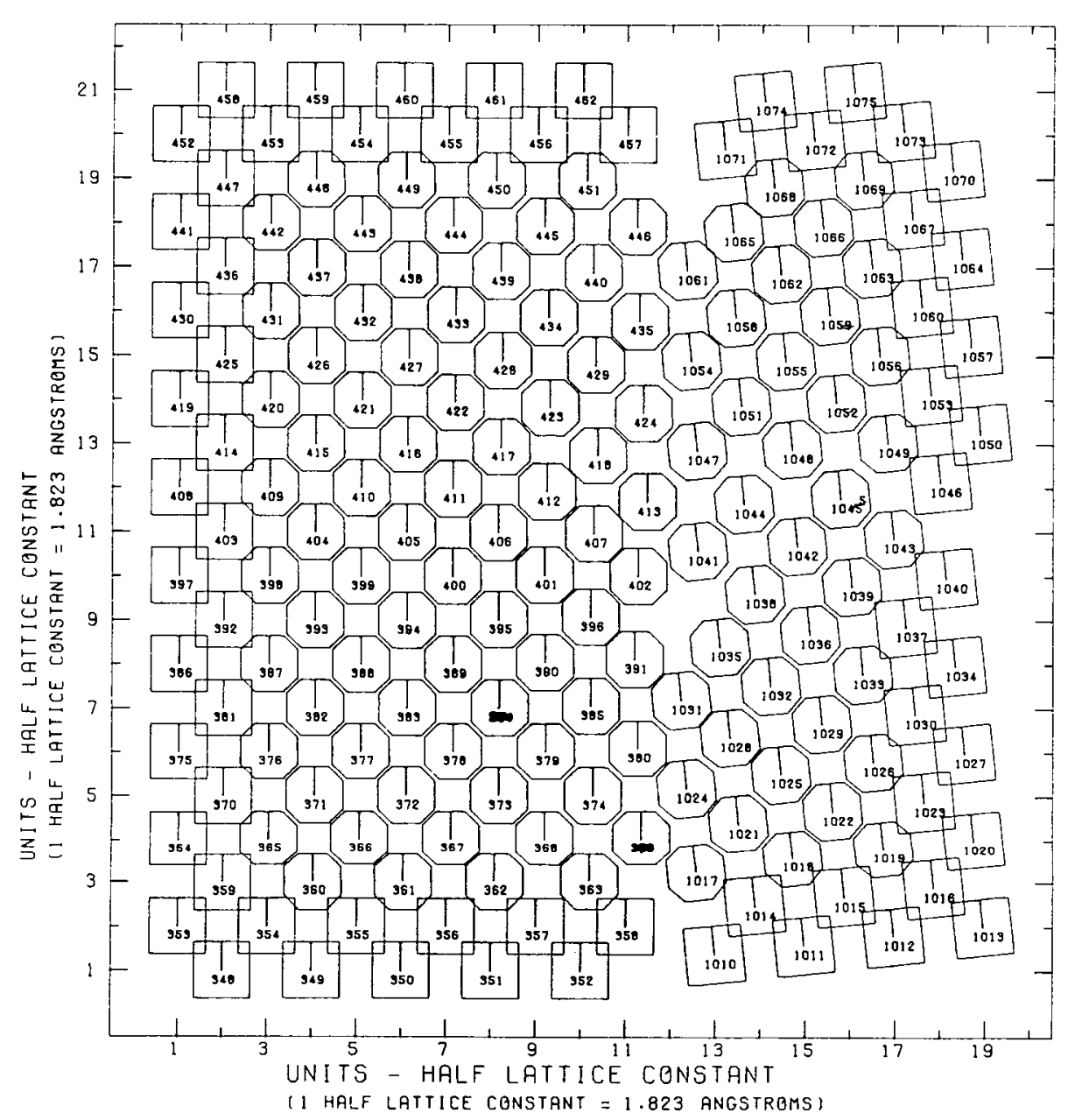

Neg PNL0692780-1

FIGURE 11.5. $\quad 6^{\circ}$ Boundary Before Carbon Atom Added (Plane z = 4) 


\section{BNWL - 1144}

THIS PLOT IS OF AN FCC LATTICE VIEWEO IN THE (IOO) PLANE GRAIN BOUNORRY AT $X=11$. IS FOR A ROTATION OF 6.00 DEGREES THERE ARE 1 INTERSTITIALS IN THIS LATTICE

THIS PLANE IS: $Z=4$

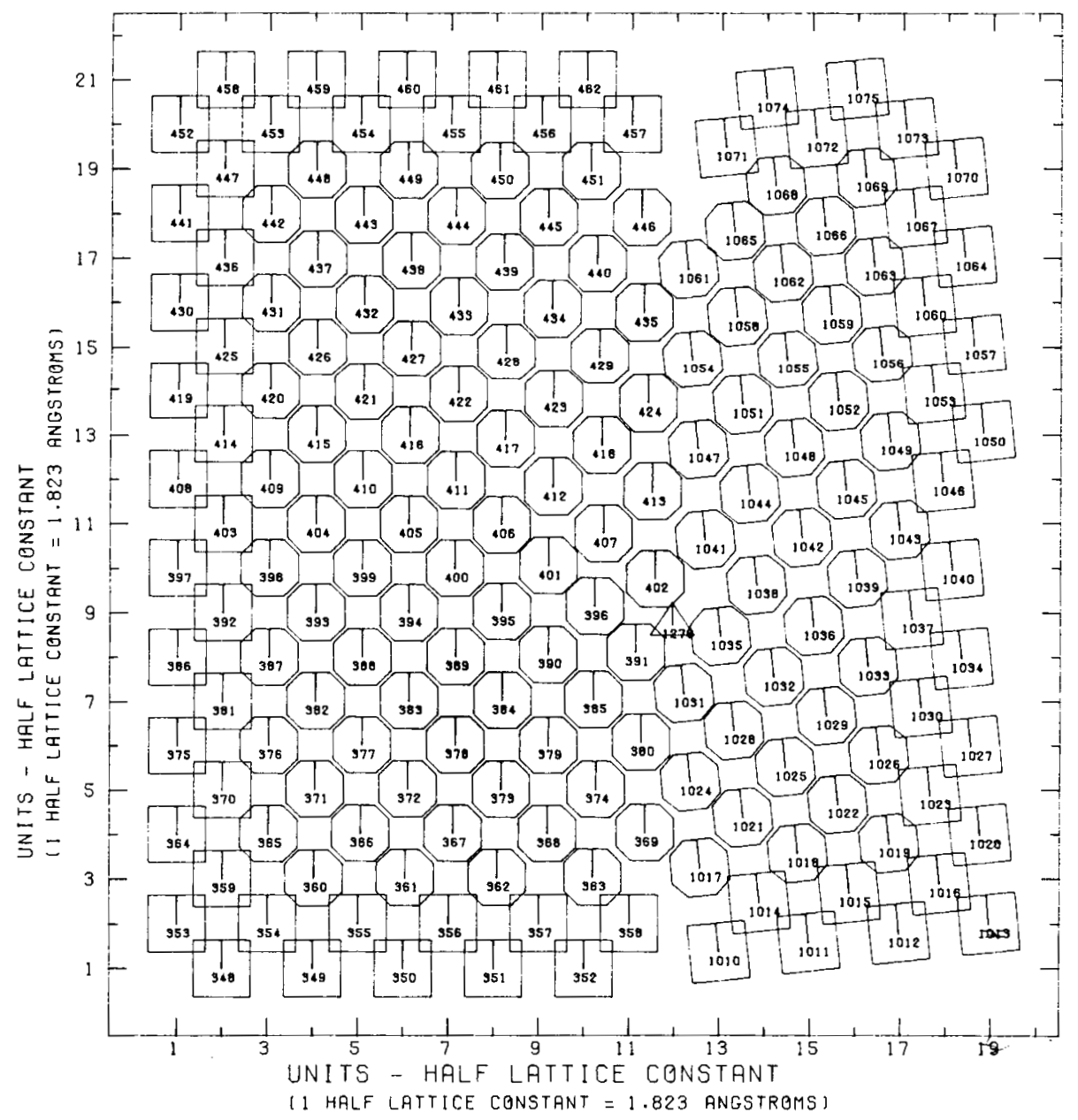

Neg PNL0692780-2

FIGURE 11.6. $6^{\circ}$ Boundary with Carbon Atom Added to Misfit Region (Plane $z=4$ ) 
observed value at $910^{\circ} \mathrm{C}$, which is the $\alpha$ to $\gamma$ transition temperature. The grain boundary lies in the (010) plane and is simulated to extend infinitely in the $\langle 100\rangle$ and $\langle 001\rangle$ directions through periodic boundaries constructed on the (100) surfaces of the computational cell. Seven (100) plane "layers" comprised the cell used to study point defects, so that the resulting strain fields could be accommodated within the cell and the boundaries would not affect the results.

The effect of the presence of an impurity atom is striking. The hole or misfit in the boundary (see Figure 11.6) is essentially healed because of the bonding of the carbon atom with the neighboring iron atoms. The introduction of the carbon lowered the energy of the computational cell appreciably, thus causing a more ordered structure.

Several more carbon atoms were introduced into the grain boundary to determine how many could be accommodated. Five atoms were finally introduced into the boundary in a region which was symmetric about the center plane of the cell, and extended one interplanar distance in each direction $<100\rangle$. The energy changes accompanying these additions are seen in Figure 11.7. Note the large reduction in energy (healing) which accompanied insertion of the first carbon atom. The energy changes accompanying subsequent carbon additions were less, but still appreciable. Relaxation occurred each time, indicating that a sizable carbon inclusion can easily be accommodated in the grain boundary and that this is a favored position. The misfit regions apparently then can have an atmosphere analogous to the dislocation atmosphere postulated by Cottrell. 


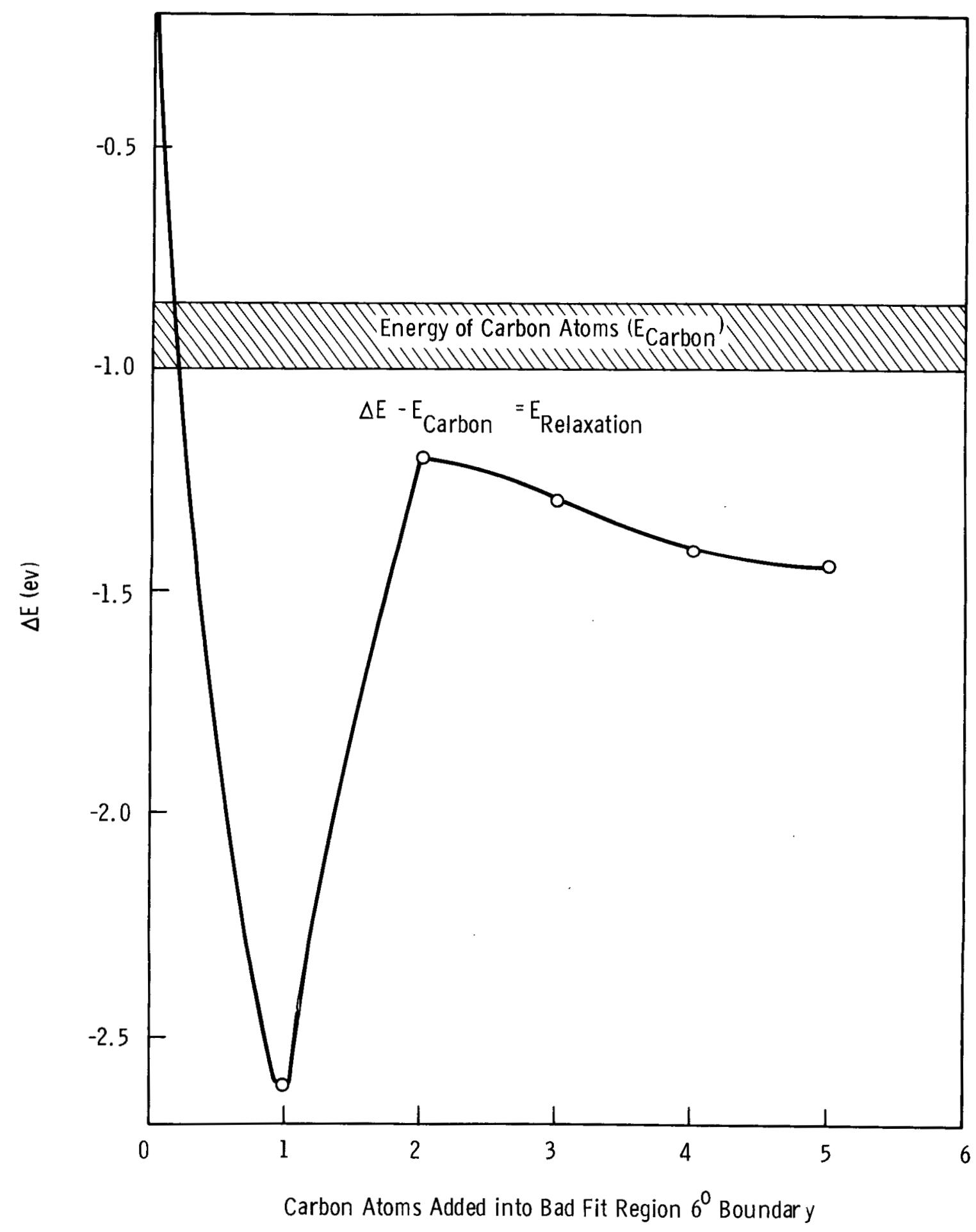

Neg PNL0692780-3

FIGURE 11.7. Energy Changes Resulting from Addition of Carbon Atoms into $6^{\circ}$ Tilt Boundary 
BNWL - 1144

\section{$\underline{\text { REFERENCES }}$}

1. W. N. MCEZroy et al. Unpublished Data. Battelze-Northwest, Richland, Washington, Apriz 25, 1969. (Preliminary Results: EBR-2 Dosimetry Test)

2. A. L. Bement, G. J. Dau, E. A. Evans, and R. E. Nightingale. Quarterly Progress Report, January, February, March, 1969, Reactor Fuels and Materials Development Programs for Fuels and Materials Branch of USAEC Division of Reactor Development and Technology, BNWL-1058. Battelie-Northwest, Richiand, Washington, May 1969.

3. A. L. Bement, G. J. Dau, E. A. Evans, and R. E. Nightingale. Quarterly Progress Report, October, November, December, 1968, Reactor Fuels and Materials Development Programs for Fuels and Materials Branch of USAEC Division of Reactor Development and Technology, BNWL-971. Battelie-Northwest, Richland, Washington, February 1969.

4. W. N. MeEZroy, C. Z. Serpan, Jr., and R. E. DahI, Jr. Damage Functions and Data Correlation. Presented at the ANS 15 th Annual Meeting, Seattie, Washington, June 1969.

5. C. Z. Serpan, Jr. and W. N. MeEZroy. Damage-Function Analysis of Neutron-Energy and Spectrum Effects Upon the Radiation Embrittiement of Steels. Presented at the Symposium on Radiation Damage in Reactor Materials, IAEA, Vienna, Austria, June 1969.

6. A. D. Rossin. "Comparison of Neutron Embrittzement of Steel in Different Reactor Spectra," Nucl. Structural Eng., vol. 1, no. 1, p. 76. 1965.

7. R. E. Dahl, Jr. and H. H. Yoshikawa. "Neutron Exposure Correlation for Radiation-Damage Studies," Nuel. Sci. Eng.: vol. 21, p. 312. 1965.

8. D. R. Harries, P. J. Barton, and S. B. Wright. "Effects of Neutron Spectrum and Dose Rate on Radiation Hardening and Embrittrement in Steels," Am. Soc. Testing Mater., spec. Tech. Publ., vol. 341, p. 276.1963.

9. K. Shure. Radiation Damage Exposure and Embrittzement of Reactor Pressure Vessels, WAPD-TM-471. Bettis Atomic Power Laboratory, Pittsburgh, Pennsylvania, November 1964.

10. A. D. Rossin. Reporting Neutron Exposure for Radiation Damage. Presented at Cairo Solid State Conference, Cairo, Egypt. September 1966. 
11. W. F. Sheely. "Correzation of Radiation Damage to Steez with Neutron Spectrum," Nucl. Sci. Eng., vol. 29, p. 165. 1967.

12. W. N. MCEZroy et al. A Computer-Automated Iterative Method for Neutron Flux Spectra Determination by Foi Activation, AFWL-TR-67-41, Vol. I, II, III, and IV. Air Force Weapons Laboratory, Albuquerque, New Mexico. september 1967.

13. J.R. Beeler, Jr. "Displacement spikes in Cubic Metals. I. a-Iron, Copper, and Tungsten," Phys. Rev., vol. 150, p. 470.1966 .

14. J. R. Beeler, Jr. "The Techniques of High-Speed Computer Experiments," Physics of Many-Particle Systems, edited by E. Merron. Gordon and Breach Science Publishers Inc., New York, 1966. pp. 1-118.

15. J. B. Gibson et al. "Dynamies of Radiation Damage," Phys. Rev., vol. 120, no. 4, p. 1229. 1960.

16. R. A. Johnson. "Cazcuzation of the Energy and Migration Characteristics of Carbon in Martensite," Acta Met.", vol. 13, p. 1259. 1965.

17. J. C. Slater. "Atomic Radii in Crystals," J. Chem. Phys., vol. 41, no. 10, p. 3199. November 1964.

18. A. H. Cottrezl. Dislocations and Plastic Flow in Crystals, oxford University Press, New York. 1963. 


\section{IRRADIATION DAMAGE TO REACTOR METALS}

L. D. Blackburn

REACTOR METALS RESEARCH

Irradiation Facilities Operation - A. L. Ward

The purpose of this phase of the program is to provide for the timely accomplishment of irradiation, testing, and subsequent processing of the data obtained from a variety of reactor structural materials. Irradiations will be performed in aqueous, gaseous, and molten metal environments. Elevated temperature irradiations and tests will be emphasized. Special testing techniques, applicable to either irradiated or unirradiated specimens, will be developed.

Facilities Operation

The experiments discharged from the various Engineering Test Reactor (ETR) core positions for Cycle 100 are given in Table 12.1, along with the estimated neutron fluxes and fluences.

The operating history of the ETR and the G-7 hot water loop for Cycles 99 and 100 is given in Table 12.2. The history for the out-of-reactor $100 \mathrm{p}$ is given in Table 12.3 .

The ATR is expected to become available for irradiation experiments in September 1969. ETR G-7 water loop use is expected to be discontinued in favor of the ATR facility at that time. Test Core I was completed on June 6, 1969, and Cores II and III are scheduled for June 15 and July 6, 1969, respectively. 
TABLE 12.1. Summary of Experiments Discharged at the Conclusion of ETR Cycle 100

\begin{tabular}{lcccc}
$\begin{array}{l}\text { Experiment } \\
\text { Designation }\end{array}$ & $\begin{array}{c}\text { No. of } \\
\text { Specimens }\end{array}$ & $\begin{array}{c}\text { Type of } \\
\text { Specimens }\end{array}$ & $\begin{array}{c}\text { Estimated } \\
\text { Flux } / \mathrm{cm}^{2} / \mathrm{sec}^{(a)}\end{array}$ & $\begin{array}{c}\text { Estimated } \\
\text { F1uence } \\
\mathrm{n} / \mathrm{cm} 2(\mathrm{a})\end{array}$ \\
\cline { 2 - 2 } & 36 & Zralloys & $5.5 \times 10^{13}$ & $3.1 \times 10^{20}$ \\
GEH-20-332 & 36 & Mixed SS & $1.04 \times 10^{14}$ & $\sim 9 \times 10^{20}$ \\
GEH-20-331 & 36 & Mixed SS & $1.05 \times 10^{14}$ & $\sim 9 \times 10^{20}$ \\
GEH-20-299 & 18 & Zr-2 & $1.06 \times 10^{14}$ & $\sim 9 \times 10^{20}$ \\
GEH-20-293 & 36 & Zr-2 & $1.0 \times 10^{14}$ & $\sim 1.7 \times 10^{22}$
\end{tabular}

(a) Neutrons with energies greater than 1 MeV.

NOTE: Total specimens discharged, ETR G-? LOOp Cyole $100=162$. Total specimens discharged, ETR G-7. Loop to date $=3962$.

TABLE 12.2. Summary of operating History for ETR and G-7 Hot Water Loop - ETR Cycles 99 and 100

Operating History

1. Reactor History

Start up (a)

End of Cycle

Megawatt Days

Effective Days at $175 \mathrm{MW}$

Number of Scrams (b)

Number of Shutdowns

2. G-7 Hot Water Loop History

Maximum Temperature

Effective Days Above $200^{\circ} \mathrm{F}$

Effective Days at

Operating Temperature

Operating Efficiency, $\frac{\circ}{0}$ (c)

Temperature Efficiency, $\%$ (d)

ETR Cycle Number

\begin{tabular}{|c|c|}
\hline Cycle 99 & Cycle 100 \\
\hline $11-15-68$ & $1-15-69$ \\
\hline $1-5-69$ & $2-22-69$ \\
\hline 5690 & 5781 \\
\hline 32.51 & 33.08 \\
\hline 5 & 10 \\
\hline 8 & 3 \\
\hline
\end{tabular}

$\begin{array}{ll}508^{\circ} \mathrm{C} & 529{ }^{\circ} \mathrm{F} \\ 33.9 & 33.85 \\ 29.05 & 31.60 \\ 95.8 & 100 \\ 85.7 & 93.3\end{array}$

(a) Includes flux runs at low power.

(b) Power arops below half of full power $(175 \mathrm{MW})$ with immediate recovery.

(c) Effective days of Zoop operation above $200{ }^{\circ} \mathrm{F}\left(95^{\circ} \mathrm{C}\right.$ ) with respect to effective days of reactor operation at $175 \mathrm{MW}$.

(d) Effective days of Zoop operation between 500 and $550{ }^{\circ} \mathrm{F}$ $\left(260\right.$ and $\left.290^{\circ} \mathrm{C}\right)$ with respect to days of operation above $200{ }^{\circ} \mathrm{F}\left(95{ }^{\circ} \mathrm{C}\right)$ 


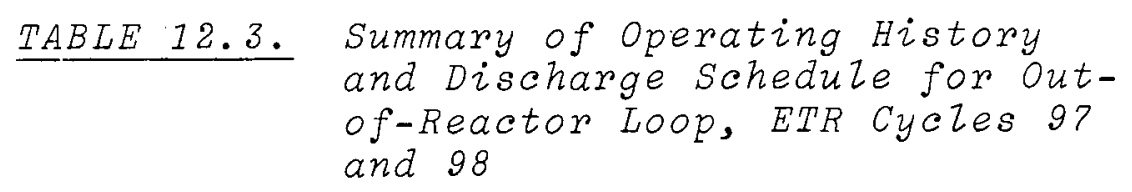

1. TIME-TEMPERATURE SUMMARY

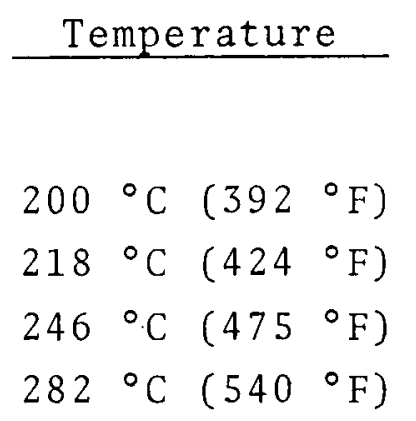

\begin{tabular}{|c|c|}
\hline \multicolumn{2}{|c|}{ Time, $\mathrm{hr}$} \\
\hline Cycle 97 & Cycle 98 \\
\hline 21.70 & 34.6 \\
\hline 9.35 & 11.0 \\
\hline 28.45 & 85.8 \\
\hline 695.0 & 623.6 \\
\hline
\end{tabular}

2. SPECIMEN DISCHARGES

$\begin{array}{llr}\text { Material } & \frac{\text { Specimen }}{\text { Type }} & \text { Number } \\ \text { Zry-2 } & \text { Tensile } & \\ \text { PDRL-120 } & \text { Tensile } & \frac{6}{34}\end{array}$

Total specimens discharged to date $=1595$

Microstructura1 Modifications to Stainless Steels and Nicke1-Base Alloys - I. S. Levy

The purpose of this program is to optimize the stability of austenitic stainless steels and nickel-base alloys to fast reactor environments through microstructural modifications. These modifications are produced by selected variations in chemical composition and/or by use of thermomechanical treatments.

Last quarter, (1) it was noted that the rate of quench from solution temperature could affect the rapidity of stacking fault hardening at $700{ }^{\circ} \mathrm{C}$ in 348 stainless steel; the faster the quench-rate, the sooner hardening occurred. This is presumably due to an increase in the number of potential stacking fault nucleating sites, i.e. dislocations. 
This past quarter, an examination was made of another potential technique from increasing the rate of stacking fault formation--tensile straining. The straining treatments involved either strain at room temperature, strain at $700^{\circ} \mathrm{C}$, or strain at $700{ }^{\circ} \mathrm{C}$ followed by a half-hour hold at load. After treatment, the specimens were aged at $700{ }^{\circ} \mathrm{C}$, and their rates of increase in strength were monitored by tensile tests. The relative effects on the rate of strength increase between quenching and the various straining treatments can be indicated by the time required at $700^{\circ} \mathrm{C}$ to achieve a significant strength increase. Because simple aging will produce a peak increase of approximately $15,000 \mathrm{psi}$, an increase of $3,000 \mathrm{psi}$ ( $20 \%$ of peak) was considered sufficiently significant and is used as the basis, in Table 12.4 for comparison of these treatments.

\section{TABLE 12.4. Aging Time at $700{ }^{\circ} \mathrm{C}$ to Achieve a 3000-psi Increase in $0.2 \%$ Yield Strength for Various As-Treated Conditions}

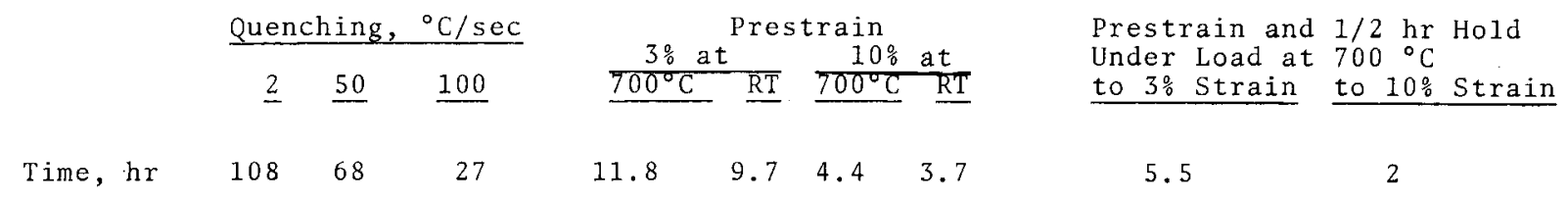

The data show that dislocation generation does increase stacking fault hardening (compare different quench-rates or strain levels). However, this is not the complete story as indicated by the difference between the results of the prestraining and prestraining plus hold treatments. These latter data indicate that while straining at $700{ }^{\circ} \mathrm{C}$ decreases the hardening rate (due to concurrent annealing out of some of the strain-induced dislocations ${ }^{(2)}$ ), straining at $700^{\circ} \mathrm{C}$ followed by a half-hour hold under load at $700{ }^{\circ} \mathrm{C}$ significantly increases the hardening rate. The recovery effect should presumably still be occurring during the half-hour hold at $700{ }^{\circ} \mathrm{C}$. This should take place because the amount of creep deformation is less than $10 \%$ of the total strain produced by the treatment, and recovery 
has also been noted during low-strain rate deformation studies at $650^{\circ} \mathrm{C}$. (2) Therefore, an additional factor must be playing an important part in this treatment (and, perhaps, as significant but less discernible part in the other strain treatments). Presumably, this factor is a strain-produced increase in vacancy concentration. This would lead to enhanced diffusion of $\mathrm{Nb}$ and would account for the more rapid growth of $\mathrm{NbC}$ to the critical size required for the nucleation of the stacking faults that have also been observed to a result of prestrain.

In-Reactor Measurements of Mechanical Properties E. R. Gilbert, N. E. Harding

The in-reactor measurements program is intended to determine the effects of irradiation on the mechanical properties of reactor structural materials, to establish property data suitable for design purposes, and to consider mechanisms through irradiation effects on macroscopic deformation. The program currently involves conducting in-reactor creep measurements on annealed $304 \mathrm{SS}$, heat-treated $\mathrm{Zr}-2.5 \mathrm{Nb}$, and Zircaloy-2. Capsule development is being pursued in order that program capabilities may be extended.

\section{Stainless Steel}

Slow, steady, in-reactor creep has been measured in annealed $304 \mathrm{SS}$ at 175 and $300^{\circ} \mathrm{C}$. The rate at 35,000 psi stress is rather insensitive to temperature with an average value of $3 \times 10^{-7} \pm 1 \times 10^{-7} \mathrm{~h}^{-1}$ at both 175 and $300^{\circ} \mathrm{C}$. Upon increasing the temperature to $370{ }^{\circ} \mathrm{C}$, discontinuous yielding was observed, as shown in Figure 12-1. The amplitude of the strain steps is 0.2 to $0.5 \%$ strain and occurs at a periodicity of 50 to $100 \mathrm{hr}$. The initial strain step occurred after a $500 \mathrm{hr}$ incubation period. If a line is drawn through the strain steps, an effective creep rate of $6 \times 10^{-5} \mathrm{~h}^{-1}$ is measured. 


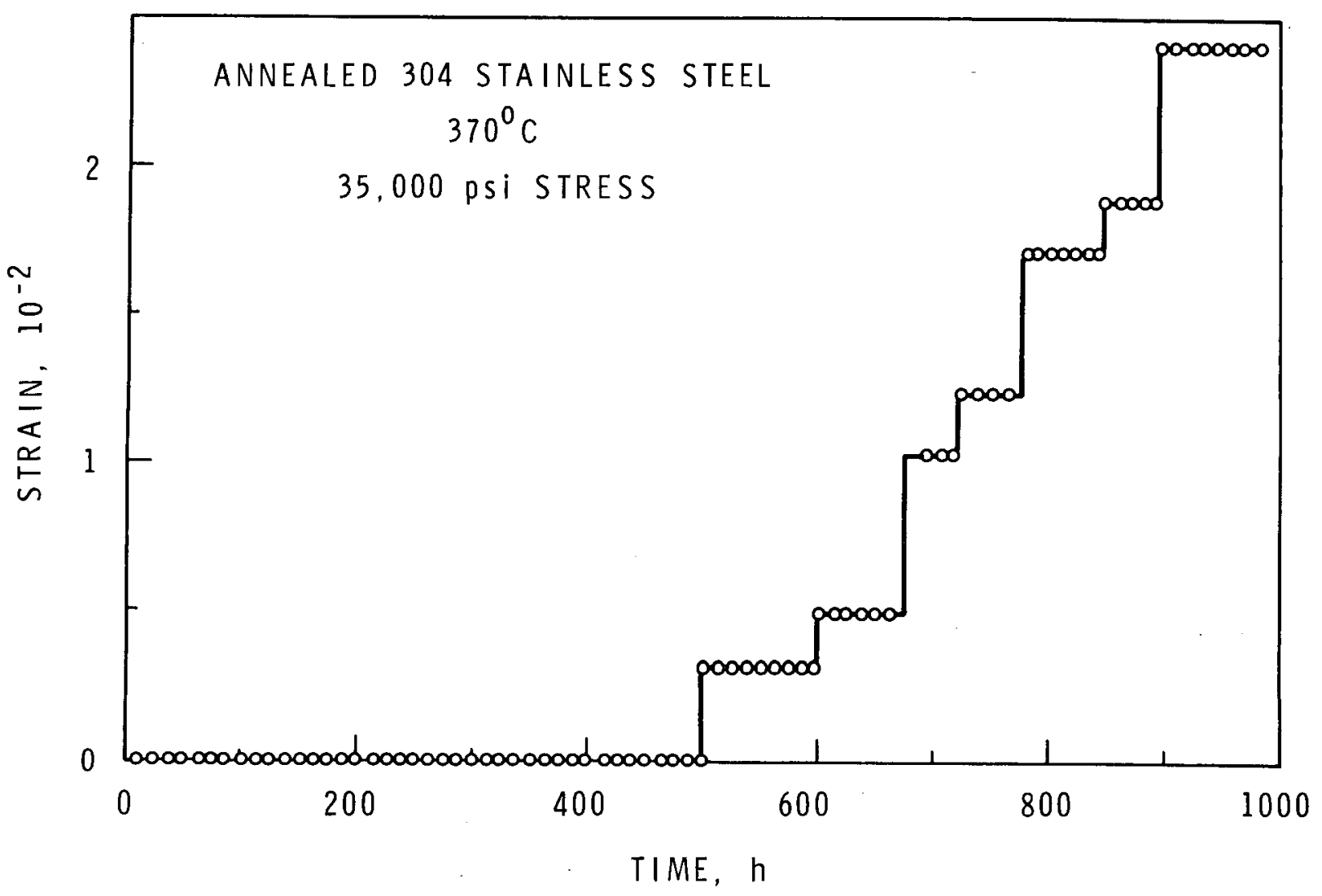

Neg $0692498-2$

FIGURE 12.1. In-Reactor Discontinuous yielding in 304 SS

The Portevin-LeChatelier effect (serrated stress-strain curve) is observed in 304 stainless steel at temperatures around 400 and $500^{\circ} \mathrm{C}$. In the pneumatically-loaded creep capsule, strain steps are observed instead of the load relaxations that are observed in a screw-driven tensile machine. The discontinuous yielding observed during neutron irradiation in the constant-load creep test may be related to the portevin-Lechatelier effect. The discontinuous yielding is not observed without the presence of irradiation. The first strain step is fairly easy to rationalize in terms of neutrons displacing solutes from their pinning points along dislocations until the dislocations are free to move. However, successive strain steps require a dislocation nucleation process at constant applied stress with 
very little straining. A potential source may be the nucleation of Frank partial dislocations due to the collapse of irradiation-produced point defects in the field of the applied stress. When the Frank partials grow to a critical radius, they can react with Shockley partials to form glide dislocations that are then released to generate a strain step. Thus, it is difficult to account for the succeeding strain steps with the solute pinning interpretation of the Portevin-LeChatelier effect. It is also difficult to visualize the cooperation of about $10^{8}$ dislocations $/ \mathrm{cm}^{2}$ in simultaneous glide.

\section{Zirconium Alloys}

The values of the activation parameters and the stressdependence of the creep-rate in $\mathrm{Zr}-2.5 \mathrm{Nb}$ are consistent with the "dislocation climb" model for creep controlled by shortcircuited diffusion. The activation energy for creep is similar to that for diffusion of $95 \mathrm{Zr}$ along dislocations, and the activation area of $3 \mathrm{~b}^{2}$ is in good agreement with that predicted for the dislocation climb model. The strain rate is proportional to the stress to the 4.8 power which is consistent with the climb model for creep.

The effect of neutron irradiation on increasing the creeprate can be considered as an irradiation-induced stress assisting the applied stress. In this case, the stress arises from an osmotic force on climbing dislocations resulting from the supersaturation of point defects created by irradiation. Since irradiation creep rates are observed in annealed 304 stainless steel that are of similar magnitudes to those observed in $\mathrm{Zr}-2.5 \mathrm{Nb}$ at similar stresses and temperatures, the anisotrophy of the $\mathrm{Zr}$ crystal structure is probably not a prerequisite for irradiation creep.

Measurement of a $\mathrm{Zr}-2.5 \mathrm{Nb}$ in-reactor creep specimen prior to and following the in-reactor creep test has indicated that the volume of the specimen was increased by approximately 
1.4 percent. Previously, it had been assumed that the inreactor creep was a constant volume process. Approximately $0.6 \%$ volume decrease was recovered upon annealing at $500{ }^{\circ} \mathrm{C}$ for 4 hours. These results suggest that the resultant jog in the dislocation climb process is the vacancy jog. No cavities were observed in the specimen upon TEM examination.

Formation of Voids in Iron During High-Temperature Neutron Irradiation - G. L. Kulcinski and B. Maste1

It has been recently discovered that high-temperature neutron irradiation of $304 \mathrm{SS}$ and some pure metals results in the formation of voids within the solid. The first voids were reported in $304 \mathrm{SS}$. $(4,5)$ Later, voids were also found in pure metals such as $\mathrm{Ni},(6-8) \mathrm{Cu},(7) \mathrm{Al},(7,9) \mathrm{Mo},(7,10)$ and $\mathrm{V}$. (11) The purpose of this study was to ascertain whether voids can be formed in high purity iron under proper irradiation conditions.

Iron foils of $99.999 \%$ purity (metallic elements only), in the form of disks $11 \mathrm{~mm}$ in diameter and $75 \mu$ thick, were annealed at $800^{\circ} \mathrm{C}$ for $2 \mathrm{hr}$ in a vacuum of $2 \times 10^{-7}$ torr. They were then irradiated in the EBR-II reactor at $450{ }^{\circ} \mathrm{C}$ to a fast neutron fluence of $3 \times 10^{21} \mathrm{n} / \mathrm{cm}^{2}$ ( $\mathrm{E}>0.1 \mathrm{MeV}$ ). After irradiation, the samples were thinned in a solution of 10 parts glacial acetic acid and one part perchloric acid at $>20{ }^{\circ} \mathrm{C}$.

The typical microstructure of the iron after the irradiation is shown in Figure 12.2. The projected shape of the voids is rather non-uniform and the average diameter is $280 \AA$. The smallest voids observed are approximately $100 \AA$ in diameter and the total density of al1 the voids is $1 \times 10^{14} / \mathrm{cm}^{3}$. This latter number was calculated for an assumed average foil thickness of $1000 \AA$. The calculated volume change is approximately $0.12 \%$. 
BNWL- 1144

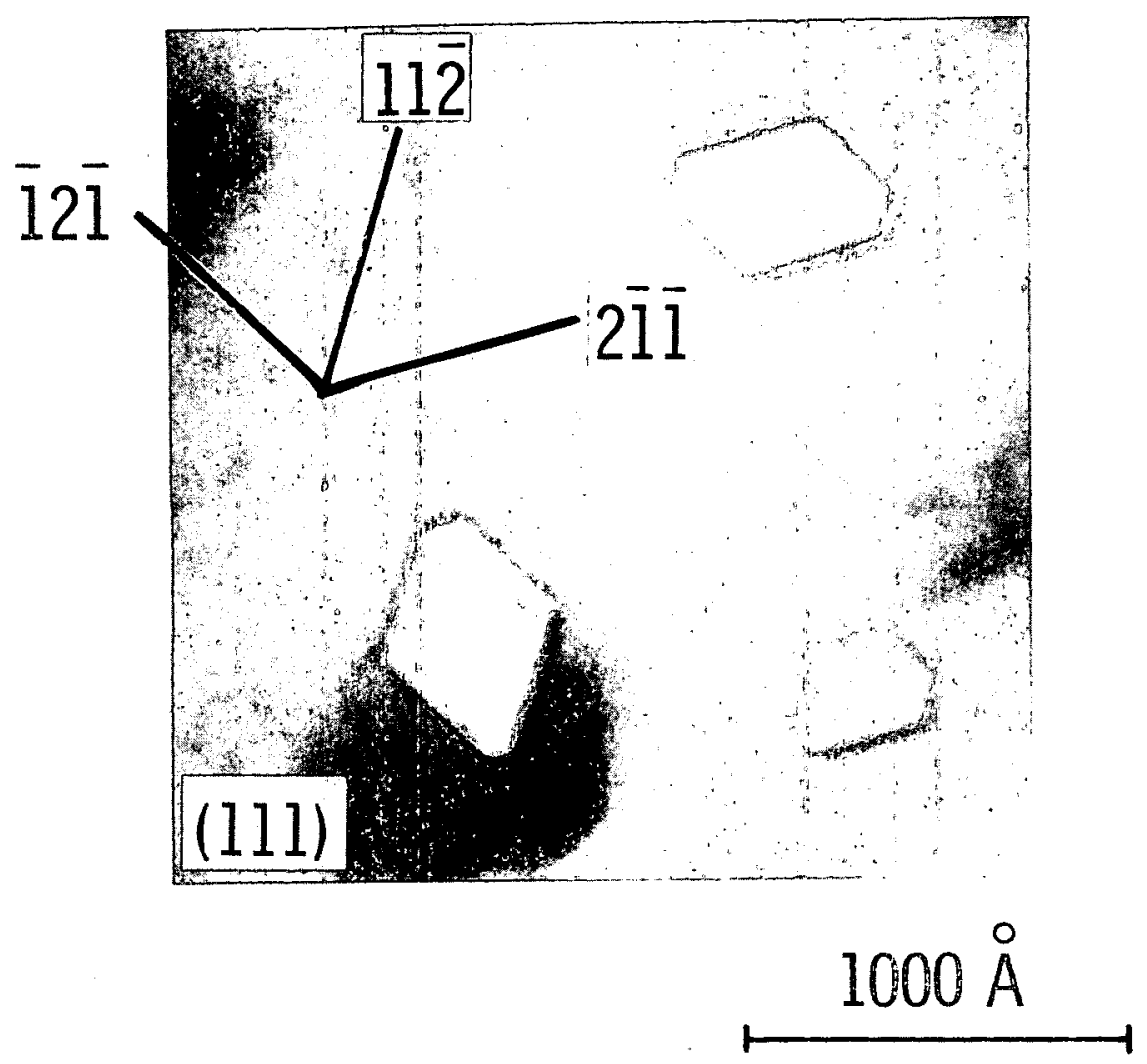

FIGURE 12.2. Voids in Iron that Has Been Irradiated to

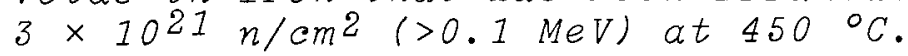

The morphology of the voids is difficult to determine specifically because of the strong (111) texture of the foils and because of the interaction of the Fe foils with the magnetic field of the objective lens. However, it was determined that the edges of the voids are parallel to the $\langle 112\rangle$ direction for a <11l> foil orientation which is consistent with octahedra bounded by $\{110\}$ planes. The irregular shape of the voids can be accounted for by truncations paralle1 to the other $\{110\}$ planes.

Calculations were also made to determine if the voids could be filled with neutronically-generated gases. If the gas atoms are under an equilibrium LaPlace pressure of $2 \gamma / \mathrm{r}$, where $\gamma$ is surface energy and equal to $1720 \mathrm{ergs} / \mathrm{cm}^{2},(12)$ one finds that 
approximately $200 \mathrm{ppm}$ (atomic) of gas is required to account for the observed cavity size and density. De Pino(13) has calculated that less than $1 \mathrm{ppm}$ of neutronic gases would be generated during a fast neutron irradiation to $3 \times 10^{21} \mathrm{n} / \mathrm{cm}^{2}$. Therefore, it seems rather unlikely that the cavities are gasfilled and it is concluded that they may properly be called voids.

Although the distribution of the voids is rather homogenous within the individual grains, a wide (0.8-1.0 micron) region denuded of voids appears at grain boundaries. Such an effect has been discovered before in $\mathrm{Ni}$ and $\mathrm{Cu}^{(7)}$ and has been explained on the basis that the grain boundaries act as sinks for vacancies.

A compilation of the present results and those obtained in other studies is shown in Table 12.5. Iron is the third example of a bcc metal in which voids have been found. The presence of fast neutron-induced voids in both fcc and bcc metals indicates that the phenomenon of void development in metals is quite universal.

An important point to note from Table 12.5 is that in all cases where voids have been discovered, the irradiation temperature has been greater than $0.3 \mathrm{~T}_{\mathrm{m}}$, where $\mathrm{T}_{\mathrm{m}}$ is the melting temperature. The present irradiation of $\mathrm{Fe}$ at $0.4 \mathrm{~T}_{\mathrm{m}}$ is well above this apparent threshold. The physical significance of this threshold is not clear at this time but it is probably connected in some manner with the mobility of vacancies.

Both purity and threshold fluence-level seem to be connected in a rather complex way, as shown by workers at Oak Rige. (9) Voids did not form in low purity (99\%) Al after 3.5 $\times 10^{20} \mathrm{n} / \mathrm{cm}^{2}$ at $50{ }^{\circ} \mathrm{C}$, whereas voids did form in high purity Al (99.9999\%) irradiated under the same conditions. It was found that irradiation exposure to $1.5 \times 10^{22} \mathrm{n} / \mathrm{cm}^{2}$ was required 
TABLE 12.5. Summary of Void Formation Data in Pure Metals

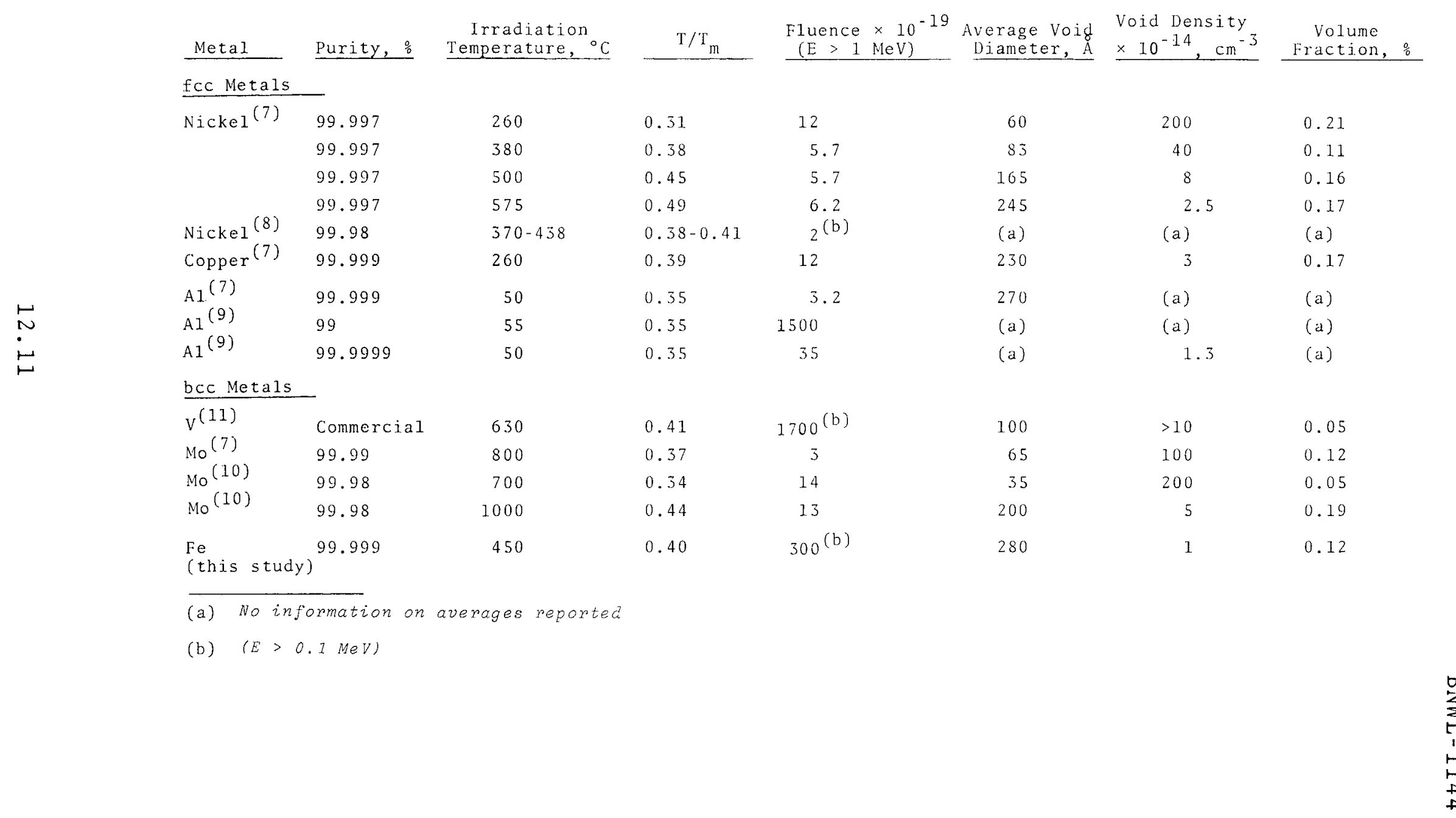


to form voids in the low purity A1. Similarly, voids were formed in commercial purity vanadium after irradiation at $630{ }^{\circ} \mathrm{C}$ to a fluence of $1.7 \times 10^{22} \mathrm{n} / \mathrm{cm}^{2}$ irradiation, whereas none were formed in a V-20\% $\mathrm{Ti}$ alloy irradiated under the same conditions. These observations indicate that the threshold fluence is likely to lower as the purity of the metal is increased and that therefore, voids may form in the present $\mathrm{Fe}$ material at fluences even $<3 \times 10^{21} \mathrm{n} / \mathrm{cm}^{2}$. Future studies on this relationship may yield important information on the mechanism of void formation. Sma11-Angle X-Ray Scattering by Voids in Irradiated Metals H. E. Kissinger

An $\mathrm{X}$-ray beam transmitted through a material containing an inhomogeneous distribution of electron density is subject to diffraction effects which result in part of the beam being scattered through very small angles. The intensity scattered and the angular distribution of the scattering depends upon the number and size of the inhomogeneous regions and the difference between the electron density of the scattering region and the matrix.

Interpretation of the experimentally determined scattering is most readily done by assuming a matrix of constant electron density, $\rho_{0}$, in which scattering centers of electron density $\rho$ are distributed in a nonregular array. Interparticle interference then does not occur, and the scattering is given approximately by Guinier's formula (1)

$$
\operatorname{Ln} I(\varepsilon)=K-\frac{4 \pi^{2} R_{o}^{2}}{3 \lambda^{2}} \varepsilon^{2},
$$

where $I(\varepsilon)=$ the intensity scattered at angle $\varepsilon$, measured in radians,

$$
\begin{aligned}
\lambda & =\text { the } \mathrm{X} \text {-ray wavelength } \\
\mathrm{R}_{0} & =\text { a parameter called the "electronic radius of }
\end{aligned}
$$
gyration."

If the scattering centers are spheres of radius $R$, then $\mathrm{R}_{\mathrm{o}}^{2}=3 / 5 \mathrm{R}^{2}$. 
The voids that result from elevated temperature irradiation of many metals provide scattering centers that should be ideal subjects for small-angle $X$-ray studies. As metals are relatively opaque to $X$-rays, the samples must be in the form of thin foils. The required foils can be prepared by essentially the same techniques used to prepare electron microscopy samples.

To assess the utility and applicability of the small-angle scattering technique to the study of voids, a number of irradiated metals previously examined with the microscope were studied by the $\mathrm{X}$-ray method. The sample types and irradiation conditions are listed in Table 12.6 .

TABLE 12.6. Samples for Smalz-Angle scattering Studies

$\begin{array}{llrl}\text { Metal } & \text { Purity, } & \text { Fluence, }(\mathrm{E}>1 \mathrm{MeV}) \mathrm{n} / \mathrm{cm}^{2} & \begin{array}{c}\text { Irradiation } \\ \text { Temperature, }\end{array} \\ \mathrm{Cu} & 99.999 & 1.2 \times 10^{20} & 260 \\ \mathrm{Ni} & 99.997 & 5.7 \times 10^{19} & 500 \\ \mathrm{Fe} & 99.999 & 2 \times 10^{21} & 450 \\ \mathrm{Zr} & 99.95 & 2 \times 10^{21} & 450\end{array}$

These samples were thinned to about $3 \mu$ by electrochemical polishing and examined in a Rigaku small-angle goniometer. Crystal monochromated copper $\mathrm{K} \alpha$ radiation (1.541 A) was used. Scattered intensity was measured at $1^{\prime}$ intervals from $10^{\prime}$ to 30' from the direct beam, the counting interval being $100 \mathrm{sec}$ at each position. Multiple runs were made in each case to eliminate random errors.

The samples were well annealed prior to irradiation and contained large, well-crystallized grains. A sample position could be found by trial for which no Bragg diffraction occurred. The present results are therefore free of double Bragg scattering which is often troublesome in small-angle scattering experiments. All samples, however, contained radiation damage in the form of loops and clusters so that some sma11 part of the 
observed scattering may arise from this source. Such scattering effects are small, and are believed negligible except for the zirconium scattering to be discussed later.

The irradiated copper was found to scatter very strongly while iron and nickel showed moderate effects. Zirconium showed extremely weak scattering effects and electron microscopy failed to disclose the presence of voids. The weak scattering observed was therefore presumed to arise from irradiation-induced artifacts other than voids or from hydrides which formed on the surfaces. For the other metals, the scattering was analyzed by the Guinier(14) relation and the equivalent spherical diameter of the scattering centers was determined. These results as compared with those determined by electron microscopy are given in Table 12.7 .

TABLE 12.7. Void Diameters Determined by SmaZl-Angle Scattering and Electron Microscopy

\begin{tabular}{|c|c|c|c|}
\hline MetaI & $\mathrm{R}_{0}, \AA$ & SAS Void Diam, $\AA$ & E.M. Void Diam, $\AA$ \\
\hline $\mathrm{Cu}$ & 105 & 270 & 230 \\
\hline $\mathrm{Ni}$ & 60 & 150 & 165 \\
\hline $\mathrm{Fe}$ & 120 & 300 & 280 \\
\hline $\mathrm{Zr} *$ & 120 & $\sim 300$ & Not Detected \\
\hline
\end{tabular}

This work demonstrates that small-angle X-ray scattering methods may be used in studies of void formation and growth in irradiated metals. The apparatus is being augmented by an improved data-collection system, and an extensive program of study on the annealing of voids in metals will be carried out by this method. 


\section{FAST REACTOR SUPPORTING STUDIES}

Damage Analysis - J. L. Straalsund and H. R. Brager

The objectives of this effort are to establish the radiation-induced swelling characteristics of FFTF alloys, relate fast-reactor-induced changes in microstructure to corresponding changes in mechanical properties and to provide a basis for extrapolation and interpolation of data using both microscopic modeling and empirical approaches.

Recent experiments concerning the effects of fast reactor irradiation on stainless steels have demonstrated that a considerable volume change occurs during neutron bombardment. (15) Unlike volume changes in fuel materials, swelling in structural alloys and pure metals is due to the condensation of irradiation-produced excess vacancies in the form of three dimensional cavities. United Kingdom investigators have found as much as $6.8 \%$ volume change in $316 \mathrm{SS}$ irradiated to $7.8 \times 10^{22}$ $\mathrm{n} / \mathrm{cm}^{2}$ total fluence. Volume changes of this magnitude, if not taken into account, are sufficient to cause distortion in reactor components.

Maximum target fluences for FFTF are as high as $10^{24} \mathrm{n} / \mathrm{cm}^{2}$. Since such a high fluence cannot be attained in a reasonable time using currently available reactors, design data for high exposures will be based on extrapolation using physically realistic swelling models. The approach taken in this study is to develop swelling data at fluence levels that can be obtained in reasonable times and to use this data to develop the required swelling models.

An equation describing the effect of fluence and temperature on swelling in solution-treated 304 SS has been refined and the results agreed upon by Westinghouse and PNL. The agreed upon equation has the general form:

$$
\frac{\Delta V}{V}=A(\phi t)^{n}\left[e^{-Q_{1} / R T}-\alpha e^{-Q_{2} / R T}\right]
$$


Specifically, the equation is as follows:

$$
\frac{\Delta V}{V}=5.0 \times 10^{-36}(\phi t)^{1.66}\left[\mathrm{e}^{-6800 / R T}-\left(1.87 \times 10^{4}\right) \mathrm{e}^{-27,000 / R T}\right]
$$

where $\frac{\Delta V}{V}=$ percent volume change

$$
\begin{aligned}
\phi t & =\text { neutron fluence, } \mathrm{E}>0.1 \mathrm{MeV} \\
Q & =\text { activation energy in } \mathrm{cal} / \mathrm{mole}-{ }^{\circ} \mathrm{K}
\end{aligned}
$$

Equation (1) was developed by using regression analysis to fit an equation of the form:

$$
\frac{\Delta V}{V}=A(\phi t)^{n} e^{-Q / R T}
$$

to 37 data points which were selected from available bulk density measurements on 304 SS components and specimens taken from the EBR-II reactor. This data is given in Table 12.8. In the selection of data, only points corresponding to locations within 10 inches of the midplane were used. The analysis resulted in the following equation

$$
\frac{\Delta V}{V}=5.0 \times 10^{-36}(\phi t)^{1.66} \mathrm{e}^{-\frac{6800}{\mathrm{RT}}}
$$

The second temperature-dependent term in Equation (1), ( $\left.\alpha \mathrm{e}^{-\mathrm{Q}_{2} / \mathrm{RT}}\right)$, was empirically fit to force the swelling to peak at $625{ }^{\circ} \mathrm{C}$ and to go to zero at $750{ }^{\circ} \mathrm{C}$.

Figure 12.3 shows the fluence dependency given by equation (2) at $400{ }^{\circ} \mathrm{C}$ and $600{ }^{\circ} \mathrm{C}$. Widening of the confidence bands is due to the $1 \mathrm{ack}$ of data beyond about $1 \times 10^{22} \mathrm{n} / \mathrm{cm}^{2}$. No confidence limits may be placed on this equation above about $600{ }^{\circ} \mathrm{C}$.

A review of PNL transmission electron microscopy data for 304 SS irradiated in the EBR-II has indicated that the nucleation rate of cavities may increase with accumulated exposure. A summary of the essential features of the void distributions 
TABLE 12.8. Swezling Data for 304 Stainzess Steel

\begin{tabular}{|c|c|}
\hline Component & $\begin{array}{c}\text { Position } \\
\text { Vert. }\end{array}$ \\
\hline $\begin{array}{l}\text { Control Rod } \\
\text { Thimble } \\
\qquad(5 \mathrm{CJ})\end{array}$ & $\begin{array}{l}-4.7 \\
+\quad 1.7 \\
+\quad 6.7 \\
+10.0\end{array}$ \\
\hline $\begin{array}{l}\text { EBR-I I Fue } 1 \\
\text { Subas semb } 1 y \\
\text { Thimble }(X-605) \\
\text { (4C2) }\end{array}$ & $\begin{array}{l}-7 \\
-\quad 5 \\
-\quad 2.5 \\
\\
+\quad 0 \\
+\quad 2.5 \\
+\quad 5 \\
+\quad 7\end{array}$ \\
\hline $\begin{array}{l}\text { EBR-II } \\
\text { Safety Rod } \\
\text { Thimble } \\
\quad 3 D 1\end{array}$ & $\begin{array}{l}-7.0 \\
-5 \\
-\quad 2.5 \\
\\
+\quad 2.5 \\
+\quad 5 \\
+\quad 7\end{array}$ \\
\hline $\begin{array}{l}\text { Experiment } \\
\text { Capsule } X-011 \\
\quad 2 F 1\end{array}$ & $\begin{array}{r}-5 \\
-\quad 2 \\
+\quad 2 \\
+\quad 6 \\
+\quad 9\end{array}$ \\
\hline $\begin{array}{l}\text { EBR-I I Control } \\
\text { Rod Thimble } \\
\qquad(5 \mathrm{C} 5)\end{array}$ & $\begin{array}{r}-\quad 9 \\
+\quad 0 \\
+\quad 6 \\
+\quad 9\end{array}$ \\
\hline $\begin{array}{l}\text { EBR-I I Safety } \\
\text { Rod Thimble } \\
\text { (3D1) }\end{array}$ & $\begin{array}{l}-4.0 \\
-\quad 0.8 \\
+\quad 2.6 \\
+\quad 5.8\end{array}$ \\
\hline $\begin{array}{l}\text { Fue } 1 \\
\text { Subassemb } 1 y \\
\text { Thimb } 1 \text { e } X-G 05 \\
\qquad(4 C 2)\end{array}$ & $\begin{array}{l}-8.4 \\
-\quad 5.4 \\
\\
+\quad 5.6\end{array}$ \\
\hline
\end{tabular}

\begin{tabular}{|c|c|}
\hline $\begin{array}{r}\text { Fluence, } \\
\mathrm{n} / \mathrm{cm}^{2} \times 10^{-22} \\
(\mathrm{E}>0.1 \mathrm{MeV}) \\
\end{array}$ & $\begin{array}{l}\text { Irrad. } \\
\text { Temp, }{ }^{\circ} \mathrm{C}\end{array}$ \\
\hline $\begin{array}{l}2.92 \\
3.50 \\
2.26 \\
1.58\end{array}$ & $\begin{array}{l}370 \\
400 \\
430 \\
440\end{array}$ \\
\hline $\begin{array}{l}2.00 \\
2.66 \\
3.16 \\
3.41 \\
3.16 \\
2.66 \\
2.00\end{array}$ & $\begin{array}{l}370 \\
370 \\
380 \\
390 \\
400 \\
420 \\
430\end{array}$ \\
\hline $\begin{array}{l}4.34 \\
5.34 \\
6.25 \\
6.75 \\
6.25 \\
5.35 \\
4.34\end{array}$ & $\begin{array}{l}370 \\
370 \\
380 \\
390 \\
400 \\
420 \\
430\end{array}$ \\
\hline $\begin{array}{l}1.92 \\
2.25 \\
2.25 \\
1.10 \\
0.66\end{array}$ & $\begin{array}{l}400 \\
420 \\
440 \\
450 \\
450\end{array}$ \\
\hline $\begin{array}{l}2.00 \\
3.76 \\
3.42 \\
2.58\end{array}$ & $\begin{array}{l}370 \\
41.0 \\
450 \\
470\end{array}$ \\
\hline $\begin{array}{l}5.91 \\
6.75 \\
6.45 \\
4.89\end{array}$ & $\begin{array}{l}385 \\
395 \\
405 \\
420\end{array}$ \\
\hline $\begin{array}{l}2.15 \\
2.96 \\
3.54 \\
2.69\end{array}$ & $\begin{array}{l}370 \\
380 \\
430 \\
460\end{array}$ \\
\hline
\end{tabular}

$\Delta p / p$, $\%$

0.51

1.15

0.88

0.31

0.37

0.54

0.80

1.27

1.35

0.92

0.47

0.93

1. 55

2. 44

5.09

2.41

1.53

0.87

0.13

0.27

0.35

0.34

0.13

0.53

1. 26

1.67

1.15

0.63

2.63

3.70

1.85

0.47

0.44

0.95

1.11

Source

PNL

PNL

PNL

ANL

ANL

ANL. 
BNWL - 1144

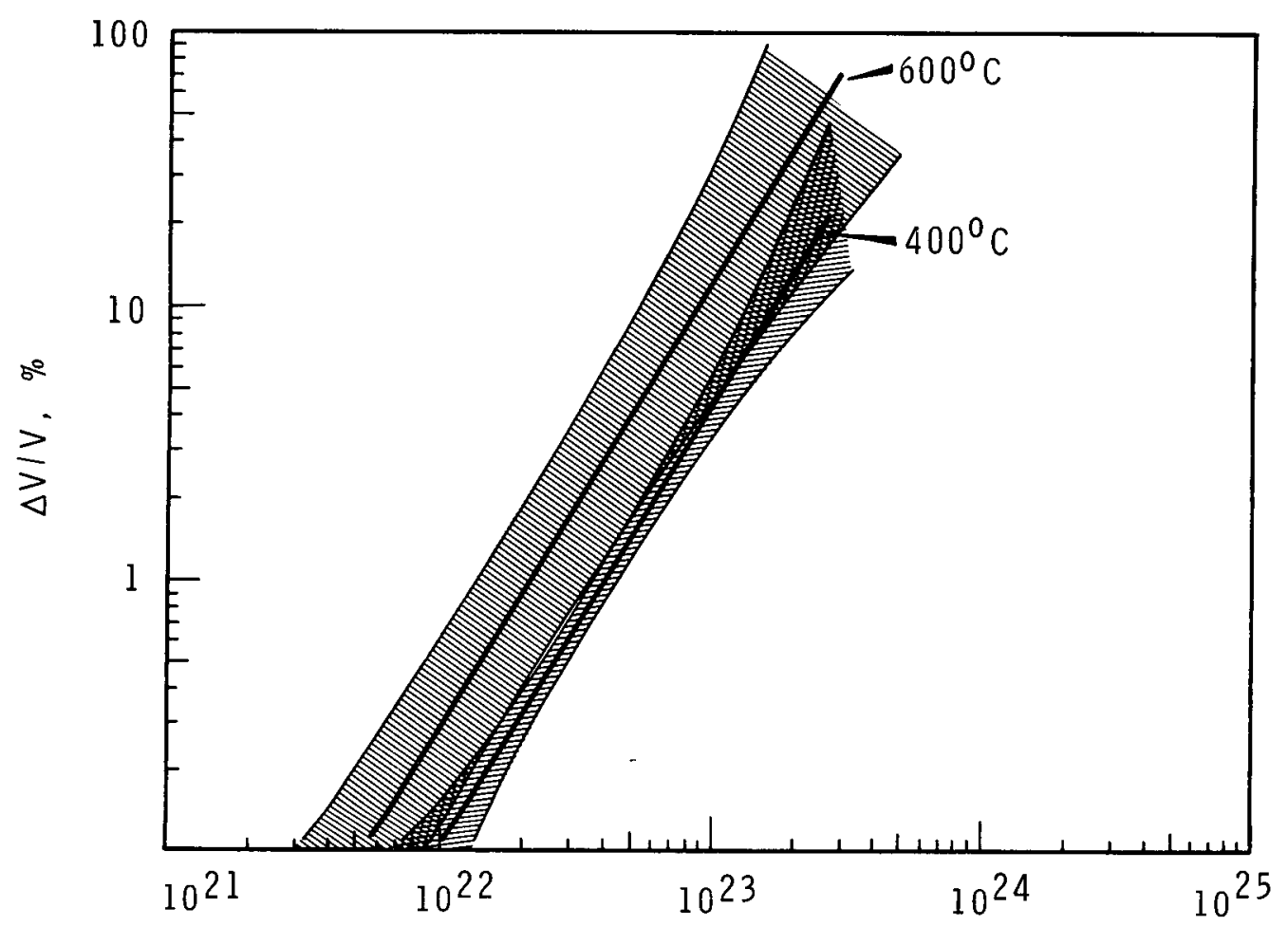

FLUENCE $\left(\mathrm{n} / \mathrm{cm}^{2}, E>0.1 \mathrm{MeV}\right)$

Neg $692163-3$

FIGURE 12.3. Swezling in Solution-Treated AISI Type 304 stainless steels

observed to date is given in Table 12.9. The void number density has been plotted as a function of fluence, using logrithmic coordinates (Figure 12.4). A regression analysis of the data indicates that the void density is related to the fluence by a power law in fluence with the exponent being $1.2 \pm 0.3$. If the exponent is greater than 1.0 , an increase in nucleationrate with accumulated exposure is indicated. It is possible that a continuously increasing helium concentration, due to transmutation reactions, could contribute to an increasing nucleation-rate by stablizing cavity nuclei. No consistent trends relating void number density to irradiation temperature were found. A correlation between void volume based upon microscopy and that based upon immersion density is indicated in Figure 12.5. In this figure, microscopy volume changes from 
TABLE 12.9. Transmission Electron Microscopy of Irradiated Type 304 stainless Steel

\begin{tabular}{|c|c|c|c|c|c|c|}
\hline Component & $\begin{array}{l}\text { Fast Fluence } \\
\mathrm{E}>0.1 \mathrm{MeV}, \\
\mathrm{n} / \mathrm{cm}^{2}-\mathrm{sec} \mathrm{c} \\
\times 10^{-22} \\
\end{array}$ & $\begin{array}{l}\text { Fast Flux } \\
\mathrm{E}>0.1 \mathrm{MeV}, \\
\mathrm{n} / \mathrm{cm}^{2}-\mathrm{sec} \\
\times 10^{-15} \\
\end{array}$ & $\begin{array}{l}\text { Irrad. } \\
\text { Temp. }{ }^{\circ} \mathrm{C}\end{array}$ & $\begin{array}{l}\text { Cavity } \\
\text { Density } \\
\mathrm{cm}^{-3}\end{array}$ & $\begin{array}{l}\text { Lineal } \\
\text { Average } \\
\text { Cavity } \\
\text { Diameter }\end{array}$ & Swelling \\
\hline $\begin{array}{l}\text { EBR-II } \\
\text { Control } \\
\text { Rod Thimble }\end{array}$ & $\begin{array}{l}0.5 \\
0.9 \\
1.5 \\
2.2 \\
2.4 \\
3.3\end{array}$ & $\begin{array}{l}0.1 \\
0.3 \\
0.5 \\
0.7 \\
0.8 \\
1.1\end{array}$ & $\begin{array}{l}460 \\
370 \\
370 \\
430 \\
420 \\
380\end{array}$ & $\begin{array}{l}0.3 \\
0.7 \\
1.9 \\
1.7 \\
2.0 \\
6.5\end{array}$ & $\begin{array}{l}245 \\
125 \\
145 \\
210 \\
200 \\
150\end{array}$ & $\begin{array}{l}0.3 \\
0.08 \\
0.3 \\
0.95 \\
1.0 \\
1.2\end{array}$ \\
\hline EBR-I I $X-G 05$ & 3.4 & 1.5 & 390 & 2.3 & 210 & 1.4 \\
\hline $\begin{array}{l}\text { EBR-II Safety } \\
\text { Rod Thimble }\end{array}$ & 5.9 & 1.6 & 400 & 8.2 & 170 & 2.7 \\
\hline
\end{tabular}

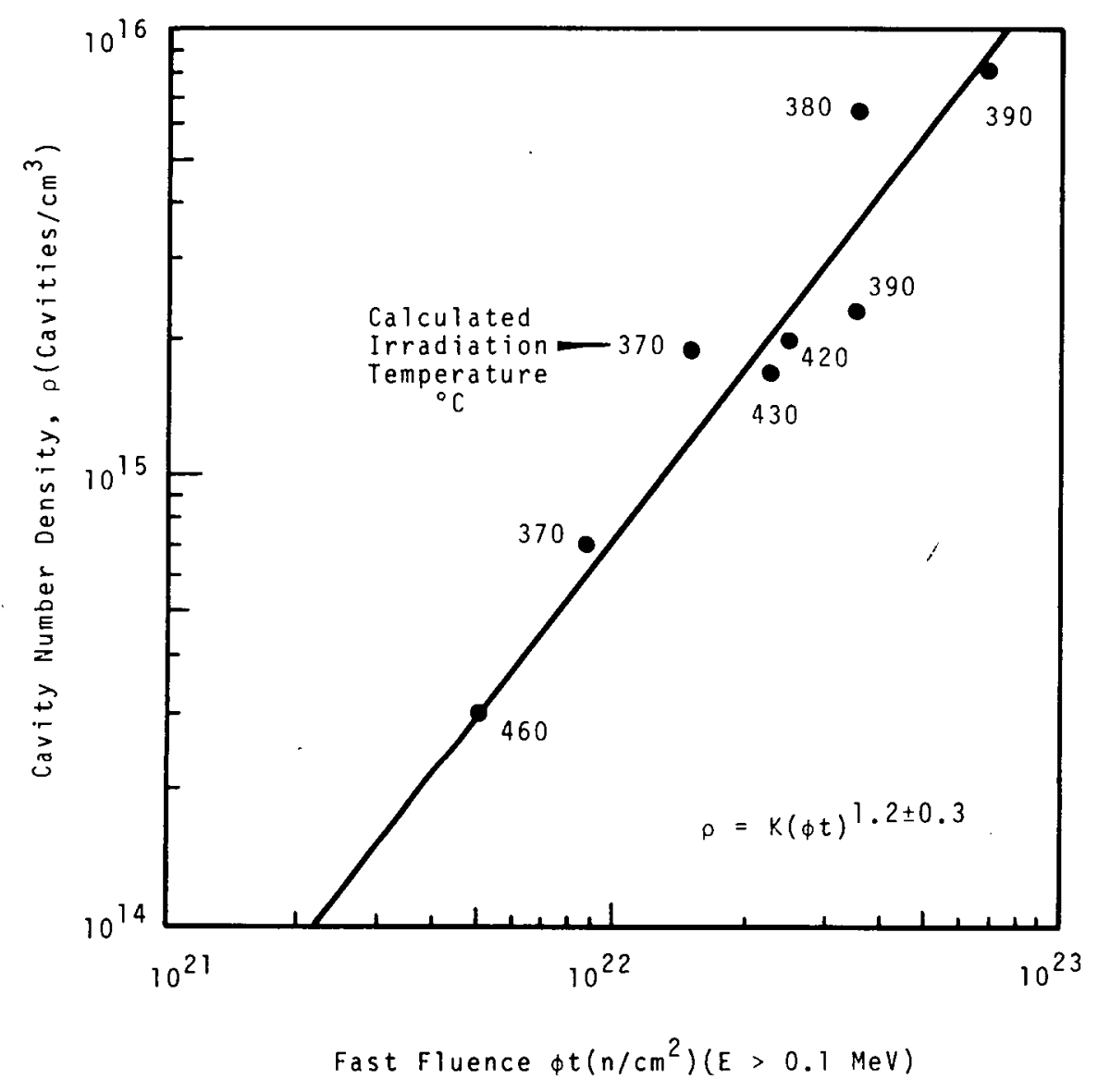

Neg $692070-1$

FIGURE 12.4. Cavity Density as a Function of Fluence for 304 stainless steel. 


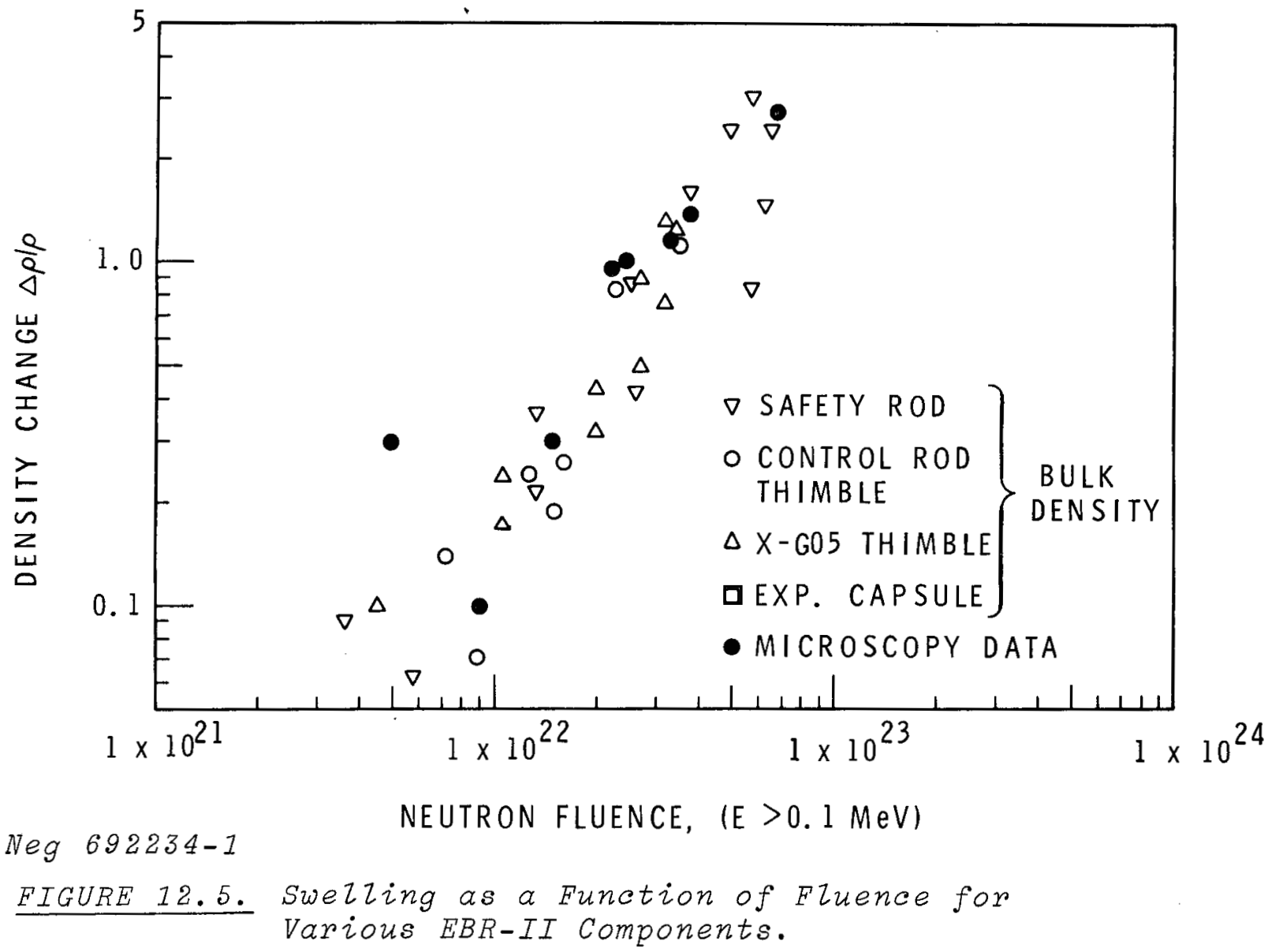

Table 12.9 are superimposed on immersion density values. Except for the point at $5 \times 10^{21} \mathrm{n} / \mathrm{cm}^{2}$, all microscopy data are in agreement with the bulk density values.

Transmission microscopy is continuing on irradiated 316 SS. In the previous quarterly report (see reference (1), p. 12.44), it was stated that solution-treated type $316 \mathrm{SS}$, irradiated to $0.8 \times 10^{22} \mathrm{n} / \mathrm{cm}^{2}(\mathrm{E}>0.1 \mathrm{MeV})$ at $900^{\circ} \mathrm{F}$, contained small polyhedral and rod-shaped $\mathrm{M}_{23} \mathrm{C}_{6}$ precipitates. It was also reported that the carbide morphology was similar to that reported in the literature for unirradiated stainless steels annealed at higher temperatures. In order to determine if a similar carbide distribution could be created in our control material, we annealed unirradiated 316 SS control samples for 3050 hours at $1200{ }^{\circ} \mathrm{F}$ and at $1400^{\circ} \mathrm{F}$ and then examined them. These specimens contained only a small concentration $\left(210^{10-11} / \mathrm{cm}^{3}\right)$ of polyhedral precipitates within the matrix. There were essentially no precipitates 
on the grain boundaries. The low concentration of carbides (as compared to the irradiated specimen and to results reported in the literature for non-irradiated specimens after similar anneals) indicates that the unirradiated thermal control sample may have been decarburized during the anneal. Chemical analyses for carbon content in irradiated and unirradiated specimens with various thermal treatments were obtained to explore this possibility. The results of these analyses are given in Table 12.10. These data do not indicate any significant amount of decarburization resulting from the long time anneals. Light microscopy specimens are presently being taken from the annealed specimens in an attempt to resolve the apparent discrepancy between the transmission electron microscopy and carbon analysis results.

Examination of the EBR-II control rod and safety rod thimbles ( 304 SS) indicates that the carbide morphology varies along the length of the thimble. Furthermore, qualitative examination of the micrographs suggests that there was more carbide from specimens near the core centerline. Accordingly, chemical analyses of carbon content in sections from the two thimbles were obtained to explore the possibility of irradiation induced carbon transfer. The results of these analyses are given in Table 12.11 .

The reproducibility of the carbon content (based on eleven National Bureau of Standard samples) was better than $10 \%$. The results were quite different than anticipated. Both samples irradiated at the peak fluence region showed lower carbon concentrations than at either the inlet or outlet regions. While there appears to have been extensive carbon transfer from the cold to the hot end of the control rod thimble, there were no large changes in the safety rod thimble. At the present, we have no explanation for these results. 
TABLE 12.10. Carbon Analyses of 316 Austenitic Stainzess Steel Subjected to Various Irradiation and Thermal Conditions

$\underline{\text { Treatment }}$

$1 \mathrm{hr}$ at $1950^{\circ} \mathrm{F}$

$1 \mathrm{hr}$ at $1950{ }^{\circ} \mathrm{F}$

$+3050 \mathrm{hr}$ at $900^{\circ} \mathrm{F}$

$1 \mathrm{hr}$ at $1950{ }^{\circ} \mathrm{F}$

$+3050 \mathrm{hr}$ at $1400^{\circ} \mathrm{F}$

$1 \mathrm{hr}$ at $1950^{\circ} \mathrm{F}$

$+1 \times 10^{21} \mathrm{n} / \mathrm{cm}^{2} \quad(\mathrm{E}>0.1 \mathrm{MeV})$

at $700{ }^{\circ} \mathrm{F}$ (3050 $\mathrm{hr}$ in Reactor)

$1 \mathrm{hr}$ at $1950^{\circ} \mathrm{F}$

$+8 \times 10^{21} \mathrm{n} / \mathrm{cm}^{2}(\mathrm{E}>0.1 \mathrm{MeV})$

at $900^{\circ} \mathrm{F}$ (3050 $\mathrm{hr}$ in Reactor)

\section{Carbon Content}

$550(\mathrm{ppm})$

$410(\mathrm{ppm})$

$565(\mathrm{ppm})$

$490(\mathrm{ppm})$

$355(\mathrm{ppm})$

TABLE 12.11. Carbon Analyses of EBR-II Components

\begin{tabular}{|c|c|c|c|c|}
\hline Component & Location & $\begin{array}{l}\text { Fluence, } \\
\mathrm{n} / \mathrm{cm}^{2}(\mathrm{E}>0.1 \mathrm{MeV}) \\
(\times 10-22)\end{array}$ & $\begin{array}{l}\text { Temperature, } \\
{ }^{\circ} \mathrm{F} \\
\end{array}$ & $\begin{array}{c}\text { Carbon, } \\
\quad \mathrm{ppm}\end{array}$ \\
\hline \multirow{4}{*}{$\begin{array}{l}\text { Control } \\
\text { Rod Thimble }\end{array}$} & & & & \\
\hline & Coolant Inlet & 0.9 & 700 & 185 \\
\hline & Peak Fluence & 3.5 & 745 & 140 \\
\hline & Coolant Outlet & 0.2 & 800 & 445 \\
\hline \multirow{4}{*}{$\begin{array}{c}\text { Safety Rod } \\
\text { Thimble }\end{array}$} & & & & \\
\hline & 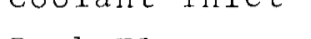 & 0.0 & 100 & 345 \\
\hline & Peak Fluence & 5.9 & 755 & 280 \\
\hline & Coolant Outlet & 1.3 & 850 & 305 \\
\hline
\end{tabular}

EBR-I I Irradiations - P. K. McDaniel

The objective of this program is to provide coordination and direction for the timely accomplishment of fast reactor irradiations of structural materials. Irradiation experiments on structural materials are in various stages of development. Some are in design; some are under construction; and others are under irradiation in the EBR-II. The status of these experiments are described. 
A number of subassemb1ies, X-009, X-101, X-014, X-018, X-021 (including $X-021 \mathrm{~A}$ ), X-022, and X-030, containing BNL structural material experiments have been discharged from EBRII. The suffix "A" designates pin interchange. A summary of these irradiation experiments is given in Table 12.12. Al1 flux monitors from these experiments, with the exception of X-010 and X-018, have been counted. Mechanical properties tests for specimens irradiated in X-009 and X-014 have been completed. Uniaxial and biaxial tests on specimens irradiated in $\mathrm{X}-022$ are in progress.

Experiments presently in EBR-II include subassemblies X-019, X-020, X-027, X-067, and full subassemblies X-021, (now X-021B), $X-041$, and $X-057$. The details of these subassemblies are given in Table 12.13. Subassembly $X-067$ consists of four pins from Battelle-Northwest, two from Argonne National Laboratory, and one from General Electric.

The four Battelle-Northwest pins contain specimens for an investigation of the effect of fast reactor irradiation on 304 and 316 SS weldments, in support of the FFTF pressure vessel and fuel duct studies. The goal exposure is $1 \times 10^{22} \mathrm{n} / \mathrm{cm}^{2}$ $(\mathrm{E}>0.1 \mathrm{MeV})$.

Acceptance Testing and Clad Characterization

M. M. Paxton

The objective of this program is to insure that acceptable cladding material is obtained and used throughout the FFTF fuel development and irradiation testing program. Under this program, lot-to-lot variations in selected mechanical properties of AISI 304 and 316 SS tubing are being determined and evaluated. 
TABLE 12.12. Summary of Experiment Discharged From EBR-II

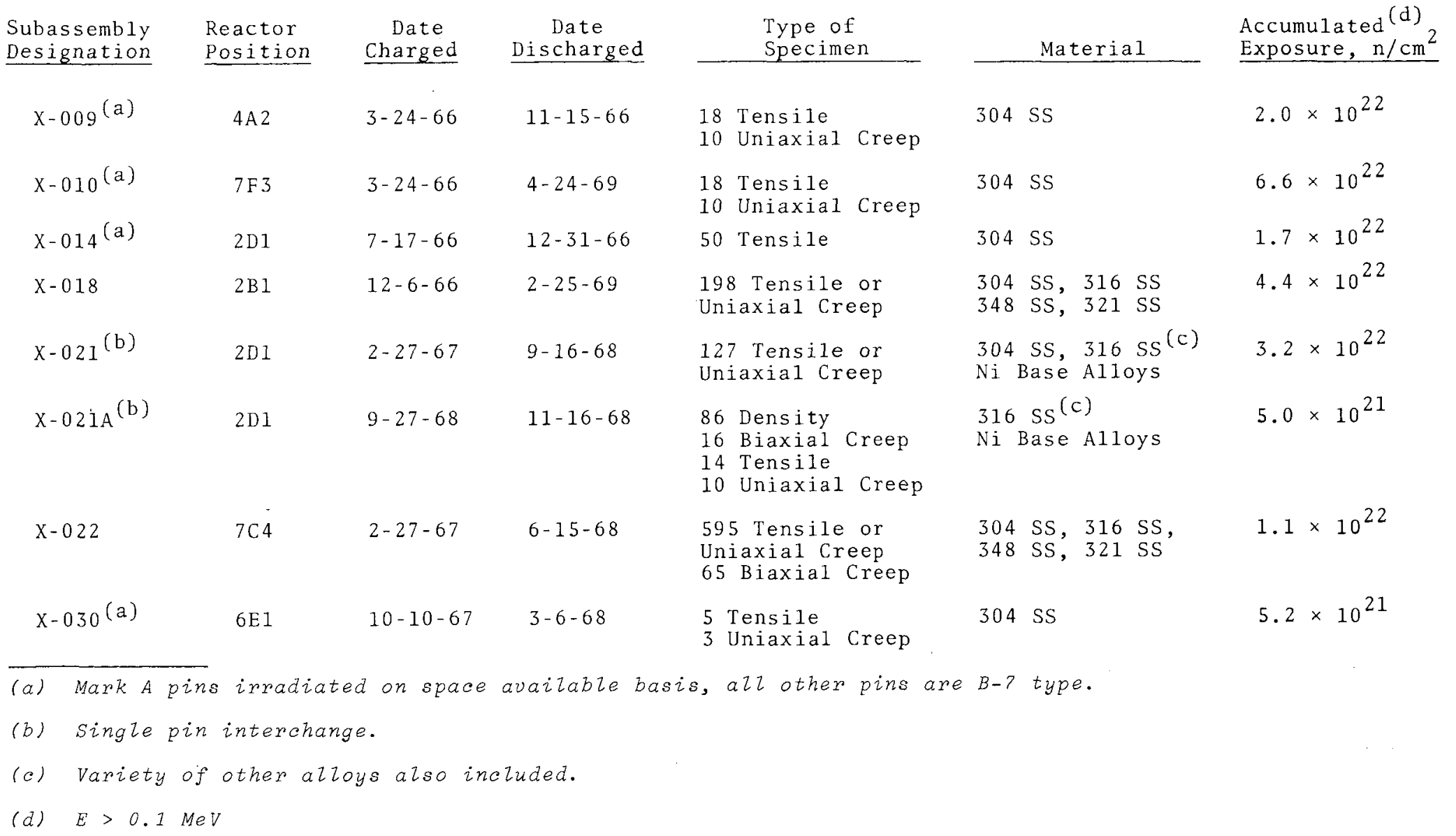




\section{TABLE 12.13. Summary of Experiment in EBR-II}

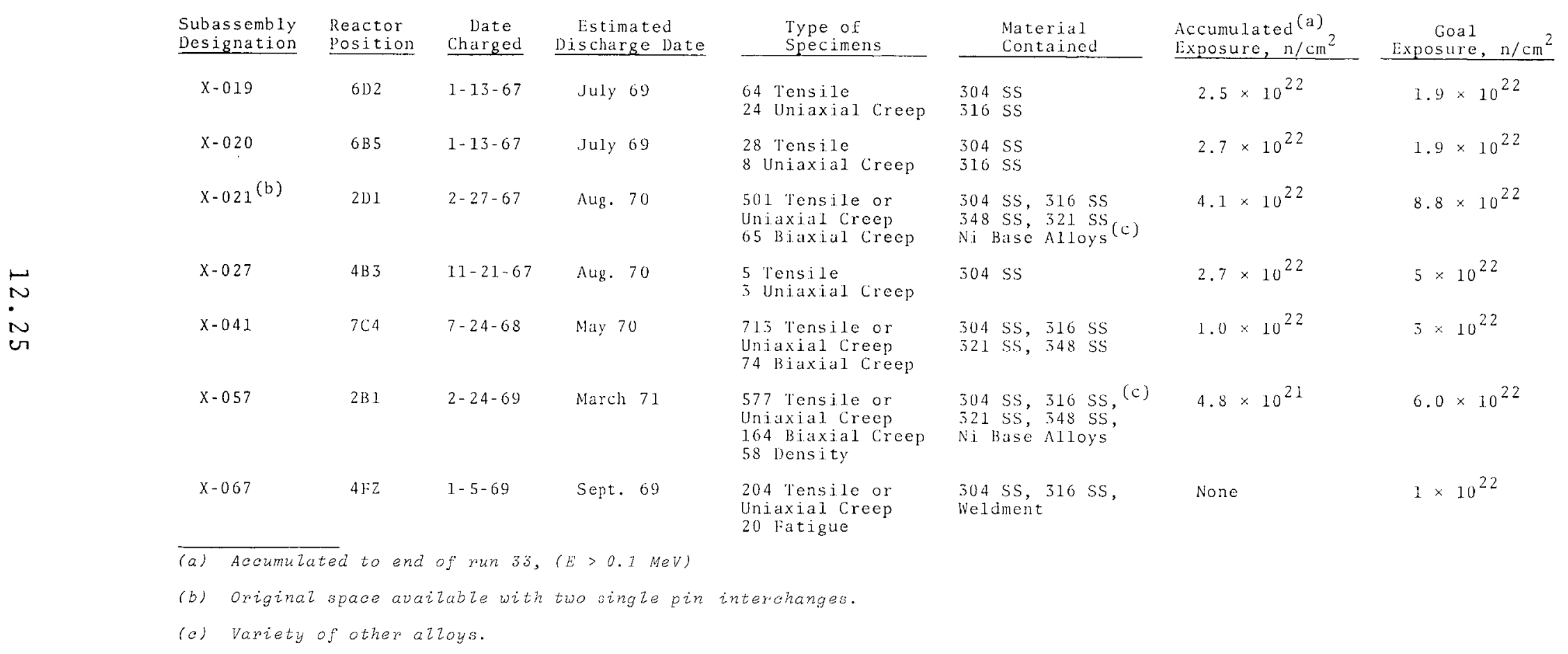


A check chemical analysis has been completed on five tube. lengths from G-lot tubing, (Table 12.14). Except for phosphorous, the check analysis agrees reasonably well with the analysis supplied by the vendor. The values supplied by the vendor are lower by a factor of two than the values received on the check analysis.

Metallography on five G-lot tube lengths has been completed. Figures 12.6-12.9 are typical transverse and longitudinal photomicrographs from $100 \mathrm{x}$ to $1000 \mathrm{X}$. The grain size as determined from the five samples varies between ASTM size 7 to 8 .

Burst tests on tubing lots E, F, G, and $H$ have been completed. The results are tabulated in Table 12.15 and shown graphically in Figures 12.10-19 in terms of internal gas pressure required to burst the tube and the reciprocal of absolute temperature. The Iines drawn through the data are for a least squares fit to the equation:

$$
y=B_{0}+B_{1}(1 / x)+B_{2}(1 / x)^{2}
$$

where $y=$ pressure, psi

$\mathrm{X}=$ temperature $\left({ }^{\circ} \mathrm{K}\right)$

$B_{0}, B_{1}$, and $B_{2}$ are the regression coefficients.

Burst pressure may be calculated at any temperature in the range 1000 to $1800^{\circ} \mathrm{F}$ using the above equation and the appropriate values for $B_{0}, B_{1}$, and $B_{2}$ given in Table 12.16 .

Burst results depend on the rate of loading, and therefore are not unique unless the rate of loading is specified and controlled. The rate of loading effect is clearly evident in tests performed on E lot reported previously, (16) in which bursts occurred at $1400 \mathrm{psi}$ in 10-14 min. and at $2500 \mathrm{psi}$ in $1-3 \mathrm{~min}$. In order to eliminate loading time as a variable, a series of short term, 0.01 - to 1-hr, stress-rupture tests were performed on $\mathrm{G}$ and $\mathrm{H}$ lot tubing. The results are tabulated in Table 12.17 and shown graphically in Figures 12.14 and 15 . If the results 
TABLE 12.14. Chemical Analysis "G" Lot Tubing 316 stainless Steel

Vendor Analysis:

\begin{tabular}{|c|c|c|c|c|c|c|c|c|c|c|c|c|}
\hline Heat No & $\mathrm{C}$ & $\mathrm{Mn}$ & $\mathrm{P}$ & $\mathrm{S}$ & $\mathrm{Si}$ & $\mathrm{Ni}$ & Cr & Mo & $B$ & $\mathrm{~N}_{2}$ & $\mathrm{Cu}$ & $\mathrm{Fe}$ \\
\hline & 0.05 & 1.60 & 0.010 & 0.012 & 0.49 & 13.32 & 17.63 & 2.41 & 0.0007 & 0.047 & 0.11 & Bal \\
\hline & 0.05 & 1.56 & 0.012 & 0.016 & 0.56 & 13.29 & 17.70 & 2.42 & 0.0013 & 0.052 & 0.10 & Ba 1. \\
\hline & 0.05 & 1.56 & 0.011 & 0.015 & 0.53 & 13.29 & 17.63 & 2.41 & 0.0009 & 0.054 & 0.11 & $\mathrm{BaI}$ \\
\hline & 0.05 & 1.53 & 0.010 & 0.015 & 0.58 & 13.34 & 1.7 .63 & 2.45 & 0.0012 & 0.050 & 0.15 & Ba.l. \\
\hline & 0.06 & 1.58 & 0.010 & 0.012 & 0.56 & 13.31 & 17.33 & 2.50 & 0.0010 & 0.049 & 0.11 & Bal. \\
\hline
\end{tabular}

Check Analysis by Lukens Steel

in

\begin{tabular}{|c|c|c|}
\hline Identification & $\mathrm{C}$ & $\mathrm{Mn}$ \\
\hline$G-081$ & 0.049 & 1.55 \\
\hline$G-163$ & 0.047 & 1.55 \\
\hline $6-238$ & 0.048 & 1.55 \\
\hline$C_{1}-257$ & 0.048 & 1. .55 \\
\hline$C_{1}-320$ & 0.050 & 1.55 \\
\hline
\end{tabular}

$\begin{array}{ll}\frac{P}{0.026} & \frac{S}{0.015} \\ 0.025 & 0.014 \\ 0.026 & 0.013 \\ 0.026 & 0.014 \\ 0.024 & 0.014\end{array}$

$\frac{S i}{0.52}$
0.53
0.52
0.52
0.52

$\frac{\mathrm{Ni}}{13.42}$
13.42
13.42
13.42
13.42

\begin{tabular}{c}
$\mathrm{Cr}$ \\
\hline 17.62 \\
17.65 \\
17.60 \\
17.60 \\
17.55
\end{tabular}

\begin{tabular}{l} 
Mo \\
\hline 2.37 \\
2.37 \\
2.37 \\
2.39 \\
2.40
\end{tabular}

$\mathrm{Cu}$

$\frac{B}{0.0008}$

0.13

0.13

0.0010

0.0010

0.13

0.0010

0.044

0.035

0.042

0.040 
BNWL - 1144

TABLE 12.15. Burst Data

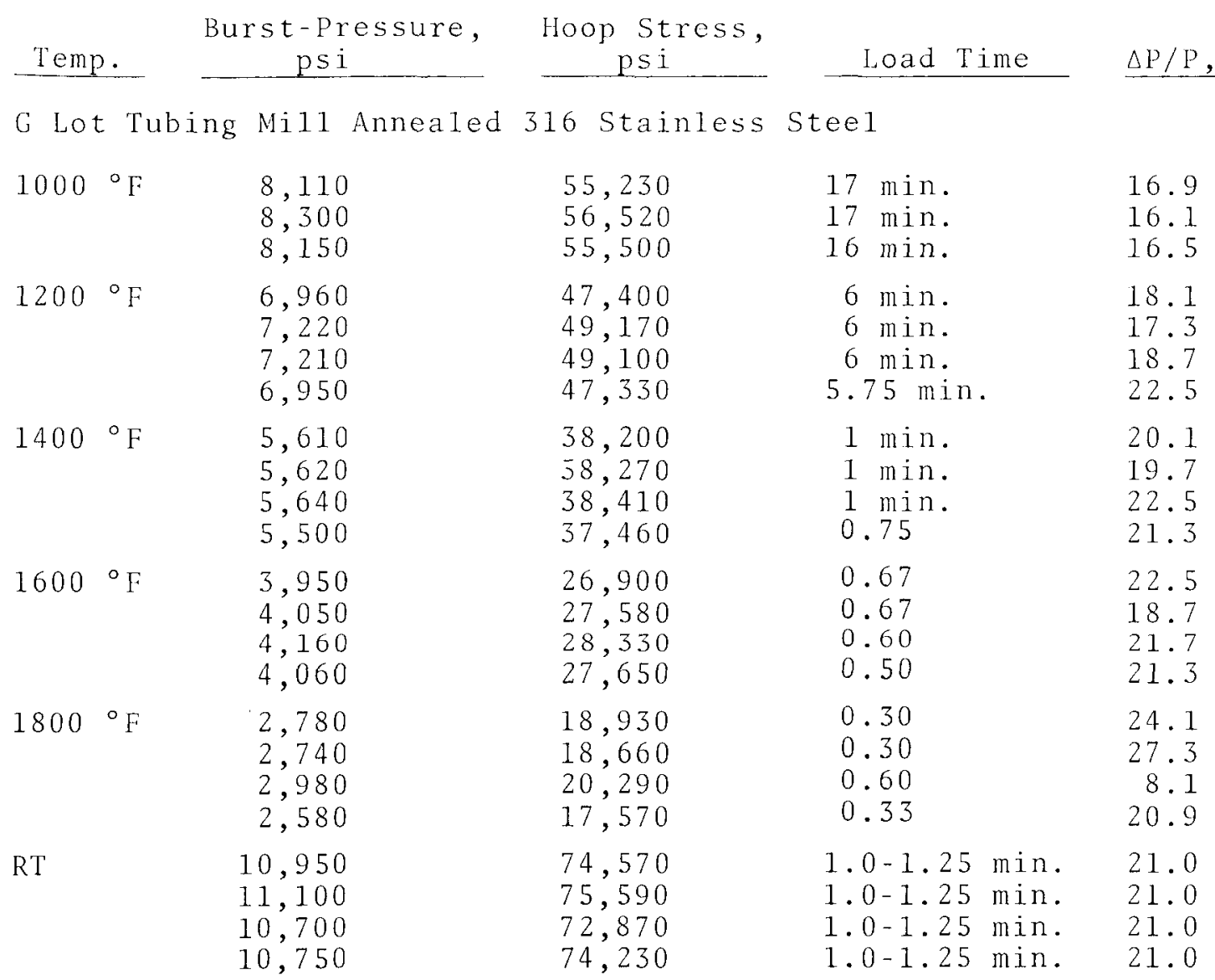

$\mathrm{H}$ Lot Tubing Mill Annealed 316 Stainless Stee 1

\begin{tabular}{|c|c|c|c|c|c|}
\hline 1000 & ${ }^{\circ} \mathrm{F}$ & $\begin{array}{l}8,380 \\
8,260\end{array}$ & $\begin{array}{l}57,070 \\
56,250\end{array}$ & $\begin{array}{c}10.75 \\
9.0\end{array}$ & $\begin{array}{l}18.9 \\
16.9\end{array}$ \\
\hline 1200 & ${ }^{\circ} \mathrm{F}$ & $\begin{array}{l}6,940 \\
7,120 \\
7,140\end{array}$ & $\begin{array}{l}47,260 \\
48,490 \\
48,620\end{array}$ & $\begin{array}{l}1.0 \\
0.75 \\
0.80\end{array}$ & $\begin{array}{l}15.3 \\
22.1 \\
19.3\end{array}$ \\
\hline $1400^{\circ}$ & $\mathrm{F}$ & $\begin{array}{l}5,450 \\
5,440 \\
5,340\end{array}$ & $\begin{array}{l}37,110 \\
37,050 \\
36,980\end{array}$ & $\begin{array}{l}0.67 \\
0.67 \\
0.50\end{array}$ & $\begin{array}{l}20.9 \\
17.7 \\
22.1\end{array}$ \\
\hline 1600 & ${ }^{\circ} \mathrm{F}$ & $\begin{array}{l}3,880 \\
3,820 \\
3,950\end{array}$ & $\begin{array}{l}26,420 \\
26,010 \\
26,900\end{array}$ & $\begin{array}{l}0.50 \\
0.50 \\
0.70\end{array}$ & $\begin{array}{l}14.5 \\
23.7 \\
23.4\end{array}$ \\
\hline 1800 & ${ }^{\circ} \mathrm{F}$ & $\begin{array}{l}2,580 \\
2,640 \\
2,630\end{array}$ & $\begin{array}{l}17,570 \\
17,980 \\
17,910\end{array}$ & $\begin{array}{l}0.50 \\
0.50 \\
0.40\end{array}$ & $\begin{array}{l}20.7 \\
14.5 \\
18.9\end{array}$ \\
\hline $\mathrm{RT}$ & & $\begin{array}{r}10,750 \\
9,750 \\
10,650 \\
11,000 \\
10,900\end{array}$ & $\begin{array}{l}73,210 \\
66,400 \\
72,530 \\
74,910 \\
74,230\end{array}$ & $\begin{array}{l}1.0-1.25 \mathrm{~min} . \\
1.0-1.25 \mathrm{~min} . \\
1.0-1.25 \mathrm{~min} . \\
1.0-1.25 \mathrm{~min} . \\
1.0-1.25 \mathrm{~min} .\end{array}$ & $\begin{array}{l}20.0 \\
16.0 \\
19.0 \\
20.0 \\
19.0\end{array}$ \\
\hline
\end{tabular}




\section{TABLE 12.15. (contd)}

\begin{tabular}{|c|c|c|c|c|}
\hline Temp. & $\begin{array}{c}\text { Burst-Pressure, } \\
\text { psi }\end{array}$ & $\begin{array}{c}\text { Hoop Stress, } \\
\text { psi }\end{array}$ & Load Time & \multirow[t]{2}{*}{$\triangle \mathrm{P} / \mathrm{P}, \%$} \\
\hline E Lot $\mathrm{T}$ & ng Mill Annealed & 504 Stainless & teel & \\
\hline $1000^{\circ} \mathrm{F}$ & $\begin{array}{l}7,390 \\
7,430 \\
7,410\end{array}$ & $\begin{array}{l}50,325 \\
50,600 \\
50,460\end{array}$ & $\begin{array}{r}10 \mathrm{~min} . \\
8 \mathrm{~min} . \\
12 \mathrm{~min} .\end{array}$ & $\begin{array}{l}18.7 \\
16.5 \\
18.9\end{array}$ \\
\hline $1200^{\circ} \mathrm{F}$ & $\begin{array}{l}6,260 \\
6,280 \\
6,230\end{array}$ & $\begin{array}{l}42,630 \\
42,770 \\
42,430\end{array}$ & $\begin{array}{l}<6 \text { min. } \\
<6 \text { min. } \\
<6 \text { min. }\end{array}$ & $\begin{array}{l}17.3 \\
18.1 \\
16.9\end{array}$ \\
\hline $1400^{\circ} \mathrm{F}$ & $\begin{array}{l}5,000 \\
5,060 \\
5,020\end{array}$ & $\begin{array}{l}34,050 \\
34,460 \\
34,190\end{array}$ & $\begin{array}{l}<6 \text { min. } \\
<6 \text { min. } \\
<6 \text { min. }\end{array}$ & $\begin{array}{l}16.9 \\
16.1 \\
15.3\end{array}$ \\
\hline $1600^{\circ} \mathrm{F}$ & $\begin{array}{l}3,530 \\
3,550 \\
3,510\end{array}$ & $\begin{array}{l}24,040 \\
24,180 \\
23,900\end{array}$ & $\begin{array}{l}<6 \text { min. } \\
<6 \text { min. } \\
<6 \text { min. }\end{array}$ & $\begin{array}{l}17.3 \\
14.5 \\
18.5\end{array}$ \\
\hline $1800^{\circ} \mathrm{F}$ & $\begin{array}{l}2,600 \\
2,460 \\
2,340\end{array}$ & $\begin{array}{l}17,710 \\
16,750 \\
15,940\end{array}$ & $\begin{array}{l}<6 \text { min. } \\
<6 \text { min. } \\
<6 \text { min. }\end{array}$ & $\begin{array}{l}13.3 \\
21.3 \\
20.7\end{array}$ \\
\hline RT & $\begin{array}{l}10,700 \\
10,700 \\
10,700 \\
10,800 \\
10,800\end{array}$ & $\begin{array}{l}72,870 \\
72,870 \\
72,870 \\
73,550 \\
73,550\end{array}$ & $\begin{array}{l}1.0-1.25 \mathrm{~min} . \\
1.0-1.25 \mathrm{~min} . \\
1.0-1.25 \mathrm{~min} . \\
1.0-1.25 \mathrm{~min} . \\
1.0-1.25 \mathrm{~min} .\end{array}$ & $\begin{array}{l}20.0 \\
22.0 \\
19.0 \\
22.0 \\
22.0\end{array}$ \\
\hline
\end{tabular}

F Lot Tubing Mill Annealed 304 Stainless Steel

$\begin{array}{lrrrr}1000{ }^{\circ} \mathrm{F} & 7,075 & 48,180 & 8 \mathrm{~min} . & 16.1 \\ & 7,070 & 48,150 & 6 \mathrm{~min} . & 17.3 \\ 1200{ }^{\circ} \mathrm{F} & 7,020 & 47,810 & 7 \mathrm{~min} . & 17.7 \\ & 5,790 & 39,430 & <6 \mathrm{~min} . & 20.1 \\ & 5,830 & 39,700 & <6 \mathrm{~min} . & 18.1 \\ 1400{ }^{\circ} \mathrm{F} & 5,820 & 29,630 & <6 \mathrm{~min} . & 18.1 \\ & 4,400 & 29,960 & <6 \mathrm{~min} . & 20.1 \\ & 4,450 & 30,300 & <6 \mathrm{~min} . & 24.1 \\ 1600{ }^{\circ} \mathrm{F} & 4,460 & 30,370 & <6 \mathrm{~min} . & 20.9 \\ & 3,090 & 21,040 & <6 \mathrm{~min} . & 21.7 \\ & 3,200 & 21,790 & <6 \mathrm{~min} . & 20.1 \\ 1800{ }^{\circ} \mathrm{F} & 3,170 & 21,590 & <6 \mathrm{~min} . & 22.7 \\ & 2,100 & 14,300 & 6 \mathrm{~min} . & \\ & 2,000 & 13,620 & 6 \mathrm{~min} . & \\ \mathrm{RT} & 2,040 & 13,890 & 6 \mathrm{~min} . & \\ & 9,950 & 67,760 & 1.0-1.25 \mathrm{~min} . & 21.0 \\ & 9,950 & 67,760 & 1.0-1.25 \mathrm{~min} . & 21.0 \\ & 9,900 & 67,420 & 1.0-1.25 \mathrm{~min} . & 20.0 \\ & 9,950 & 67,760 & 1.0-1.25 \mathrm{~min} . & 21.0 \\ & 9,950 & 67,760 & 1.0-1.25 \mathrm{~min} . & 24.0\end{array}$




\section{TABLE 12.16. Regression Coefficients for Burst Data}

$$
\begin{aligned}
& \text { Tubing Lot } \\
& \mathrm{B}_{\mathrm{O}} \\
& -1.9714 \times 10^{4} \\
& \frac{\mathrm{B}_{1}}{3.71978 \times 10^{7}} \frac{\mathrm{B}_{2}}{-1.26778 \times 10^{10}} \\
& \text { F } \\
& -1.68999 \times 10^{4} \\
& 3.16296 \times 10^{7} \\
& -9.88663 \times 10^{10} \\
& \text { G } \\
& -2.94949 \times 10^{4} \\
& 5.70268 \times 10^{7} \\
& -2.14467 \times 10^{10} \\
& -2.24968 \times 10^{4}
\end{aligned}
$$

of the burst tests are treated as very short-term stress-rupture tests, Figures 12.16 and 17 , the two tests give comparable results, except at $1800^{\circ} \mathrm{F}$. In treating a burst test as a stressrupture test, the stress at rupture is taken as the stress to cause rupture and the time to rupture is the load-time for the burst test.

Stress-rupture tests on tubing lots $E, F, G$, and $H$ have been completed at $1200^{\circ} \mathrm{F}$ for rupture times less than 1400 hours. The tests completed to date are tabulated in Table 12.18 and shown graphically in Figures 12.19-23. The ductilities, shown as $\Delta \mathrm{P} / \mathrm{P}$ were taken well away from the failed region since most specimens failed in an explosive manner.

The difference between the creep-rupture properties of lots $E$ and $F$ is being investigated. Lot $E$ was found to be considerably stronger than lot $\mathrm{F}$. The main metallurgical differences between these two is a larger grain size in $E$ than in $F$ and a lower interstitial concentration in $F$ than in $E$. Research literature (17-19) has shown that creep-rates are related to total interstitial concentration. In order to more fully understand how these differences affect rupture-life, a series of biaxial creep tests was conducted. The biaxial creep curves were determined by periodically interrupting the test and measuring diametrical 


\section{TABLE 12.17. Short Term Stress Rupture Data}

\begin{tabular}{|c|c|c|c|c|}
\hline & $\mathrm{Ga}$ & $\begin{array}{l}\text { Pressure, } \\
\text { osi }\end{array}$ & $\begin{array}{c}\text { Hoop Stress, } \\
\text { psi }\end{array}$ & $\begin{array}{l}\text { Rupture Time, } \\
\text { Hours }\end{array}$ \\
\hline
\end{tabular}

G Lot Mill Annealed 316 Stainless Steel

$\begin{array}{rrrrr}1800{ }^{\circ} \mathrm{F} & 1,620 & 11,030 & 0.026 & 17.3 \\ & 1,320 & 8,990 & 0.189 & 20.1 \\ & 1,170 & 7,970 & 0.251 & 18.7 \\ & 1,030 & 7,010 & 0.449 & 20.5 \\ 1600^{\circ} \mathrm{F} & 940 & 6,400 & 0.756 & 24.1 \\ & 3,810 & 25,950 & 0.008 & 20.1 \\ & 2,960 & 20,160 & 0.045 & 28.9 \\ & 2,640 & 17,980 & 0.100 & 25.3 \\ & 2,350 & 16,000 & 0.178 & 22.9 \\ 1400{ }^{\circ} \mathrm{F} & 1,130 & 14,500 & 0.394 & 20.5 \\ & 5,210 & 13,010 & 0.852 & 24.1 \\ & 5,000 & 35,480 & 0.018 & 22.8 \\ & 4,670 & 34,050 & 0.028 & 24.9 \\ & 4,130 & 28,800 & 0.061 & 26.1 \\ & 3,860 & 26,290 & 0.175 & 27.7 \\ 1200{ }^{\circ} \mathrm{F} & 3,660 & 24,920 & 0.371 & 31.7 \\ & 6,800 & 46,310 & 0.636 & 27.3 \\ & 6,600 & 44,950 & 0.034 & 21.6 \\ & 6,320 & 43,040 & 0.072 & 20.8 \\ & 6,170 & 42,020 & 0.450 & 21.3 \\ & 6,020 & 41,000 & 0.562 & 19.3 \\ & & & 0.818 & 23.3\end{array}$

H Lot Mill Annealed 316 Stainless Steel

$\begin{array}{crrll}1800{ }^{\circ} \mathrm{F} & 1,610 & 10,960 & 0.044 & 20.1 \\ & 1,320 & 8,990 & 0.117 & 18.1 \\ & 1,170 & 7,970 & 0.233 & 20.9 \\ & 1,030 & 7,010 & 0.716 & 25.7 \\ 1600^{\circ} \mathrm{F} & 2,930 & 6,400 & 1.00 & 22.1 \\ & 2,640 & 19,950 & 0.048 & 22.1 \\ & 2,350 & 17,980 & 0.110 & 23.7 \\ & 2,130 & 16,000 & 0.195 & 23.7 \\ 1400{ }^{\circ} \mathrm{F} & 1,910 & 13,500 & 0.446 & 23.3 \\ & 4,700 & 32,010 & 1.00 & 18.9 \\ & 4,130 & 28,130 & 0.044 & 21.3 \\ & 3,860 & 26,290 & 0.194 & 22.9 \\ 1200{ }^{\circ} \mathrm{F} & 3,660 & 24,920 & 0.346 & 22.5 \\ & 3,550 & 24,180 & 0.789 & 24.1 \\ & 6,800 & 46,310 & 1.00 & 23.3 \\ & 6,600 & 44,950 & 0.056 & 21.7 \\ & 6,320 & 43,040 & 0.133 & 22.0 \\ & 6,170 & 42,020 & 0.340 & 20.5 \\ & 6,020 & 41,000 & 0.413 & 18.1 \\ & & & 0.672 & 17.3\end{array}$


TABLE 12.18. Long Term Stress Rupture Data

Gas Pressure, Hoop Stress, Rupture Time,

Temp psi psi

$\mathrm{hr}$

$\triangle \mathrm{P} / \mathrm{P}, \%$

E Lot Mill Annealed 304 Stainless Stee1

\begin{tabular}{|c|c|c|c|c|}
\hline $1200^{\circ} \mathrm{F}$ & $\begin{array}{l}4,810 \\
4,260 \\
3,700 \\
3,310^{\circ} \\
3,820 \\
3,010 \\
3,010\end{array}$ & $\begin{array}{l}32,760 \\
29,010 \\
25,200 \\
22,540 \\
26,010 \\
20,500 \\
20,500\end{array}$ & $\begin{array}{r}9.8 \\
44.5 \\
125.0 \\
268.2 \\
80.0 \\
816.0 \\
853.0\end{array}$ & $\begin{array}{r}10.1 \\
12.8 \\
6.5 \\
4.4 \\
--. \\
6.0 \\
7.0\end{array}$ \\
\hline
\end{tabular}

F Lot Mil1 Annealed 304 Stainless Steel

\begin{tabular}{|c|c|c|c|c|}
\hline $1200^{\circ} \mathrm{F}$ & $\begin{array}{l}4,260 \\
3,790 \\
2,950 \\
2,580 \\
3,670\end{array}$ & $\begin{array}{l}29,010 \\
25,800 \\
20,090 \\
17,570 \\
24,990 \\
22\end{array}$ & $\begin{array}{r}5.8 \\
17.8 \\
281.9 \\
1388.9 \\
41.8\end{array}$ & $\begin{array}{r}10.1 \\
10.9 \\
13.3 \\
7.7 \\
-.-\end{array}$ \\
\hline
\end{tabular}

G Lot Mill Annealed 316 Stainless Steel

\begin{tabular}{|c|c|c|c|c|}
\hline $1200^{\circ} \mathrm{F}$ & $\begin{array}{l}5,150 \\
4,730 \\
4,400 \\
4,110 \\
4,130 \\
3,840 \\
3,670 \\
3,250\end{array}$ & $\begin{array}{l}35,070 \\
32,210 \\
29,960 \\
27,990 \\
28,130 \\
26,150 \\
25,000 \\
22,130\end{array}$ & $\begin{array}{r}8.3 \\
20.9 \\
42.4 \\
84.2 \\
94.9 \\
172.1 \\
327.8 \\
818.4\end{array}$ & $\begin{array}{r}15.7 \\
22.5 \\
20.9 \\
20.5 \\
18.9 \\
14.5 \\
11.3 \\
9.3\end{array}$ \\
\hline
\end{tabular}

H Lot Mill Annealed 316 Stainless Steel

$\begin{array}{rlr}1200{ }^{\circ} \mathrm{F} & 5,580 & 38,000 \\ & 5,150 & 35,070 \\ & 4,730 & 32,210 \\ & 4,110 & 27,990 \\ & 3,670 & 24,990\end{array}$

$\begin{array}{rr}1.5 & 26.1 \\ 3.6 & 13.0 \\ 10.5 & 13.5 \\ 60.5 & 11.0 \\ 222.9 & 6.9\end{array}$



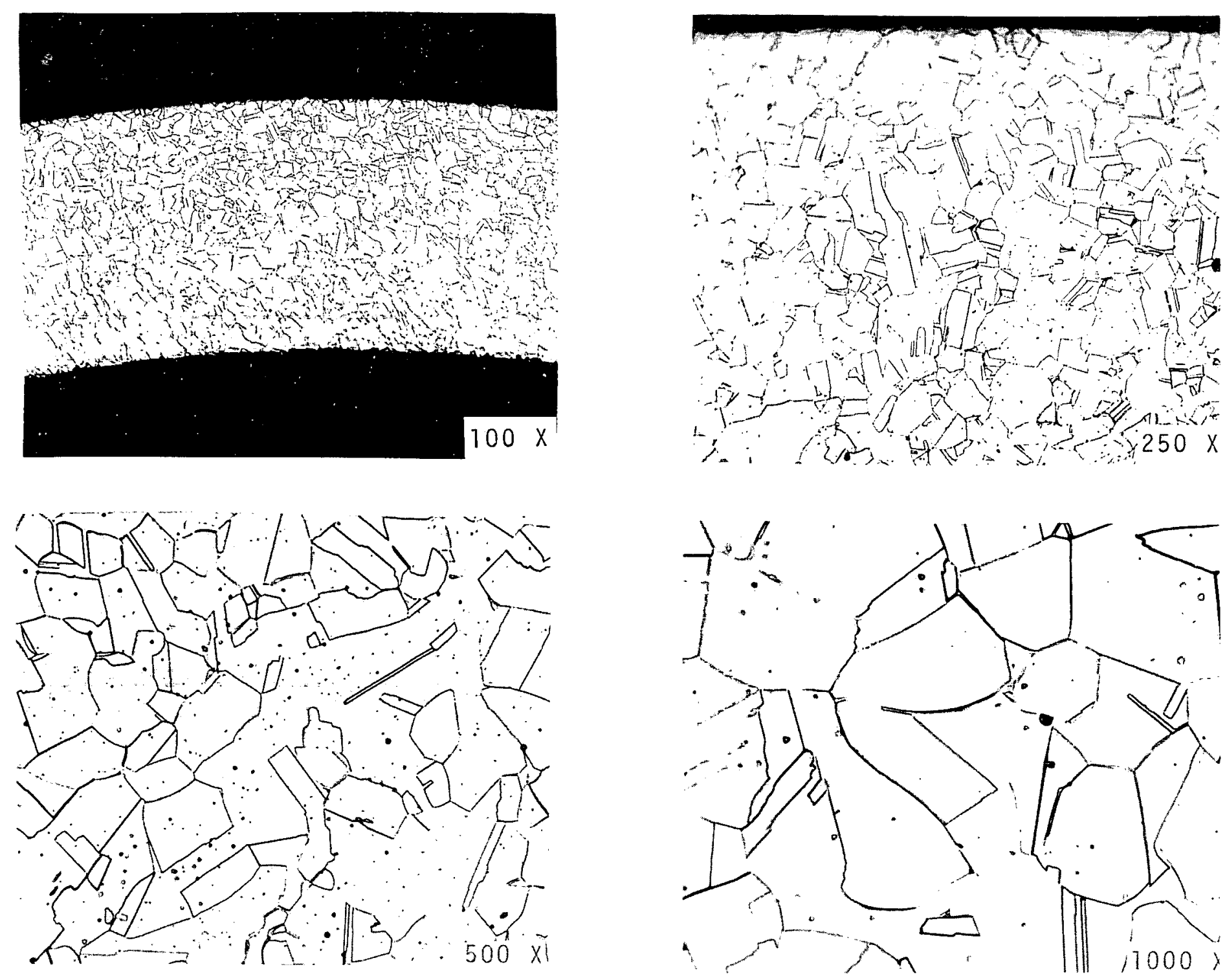

FIGURE 12.6. Tubing Lot GMill Annealed 316 stainless Transverse Tube Length G-099. Etch 25\% Alcohol $75 \% \mathrm{HCl}$ (elec.) (Neg 46972A;469-74;46972B;46972C) 

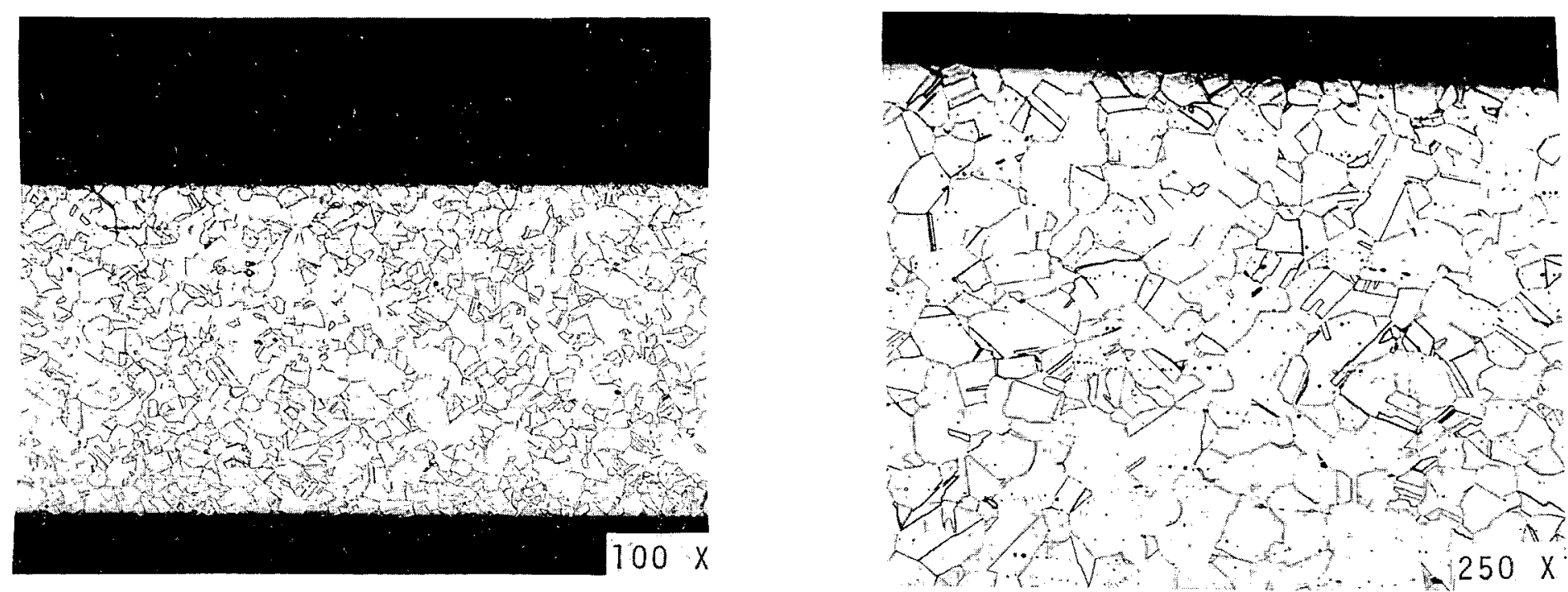

$\stackrel{\varpi}{\sim}$
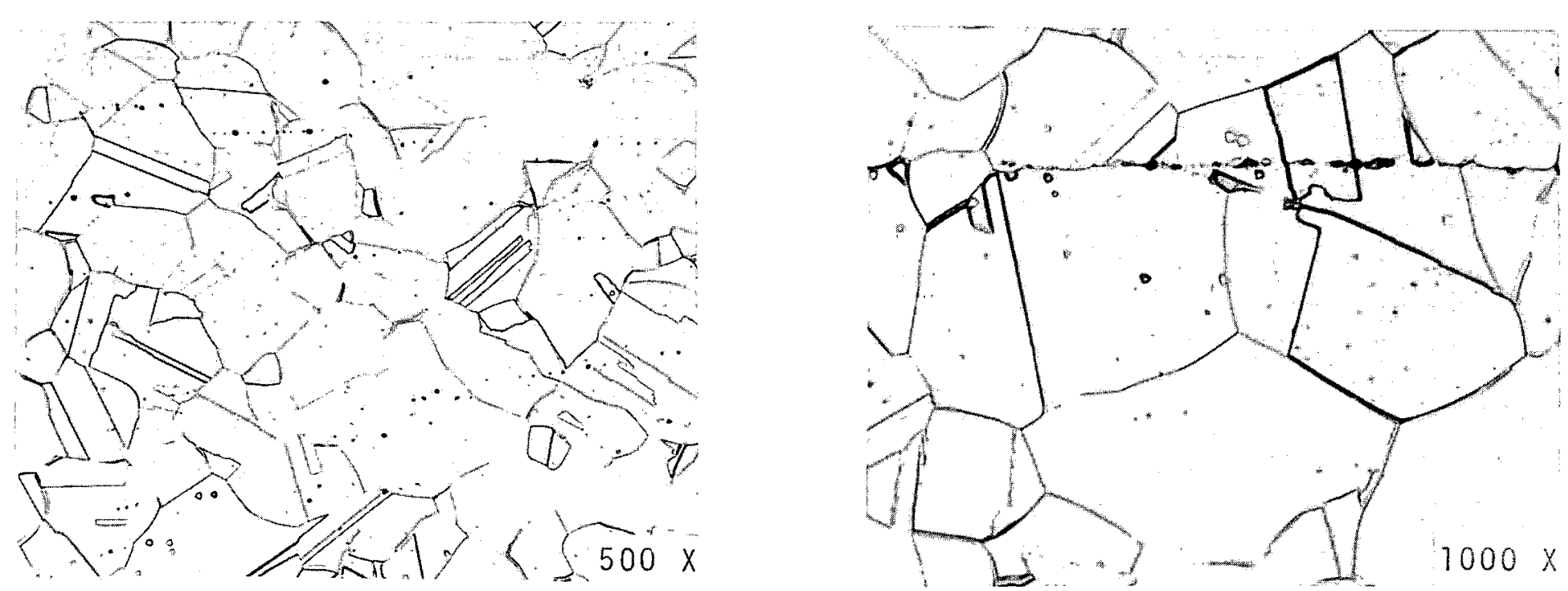

FIGURE 12.7. Tubing Lot G MiZZ Annealed 316 Stainless Longitudinal Tube Length G-099. Etch 25\% Alcohol $75 \% \mathrm{HCl}$ (elec.) 

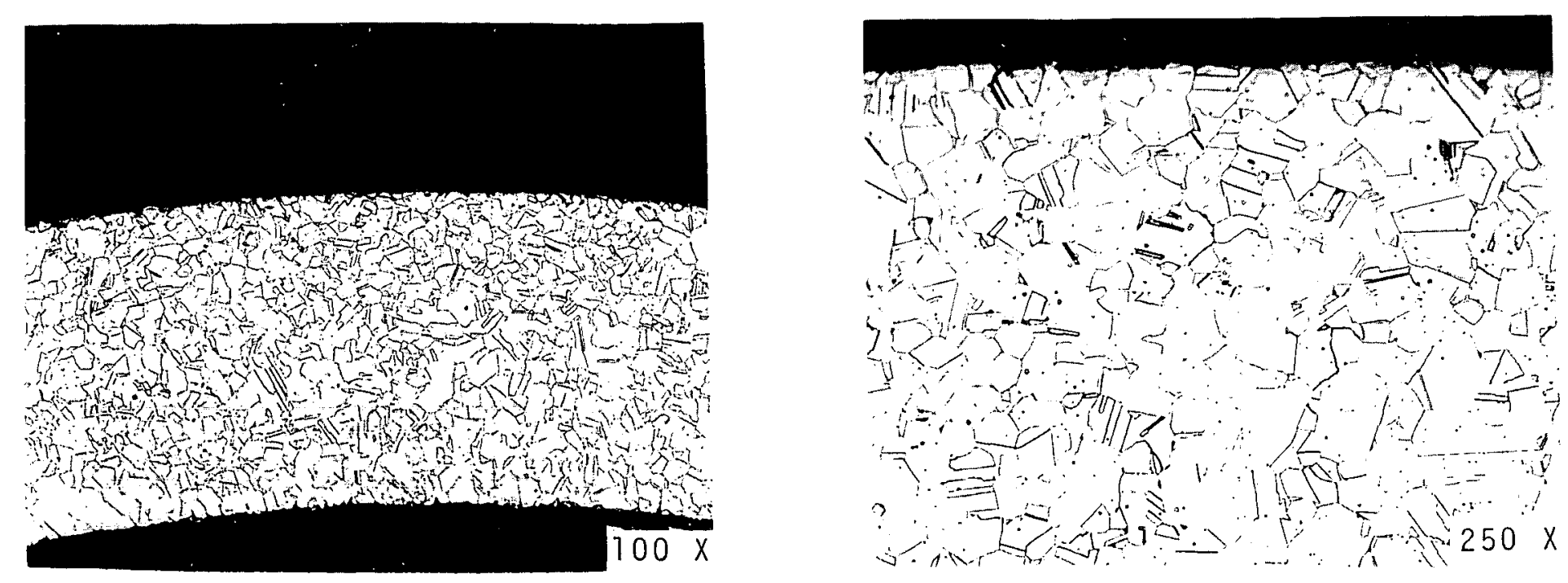

$\stackrel{N}{N}$
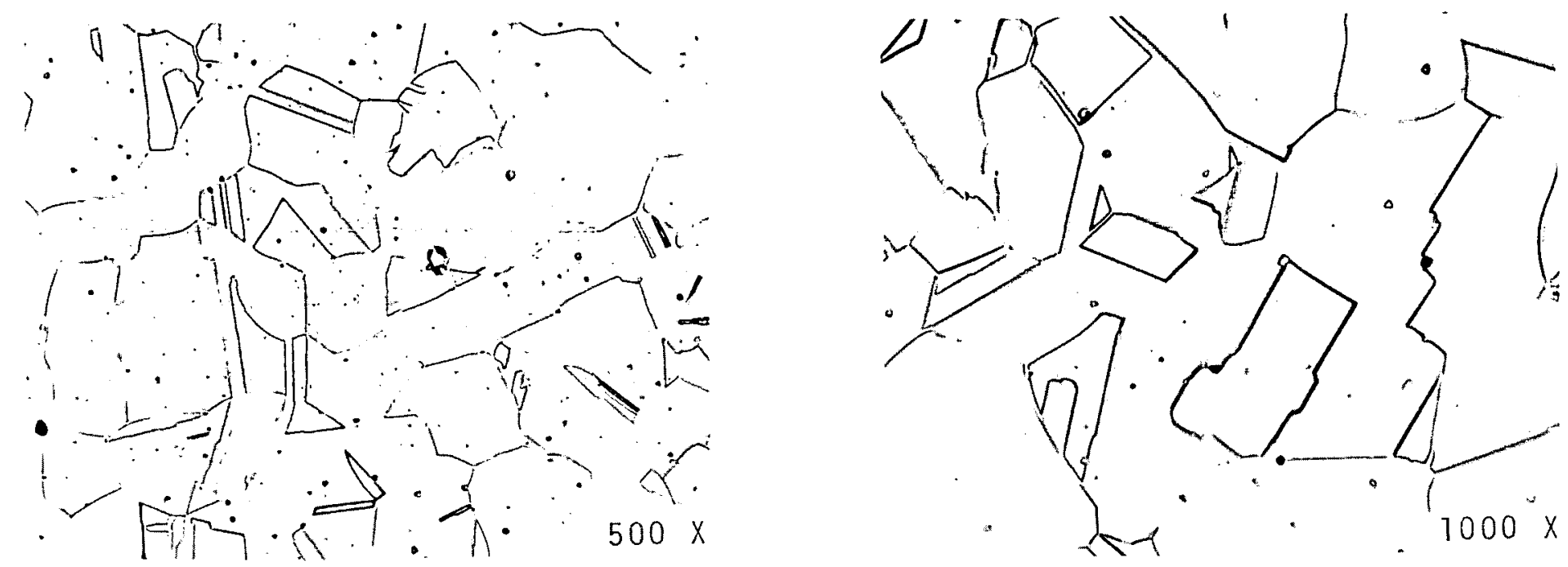

FIGURE 12.8. Tubing Lot G MiZI Annealed 316 Stainless Transverse Tube Length G-177. Etch 25\% Alcohol 75\% HCl (elec.).

(Neg 46976A; 469-78; 46976B; 46976C) 

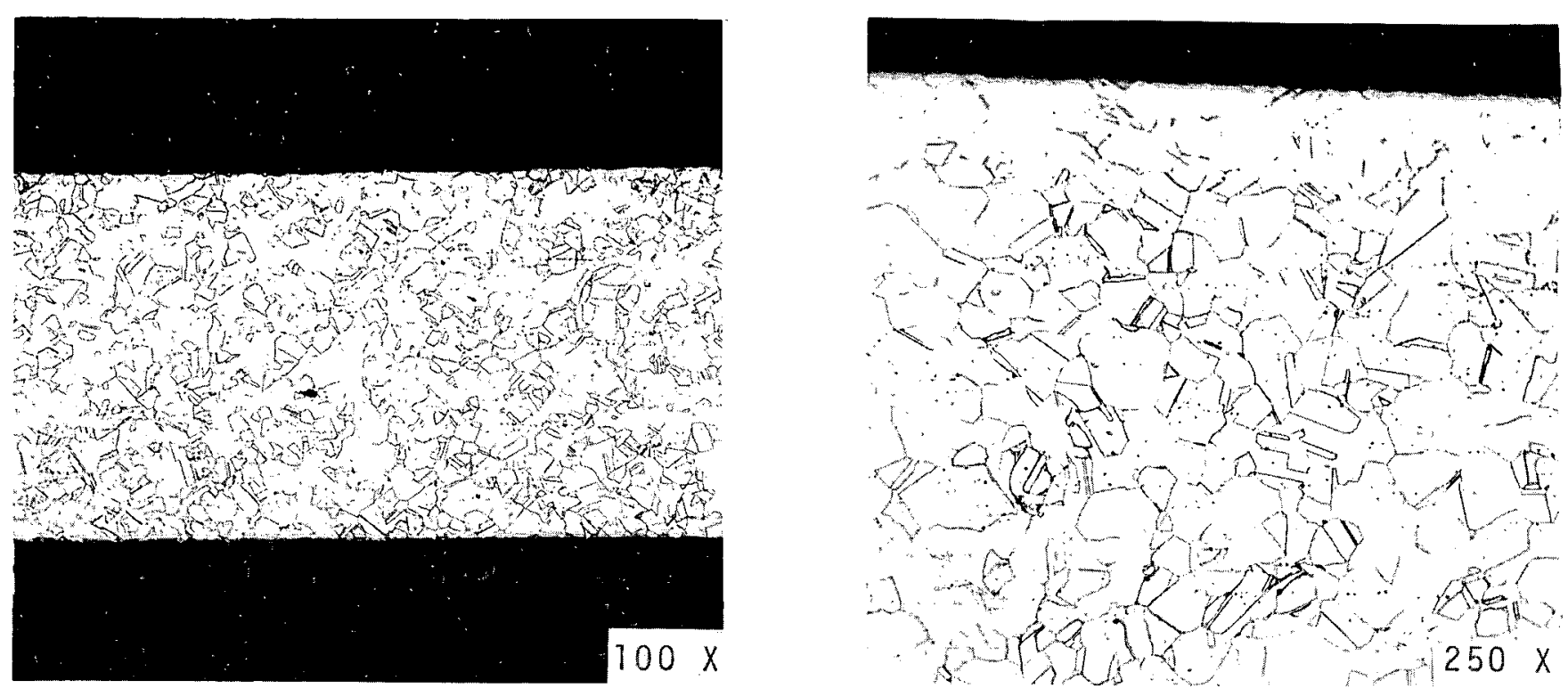

$w$
$\omega$
$\omega$
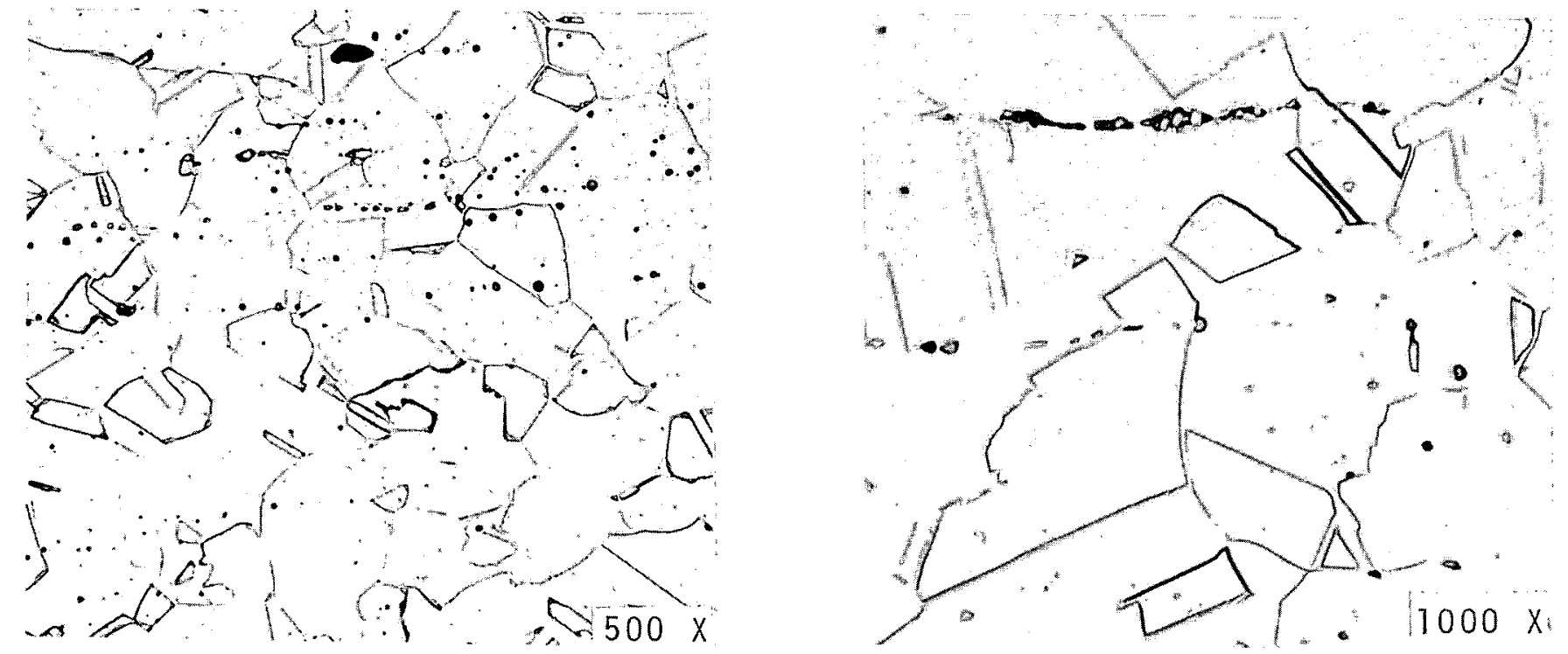

FIGURE 12.9. Tubing Lot G Mill Annealed 316 Stainless Longitudinal Tube Length G-177. Etch 25\% Alcohol $75 \% \mathrm{HCl}$ (elec.). (Neg 46973A;469-75;46973B;46973C) 
BNWL - 1144

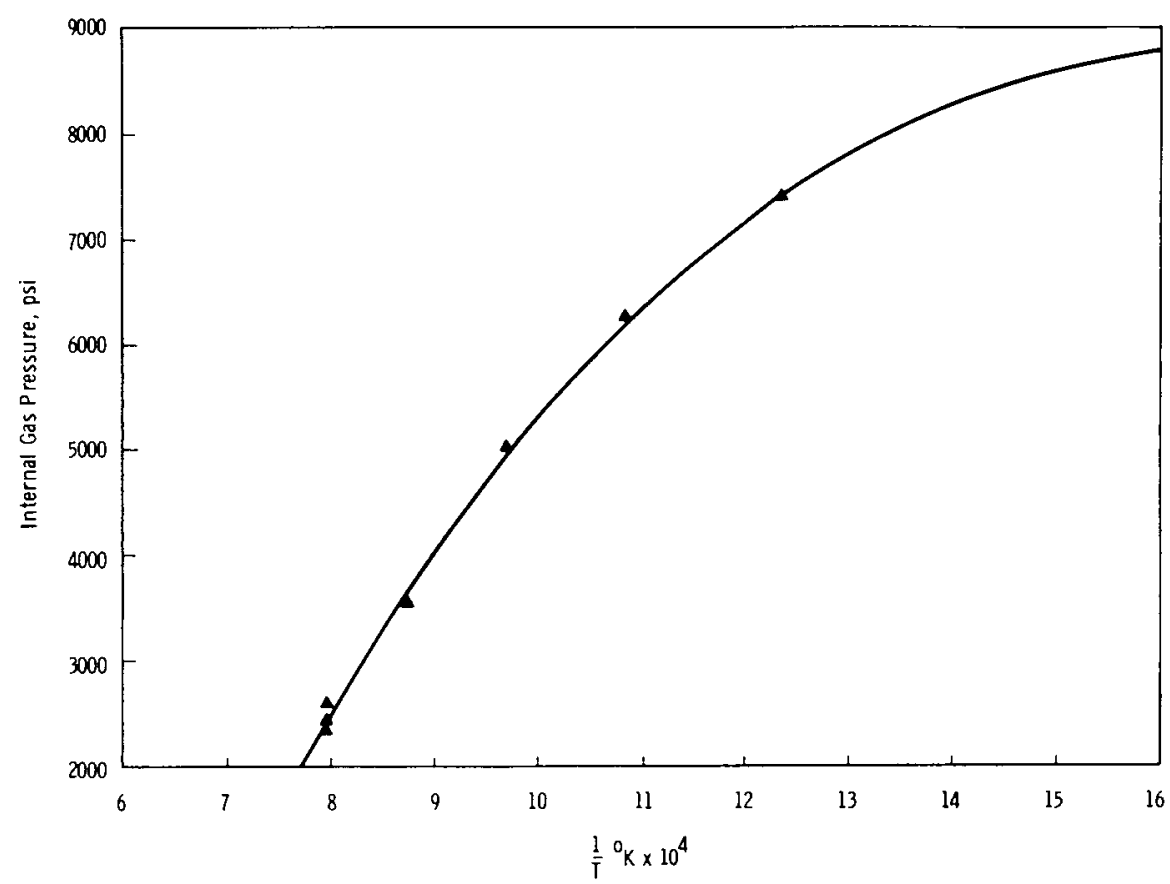

Neg $0692361-16$

EIGURE 12.10. E Lot Burst Data 1000-1800 ${ }^{\circ} \mathrm{F} \mathrm{MiZl}$ Annealed 304 Stainless steel

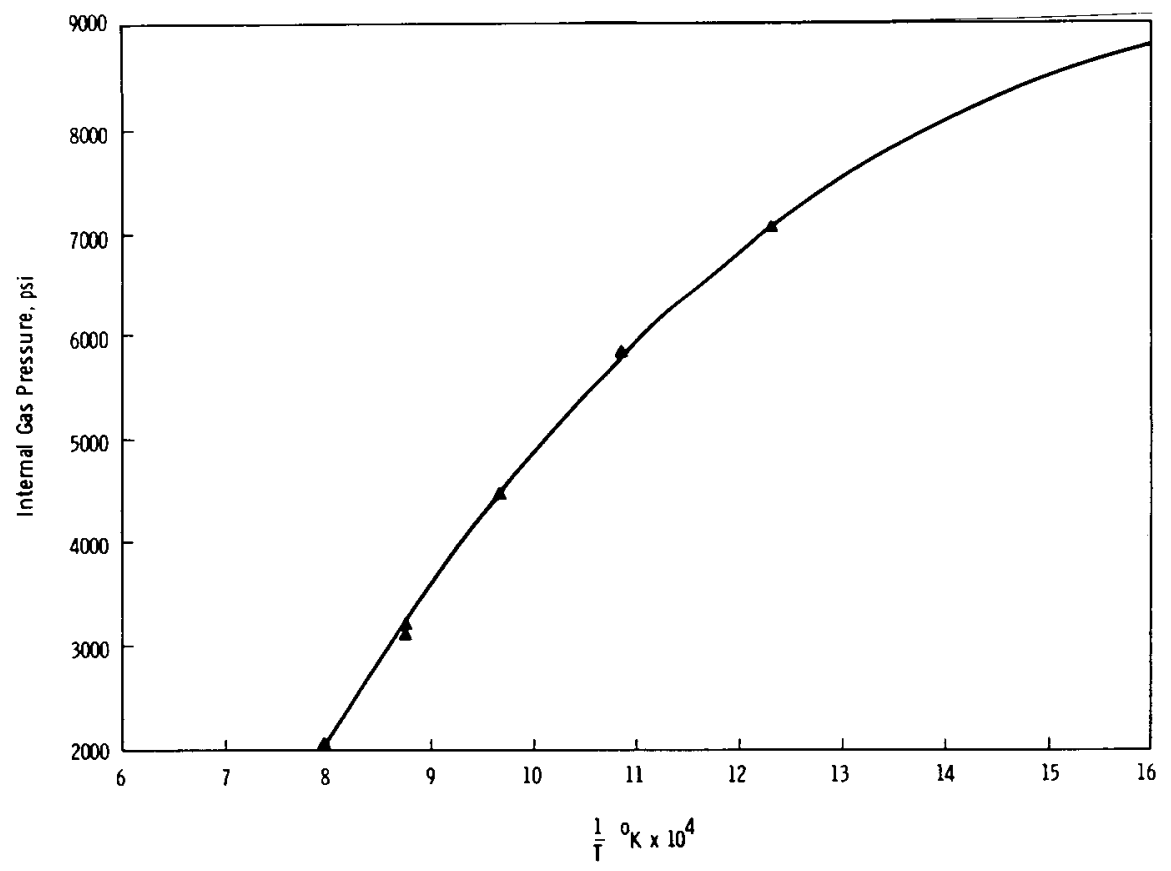

Neg $0692361-12$

FIGURE 12.11. F Lot Burst Data 1000-1800 ${ }^{\circ}$ Mill Annealed 304 Stainless Steel 
BNWL -1144

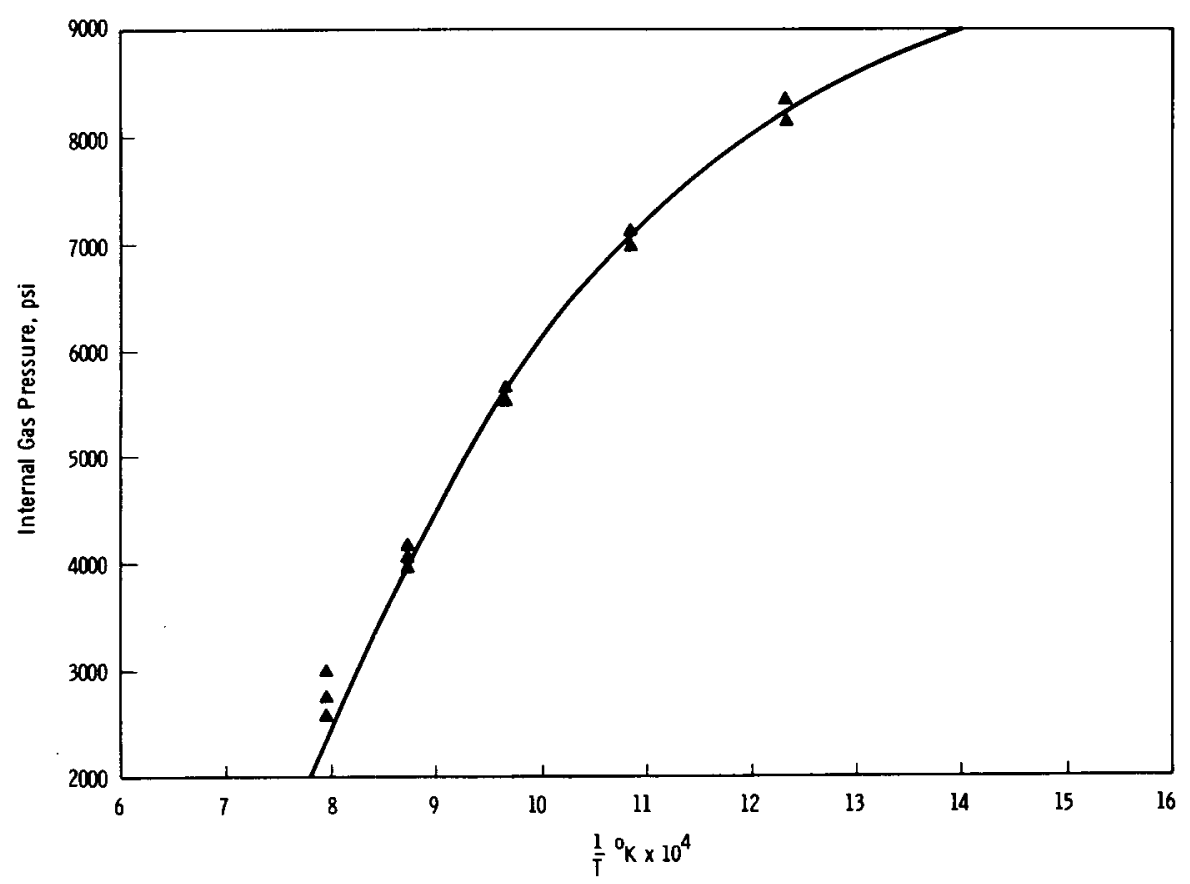

Neg $0692361-15$

FIGURE 12.12. G Lot Burst Data 1000-1800 ${ }^{\circ} \mathrm{F}$ MiZZ Annealed 316 Stainless Steel

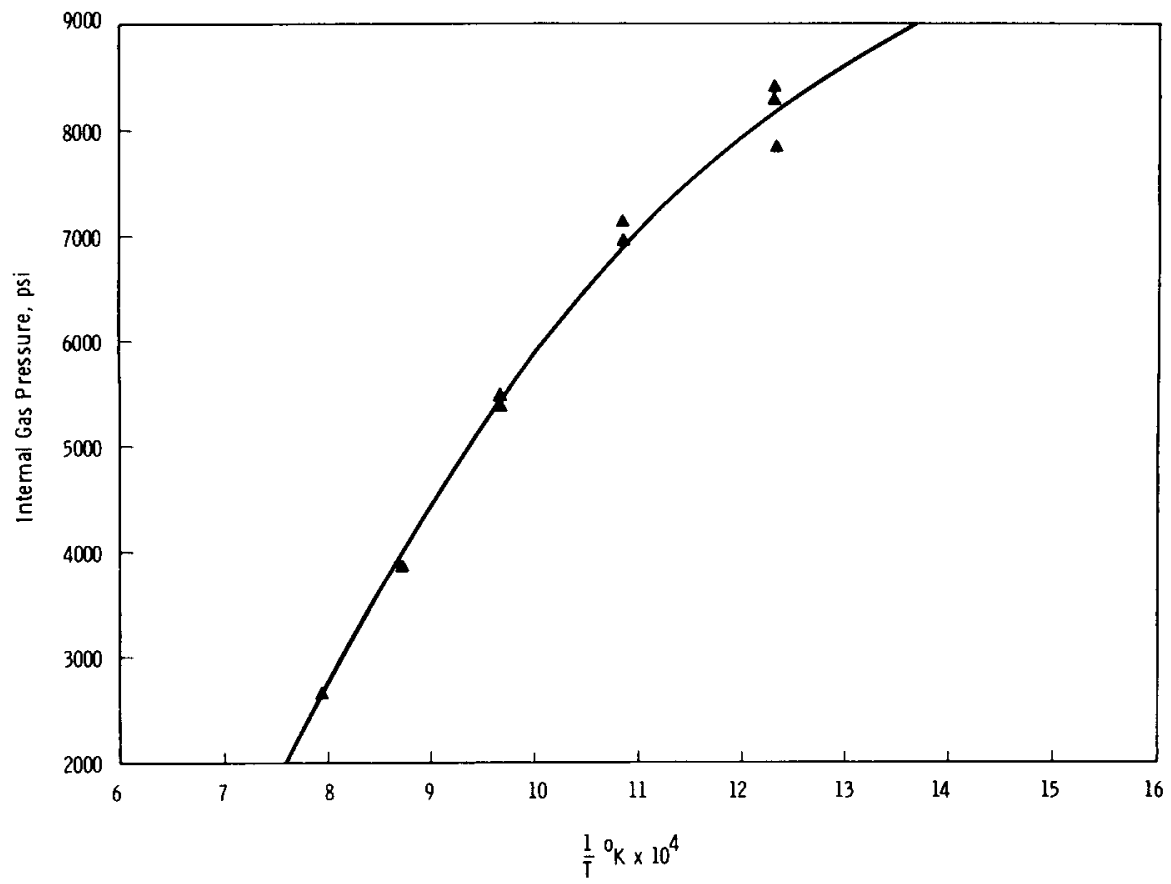

Neg $0692361-13$

FIGURE 12.13. H Lot Burst Data 1000-1800 ${ }^{\circ} \mathrm{F}$ MiZl Annealed 316 Stainless Steel 
BNWL -1144

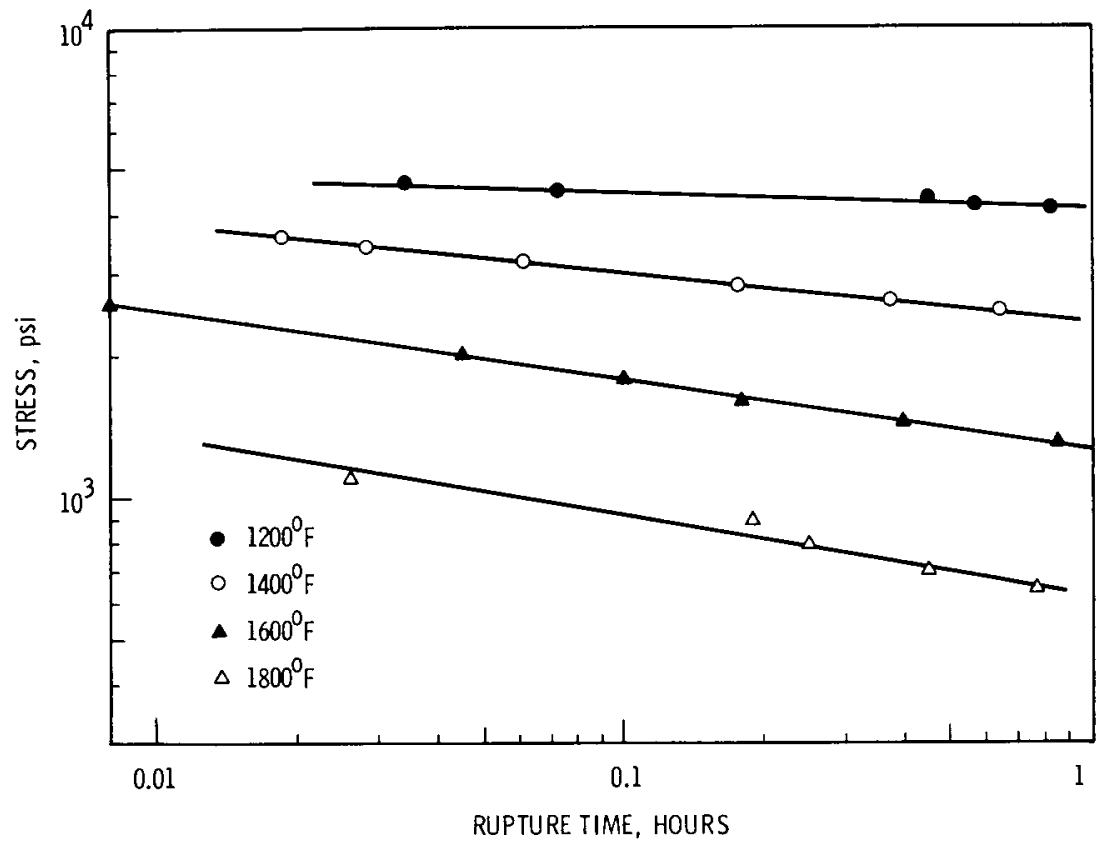

Neg $0692361-14$

FIGURE 12.14. Short Term Stress Rupture G Lot Tubing Mill Annealed 316 stainless Steel

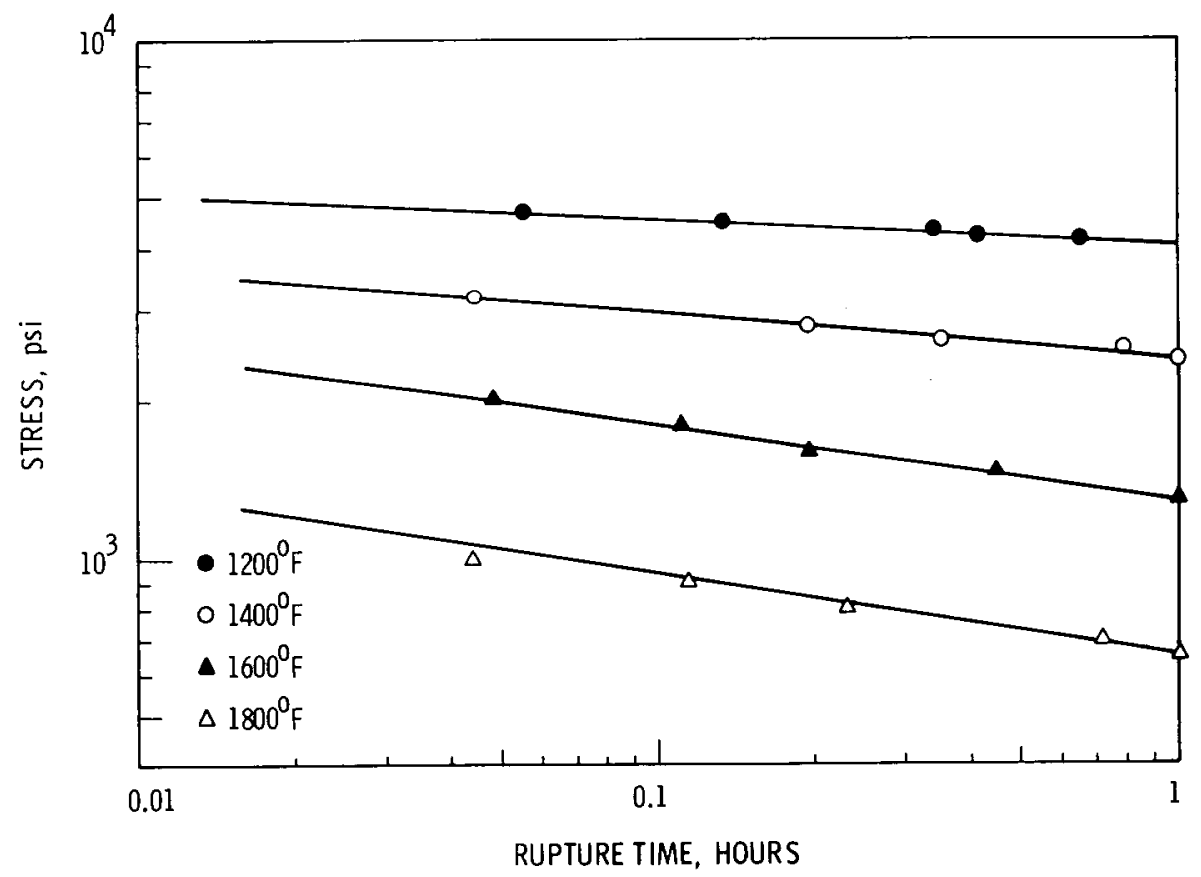

Neg $0692361-9$

FIGURE 12.15. Short Term Stress Rupture H Lot Tubing Mizl Annealed 316 Stainless Steel 
BNWL -1144

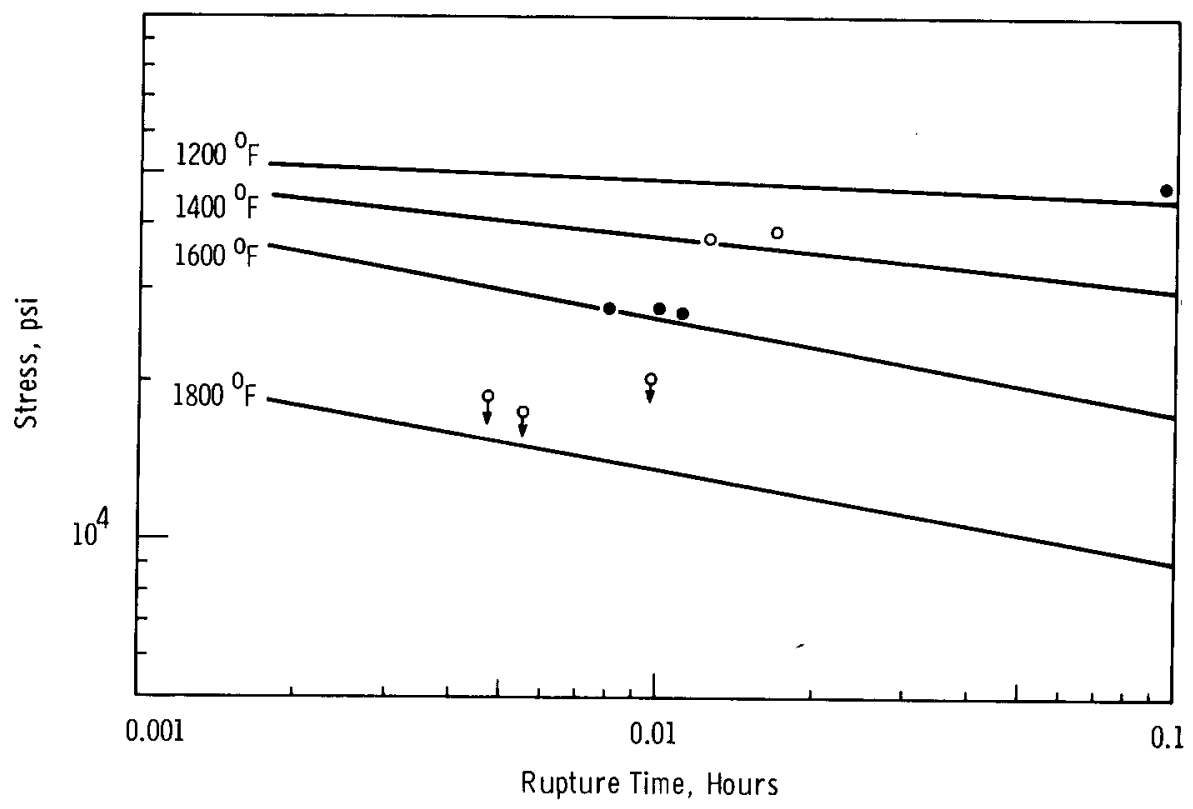

Neg $0692361-6$

FIGURE 12.16. Comparison of Burst and Short Term Stress Rupture Data for G Lot Tubing - Mill Annealed 316 stainzess Steel

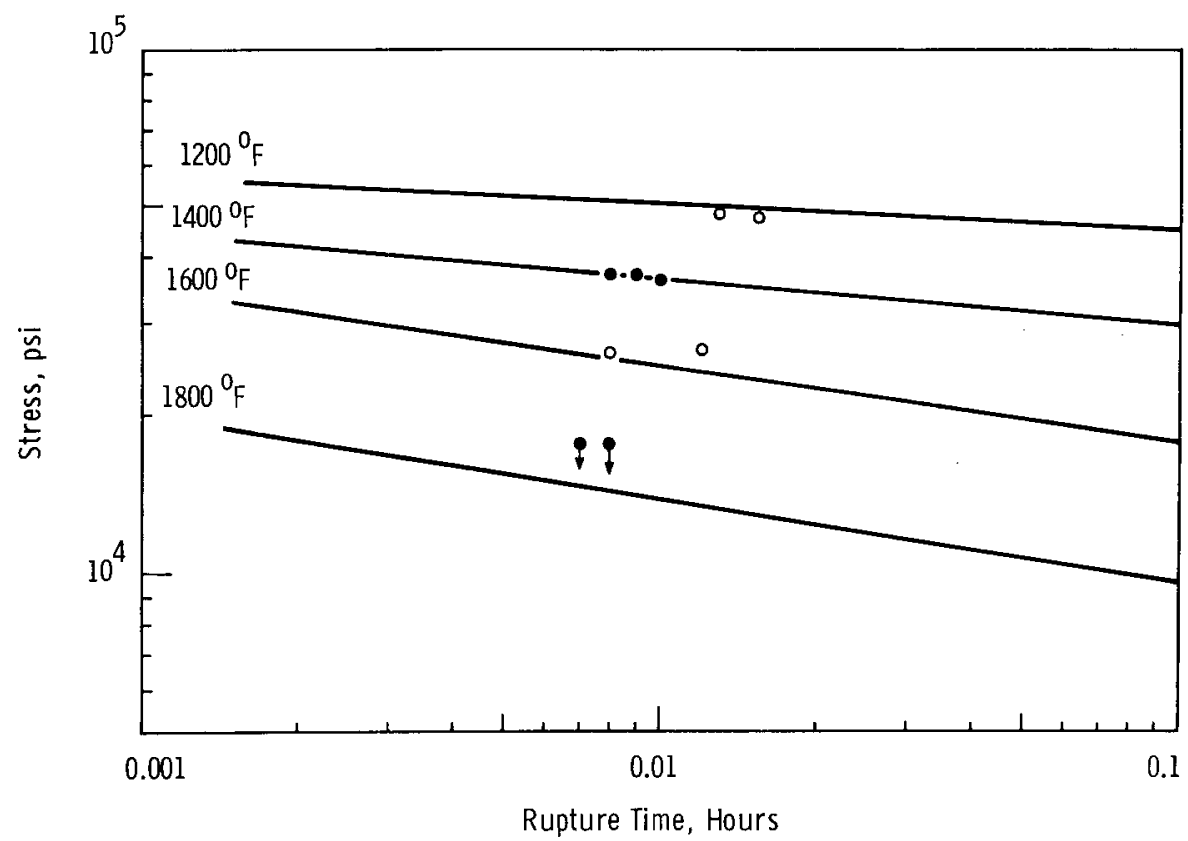

Neg $0692361-10$

FIGURE 12.17. Comparision of Burst and Short Term Stress Rupture Data for $H$ Lot Tubing - Mill Annealed 316 Stainzess Steel 
BNWL -1144

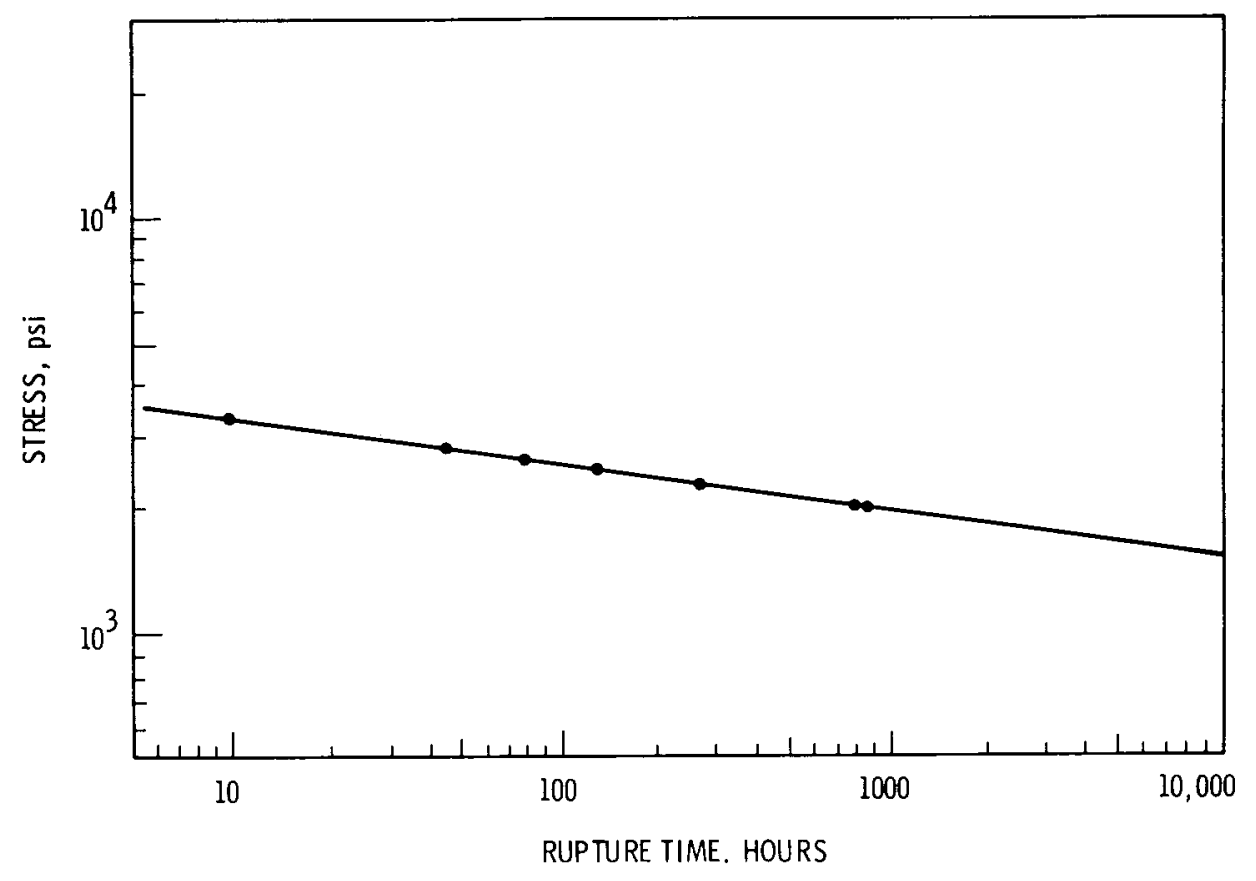

Neg $0692361-2$

FIGURE 12.18. Stress Rupture $1200^{\circ} \mathrm{F}$ E Lot Tubing Milz Annealed 304 Stainless Steel

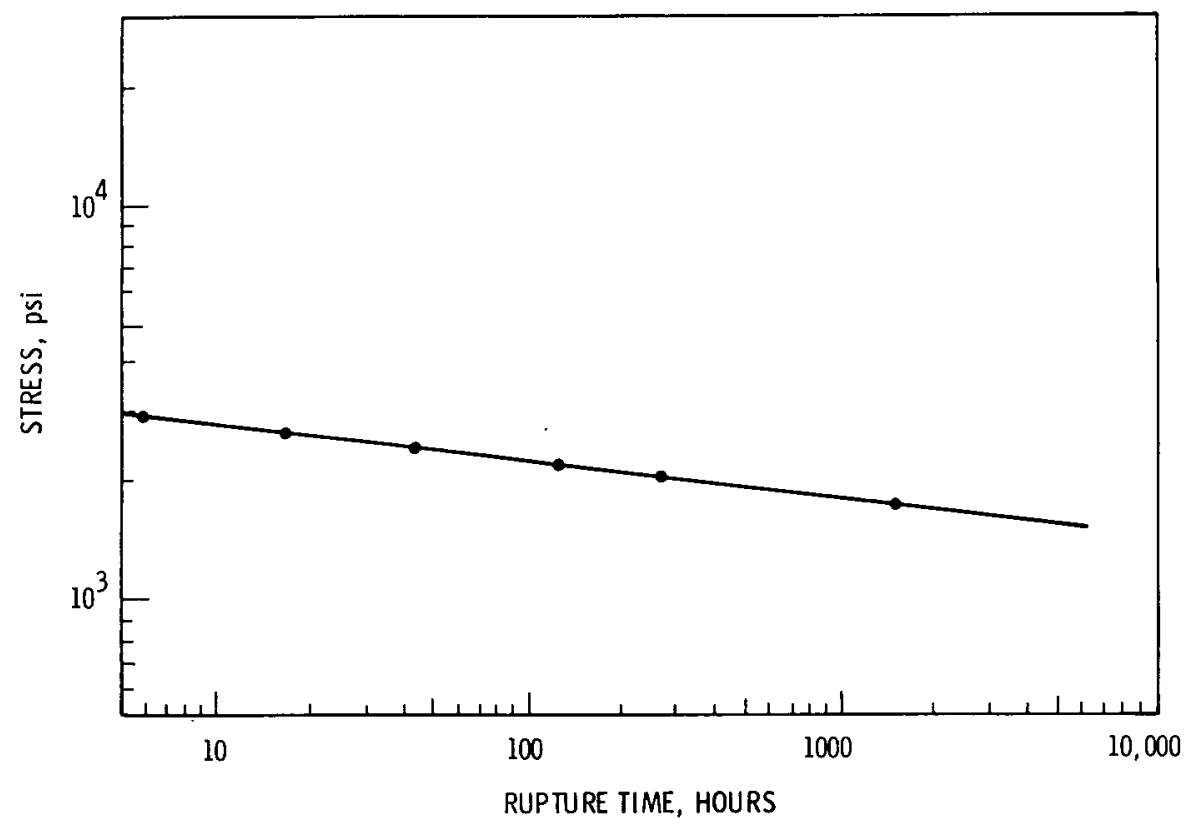

Neg $0692361-11$

FIGURE 12.19. Stress Rupture $1200^{\circ} \mathrm{F}$ F Lot Tubing Mizl Annealed 304 Stainless Steel 
BNWL -1144
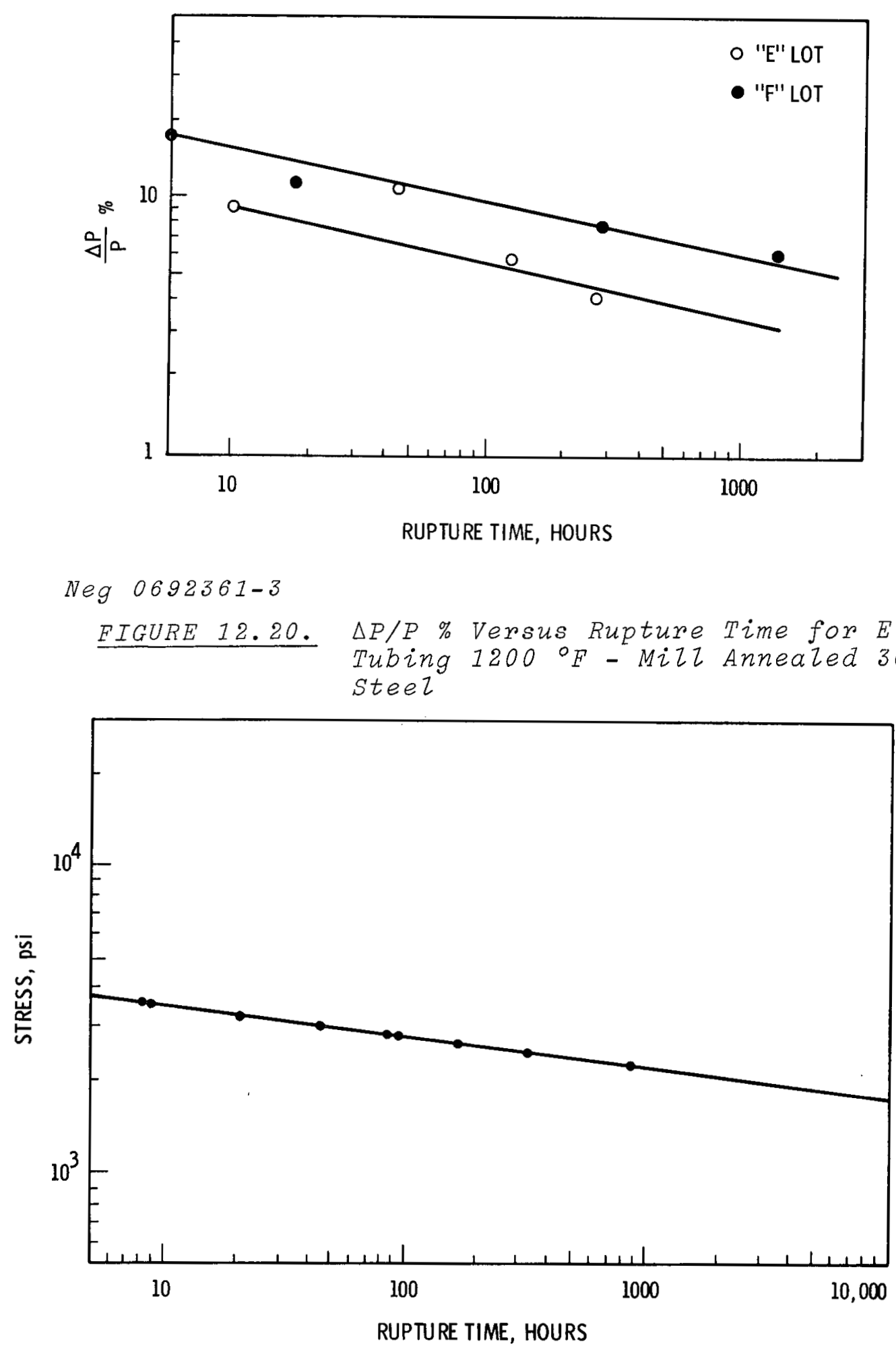

Neg $0692361-7$

FIGURE 12.21. Stress Rupture $1200^{\circ} \mathrm{F}$ G Lot Tubing Mill Annealed 316 stainless steel 
RNWL -1144

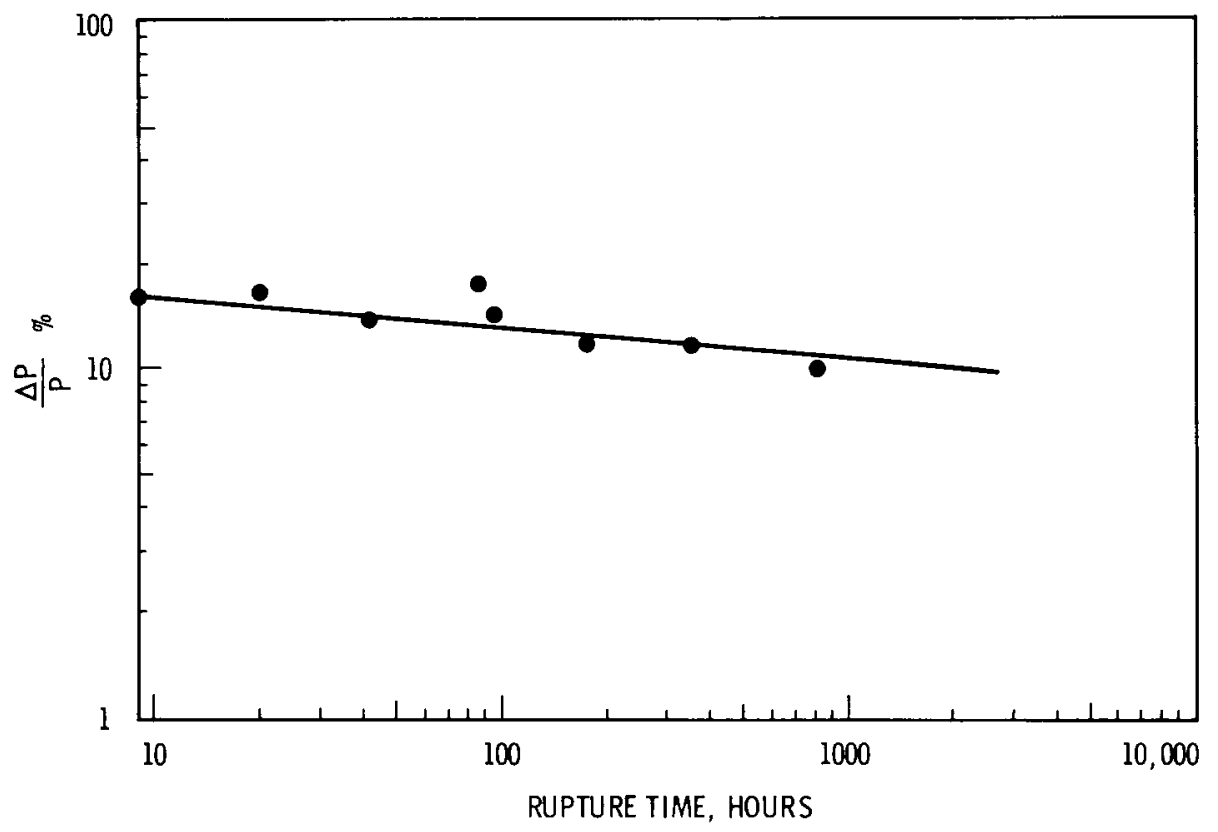

Neg $0692361-8$

FIGURE 12.22. $\triangle P / P$ \% Versus Rupture Time for G Lot Tubing $1200^{\circ} \mathrm{F}$ - Milz Annealed 316 stainless steel

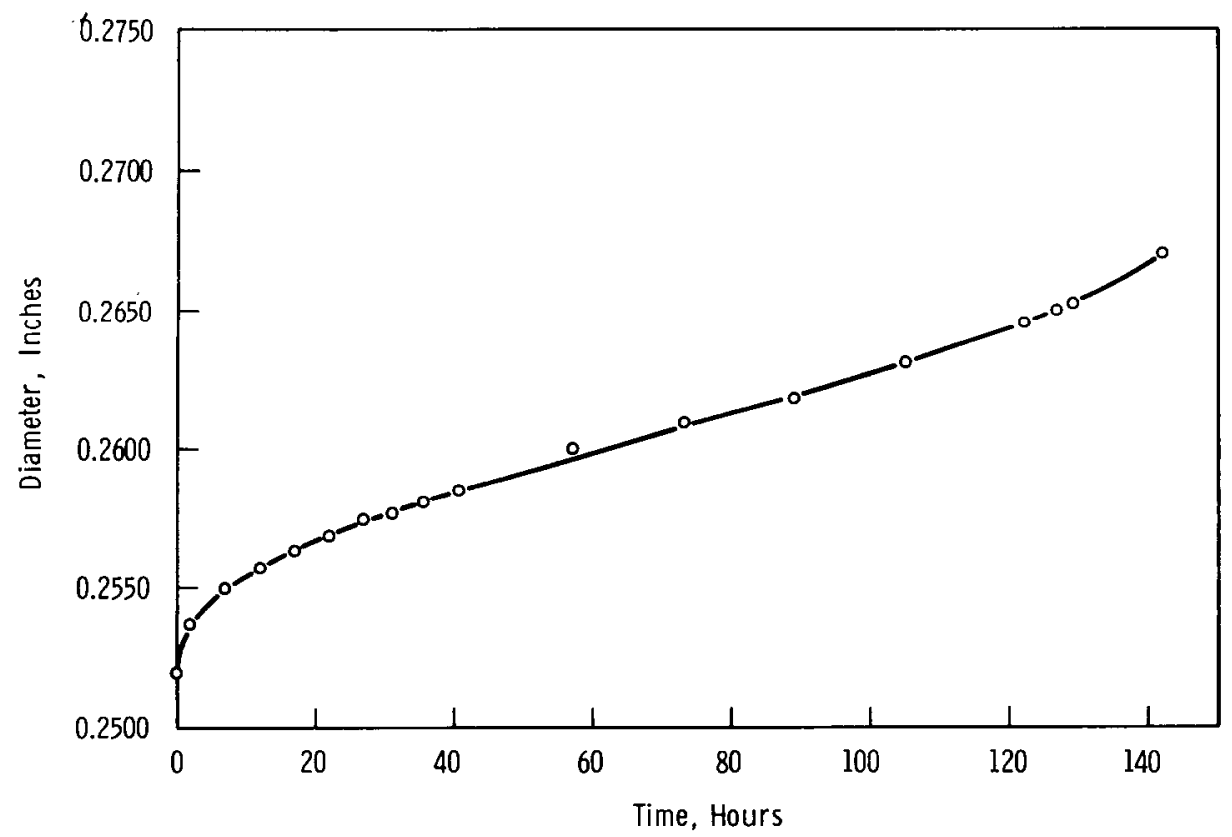

Neg $0692361-5$

FIGURE 12.23. Biaxial Creep - Specimen E-1 $1200^{\circ} \mathrm{F}$ omax $=26,850$ psi, Tubing Lot $E$, Mizz Annealed 304 Stainless Steel. 
strain every $1 / 4$ inch along the specimen. The minimum creeprates for these tests are given in Table 12.19 and the creep curves are presented in Figures 12.23-26. The effects of grain size and composition cannot be unambiguously accounted for in these tests; however, if one assumes that the relationship between interstitial content and creep-rate given by stone (17) holds and that rupture 1 ife is proportional to minimum creeprate, then the rupture life of the two lot $F$ tests would increase from 24 to $30 \mathrm{hr}$ and 84 to $105 \mathrm{hr}$ at an interstitial concentration equivalent to $\mathrm{E}$ lot.

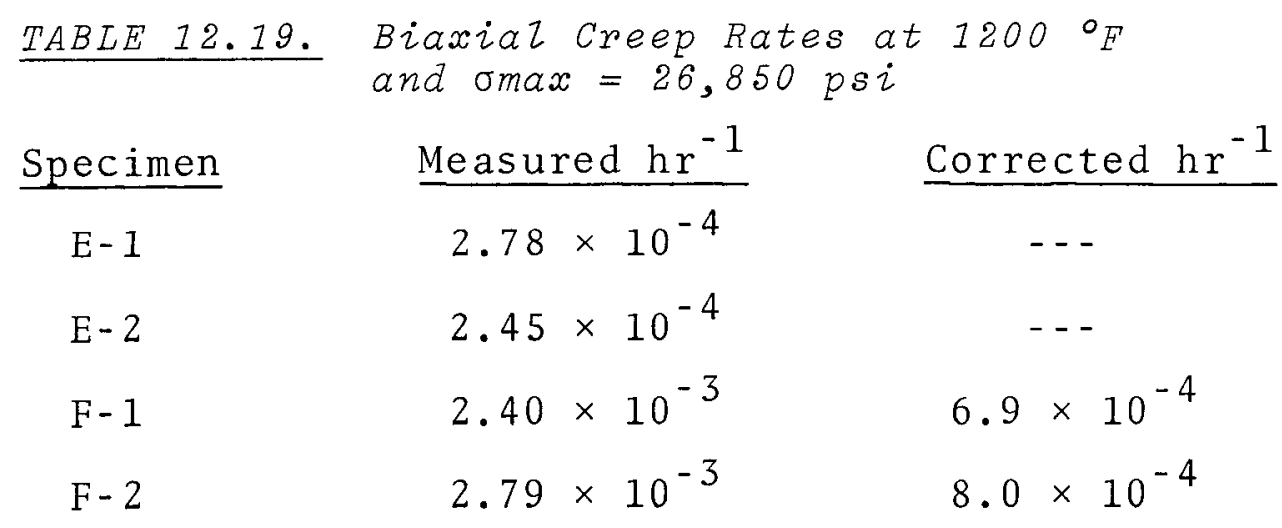

The remaining differences in rupture-1ife should be attributed to grain size differences in the absence of side effects such as heat treatment or fabrication variables. Garofalo's equation (20) can be used to estimate the grain size that gives minimum creep rates for 304 stainless steel. This analysis indicates that a grain size of ASTM 7 is optimum for creep resistance.

The biaxial creep curves on lot $\mathrm{F}$ specimens, Figures 12.25 and 26, are shown as two curves. In both tests, the upper curve, dashed line, represents the creep of a localized bulge that appeared near the top of each specimen. Specimen F-1, Figure 12.26, failed in the bulged area, whereas specimen F-2, Figure 12.25, did not fail in the bulge. Close examination of the diametrical measurement throughout the test shows 
BNWL- 1144

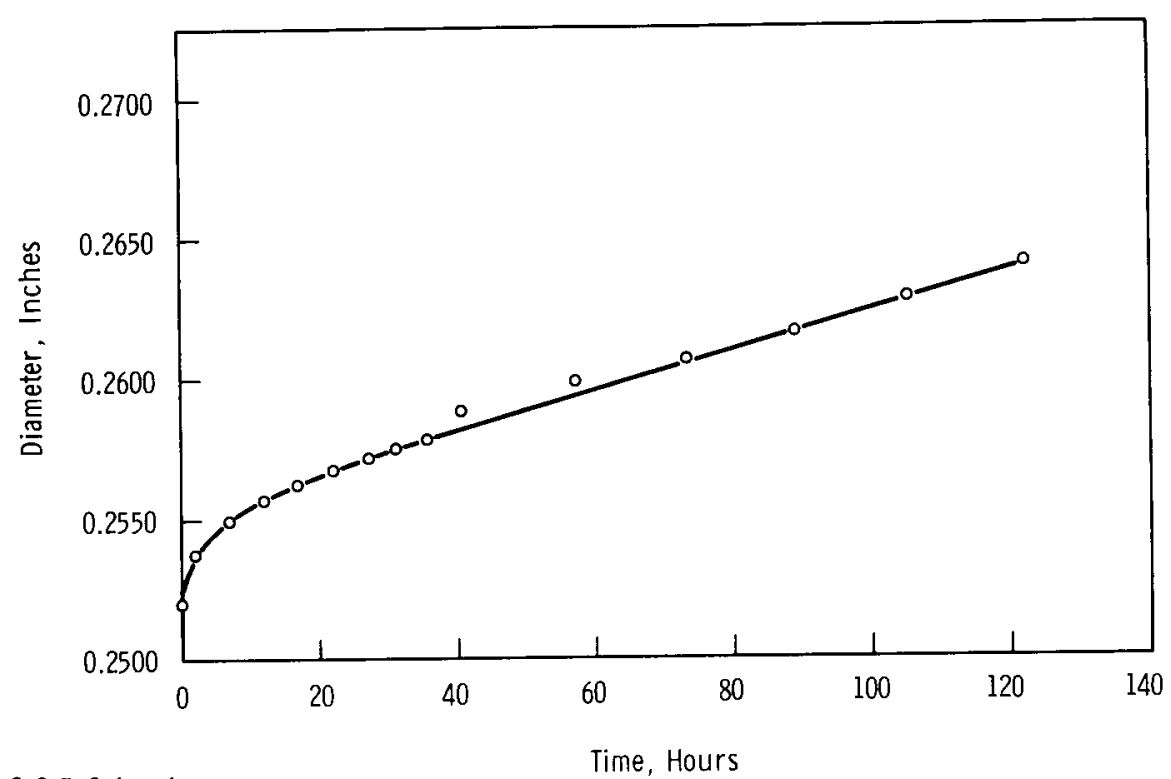

Neg $0692361-4$

FIGURE 12.24. Biaxial Creep - Specimen E-2 $1200^{\circ} \mathrm{F}$ omax = 26,850 psi, Tubing Lot $E$, Milz Annealed 304 Stainzess steel

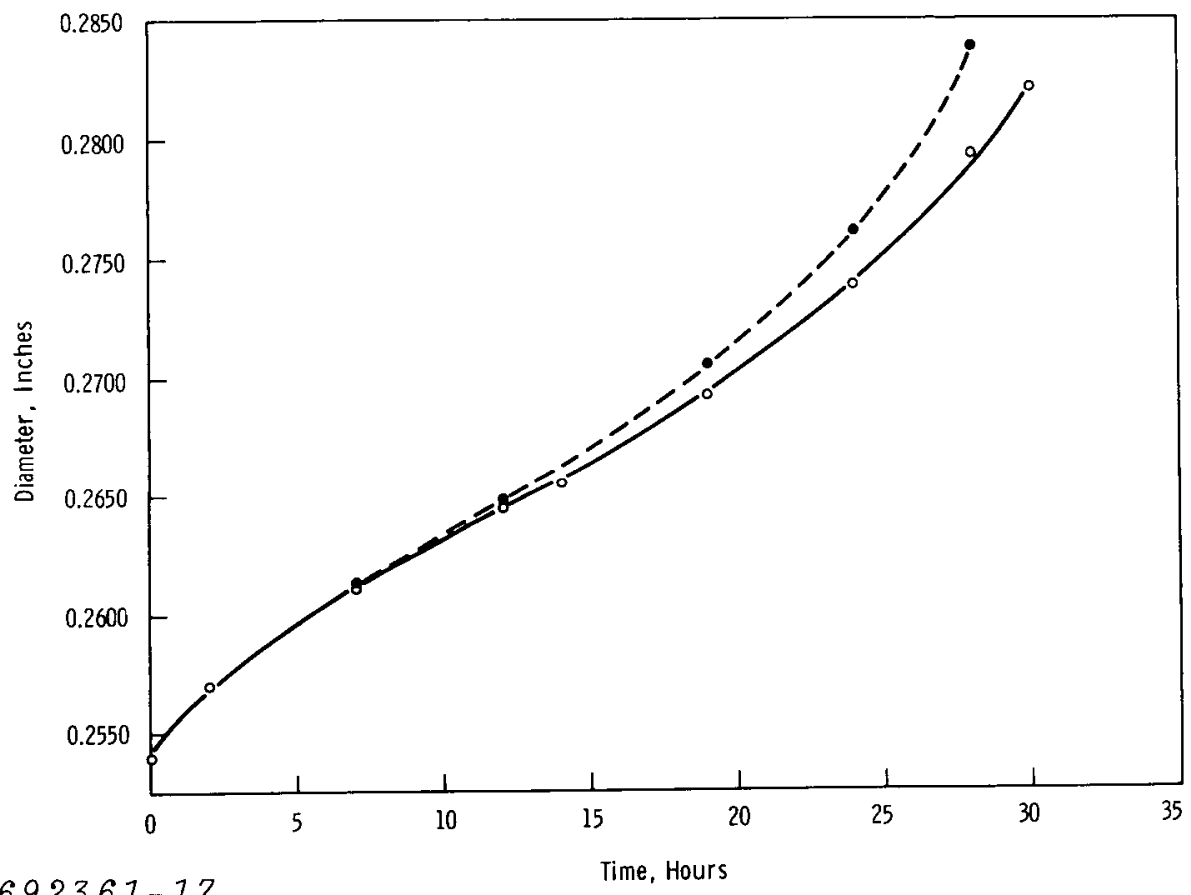

Neg $0692361-17$

FIGURE 12.25. Biaxial Creep - Specimen F-1 $1200^{\circ} \mathrm{F}$ omax = 26,850 psi, Tubing Lot F, Mill Annealed 304 stainzess steel 


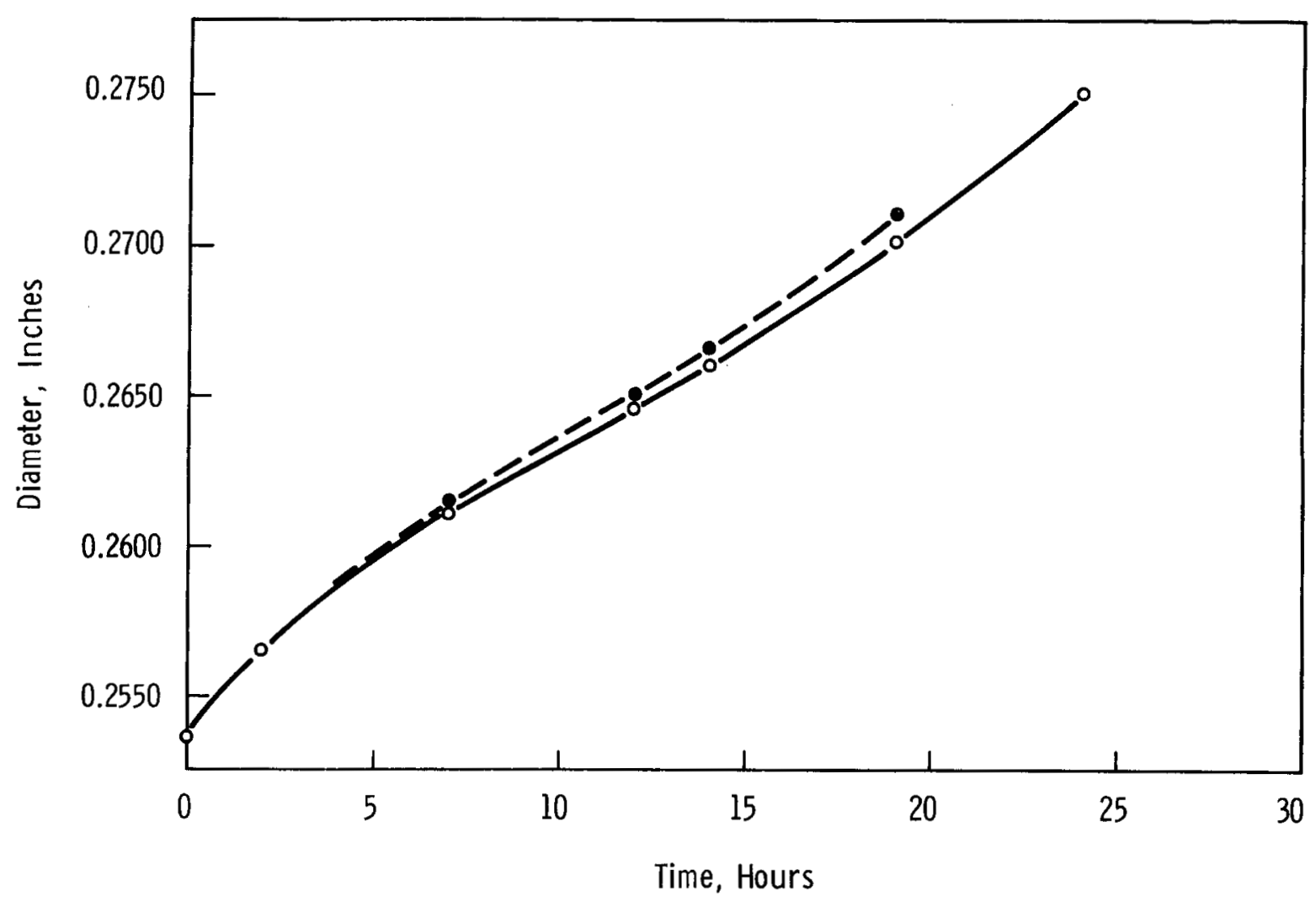

Neg $0692361-1$

FIGURE 12.26. Biaxial Creep - Specimen F-2 $1200^{\circ} F$ omax $=$ 26,850 psi, Tubing Lot F, Mill Annealed 304 stainless steel

the failed region of F-2 to be slightly constricted by approximately $0.0005 \mathrm{in.}$ Such a restricted area did not appear on the F-I specimen. In order to explain this anomalous behavior, the two $F$ specimens are being subjected to optical metallography.

Test E-2 was terminated before failure. Inspection of the specimen after $122 \mathrm{hr}$ revealed a crack (Figure 12.27) which would have resulted in failure had the test been continued. 


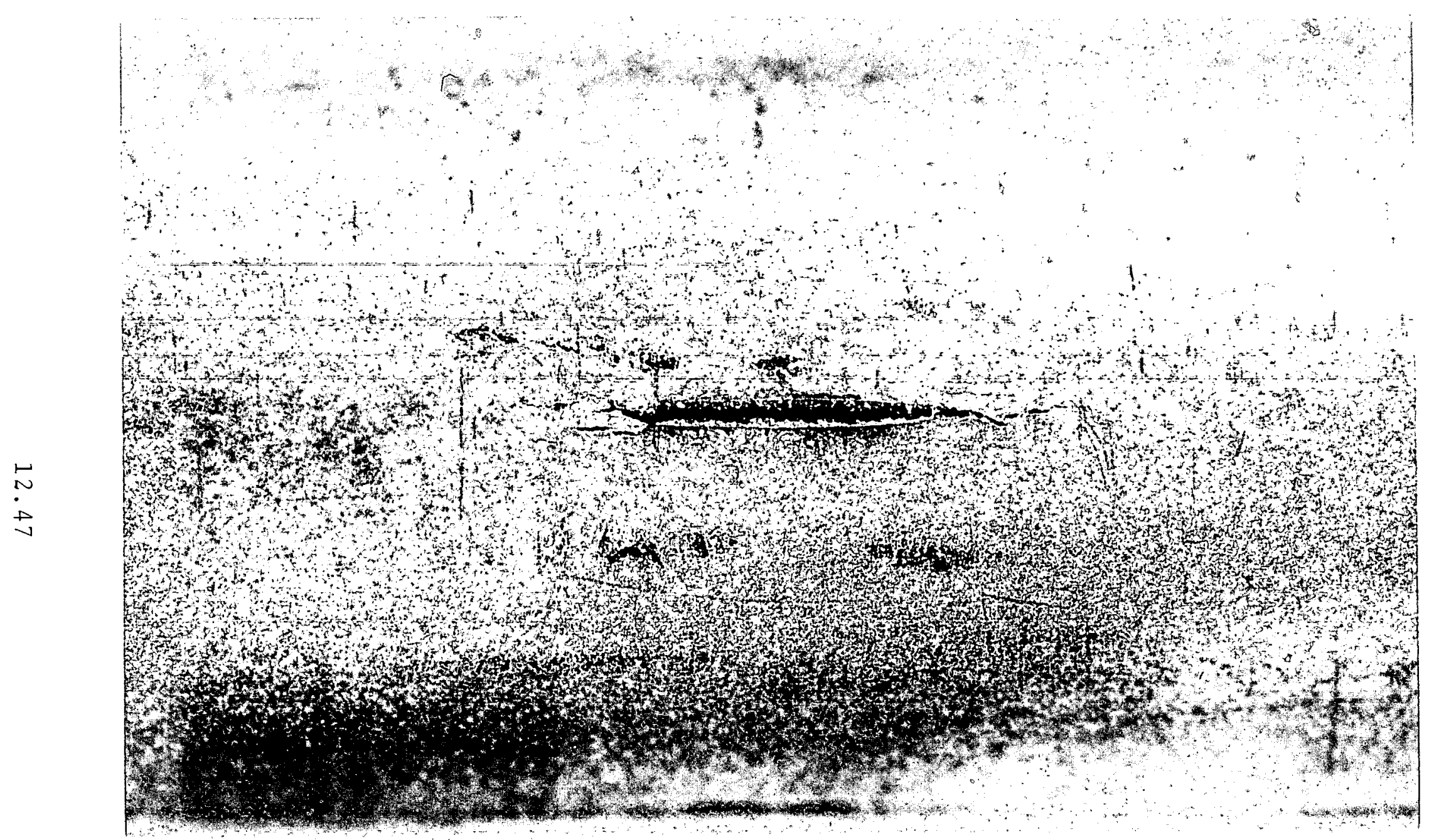

Neg 469635

FIGURE 12.27. Macrograph of Crack in Biaxial Creep - Specimen E-2 $12000^{\circ}$ omax = 26,850 for $122 h r$ 
Uniaxial Creep-Rupture Studies - A. J. Love11

The objectives of this program are to evaluate the effects of fast neutron irradiation and environment on the pre- and postirradiation uniaxial creep-rupture properties of candidate vessel and core structural materials for LMFBR and to establish the usable materials limits to assure their safe and reliable performance.

Tests are continuing on specimens from the program heat of AISI 304 stainless steel in the solution-treated, unirradiated condition and after irradiation in the static sodium environment of the EBR-II MK-B-X022 subassembly. The 1000 and $1100^{\circ} \mathrm{F}$ test results on the solution-treated controls show the same poor creep-rupture properties observed earlier in the tests at $1200^{\circ} \mathrm{F}$. That is, the creep rates are high and the rupture lives are short compared to standard published values for this a1loy. This non-typical data points out the necessity, in an irradiation effects study, to compare postirradiation test data with that from controls.

The results of 1000 and $1100^{\circ} \mathrm{F}$ creep-rupture tests on this material after irradiation are tabulated in Table 12.20. Stress versus rupture-1ife plots for control and irradiated specimens tested at 1000 and $1100^{\circ} \mathrm{F}$ are shown in Figure 12.28. The reduction in rupture-life due to irradiation is substantial. The comparison of the minimum creep-rates for the unirradiated solution-treated controls and the irradiated specimens are shown in Figure 12.29. There is a reduced creep-rate at $1100^{\circ} \mathrm{F}$ when the stress level is low for specimens irradiated at the highest fluence. A comparison of the creep curves of control and irradiated specimens produced from tests at $1100^{\circ} \mathrm{F}$ and 30,000 and $35,000 \mathrm{psi}$ are shown in Figures 12.30 and 12.31 respectively. These curves show that irradiation has affected both rupture-Iife and the first-and second-stage creep rates. The lowered creep-rates in stage one and stage two indicate 


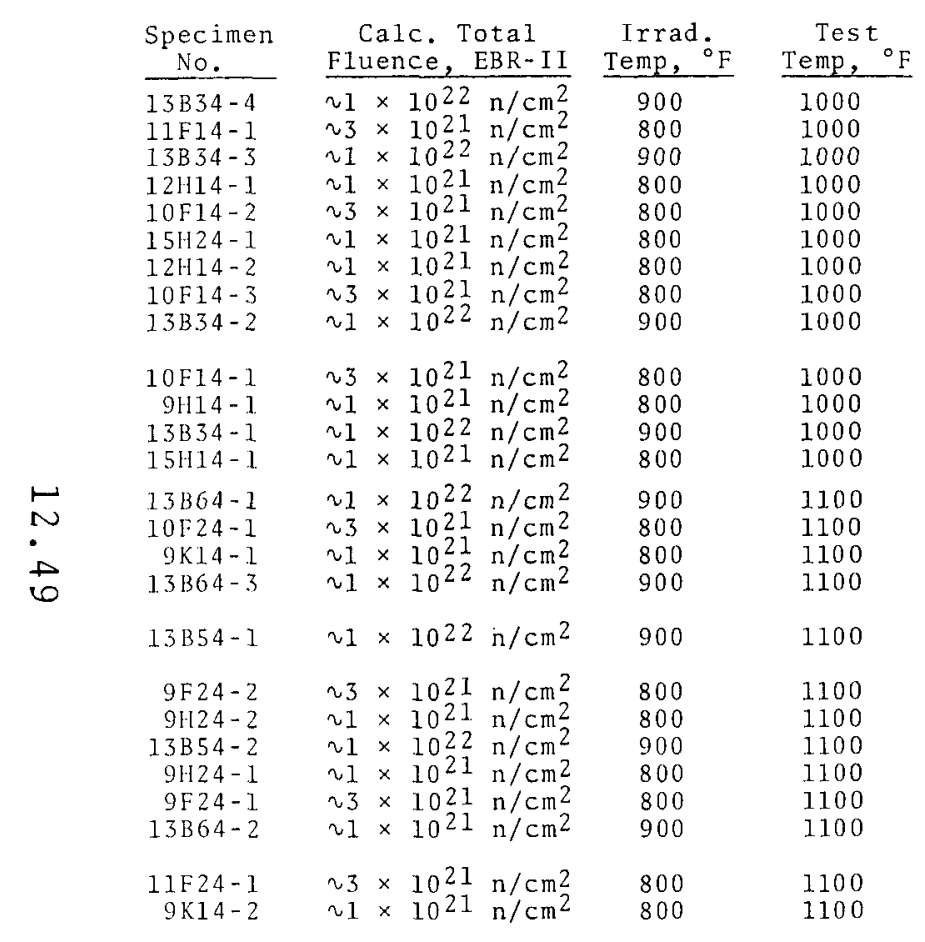

\begin{tabular}{|c|c|c|}
\hline $\begin{array}{c}\text { Stress, } \\
\text { psi }\end{array}$ & $\begin{array}{c}\text { Minimum } \\
\text { in } / \\
\end{array}$ & $\begin{array}{l}\text { Zreep-Rate, } \\
\text { in } / \mathrm{hr}\end{array}$ \\
\hline $\begin{array}{l}30,000 \\
30,000 \\
35,000 \\
35,000 \\
35,000 \\
35,000 \\
40,000 \\
40,000 \\
45,000\end{array}$ & $\begin{array}{l}0.00000345 \\
0.00000814 \\
0.0000322 \\
0.0000435 \\
0.0000336 \\
0.0000582 \\
0.000102 \\
0.000147 \\
0.00037\end{array}$ & $\begin{array}{l}(0.00000605) \\
(0.00000605) \\
(0.0000189) \\
(0.0000189) \\
(0.0000189) \\
(0.0000189) \\
(0.000113) \\
(0.000113)\end{array}$ \\
\hline $\begin{array}{l}45,000 \\
45,000 \\
50,000 \\
50,000\end{array}$ & $\begin{array}{l}0.000456 \\
0.000258 \\
0.001 .12 \\
0.00074\end{array}$ & $\begin{array}{l}(\text { Av. of } 4 \\
0.000359) \\
(0.000942) \\
(0.000942)\end{array}$ \\
\hline $\begin{array}{l}25,000 \\
25,000 \\
25,000 \\
28,000\end{array}$ & $\begin{array}{l}0.0000694 \\
0.0000855 \\
0.000089\end{array}$ & $\begin{array}{c}(0.000117) \\
(0.000117) \\
(0.0001117) \\
(4 \vee .0 \text { of } 3 \\
0.000385)\end{array}$ \\
\hline 30,000 & 0.00019 & $\begin{array}{l}\text { (Av. of } 2 \\
0.000475)\end{array}$ \\
\hline $\begin{array}{l}30,000 \\
35,000 \\
35,000 \\
35,000 \\
40,000\end{array}$ & $\begin{array}{l}0.000502 \\
0.001245 \\
0.00254 \\
0.00312 \\
0.0066\end{array}$ & $\begin{array}{l}(0.00306) \\
(0.00306) \\
(0.00306\end{array}$ \\
\hline $\begin{array}{l}40,000 \\
40,000\end{array}$ & $\begin{array}{l}0.00507 \\
0.0121\end{array}$ & $\begin{array}{l}(A v . \text { of } 2 \\
0.00734)^{2}\end{array}$ \\
\hline
\end{tabular}

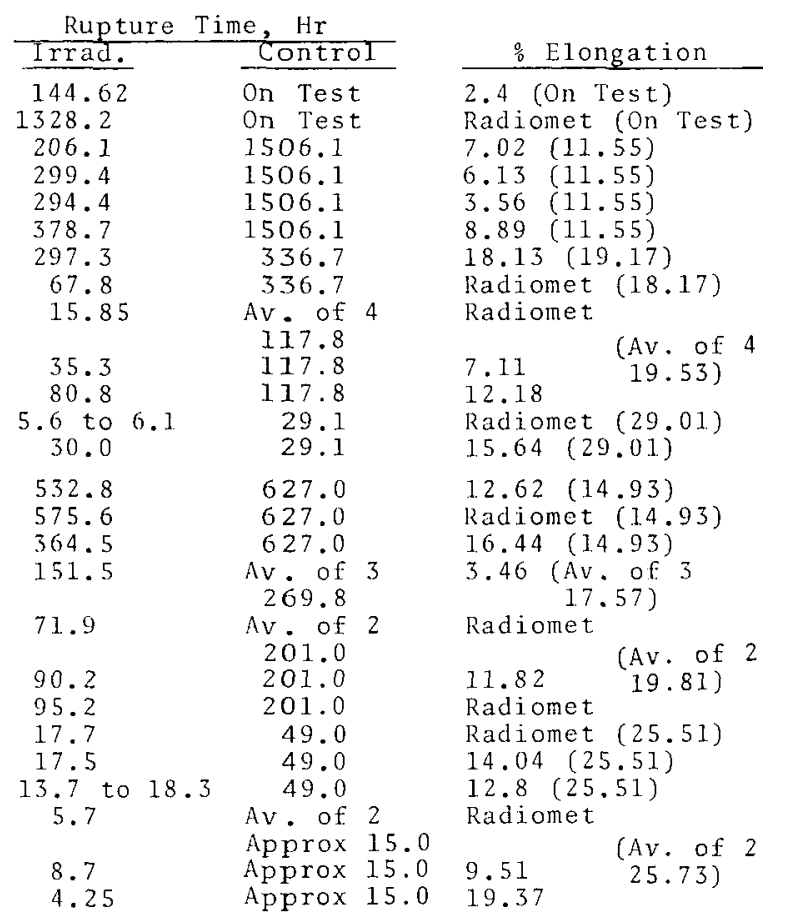

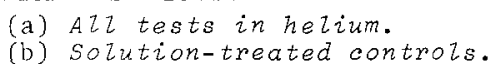




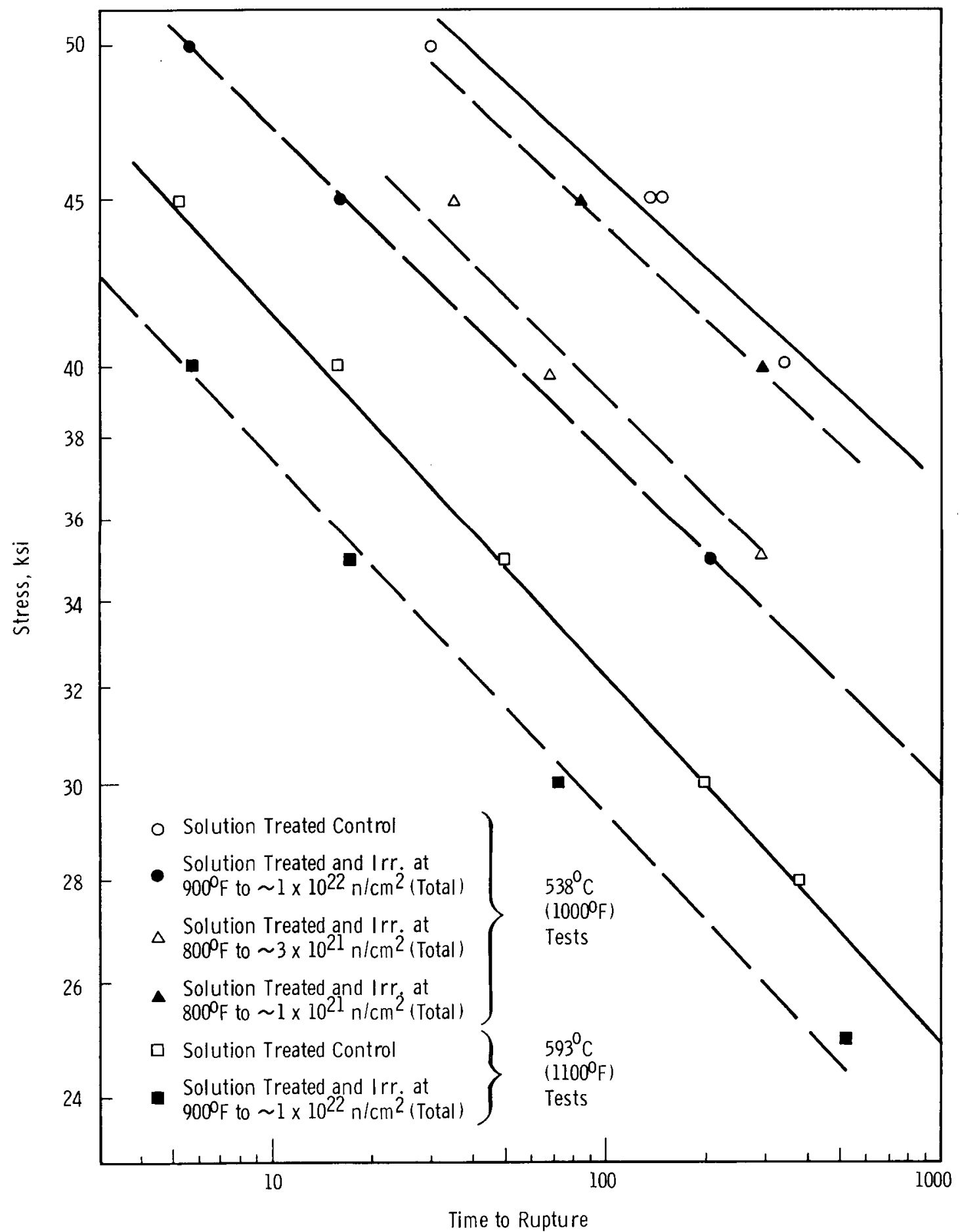

Neg 0691009-2

FIGURE 12.28. Effect of Irradiation on the Postirradiation Creep-Rupture Properties of AISI Type 304 Stainzess Steel 


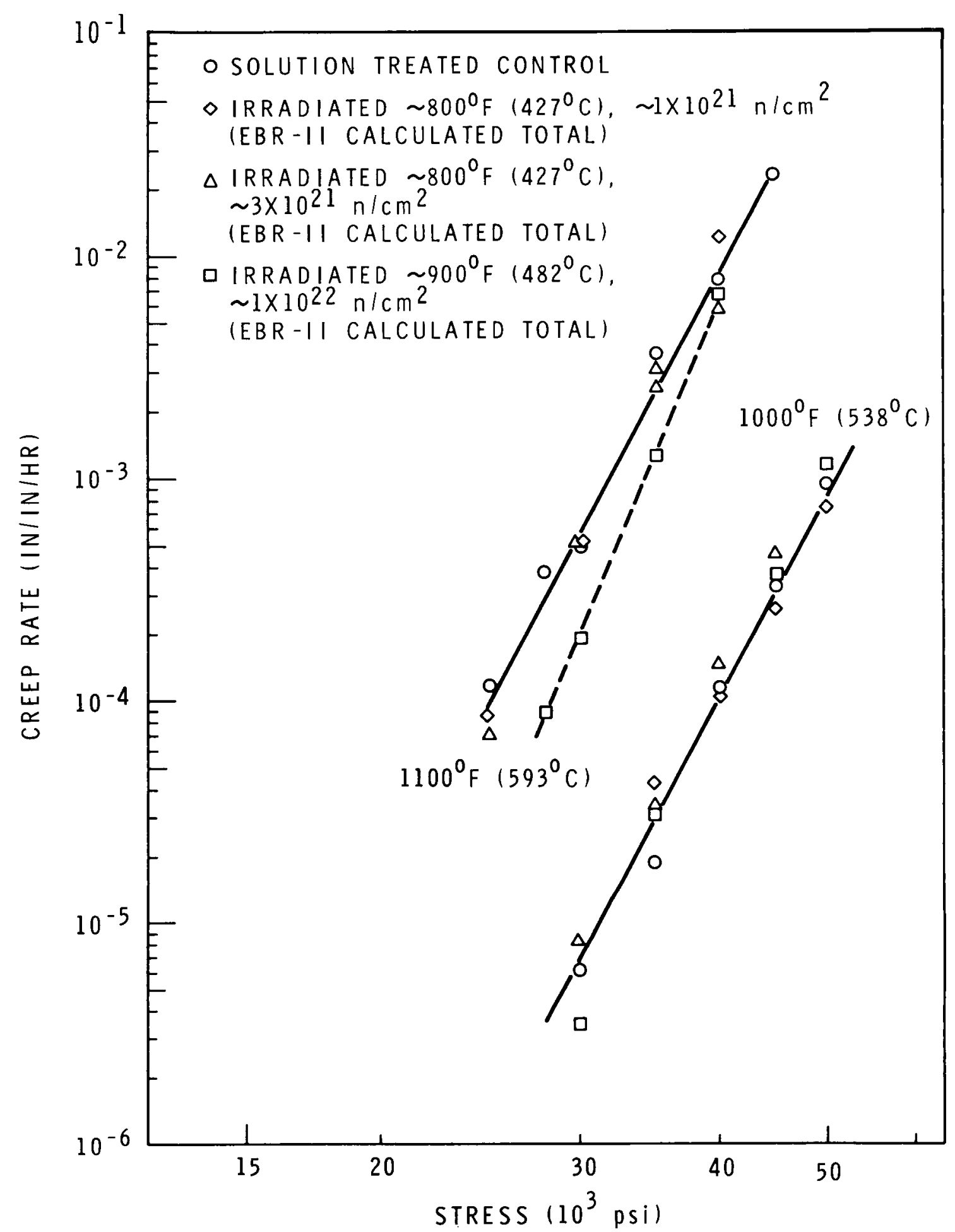

Neg $0692296-2$

FIGURE 12.29. Effects of Irradiation on the Postirradiation Creep Rate of AISI Type 304 Stainless Steel 
BNWL - 1144

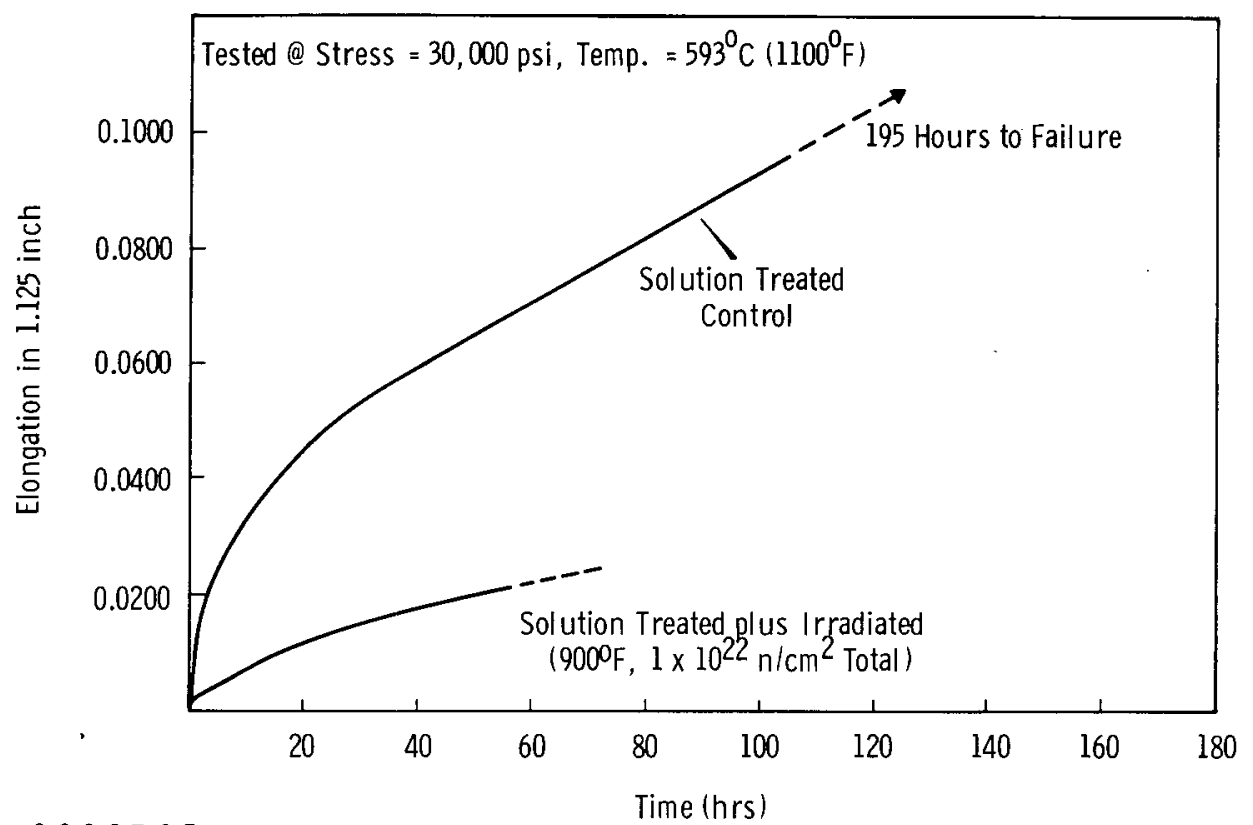

Neg $0690705-1$

Time (hrs

FIGURE 12.30. Effect of Irradiation on the Postirradiation Creep Properties of AISI Type 304 stainless steel

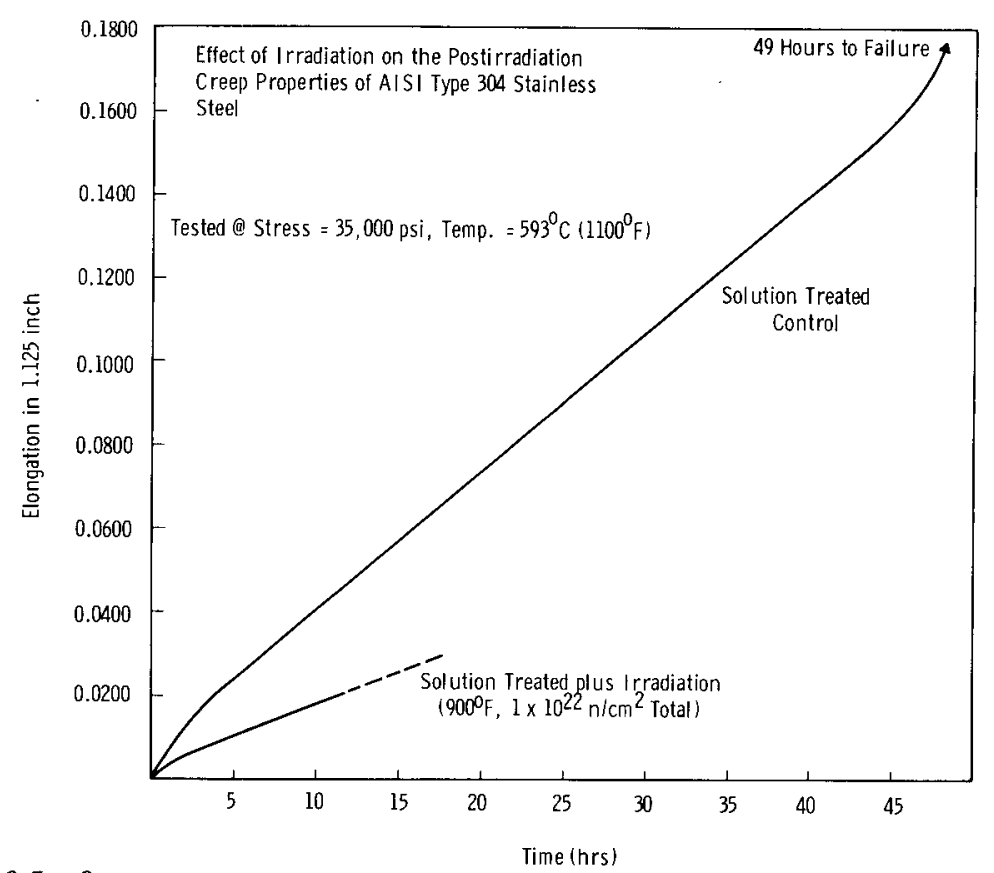

Neg $0690705-2$

FIGURE 12.31. Effect of Irradiation on the Postirradiation Creep Properties of AISI Type 304 Stainless Steel 
the presence of an irradiation-induced defect that is impeding creep. The final measurements of all failed specimens are not available, but the creep elongations, as indicated by the data shown in Figures 12.30 and 12.31 , are rather 1 ow.

Creep-rupture data obtained on 316 specimens irradiated in the first EBR-II Mark B-7 subassembly are tabulated in Table 12.21. The stress versus time-to-rupture curves for test temperatures of $1000,1100,1200$, and $1400^{\circ} \mathrm{F}$ are shown in Figures $12.32,33,34$, and 35 . The effect of irradiation on the minimum creep-rates are shown in Figures 12.36 and 12.37 . Highfluence irradiation results in increased creep-rates for lowtemperature, high stress tests and decreased rates for hightemperature, $10 \mathrm{w}-\mathrm{stress}$ tests, particularly at $1200^{\circ} \mathrm{F}$. Creep curves from these two test conditions are shown in Figures 12.38 and 12.39 .

Biaxial Stress-Rupture Studies - R. W. Barker

The objective of this program is to determine the combined effects of environment and fast reactor irradiation on the biaxial stress-to-rupture properties of candidate fast reactor cladding a11oys.

Biaxial stress-rupture tests have been initiated on AISI Type 304 stainless steel irradiated to $\sim 0.8 \times 10^{22} \mathrm{n} / \mathrm{cm}^{2}$ $(E>0.1 \mathrm{MeV})$ in EBR-II. The specimens being tested are composed of segments of irradiated cladding $(0.208-i n$. diameter $\times 0.008-i n$. wa11) to which unirradiated fittings have been welded. $(21,22)$

Four tests on the irradiated cladding have been completed. The test temperature was $1200^{\circ} \mathrm{F}$ and the environment and pressurizing gas were argon. Specimens were stressed sufficiently to cause rupture in 0.1 to $1,000 \mathrm{hr}$ in unirradiated material. 


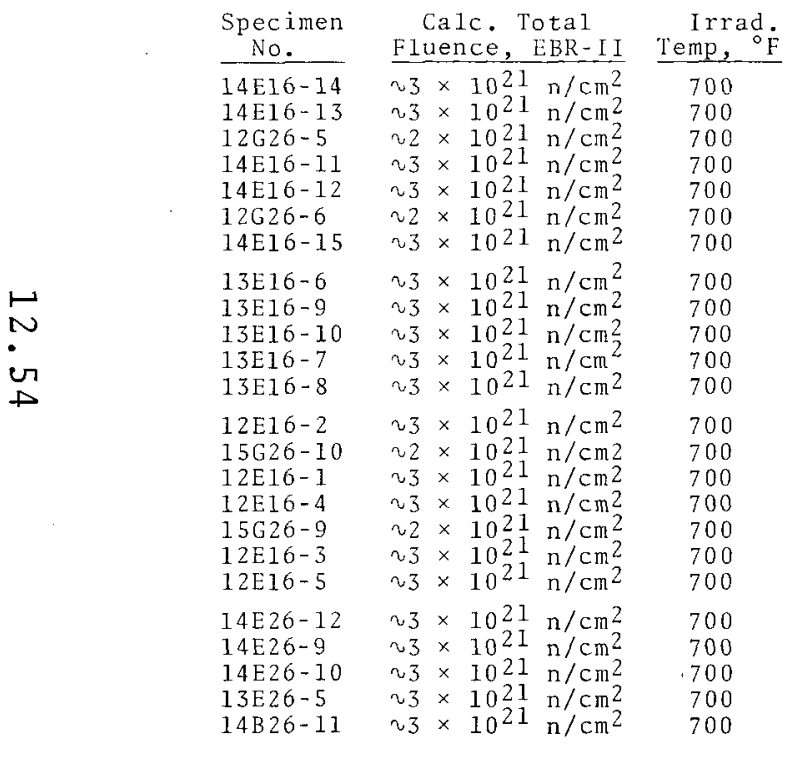

\begin{tabular}{c} 
Test \\
Temp, ${ }^{\circ} \mathrm{F}$ \\
\hline 1000 \\
1000 \\
1000 \\
1000 \\
1000 \\
1000 \\
1000 \\
1100 \\
1100 \\
1100 \\
1100 \\
1100 \\
1200 \\
1200 \\
1200 \\
1200 \\
1200 \\
1200 \\
1200 \\
1400 \\
1400 \\
1400 \\
1400 \\
1400
\end{tabular}

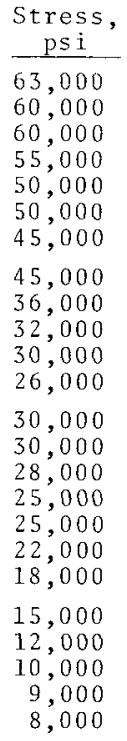

\begin{tabular}{ll}
\multicolumn{1}{c}{$\begin{array}{c}\text { Mininum } \\
\text { in } / \text { Creep-Rate }\end{array}$} \\
\hline 0.00037 & $(0.000949)$ \\
0.000507 & $(0.000329)$ \\
0.000307 & $(0.000329)$ \\
0.00027 & $(0.0000915)$ \\
0.0000385 & $(0.0000293)$ \\
0.000050 & $(0.0000293)$ \\
0.000011 & $(0.0000115)$ \\
0.0026 & $(0.00240)$ \\
0.00040 & $(0.0002667)$ \\
0.00012 & \\
0.000065 & $(0.000036)$ \\
0.000015 & $(0.0000052)$ \\
0.00125 & $(0.00239)$ \\
0.00299 & $(0.00239)$ \\
0.00178 & $(0.001049)$ \\
0.000425 & $(0.000631)$ \\
0.000415 & $(0.000631)$ \\
0.000136 & $(0.000169)$ \\
-- & $(0.00002107)$ \\
0.0036 & $(0.00453)$ \\
0.00084 & $(0.00115)$ \\
0.000255 & $(0.000293)$ \\
0.00018 & $(0.000184)$ \\
$0 n$ Test &
\end{tabular}

\begin{tabular}{rr}
\multicolumn{2}{r}{ Rupture Time, $h r$} \\
Irrad. & $\frac{\text { Control }}{6}$ \\
\hline 27.6 & 60 \\
104.6 & 106 \\
98.1 & 106 \\
120.2 & 263 \\
410.1 & 433 \\
$247-268$ & 433 \\
657.1 & 1032 \\
11.4 & 23 \\
56.4 & 236 \\
164.1 & 2800 \\
272.1 & 1600 \\
700.6 & 26000 \\
15.7 & 95 \\
7.0 & 95 \\
26.3 & 170 \\
55.9 & 375 \\
54.3 & 375 \\
346.7 & 1295 \\
1512.5 & 27000 \\
16.4 & 72 \\
73.0 & 270 \\
146.0 & 870 \\
294.0 & 22000 \\
On Test & $\sim 4000$
\end{tabular}

C. Elongation

11.0 (18)

$18.0(18)$

$6.2(220)$ 4.1 ( 218$)$ $5.2(\sim 50)$ 8.8 (51) $3.5 \quad(66)$ $5.5 \quad(66)$

$4.9 \quad 59)$

TABLE 12.21. Uniaxial Creep-Rupture Properties of Irradiated AISI Type 316 Stainless Steel Irradiated in the Solution Treated Condition(a) 


\begin{tabular}{|c|c|c|c|}
\hline $\begin{array}{c}\text { Specimen } \\
\text { No. }\end{array}$ & $\begin{array}{l}\text { Calc. } \\
\text { Fluence, }\end{array}$ & $\begin{array}{l}\operatorname{ota} 1 \\
\text { EBR-II }\end{array}$ & $\begin{array}{r}\text { Irrad. } \\
\text { Temp, of: }\end{array}$ \\
\hline $\begin{array}{l}14 B 36-3 \\
14 B 36-4 \\
14 B 66-1 \\
14 B 36-5 \\
14 B 46-3\end{array}$ & $\begin{array}{l}\sim 1 \times 10^{22} \\
\sim 1 \times 10^{2} \\
\sim 1 \times 1022 \\
\sim 1 \times 10^{2} \\
\sim 1 \times 10^{2}\end{array}$ & $\begin{array}{l}\mathrm{n} / \mathrm{cm}^{2} \\
\mathrm{n} / \mathrm{cm}^{2} \\
\mathrm{n} / \mathrm{cm}^{2} \\
\mathrm{n} / \mathrm{cm}^{2} \\
\mathrm{n} / \mathrm{cm}^{2}\end{array}$ & $\begin{array}{l}900 \\
900 \\
900 \\
900 \\
900\end{array}$ \\
\hline $\begin{array}{l}14 B 56-3 \\
14 B 46-1 \\
14 B 56-1 \\
14 B 56-5\end{array}$ & $\begin{array}{l}\sim 1 \times 1022 \\
\sim 1 \times 1022 \\
\sim 1 \times 1022 \\
\sim 1 \times 10^{2}\end{array}$ & $\begin{array}{l}\mathrm{n} / \mathrm{cm}^{2} \\
\mathrm{n} / \mathrm{cm}^{2} \\
\mathrm{n} / \mathrm{cm}^{2} \\
\mathrm{n} / \mathrm{cm}^{2}\end{array}$ & $\begin{array}{l}900 \\
900 \\
900 \\
900\end{array}$ \\
\hline $\begin{array}{l}14 B 36-2 \\
14 B 56-2 \\
14 B 46-2 \\
14 B 60-2\end{array}$ & $\begin{array}{l}\sim 1 \times 10^{22} \\
\sim 1 \times 10^{2} \\
\sim 1 \times 10^{2} 2 \\
\sim 1 \times 10^{2}\end{array}$ & $\begin{array}{l}\mathrm{n} / \mathrm{cm}^{2} \\
\mathrm{n} / \mathrm{cm}^{2} \\
\mathrm{n} / \mathrm{cm}^{2} \\
\mathrm{n} / \mathrm{cm}^{2}\end{array}$ & $\begin{array}{l}900 \\
900 \\
900 \\
900\end{array}$ \\
\hline $\begin{array}{l}14 B 46-4 \\
14 B 66-3 \\
14 B 66-4 \\
14 B 66-5\end{array}$ & $\begin{array}{l}\sim 1 \times 10^{22} \\
\sim 1 \times 1022 \\
\sim 1 \times 102 \\
\sim 1 \times 10^{2}\end{array}$ & $\begin{array}{l}\mathrm{n} / \mathrm{cm}^{2} \\
\mathrm{n} / \mathrm{cm}^{2} \\
\mathrm{n} / \mathrm{cm}^{2} \\
\mathrm{n} / \mathrm{cm}^{2}\end{array}$ & $\begin{array}{l}900 \\
900 \\
900 \\
900\end{array}$ \\
\hline
\end{tabular}

\begin{tabular}{l} 
Test \\
Temp. ${ }_{2}^{\circ}$ \\
\hline 1000 \\
1000 \\
1000 \\
1000 \\
1000 \\
1100 \\
1100 \\
1100 \\
1100 \\
1200 \\
1200 \\
1200 \\
1200 \\
1400 \\
1400 \\
1400 \\
1400
\end{tabular}

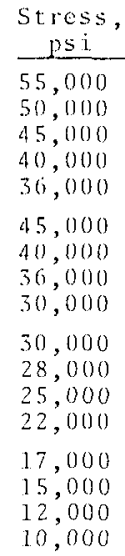

\begin{tabular}{ll} 
Minimum Creep-Rate, & \multicolumn{1}{c}{ in/in/hr } \\
\hline 0.00102 & $(0.0000915)$ \\
0.000282 & $(0.0000293)$ \\
0.000230 & $(0.0000115)$ \\
$0.00005(05$ & $(0.0000005)$ \\
0.0000105 & \\
0.000996 & $(0.0024)$ \\
0.000067 & $(0.000267)$ \\
0.000213 & $(0.0026)$ \\
0.0000507 & $(0.000036)$ \\
0.000845 & $(0.00239)$ \\
0.0000037 & $(0.00105)$ \\
0.0000445 & $(0.000635)$ \\
0.0000148 & $(0.000168)$ \\
0.00889 & $(0.01000)$ \\
0.00222 & $(0.00453)$ \\
0.0006 & $(0.00115)$ \\
0.000222 & $(0.000293)$
\end{tabular}

\begin{tabular}{cc}
\multicolumn{2}{c}{ Rupture Time, Hr } \\
\hline Trrid. & $\frac{\text { Control }}{26.3}$ \\
\hline 26.7 & 43.7 \\
85.2 & 1032 \\
107.8 & 2795 \\
149.6 & \\
On Test & \\
11.5 & 23 \\
45.5 & \\
202.8 & 236 \\
On Test & On T'est \\
56.8 & 95 \\
2157.0 & 168 \\
262.0 & 375 \\
2800.0 & 1295 \\
9.3 & 28 \\
20.1 & 72 \\
55.1 & 246 \\
146.5 & 1050
\end{tabular}

\begin{tabular}{ll}
\multicolumn{3}{c}{ Elongation } \\
\hline $\begin{array}{ll}17.6 & (38.93) \\
12.27 & (18.2) \\
5.78 & (15.4) \\
& (1.4)\end{array}$ \\
$14.13(25.1)$ \\
$7.9 \quad(25)$ \\
$8.0 \quad(20.9)$ \\
& $(250)$ \\
& $(51)$ \\
& $(66)$ \\
& $(35)$ \\
& $(72)$ \\
$7.2 \quad(70)$ \\
$5.33 \quad(64)$ \\
$(59)$
\end{tabular}

(a) Alt tests in helium

(b) solution treated controls 


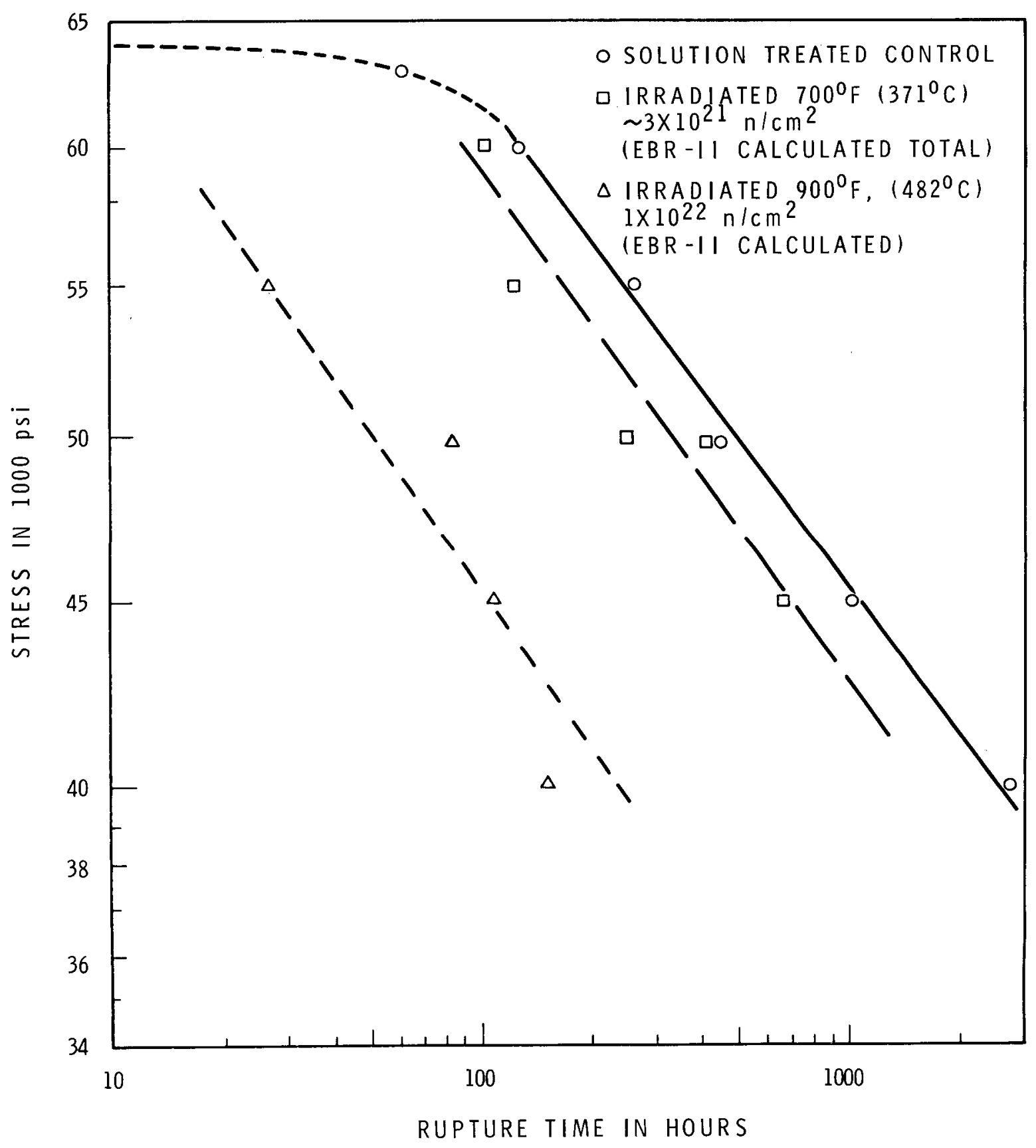

Neg $0692157-6$

FIGURE 12.32. Effect of Irradiation on the Postirradiation Creep Rupture Properties of the 316 Stainless Tested at $1000^{\circ}$ F 


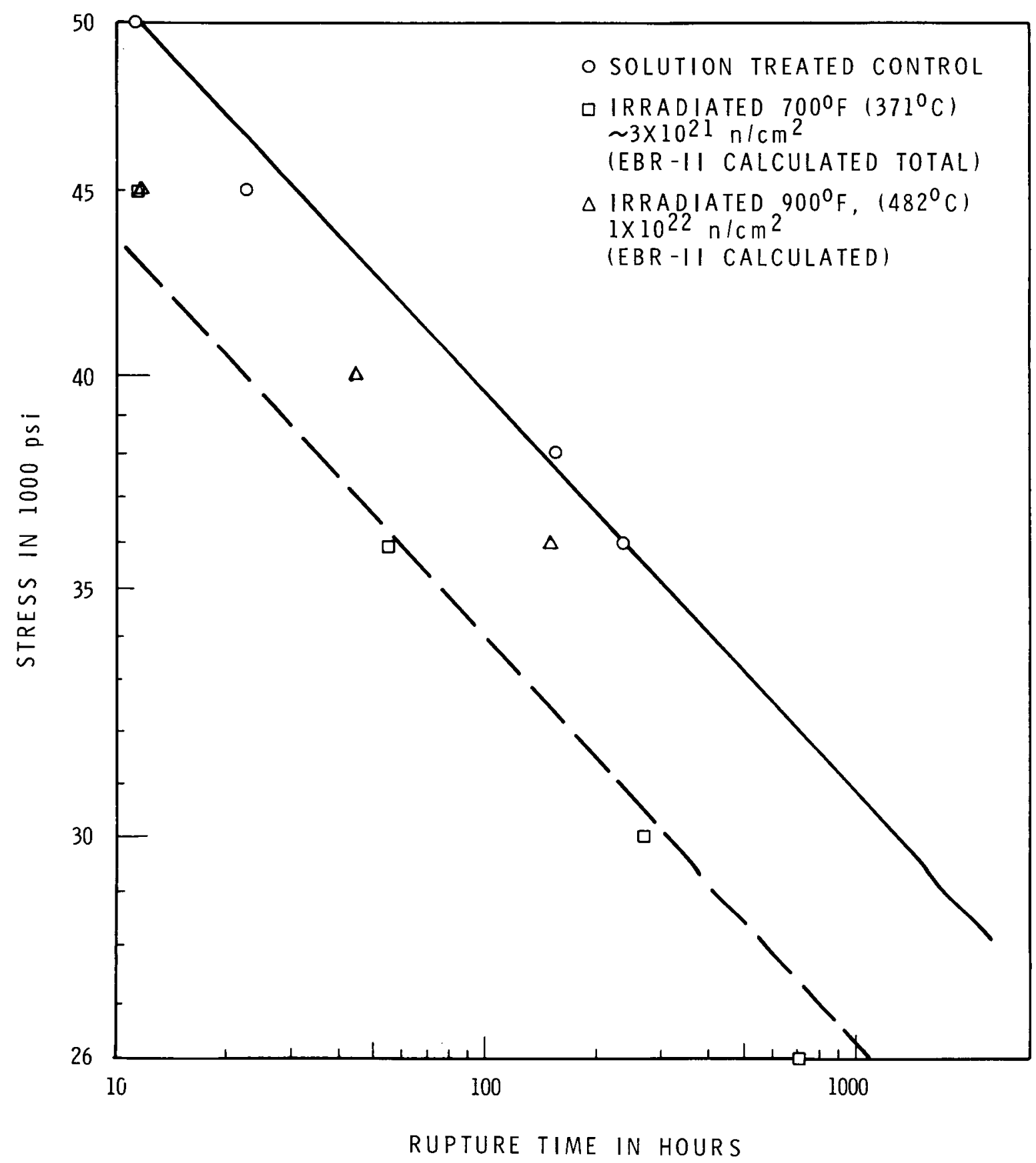

Neg 0692157-5

FIGURE 12.33. Effect of Irradiation on the Postirradiation Creep Rupture Properties of 316 Stainless
Tested at $11000_{F}$ 


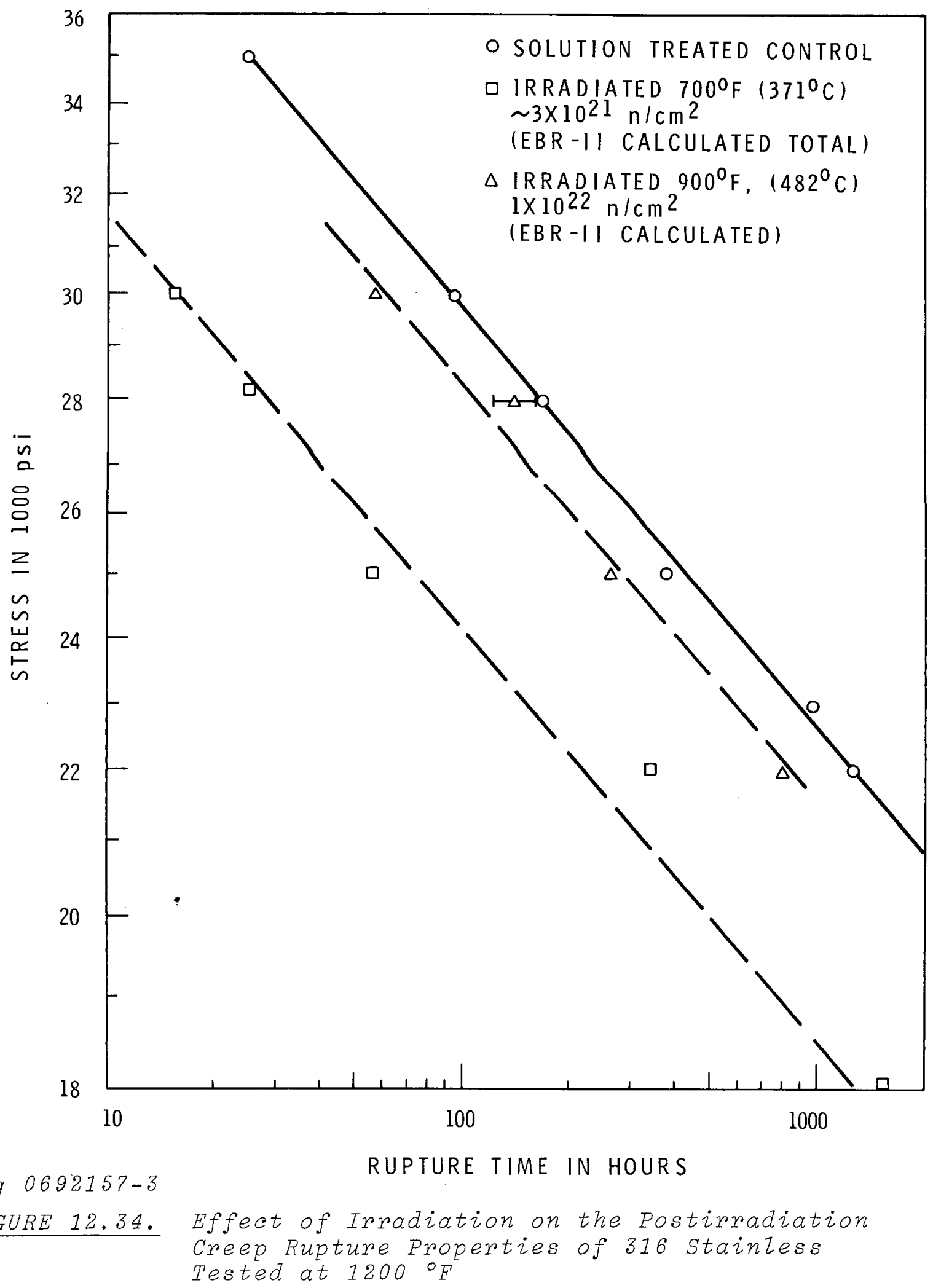




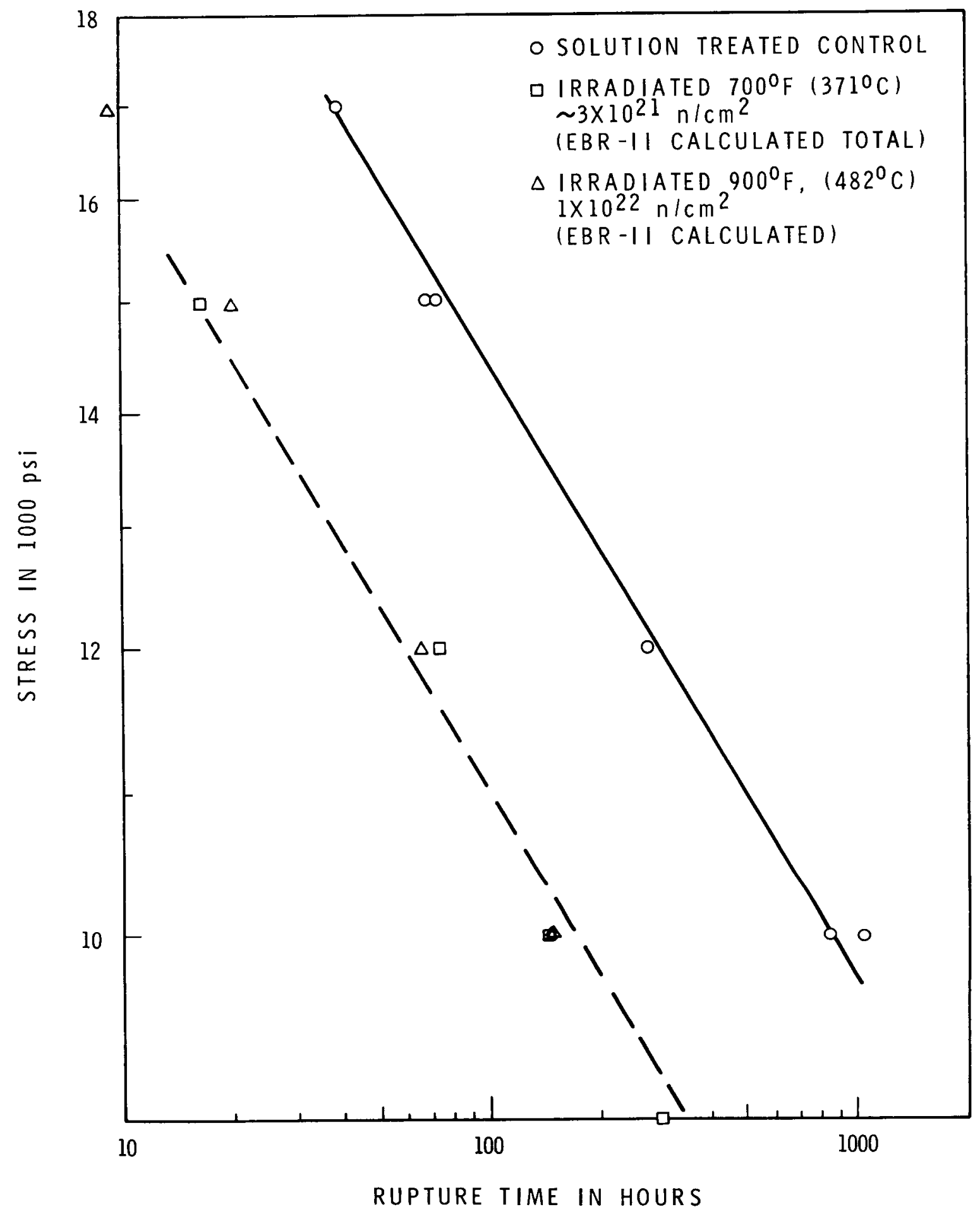

Neg $0692157-7$

FIGURE 12.35. Effect of Irradiation on the Postirradiation Creep Rupture Properties of 316 Stainiess
Tested at $14000_{F}$ 


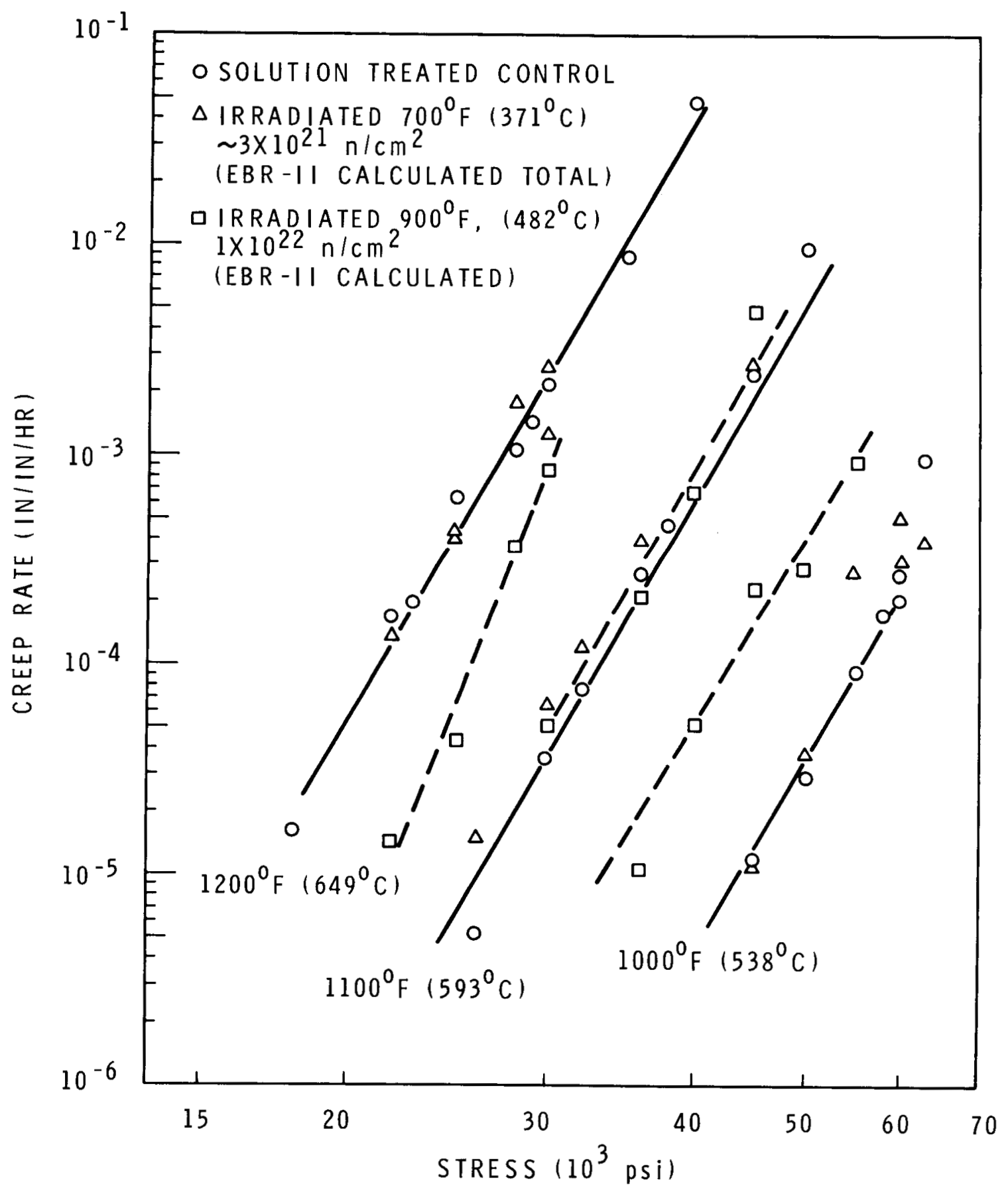

Neg $0692157-4$

FIGURE 12.36. Effects of Irradiation on the Postirradiation Creep Rate of AISI Type 316 stainless Steel 


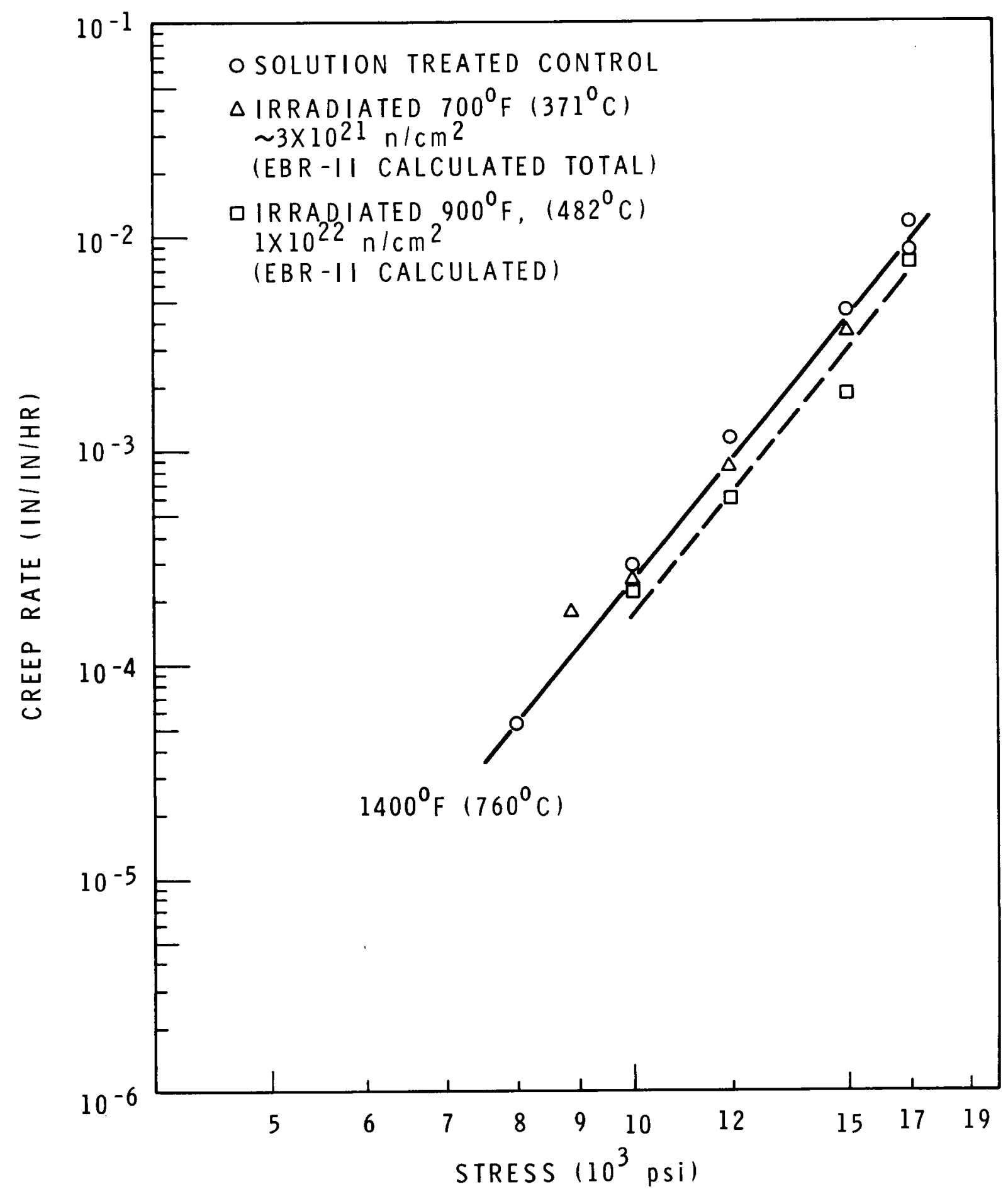

Neg 0692296-1

EIGURE 12.37. Effects of Irradiation on the Postirradiation Creep Rate of AISI Type 316 Stainless Steel 


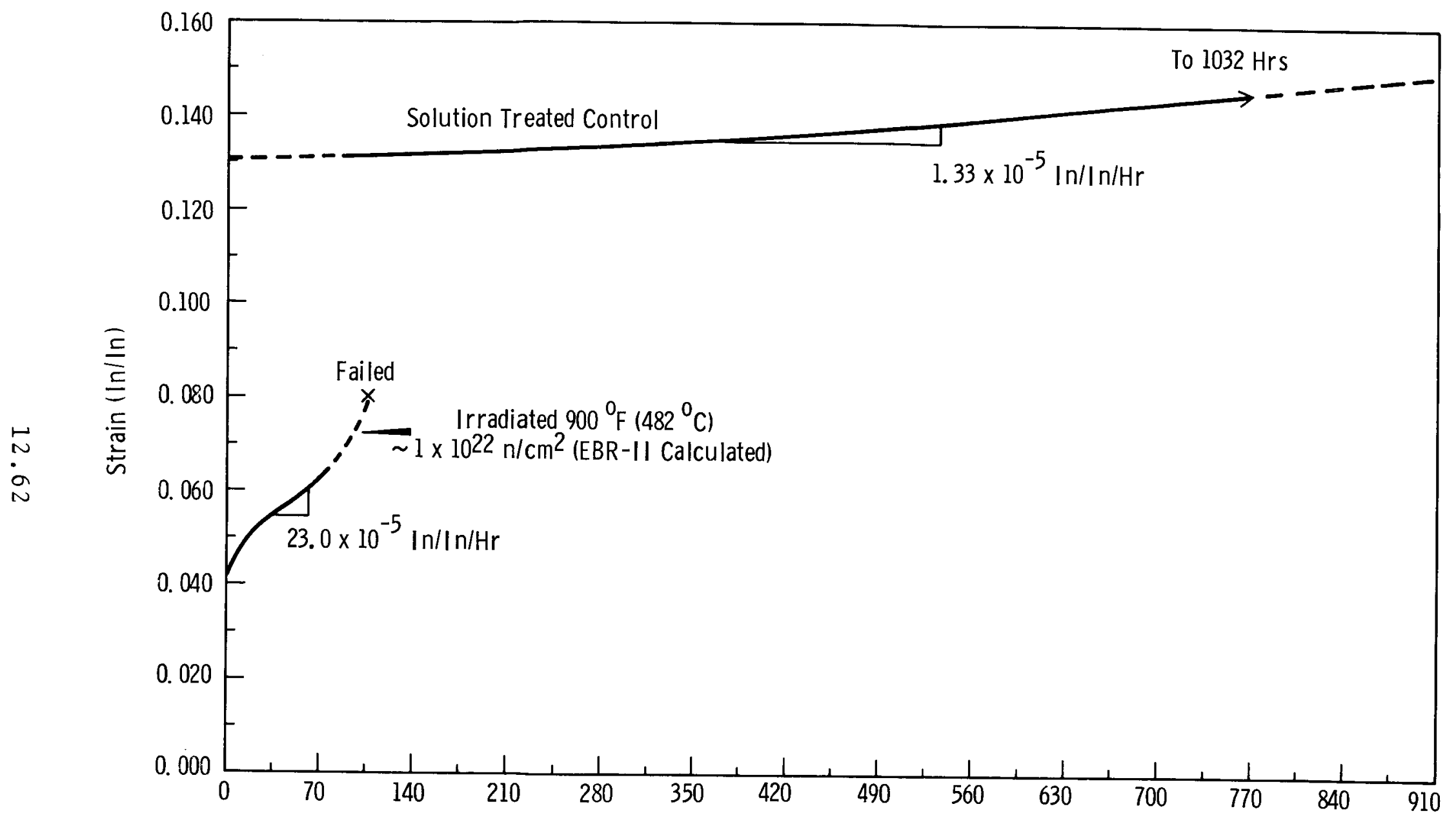

Neg $0692757-2$

Time, Hours

FIGURE 12.38. Effects of Irradiation on the Postirradiation Creep Properties of 316 Stainless Steel Tested at $1000^{\circ} \mathrm{F}$ at a Stress

of 45,000 psi 


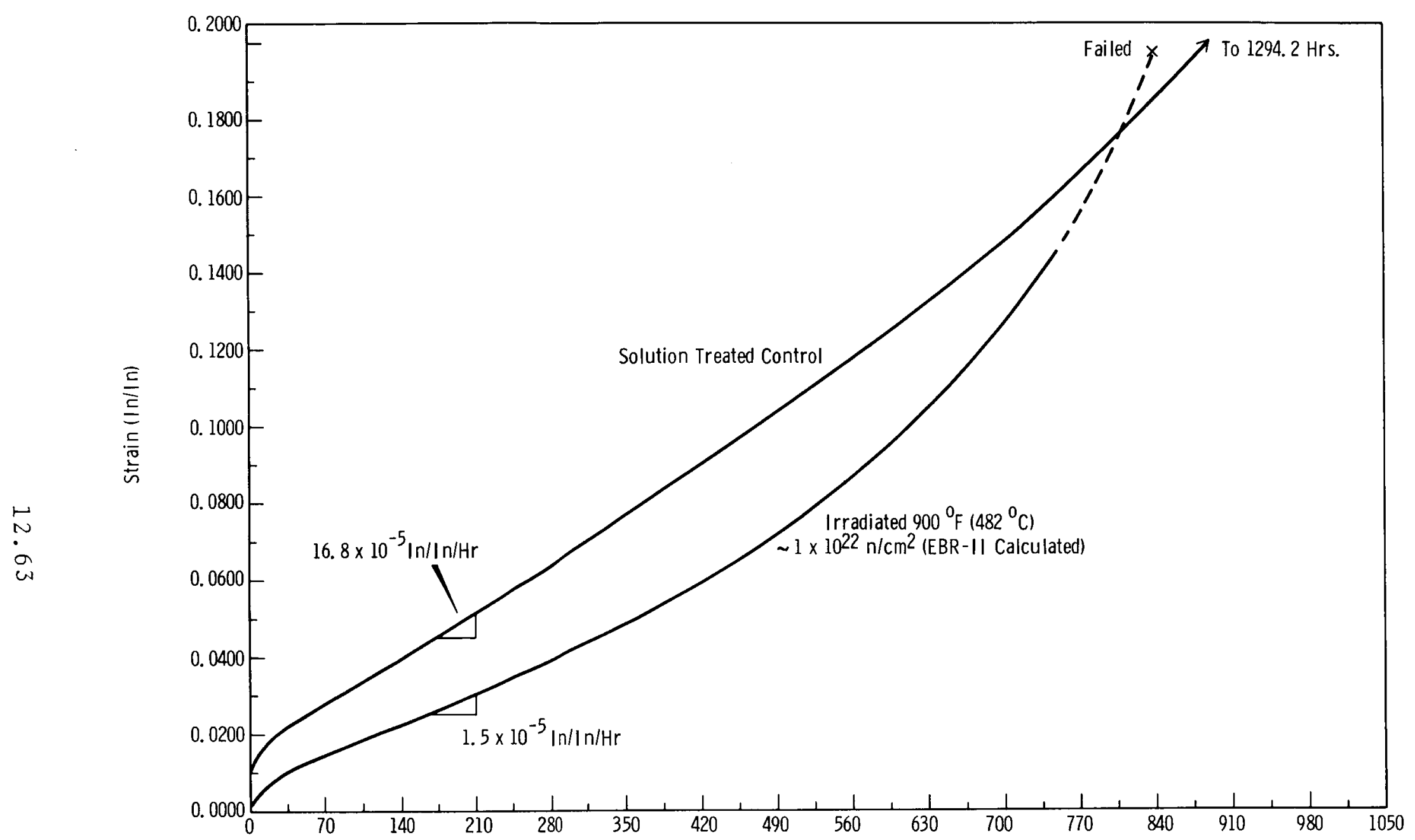

Time, Hours

Neg $0692459-2$

FIGURE 12.39. Effect of Irradiation on the Postirradiation Creep Properties of 316 Stainzess Steel Tested at $1200^{\circ} \mathrm{F}$ at a stress of 22,000 psi 
The test results are summarized in Table 12.22. Hoop stresses were determined using the hoop stress formula for thin-walled tubes:

$$
\sigma=\frac{P D}{2 t}
$$

where $P=$ internal gas pressure

$\mathrm{D}=$ inside diameter

$t=$ minimum wall thickness

Irradiated tests 4 and 5 failed when the gas leaked through a pin hole or fissure in the cladding. Test number 7 failed in an explosive manner, tearing the specimen into three separate pieces. The fourth test, number 11, lost pressure slowly at failure, the rupture being a very small fissure or pin hole. The small localized rupture is not characteristic of other tests at the pressures required for short rupture times. Normally, the energy of the compressed gas serves to explode the test piece in a violent manner once the fissure has developed. Rupture strain appears lower than that which might be expected at rapid creep rates. As a result of the peculiar behavior, this test is weighted very low in comparison with the other tests in analyzing the data.

The data from these initial tests, for irradiated AISI Type 304 stainless steel cladding suggests an increase in rupture strength for short rupture times and loss in rupture strength for longer rupture times (Figure 12.40). Thus, the 1ine describing the irradiated data crosses the unirradiated control curve at about 3 to $5 \mathrm{hr}$. The data further suggests an increasing loss in rupture life with increasing rupture times.

A great deal of scatter is observed in the rupture strain shown in Figure 12.41. However, it can be observed that rupture strain for irradiated cladding will be markedly lower than the unirradiated values of the longer rupture times. 


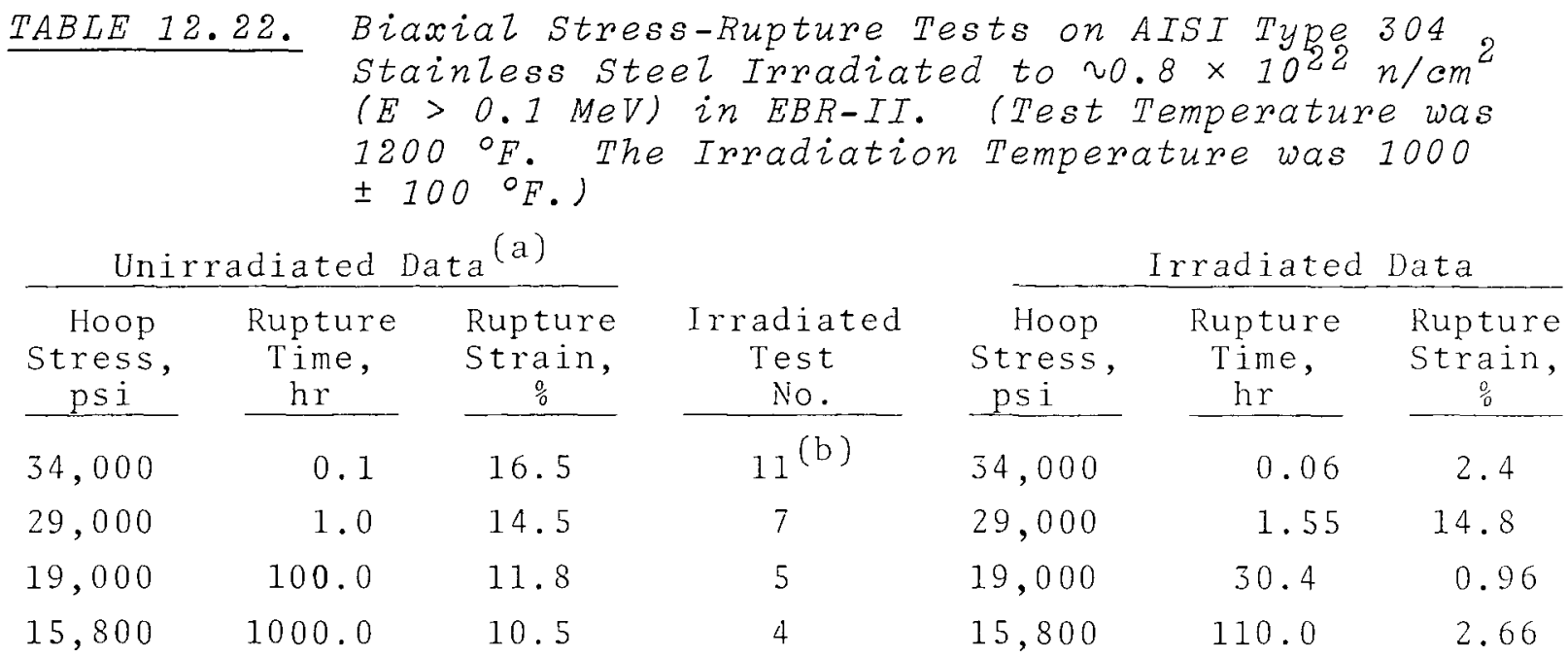

(a) Stress and strain values were taken from unirradiated test curves at rupture times shown.

(b) Test appeared to have failed prematurely.

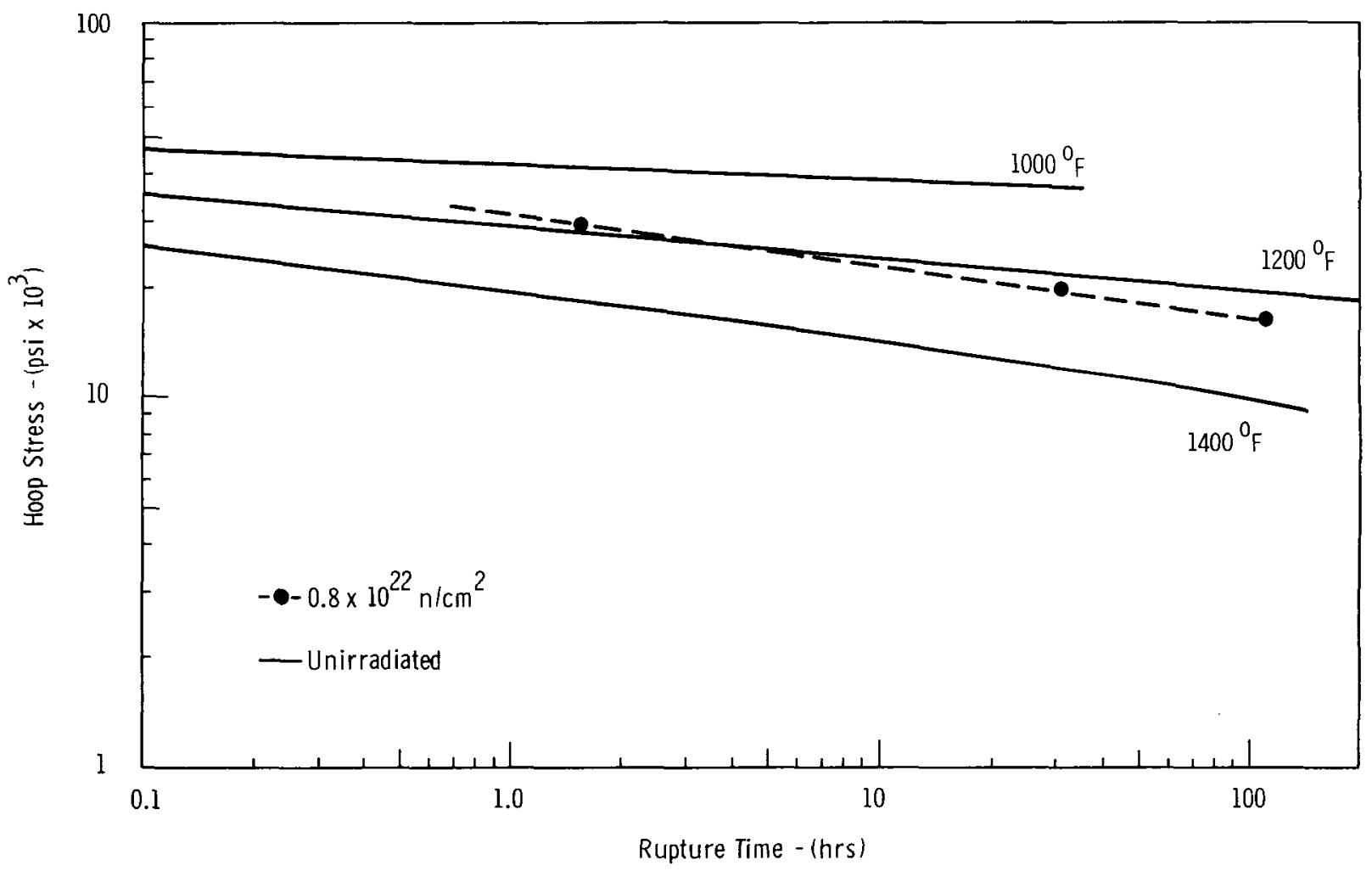

Neg $0691998-1$

FIGURE 12.40. The Effect of Biaxial Stress on the Rupture Iife of AISI Type 304 stainless steel Irradiated to 20.8 $81022 \mathrm{n} / \mathrm{cm}^{2}(\mathrm{E}>0.1 \mathrm{MeV})$ at Approximately $1000^{\circ} \mathrm{F}$. 
BNWL-1144

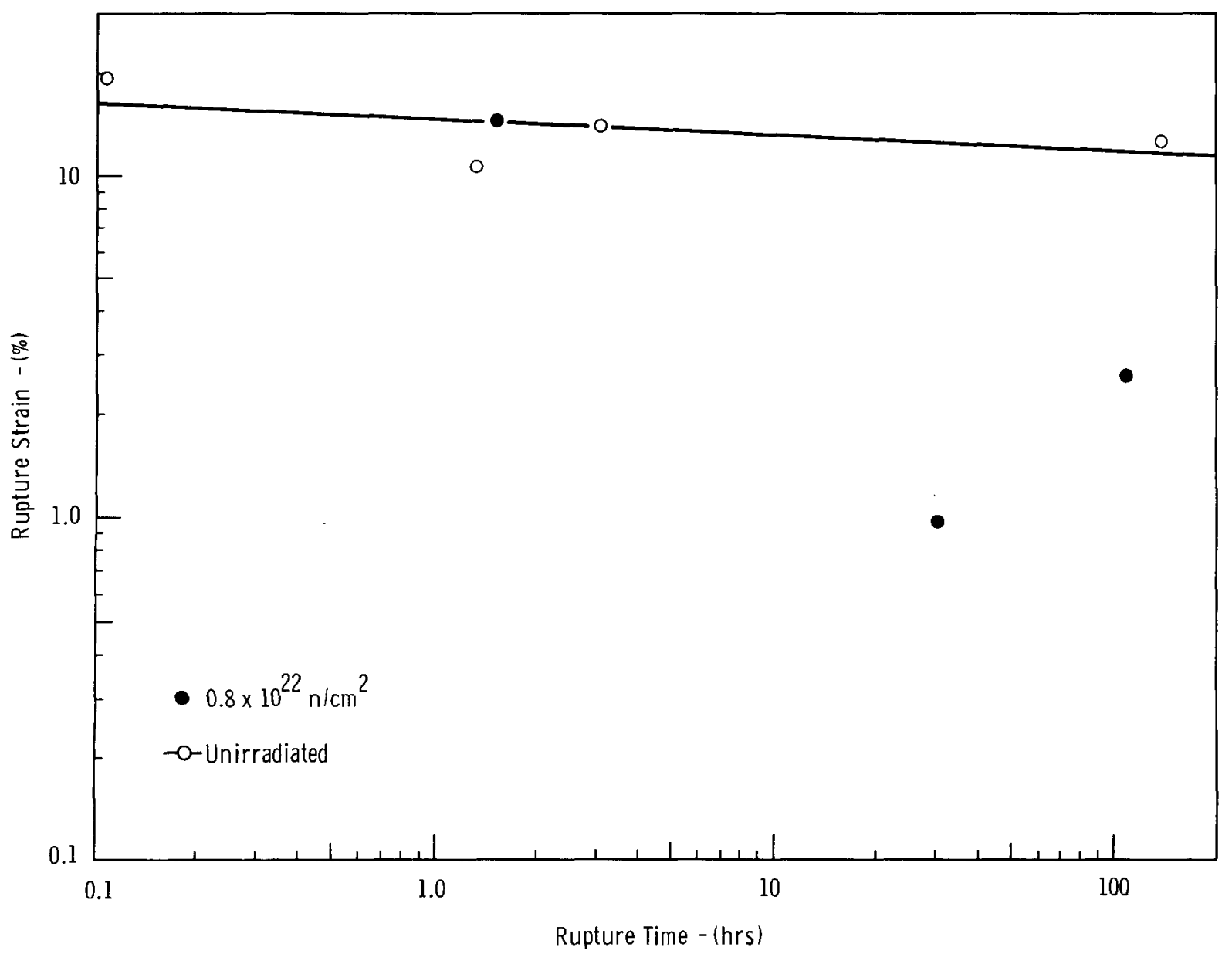

Neg $0691998-2$

FIGURE 12.41. The Effect of Biaxial Stress on the Rupture Strain of AISI Type 304 Stainless Steel Irradiated to $20.8 \times 10^{22} \mathrm{n} / \mathrm{cm}^{2}(E>0.1$ Mev $)$ at approximately $1000^{\circ} \mathrm{F}$.

Biaxial stress-rupture tests on AISI Type 316 stainless stee1 irradiated in EBR-II to $0.8 \times 10^{22} \mathrm{n} / \mathrm{cm}^{2}$ ( $\mathrm{E}>0.18 \mathrm{MeV}$ ) have been initiated. At this time, tests for short rupture times at $1200^{\circ} \mathrm{F}$ have been completed. The data obtained from these tests is given in tabular form in Table 12.23 . 
TABLE 12.23. Biaxial Stress-Rupture Tests on AISI Type 316 Stainless Steel Irradiated to $0.8 \times 10^{22} \mathrm{n} / \mathrm{cm}^{2}$ ( $E>0.1 \mathrm{MeV}$ ) in EBR-II. (Test Temperature was $1200^{\circ} \mathrm{F}$. The Irradiation Temperature was 815 $\left.\pm 500^{\circ} \mathrm{F}.\right)$

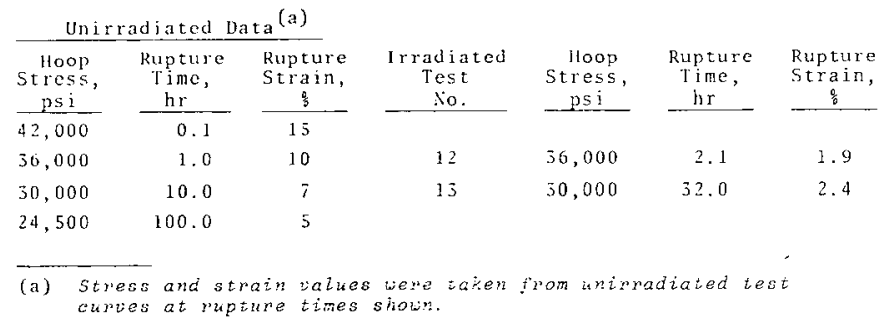

FTR Vesse1 Weldment Studies - A. L. Ward

The objective of this program is to provide mechanical property and metallurgical stability data on LMFBR vessel weldments in direct support of FFTF in order to define adequate lifetime performance under anticipated FTR service conditions.

A tensile testing matrix involving 60 as-fabricated weldment specimens has been completed. Included in this matrix are four welding processes (TIG, Submerged-Arc, Stick-Electrode, and MIG), three specimen types (weld metal, fusion Iine, and base meta1), and four testing temperatures $(600,700,800$, and $\left.900^{\circ} \mathrm{F}\right)$. In addition, 20 specimens were annealed at $1200^{\circ} \mathrm{F}$ and $1850^{\circ} \mathrm{F}$ to determine whether residual stresses caused the observed yield strength increases and ductility decreases in weld and fusion line specimens relative to base metal values. Optical metallography is being employed to relate observed mechanical properties to microstructural features. These results will be used in conjunction with an EBR-II irradiation experiment and a thermal aging study to characterize the behavior of FTR vessel weldments under projected conditions.

Based upon the results of the tests described above and in the tensile data 1isted in Tables $12.24,25,26$, and 28 , the following preliminary conclusions are drawn:

- For each welding process, the weld and fusion line specimens exhibit similar strength and ductility values under 
TABLE 12.24. TIG Process, Tensize Properties

\begin{tabular}{|c|c|c|c|c|c|c|}
\hline Specimen & $\begin{array}{l}\text { Test } \\
\text { Temp, }{ }^{\circ} \mathrm{F} \\
\end{array}$ & $\begin{array}{l}0.2 \% \text { Yield } \\
\text { Stress, psi }\end{array}$ & $\begin{array}{l}\text { Ultimate } \\
\text { Stress, psi } \\
\end{array}$ & $\begin{array}{l}\text { Uniform } \\
\text { Elong, \% }\end{array}$ & $\begin{array}{r}\text { Total } \\
\text { Elong, } \% \\
\end{array}$ & RA, : \\
\hline Weld & 600 & 51,900 & 63,700 & 7.5 & 12.4 & 64 \\
\hline We1d & 600 & 52,200 & 64,800 & 12.3 & 16.5 & 66 \\
\hline We $1 \mathrm{~d}$ & 600 & 52,200 & 64,800 & 12.3 & 16.5 & 66 \\
\hline We $1 \mathrm{~d}$ & 700 & 52,500 & 64,600 & 11.5 & 16.1 & 66 \\
\hline We $1 \mathrm{~d}$ & 800 & 51,600 & 62,700 & 10.3 & 15.4 & 59 \\
\hline We $1 \mathrm{~d}$ & 900 & 48,100 & 59,400 & 10.9 & 15.4 & 69 \\
\hline Fusion Line & 600 & 58,500 & 70,800 & 6.6 & 12.1 & 74 \\
\hline Fusion Line & 700 & 52,000 & 63,800 & 8.7 & 13.4 & 66 \\
\hline Fusion Line & 800 & 55,500 & 67,600 & 13.3 & 17.5 & 59 \\
\hline Fusion Line & 900 & 53,700 & 62,100 & 7.8 & 11.6 & 67 \\
\hline Weld $(1200) *$ & 800 & 43,200 & 57,700 & 11.0 & 16.1 & 62 \\
\hline Weld $(1850) *$ & 800 & 16,000 & 63,000 & 31.0 & 36.3 & 72 \\
\hline F.L. $(1200) *$ & 800 & 41,900 & 57,600 & 8.3 & 12.2 & 54 \\
\hline F.L。(1850)* & 800 & 12,300 & 62,800 & 34.9 & 38.7 & 59 \\
\hline
\end{tabular}

* Annealed at the indicated temperature ( $\left.{ }^{\circ} F\right)$ for 1 hr prior to tensize test. 
BNWL- 1144

\section{TABLE 12.25. Submerged-Arc Process, Tensile Properties}

\begin{tabular}{|c|c|c|c|c|c|c|}
\hline Specimen & $\begin{array}{l}\text { Test } \\
\text { Temp, }{ }^{\circ} \mathrm{F}\end{array}$ & $\begin{array}{l}0.2 \% \text { Yield } \\
\text { Stress, psi } \\
\end{array}$ & $\begin{array}{l}\text { Ultimate } \\
\text { Stress, psi }\end{array}$ & $\begin{array}{l}\text { Uniform } \\
\text { Flong, : }\end{array}$ & $\begin{array}{l}\text { Total } \\
\text { Elong, }\end{array}$ & RA, : \\
\hline We $1 \mathrm{~d}$ & 600 & 58,000 & 66,200 & 22.0 & 23.7 & 40 \\
\hline Weld & 600 & 44,400 & 67,500 & 18.7 & 20.8 & 45 \\
\hline Weld & 700 & 33,500 & 66,900 & 28.6 & 30.9 & 46 \\
\hline We $1 \mathrm{~d}$ & 700 & 41,100 & 58,000 & 18.2 & 19.2 & 50 \\
\hline We $1 \mathrm{~d}$ & 800 & 37,900 & 61,000 & 18.5 & 19.5 & 35 \\
\hline We $1 \mathrm{~d}$ & 900 & 34,800 & 63,300 & 24.0 & 25.8 & 39 \\
\hline We ld & 900 & 34,800 & 56,300 & 17.1 & 18.5 & 35 \\
\hline Fusion Line & 600 & 34,100 & 65,600 & 25.6 & 30.0 & 66 \\
\hline Fusion Line & 600 & 46,500 & 65,400 & 19.5 & 24.9 & 76 \\
\hline Fusion Line & 700 & 40,200 & 69,100 & 24.1 & 29.6 & 72 \\
\hline Fusion Line & 700 & 41,600 & $6 \overline{3}, 500$ & 21.1 & 25.7 & 73 \\
\hline Fusion Line & 800 & 46,700 & 62,600 & 19.0 & 26.4 & 75 \\
\hline Fusion Line & 800 & 31,600 & 62,500 & 26.2 & 32.8 & 66 \\
\hline Fusion Line & 800 & 41,800 & 65,100 & 20.4 & 25.7 & 63 \\
\hline Fusion Line & 900 & 31,600 & 59,500 & 22.9 & 29.6 & 70 \\
\hline Fusion Line & 900 & 46,900 & 57,900 & 13.3 & 15.3 & 36 \\
\hline We 1 d $(1200)$ * & 600 & 32,600 & 63,900 & 17.4 & 21.1 & 44 \\
\hline Weld $(1850) *$ & 600 & 26,900 & 59,600 & 23.9 & 25.6 & 37 \\
\hline We $1 \mathrm{~d}(1200) *$ & 700 & 27,900 & 60,300 & 21.9 & 23.6 & 36 \\
\hline Weld $(1850)^{*}$ & 700 & 23,800 & 64,700 & 32.3 & 33.1 & 42 \\
\hline F.L. $(1200)^{*}$ & 700 & 28,700 & 57,900 & 22.1 & 25.2 & 45 \\
\hline F.L. $(1850)^{*}$ & 700 & 13,600 & 60,200 & 30.8 & 35.3 & 71 \\
\hline F.L. $(1200) *$ & 800 & 25,600 & 57,900 & 22.8 & 24.9 & 43 \\
\hline F.L. $(1850)^{*}$ & 800 & 12,500 & 59,600 & 33.2 & 38.3 & 64 \\
\hline
\end{tabular}


BNWL- 1144

TABLE 12.26. Stick-Electrode Process, Tensile Properties

\begin{tabular}{|c|c|c|c|c|c|c|}
\hline Specimen & $\begin{array}{l}\text { Test } \\
\text { Temp, }{ }^{\circ} \mathrm{F}\end{array}$ & $\begin{array}{l}0.2 \% \text { Yield } \\
\text { Stress, psi }\end{array}$ & $\begin{array}{l}\text { Ultimate } \\
\text { Stress, psi } \\
\end{array}$ & $\begin{array}{l}\text { Uniform } \\
\text { E1ong, : }\end{array}$ & $\begin{array}{r}\text { Total } \\
\text { Elong, : } \\
\end{array}$ & RA, \% \\
\hline field & 600 & 53,100 & 71,100 & 16.6 & 19.1 & 44 \\
\hline Weld & 600 & 47,000 & 69,700 & 20.3 & 24.0 & 52 \\
\hline We $1 \mathrm{~d}$ & 700 & 48,400 & 67,200 & 16.3 & 18.7 & 48 \\
\hline We1d & 700 & 43,800 & 67,500 & 20.7 & 24.4 & 50 \\
\hline lie 1d & 700 & 46,400 & 66,100 & 18.6 & 21.8 & 55 \\
\hline Weld & 800 & 45,400 & 66,800 & 15.6 & 19.6 & 47 \\
\hline Weld & 900 & 43,600 & 62,300 & 15.8 & 17.6 & 43 \\
\hline Weld & 900 & 45,000 & 65,300 & 16.7 & 19.4 & 42 \\
\hline Fusion Line & 600 & 51,200 & 65,400 & 15.0 & 20.0 & 70 \\
\hline Fusion Line & 600 & 42,500 & 68,600 & 18.2 & 22.4 & 63 \\
\hline Fusion Line & 700 & 46,700 & 68,100 & 20.9 & 26.7 & \\
\hline Fusion Line & 800 & 45,500 & 68,400 & 16.7 & 22.0 & 71 \\
\hline Fusion Line & 800 & 42,500 & 67,400 & 18.4 & $24=6$ & 72 \\
\hline Fusion Line & 800 & 43,100 & 64,800 & 20.5 & 27.5 & 66 \\
\hline Fusion Line & 900 & 40,200 & 59,200 & 14.8 & $21: 6$ & 73 \\
\hline Fusion Line & 900 & 46,800 & 63,600 & 18.5 & 23.1 & 66 \\
\hline Veld $(1200) *$ & 700 & 42,800 & 67,000 & 20.7 & 25.8 & 56 \\
\hline Weld $(1850) *$ & 700 & 15,100 & 62,000 & 30.7 & 34.6 & 74 \\
\hline Weld $(1200) *$ & 800 & 38,800 & 62,900 & 17.4 & 20.8 & 54 \\
\hline Weld $(1850) *$ & 800 & $1.4,400$ & 61,000 & 32.4 & 38.3 & 67 \\
\hline weld $(1850) *$ & 800 & 30,300 & 68,000 & 41.2 & 45.7 & 56 \\
\hline F.L. $(1200)^{*}$ & 700 & 41,100 & 64,500 & 20.5 & 23.9 & 48 \\
\hline F. I. . $(1200)^{*}$ & 800 & 40,000 & 65,800 & 24.4 & 28.9 & 71 \\
\hline F.L. $(1850)^{*}$ & 800 & 12,600 & 62,000 & 35.5 & 39.7 & 65 \\
\hline
\end{tabular}




\section{TABLE 12.27. MIG Process, Tensize Properties}

\begin{tabular}{|c|c|c|c|c|c|c|}
\hline Specimen & $\begin{array}{l}\text { Test } \\
\text { Temp, }{ }^{\circ} \text { : }\end{array}$ & $\begin{array}{l}0.2 \% \text { Yield } \\
\text { Stress, psi }\end{array}$ & $\begin{array}{l}\text { Ultimate } \\
\text { Stress, psi }\end{array}$ & $\begin{array}{l}\text { UniEorm } \\
\text { Elong, \% }\end{array}$ & $\begin{array}{l}\text { Total } \\
\text { Elong, } \\
\end{array}$ & $R A, 8$ \\
\hline Weld & 600 & $44, .500$ & 63,900 & 11.4 & 15.1 & 56 \\
\hline We $1 \mathrm{~d}$ & 600 & 45,000 & 67,600 & 19.4 & 21.5 & 61. \\
\hline Weld & 600 & 35,200 & $6 . \overline{3}, 900$ & 17.3 & 20.8 & 59 \\
\hline We $1 \mathrm{~d}$ & 600 & 41,500 & 61,700 & 20.2 & 23.8 & 50 \\
\hline We1d & 700 & 46,200 & 66,200 & 19.5 & 21.9 & 37 \\
\hline We $1 \mathrm{~d}$ & 700 & 39,800 & 67,800 & 18.6 & 23.1 & 71. \\
\hline Weld & 700 & 37,300 & 61,600 & 21.8 & 25.6 & 50 \\
\hline We $1 \mathrm{~d}$ & 700 & 39,800 & 66,200 & 22.0 & 26.9 & 61 \\
\hline Weld & 800 & 48,600 & 64,500 & 14.7 & 19.2 & 57 \\
\hline Weld & 800 & 39,800 & 61,300 & 13.2 & 17.7 & 64 \\
\hline Weld & 800 & 36,200 & 60,600 & 21.6 & 25,6 & 59 \\
\hline weld & 800 & 34,400 & 60,100 & 21.9 & 24.9 & 55 \\
\hline Weld & 900 & 48,400 & 59,600 & 11,1 & 14.5 & 51. \\
\hline Weld & 900 & 35,800 & 56,700 & 1.4 .8 & 19.4 & 67 \\
\hline Weld & 900 & 37,500 & 56,600 & 15.9 & 19.4 & 57 \\
\hline Fusion Line & 600 & 46,400 & 67,800 & 22.3 & 27.9 & 71 \\
\hline Fusion Line & 700 & 45,100 & 62,700 & 15.2 & 19.5 & 57 \\
\hline Fusion Line & 800 & 42,800 & 64,900 & 22.4 & 29.4 & 55 \\
\hline Fusion Line & 900 & 41,600 & 59,000 & 16.8 & 19.7 & 50 \\
\hline
\end{tabular}

TABLE 12.28. Base Metal, Tensile Properties

\begin{tabular}{|c|c|c|c|c|c|c|}
\hline Specimen & $\begin{array}{l}\text { Test } \\
\text { Temp, }{ }_{0} \text { : }\end{array}$ & $\begin{array}{l}0.2 \% \text { Yield } \\
\text { Stross, psi }\end{array}$ & $\begin{array}{l}\text { Ultimate } \\
\text { Stress, psi }\end{array}$ & $\begin{array}{l}\text { Uniform } \\
\text { Elong, : }\end{array}$ & $\begin{array}{l}\text { Total } \\
\text { Elong, }\end{array}$ & RA, $\frac{\circ}{0}$ \\
\hline As-Fab. & 600 & 22,200 & 64,600 & 38.5 & 43.2 & 65 \\
\hline $\mathrm{As}-\mathrm{Fab}$ & 700 & 24,700 & 61,000 & 33.6 & 38.9 & 62. \\
\hline$A s-F a b$. & 800 & 23,400 & 65,600 & 40.0 & 44.6 & 64 \\
\hline $\mathrm{As}-\mathrm{Fab}$ & 900 & 18,300 & 56,900 & 27.6 & 35.4 & 67 \\
\hline Ann. $1850^{\circ} \mathrm{F}$ & 800 & 14,600 & $6 \overline{3}, 000$ & 38.1 & 42.9 & 71. \\
\hline
\end{tabular}


the same test conditions. Ductility of welds can be significantly lower than the ductility of base metal. Total elogation of some as-fabricated welds was as $10 \mathrm{w}$ as $15 \%$, compared to $35 \%$ for the base metal. This value is already close to an end-of-life limit of $10 \%$ total elongation, without the additional effects of irradiation.

- Post-annealing property comparisons between weld and base metal specimens are complicated by variations in structure and composition; however, it is apparent that the increased strengths are the result of residual stresses in the weld metal. Minimal recovery of ductility was observed for a short anneal at $1200^{\circ} \mathrm{F}$, while full recovery was achieved at $1850^{\circ} \mathrm{F}$. These results indicate that very high annealing temperatures for a component as large as the vessel may be required if post-weld heat treatments are to be applied for improved ductility.

- Tensile test results and optical metallography suggest that the mechanical properties exhibited by fusion line specimens are those of the composite material--including weld metal, base metal, and heat affected zone--and are not controlled by a single component.

Four MK-B7 type pins were assembled and shipped to the EBRII site for inclusion in subassembly number X067-4F2. Contained in the four pins are 159 tensile and creep-rupture weldment specimens; 21 solution-treated 304 stainless steel tensile specimens; 24 tensile specimens of 316 stainless steel in annealed and $10 \%$, and $20 \%$ cold-worked conditions; and 20 low cycle fatigue specimens of 304 stainless steel. This experiment will be used to determine the effects of neutron irradiation on the mechanical properties of the weldment materials. 
LMFBR Fuel and Cladding Information Center - F. R. Shober

An information center was established to document and to record all qualitative and quantitative information relating to the irradiation performance of LMFBR fuel pins. The system includes materials information on melting processes, fabrication techniques, heat treatments, mechanical properties, physical properties, quality inspeciton results, and performance records of individual lots of material. The system is a computerized information storage, retrieval, and data analysis system consisting of six sections: cladding fabrication, fuel fabrication, fuel pin fabrication, fuel subassembly fabrication, irradiating history, and postirradiation examination. The sectional nature of the system permits analysis and evaluation of data from each section, independent of others or, if preferred, allows a multisection analysis.

Activities of the information center presently include:

- Identification of terms and fields related to the expansion of the system.

- Preparation of a format for storage of data available on fabricated fuel-pins and experimental subassemblies.

- Identification of, and formation of, interfaces with data sources and information needs.

- Storage of data from stainless steel cladding procured by: (a) BNW (lots $\mathrm{G}$ and $\mathrm{H}$ )

(b) Argonne National Laboratory

- Evaluation of data logging systems for reactor operation with respect to pertinent irradiation history section of system.

It appears that the major problems confronting the staff is to identify onsite and offsite sources of data and to interface with these sources. 
BNWL -1144

\section{REFERENCES}

1. A. I. Bement, G. J. Dau, E. A. Evans, and R. E. Nightingaze. Quarteriy Progress Report, January, February, March, 1969, Reactor Fuels and Materials Development Programs for Fuels and Materials Branch of USAEC Division of Reactor Development and Technology, BNWL-1058. Battelle-Northwest, Richland, Washington. May 1963.

2. J. M. Silcock. "Precipitation of NbC in Niobium stabilized Austenitic Steels observed by Thin Foil Electron Microscopy," J. Iron and Steel Inst., vol. 201, p. 409. 1963.

3. R. W. K. Honeycomb, J. S. T. Van Aswegen, and D. H. Warrington. "Precipitation on Stacking Faults in Cr-Ni Austenitic Steels," Acta Met., vol. 12, p. 1. January 1964.

4. C. Cawthorne and E. J. Fulton. Harwelz Symposium on "The Nature of Small Defect Clusters," edited by M. J. Makin, AERE-R-5269, p. 446. Atomic Energy Research Establishment, Harwezz, Berks, England, 1966.

5. J. J. Holmes, R. E. Robbins, J. L. Brimhall, and B. Mastel. "Elevated Temperature Irradiation Hardening in Austenitic Stainiess Steel," Acta Met., vol. 16, p. 955. 1968.

6. B. Mastel and J. L. Brimhall. Unpublished Data. BattelleNorthwest, Richland, Washington.

7. J. L. Brimhall and B. Mastel. "Voids in Neutron Irradiated Nickel," Quarterly Progress Report, Irradiation Effects on Reactor Structural Materials, November, December 1968, January 1969, BNWL-1020, p. 12.119. Battelle-Northwest, Richland, Washington, March 1969.

8. J. o. Stiegler. Unpublished Data. Battelze-Northwest, Richland, Washington. (Personal Communication)

9. J. 0. Stiegler. High Fluence Irradiation Damage in Aluminum. Presented at IAEA Symposium on Radiation Damage in Reactor Materials, Vienna, June 2-6, 1969.

10. J. Moteff. The Influence of Irradiation Temperature on the Creep-rupture Properties of Polycrystalizne Molybdenum. Presented at IAEA Symposium on Radiation Damage in Reactor Materials, Vienna, June 2-6, 1969.

11. F. W. Wiffen and $J$. O. Stiegler. "Voids in Neutron-Irradiated Vanadium," J. Metals, vol. 117A, August 1968.

12. Y. S. Avraamov and A. G. Grozdev. "Calculating the Surface Energy of bec Metals," Fiz. Met. in MetalZoved, vol. 23, p. 405, 1967 .

13. A. De Pino, "Helium Production by $(n, a)$ Reactions in Stainless Steel," Nucl. Appl., vol. 3, p.620. 1967 
14. A. Guinier, and G. Fourmet: Smazl-Angle scattering of X-rays. John Wiley and Sons, New York, 1955. p. 127.

15. C. Cawthorne and E. Fuzton. "Voids in Irradiated StainZess Steel," Nature, vol. 216, p. 575. 1967.

16. Unpublished Data. Battelle-Northwest, Richland, Washington, April 1969. (Preliminary Report: FFTE Monthly Report)

17. D. H. Stone. Some High Temperature Mechanical Properties of Zircaloy-2, Type 304 Stainless Steel, and AM 350 StainLess Steel, NAA-SR-11047. Atomics International, Canoga Park, California, June 15, 1965.

18. G. D. Johnson. The Effect of Variations in Chemical Composition on the Creep Rupture Behavior of Austenitic StainZess Steels, NAA-SR-11788. Atomics International, Canoga Park, California, December 15, 1965.

19. N. J. Grant, F. C. Monkman, and P.E. Price. "The Effect of Composition and Structure on the Creep Properties of 18-8 Stainless Steel," Am. Soc. Metals, vol. 48, pp. 418445. 1956 .

20. F. Garolazo. "Fundamentals of Creep and Creep-Rupture in Metals," Macmillian Series in Materials Science. p. 29, 1965.

21. F. W. Woodfield. Unpublished Data. Battelle-Northwest, Richland, Washington, March, 1969. (Preliminary Report: FFTF Monthly Development Progress Report)

22. F. W. Woodfield. Unpublished Data. Battelle-Northwest, Richland, Washington, February, 1969. (Preliminary Report: EFTF Monthly Development Progress Report) 


\section{DISTRIBUTION}

No. of

Copies

OFFSITE

1

AEC Division of Naval

Reactors, HQS

R. H. Steele

26

AEC Division of Reactor

Development and Technology

L. J. Colby

J. C. Crawford

G. W. Cunningham

D. E. Erb

A. Giambusso

N. Grossman

H. G. Hembree

K. E. Horton

$J$. R. Hunter

R. H. Jones

E. E. Kintner

W. R. Kornack

J. A. Lieberman

W. H. McVey

J. J. Morabito

R. E. Pahler

M. A. Rosen

$J$. M. Simmons

E. E. Sinclair

R. F. Sweek

S. A. Szawlewicz

A. N. Tardiff

A. Van Echo

C. E. Weber

G. W. Wensch

M. J. Whitman

AEC Division of Research

P. W. McDaniel

D. K. Stevens

Distr-1 
AEC Division of Space Nuclear

Systems

D. Beard

J. F. Griffo

C. E. Johnson

J. A. Powers

F. C. Schwenk

E. S. Wilson

AEC Division of Technical Information Extension

AEC Library, Washington

AEC RDT Site Representatives

M. E. Jackson, ANL

D. J. Wille, APDA

G. U. Mercke1, CE

R. L. Morgan, CPAI

J. V. Levy, GE, San Jose

$\mathrm{J}$. R. Weis senberg, GE-NMPO

R. H. Ball, GGA

J. E. Hebert, ID

D. F. Cope, OR

M. Napack, UNC

11

Argonne National Laboratory

R. Bane

S. Greenberg

J. H. Kitte 1

K. Kuczen

M. V. Nevitt

P. G. Shewmon

F. Smith

R. C. Voge 1

LMFBR Program Office

A. Amorosi

J. R. Humphreys

L. R. Kelman

1

$\frac{\text { Atomic Energy Division }}{\text { Allis-Chalmers Mfg. Co }}$
$\frac{6935 \text { Arlington Road }}{\text { P.O. Box } 5976}$
Bethesda, Maryland 20014
L. Phillips

Distr-2 
No. of

Copies

3

Atomic Power Development

Associates, Inc. (AEC)

E. C. Kovacic

A. A. Shoudy

Technical Director

4

Atomics International (AEC)

J. Balif (2)

R. W. Dickinson

H. Pearlman

5

Babcock \& Wilcox Company (AEC)

C. Baroch

S. P. Grant

C. Johnson

P. B. Probert

L. Weissert

1

Baldwin-Lima-Hamilton Corporation

Eddystone, Pennsylvania 19013

P. S. Otten

Battel1e Memorial Institute (AEC)

D. Keller

S. Paprocki

E. M. Simons

Bettis Atomic Power Laboratory (AEC)

E. J. Kreh

Laboratory Library

3

Brookhaven National Laboratory (AEC)

O. E. Dwyer

D. H. Gurinsky

C. Klamut

1

Bureau of Mines, Albany (INT)

H. Kato

2

Combustion Engineering, Inc. (AEC)

W. P. Chernock

S. Christopher 
duPont Company, Aiken (AEC) Savannah River Laboratory

P. H. Permar

S. P. Rideout

General Electric Company Cincinnati (AEC)

D. H. Ahmann

H. C. Brassfield

V. P. Calkins

J. McGurty

J. Moteff

W. E. Niemuth

1

General Electric Company Nuclear Systems Programs Cincinnati, Ohio 45215

E. E. Hoffman

General Electric Company Pleasanton (AEC)

L. P. Bupp

General Electric Company, San Jose (AEC)

R. Duncan

H. Klepfer

5

General Electric Company, Sunnyvale

K. P. Cohen

F. Compre11i

R. Skavdah 1

C. Spalaris

E. L. Zebroski

4

Gulf General Atomic Incorporated

D. B. Coburn

A. J. Goodjohn

S. Jaye

J. F. Watson

1

Idaho Nuclear Corporation

W. C. Francis

$$
\text { Distr }-4
$$


No. of

Copies

1

IIT Research Institute

D. J. McPherson

4

Iowa State University

O. N. Carlson

W. L. Larsen

M. Smutz

F. H. Spedding

1

Jet Propulsion Laboratory (NASA)

J. Davis

1

Knol1s Atomic Power Laboratory (AEC)

Document Library

1

Lawrence Radiation Laboratory, Livermore (AEC)

J. S. Kane

8

Los Alamos Scientific Laboratory (AEC)

R. D. Baker

D. B. Hall

J. A. Leary

R. Perkins

R. Peterson

G. Waterbury

L. E. Whinery

W. R. Wykoff

1

Mound Laboratory (AEC)

R. Grove

1

MSA Research Corporation

Evans City, Pa.

R. C. Andrews

NASA Lewis Research Center

J. J. Lombardo

C. M. Scheuermann

Distr -5 
No. of

Copies

ONSITE - HANFORD

1

AEC Chicago Patent Group

R. K. Sharp (Richland)

4

AEC RDT Site Representative

P. G. Holsted

(2)

L. R. Lucas

A. D. Toth

1

AEC Richland Operations Office

C. L. Robinson

3

Douglass United Nuclear Inc.

P. A. Carlson

D. W. Peacock

L. H. Rice

75

Batteile-Northwest

F. W. Albaugh

H. J. Anderson

E. R. Astley

D. E. Baker

J. M. Batch

J. L. Bates

A. L. Bement

C. A. Bennett

T. K. Bierlein

S. H. Bush

J. J. Cadwe 11

T. D. Chikalla

J. A. Christensen

T. T. Claudson

P. D. Cohn

R. E. Dah 1

J. L. Danie 1

F. G. Dawson

D. R. de Halas

R. L. Dillon

D. G. Doran

K. Drumheller

E. A. Eschbach

E. A. Evans

P. L. Farnsworth

J. J. Fuguay

R. L. Gibby 
S. Goldsmith

W. L. Hamps on

J. E. Hanson

L. A. Hartcorn

H. Harty

B. R. Hayward

S. S. Jones

D. C. Kaulitz

A. R. Keene

R. S. Kemper

R. L. Knecht

H. A. Kornberg

G. A. Last

R. D. Leggett

D. C. Lehfeldt

C. E. MCNeilly

J. E. Minor

R. P. Nelson

R. E. Nightingale

D. P. O'Keefe

R. S. Paul

L. T. Pederson

W. D. Richmond

W. E. Roake

R. K. Robinson

C. A. Rohrmann

R. C. Smith

J. C. Spanner

R. W. Stewart

H. A. Taylor

G. L. Tingey

J. C. Tuerberg

C. E. Voge 1

E. E. Voiland

R. E. Westerman

R. G. Wheeler

E. T. Weber

O. J. Wick

D. C. Worlton

H. H. Yoshikawa

Patent Section (2)

Technical Information File

(5)

Technical Publications (3)

Distr -9 